\title{
Conceptual Design of an Open-Cycle Ocean Thermal Energy Conversion Net Power-Producing Experiment (OC-OTEC NPPE)
}

\author{
A cooperative effort of \\ Solar Energy Research Institute \\ Pacific International Center for \\ High Technology Research \\ Argonne National Laboratory \\ D. Bharathan \\ H. J. Green \\ H. F. Link \\ B. K. Parsons \\ J. M. Parsons \\ F. Zangrando
}

July 1990

Prepared under Field Work Proposal OE91

Solar Energy Research Institute

A Division of Midwest Research Institute

1617 Cole Boulevard

Golden, Colorado 80401-3393

Prepared for the U.S. Department of Energy Contract No. DE-AC02-83CH10093 


\title{
NOTICE
}

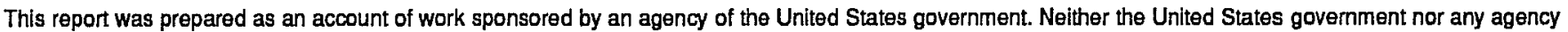

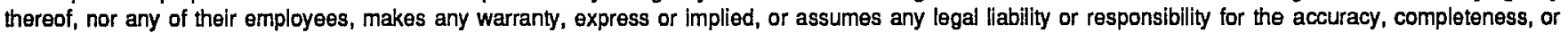

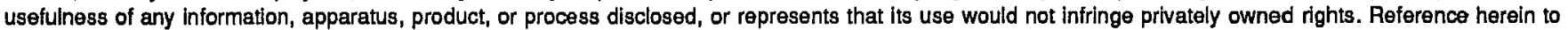

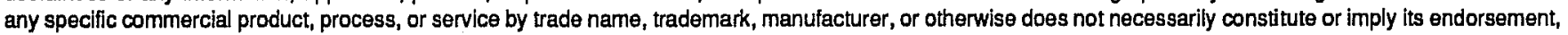

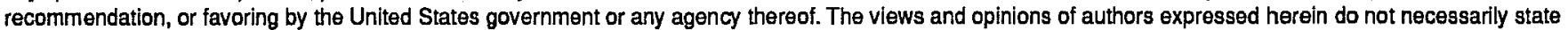
or reflect those of the United States government or any agency thereof.

\author{
Printed in the United States of America \\ Available from: \\ National Technical Information Service \\ U.S. Department of Commerce \\ 5285 Port Royal Road \\ Springfield, VA 22161 \\ Price: Microfiche A01 \\ Printed Copy A08
}

Codes are used for pricing all publications. The code is determined by the number of pages in the publication. Information pertaining to the pricing codes can be found in the current issue of the following publications which are generally available in most libraries: Energy Research Abstracts (ERA); Government Reports Announcements and Index (GRA and I); Sclentific and Technical Abstract Reports (STAR); and publication NTIS-PR-360 available from NTIS at the above address. 


\section{PREFACE}

The mission of the Ocean Energy Technology (OET) program of the U.S. Department of Energy (DOE) is to

develop ocean energy technology to a point where the commercial sector can make competent assessments of whether applications of the technology are viable energy conversion alternatives, or supplements, to systems presently in use (U.S. DOE 1985).

Toward this mission, the program is aimed to advance the technology over the next several years. To address research and developmental issues, focus is placed on resolving the technical uncertainties related to near-shore ocean thermal energy conversion (OTEC) systems with capacities ranging from 2 to $5 \mathrm{MW}_{\mathrm{e}}$. Efforts will include

- Emphasizing power conversion research by improving heat- and masstransfer process, reducing component size and water flow requirements, and using less costly materials and components

- Increasing experimental verification and testing activities needed to confirm the feasibility and performance boundaries of critical components.

In 1987, a cooperative effort by DOE, the State of Hawaii, and the Pacific International Center for High Technology Research (PICHTR) upgraded the seawater supply system at the Seacoast Test Facility (STF) at the Natural Energy Laboratory of Hawaii (NELH). This upgrade expands the OET program's capability to experimentally investigate critical components and precommercial OTEC systems.

The recent tests of heat exchangers at the Heat- and Mass-Transfer Scoping Test Apparatus (HMTSTA) have confirmed their performance projections using seawater. Research has led to the conceptual design of the Heat- and Mass-Transfer Experimental Apparatus and the Net PowerProducing Experiment (HMTEA/NPPE), which extend the testing capability sixfold from HMTSTA and provide for full system tests to be carried out. The design was pursued cooperatively by the Argonne National Laboratory (ANL), PICHTR, and the Solar Energy Research Institute (SERI).

This design, based on an extensive array of analytical tools and experimental data, permits the OET program to proceed with confidence in development and operation of the HMTEA/NPPE. 
The HMTEA/NPPE system is built around a single, vertical-axis, mixed-flow turbine rotor $2.9 \mathrm{~m}(9.5 \mathrm{ft})$ in diameter, as is illustrated on the opposite page. The rotor is supported by a vacuum vessel $7.3 \mathrm{~m}(24 \mathrm{ft})$ in diameter and $7.6 \mathrm{~m}(25 \mathrm{ft})$ high which is the structural backbone of the system. The electrical generator is an air-cooled, salientpole, synchronous generator located above the turbine assembly and outside the vacuum enclosure.

Steam is produced in an annular flash evaporator at the periphery of the vacuum vessel, which consists of 12 vertical spouts, each $0.24 \mathrm{~m}(10 \mathrm{in}$.$) in diameter. The steam flows$ up from the evaporator, through a mist eliminator located at the turbine inlet flange, and enters the turbine radially inward. The steam exits the turbine axially in the center of the vessel. A conical exhaust diffuser with center body is used to recover most of the kinetic energy of the steam discharged from the turbine. The diffuser is $3.65 \mathrm{~m}$ (12 ft) long and provides an annular entry to the first condenser stage.

The condenser is a direct-contact, structured-packing condenser composed of two coaxial stages. The first stage fills the outer annular space of the condenser assembly, between the diameters of $4.11 \mathrm{~m}(13.5 \mathrm{ft})$ and $2.43 \mathrm{~m}(8 \mathrm{ft})$, and it receives steam from the turbine diffuser. It operates in cocurrent flow, with seawater and steam flowing vertically downward through $0.61-\mathrm{m}-(2-\mathrm{ft})$-high packing material. The second stage is in the center of the condenser assembly and operates in countercurrent flow to condense the steam left over from the first stage, so that less pumping is required of the vacuum vent system. The countercurrent stage contains the same packing material as the first stage. It is smaller and longer, with an overall packing height of $0.91 \mathrm{~m}(3 \mathrm{ft})$. Cold seawater is supplied from below the condenser through a pipe that rises above the condensers at the center of the structure and that delivers all the seawater for both stages. The distribution manifold provides cold seawater to both stages through a drip tray for the countercurrent stage and a series of radial pipes for the cocurrent stage.

The noncondensable gases liberated from the seawater streams and a small amount of uncondensed steam are compressed and exhausted using a vacuum vent system.

A surface condenser outside the vacuum enclosure condenses $10 \%$ of the steam flow in order to produce desalinated water as a by-product of power generation.

At the end of the conceptual design, the components have been specified in sufficient detail that overall system performance may be predicted. Analysis projects a gross power of $213 \mathrm{~kW}$ and a net power of $84 \mathrm{~kW}$ for the system at the baseline design condition. The sensitivity of system performance to uncertainties in key variables results in a standard deviation of $5 \mathrm{~kW}$ for the net power. Considering these uncertainties, a minimum net power from the NPPE is projected to be no less than $67 \mathrm{~kW}_{\mathrm{e}}$ at design.

The small fraction of gross power available as net for the NPPE makes design and implementation of the system challenging. Replacement of existing onshore seawater supply lines is required. Less-than-projected performance by the offshore pipes, vacuum system, and seawater disposal trench under development can result in a net power of around $50 \mathrm{~kW}$. However, at this stage of the design, projections indicate that the goal of the project will be met.

Project cost is estimated at $\$ 15$ million over the next three fiscal years for the design and development. The HMTEA will be operational in mid-1991 and the NPPE in mid1992. 


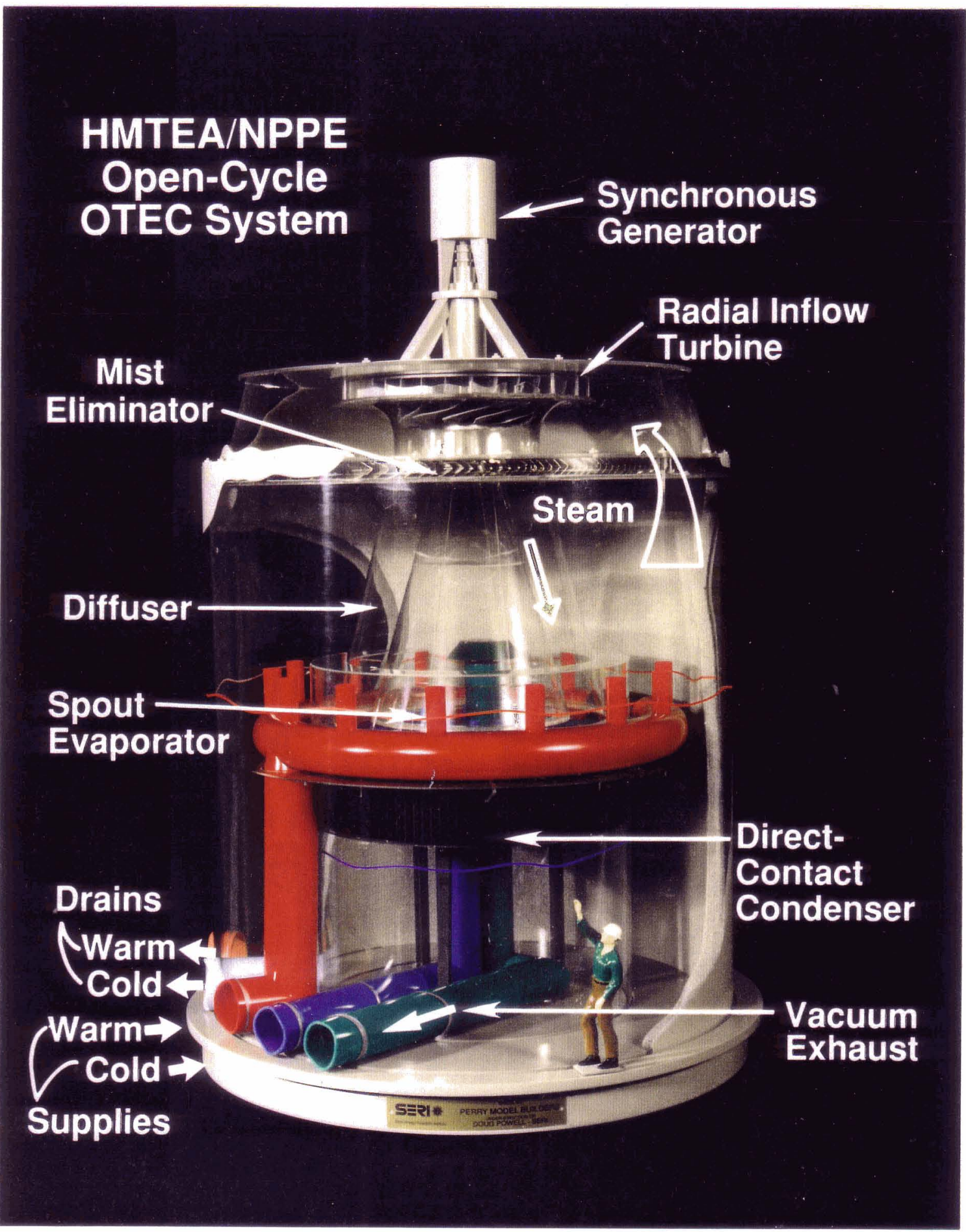

Photograph of vacuum structure showing internal arrangement of HMTEA/NPPE system components 


\section{TABLE OF CONTENTS}

$\underline{\text { Page }}$

1.0 Introduction

1.1 Background on Open-Cycle Development ................... 2

1.1.1 Background on the Seawater Systems ............... 3

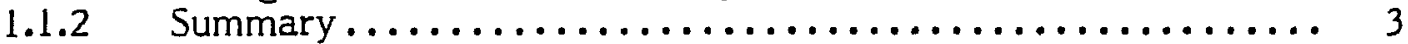

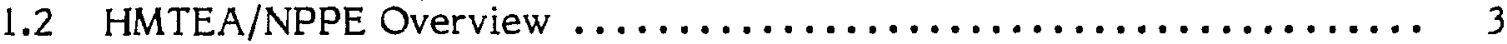

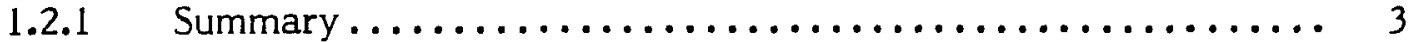

1.2 .2 Task Areas .............................. 4

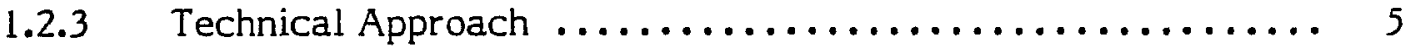

1.3 Management Approach ............................. 5

1.3.1 Organizational Roles and Responsibilities.............. 5

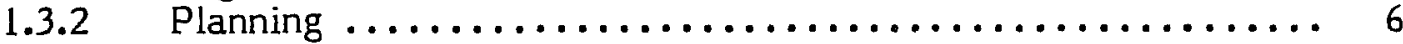

1.3.3 Project Review and Control $\ldots \ldots \ldots \ldots \ldots \ldots \ldots \ldots \ldots \ldots \ldots \ldots \ldots$

1.4 Experiment Constraints ............................. 10

2.0 System Integration $\ldots \ldots \ldots \ldots \ldots \ldots \ldots \ldots \ldots \ldots \ldots \ldots \ldots \ldots \ldots \ldots \ldots \ldots \ldots \ldots$

2.1 Goals and Objectives $\ldots \ldots \ldots \ldots \ldots \ldots \ldots \ldots \ldots \ldots \ldots \ldots \ldots \ldots \ldots \ldots \ldots \ldots 11$

2.2 Design Requirements $\ldots \ldots \ldots \ldots \ldots \ldots \ldots \ldots \ldots \ldots \ldots \ldots \ldots \ldots \ldots \ldots \ldots \ldots 11$

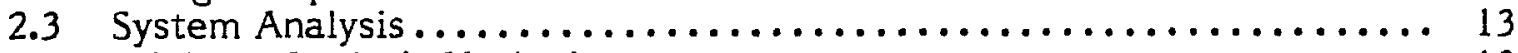

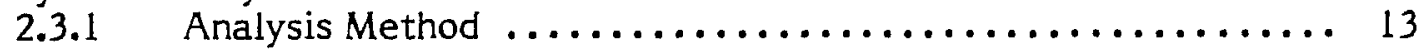

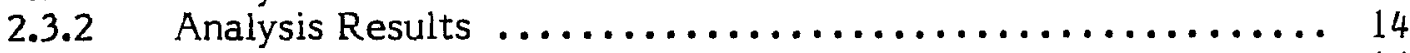

2.3 .3 Sensitivity Analysis ........................ 16

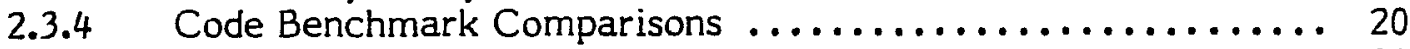

2.3.5 System Control .......................... 21

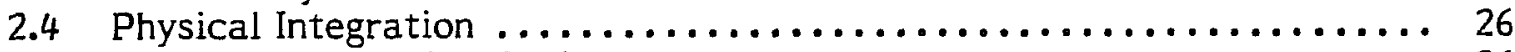

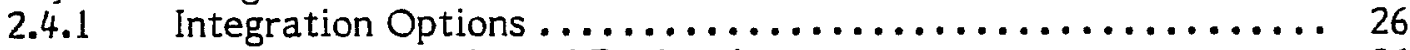

2.4.2 Selection Criteria and Rationale .................. 26

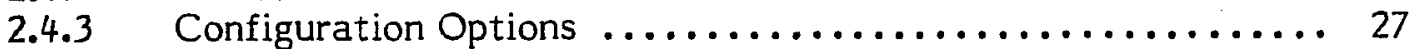

2.4.4 The Integrated NPPE System Design ................ 30

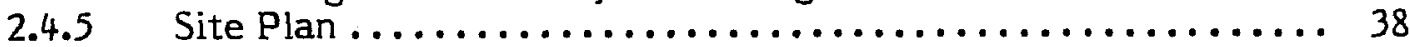

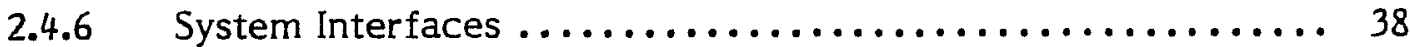

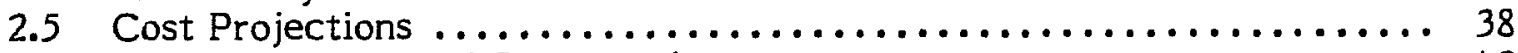

2.5 .1 Design and Construction .................... 42

2.5.2 Technical Management....................... 42

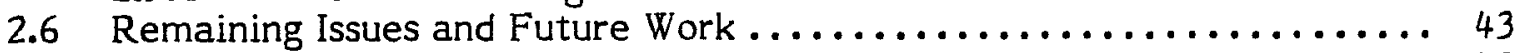

2.6 .1 Technical Issues.......................... 43

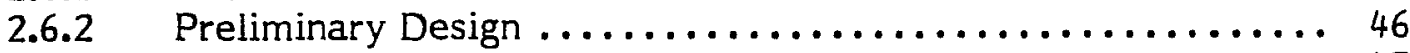

2.6.3 Final Design ............................ 47

3.0 Turbine and Structures ............................. 49

3.1 Development of the Turbine $\ldots \ldots \ldots \ldots \ldots \ldots \ldots \ldots \ldots \ldots \ldots \ldots \ldots \ldots$

3.1 .1 Goal and Objective ........................ 49

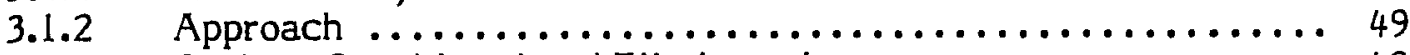

3.1.3 Options Considered and Eliminated ................. 49

3.1.3.1 Existing Hardware vs. Existing Technology ........ 49

3.1.3.2 Horizontal vs. Vertical Axis .............. 50

3.1.4 Other Major Considerations ..................... 51

3.1.4.1 Radial-Inflow vs. Axial Configuration .......... 51 


\section{TABLE OF CONTENTS (Continued)}

3.1.4.2 Modified Steam Conditions ............... 52

3.1.4.3 Speed Control ....................... 52

3.1.4.4 Variable-Position Stator Vanes .............. 53

3.1.5 Design Performance and Uncertainties ............... 53

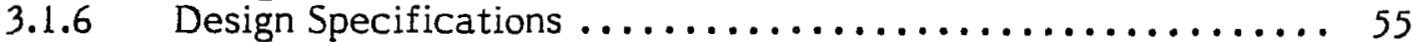

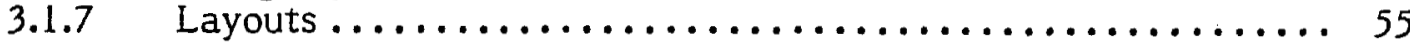

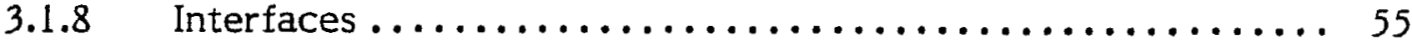

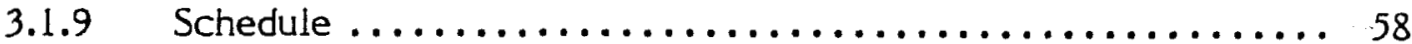

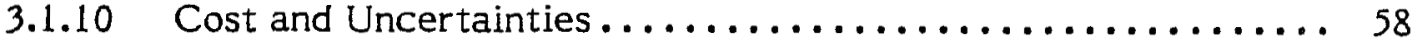

3.2 Structures................................... 58

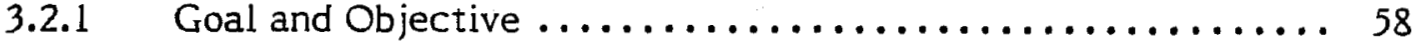

3.2 .2 Approach $\ldots \ldots \ldots \ldots \ldots \ldots \ldots \ldots \ldots \ldots \ldots \ldots \ldots \ldots \ldots \ldots \ldots \ldots . \ldots \ldots$

3.2.3 Options Considered and Eliminated ................ 61

3.2.3.1 Dome vs. Telephone Configuration ............ 61

3.2.3.2 Materials for Vacuum Vessel Walls ............ 62

3.2.4 Other Major Considerations ..................... 65

3.2.4.1 Position of the Condenser ............... 65

3.2.4.2 Diameter of the Vacuum Vessel ............ 65

3.2.4.3 Height of the Vacuum Vessel.............. 65

3.2.5 Design Performance and Uncertainties ............... 66

3.2 .6 Design Specifications ........................ 67

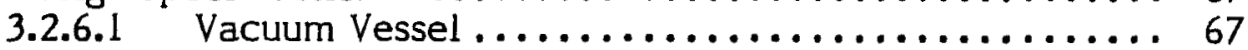

3.2.6.2 Control and Auxiliary Buildings ............. 69

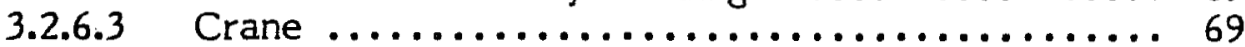

$3.2 .7 \quad$ Layouts $\ldots \ldots \ldots \ldots \ldots \ldots \ldots \ldots \ldots \ldots \ldots \ldots \ldots \ldots \ldots \ldots \ldots \ldots \ldots \ldots . \ldots \ldots$

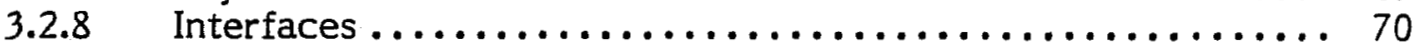

3.2 .9 Schedule $\ldots \ldots \ldots \ldots \ldots \ldots \ldots \ldots \ldots \ldots \ldots \ldots \ldots \ldots \ldots \ldots \ldots \ldots \ldots \ldots$

3.2 .10 Cost and Uncertainties ....................... 71

4.0 Seawater Systems $\ldots \ldots \ldots \ldots \ldots \ldots \ldots \ldots \ldots \ldots \ldots \ldots \ldots \ldots \ldots \ldots \ldots \ldots \ldots$

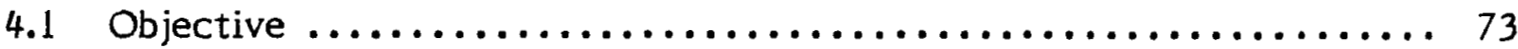

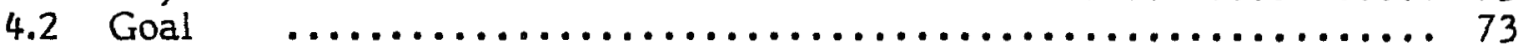

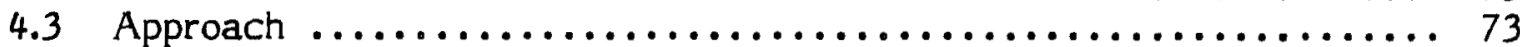

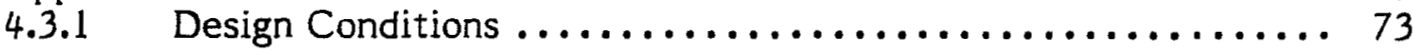

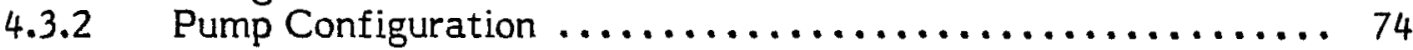

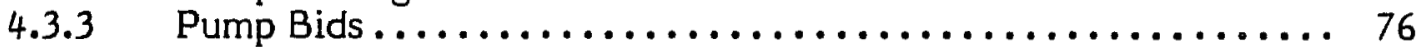

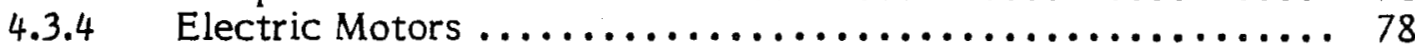

4.3 .5 Control of Flow Rate ......................... 81

4.3 .6 Supply and Discharge Pipes .................... 81

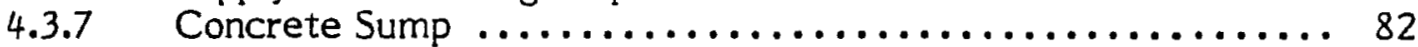

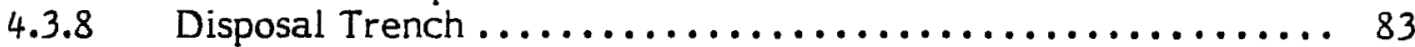

4.3 .9 Seawater System Tests ........................... 84

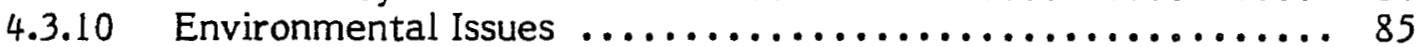

$4.3 .11 \quad$ Plant Safety .............................. 85

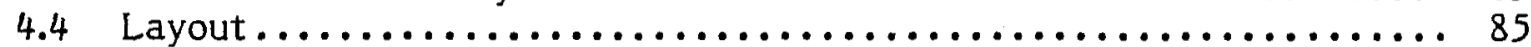

4.5 Performance ................................. 87

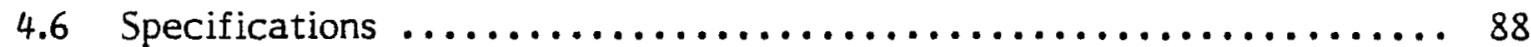

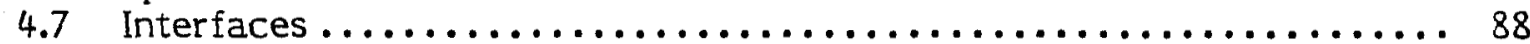

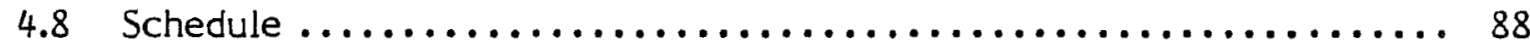




\section{TABLE OF CONTENTS (Continued)}

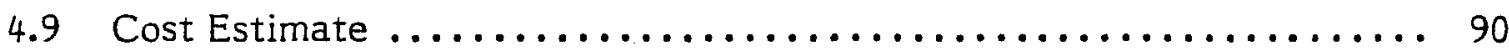

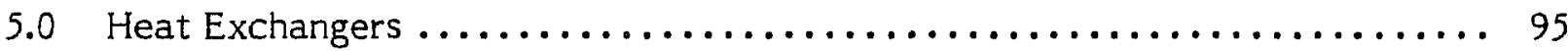

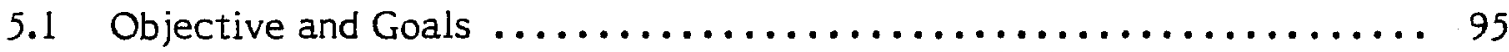

5.1.1 Composition of the Heat Exchanger Task Team

and Documentation ............................ 95

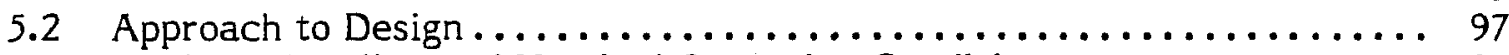

5.2.1 Baseline and Nominal Operating Conditions ............ 97

5.2.2 Major Geometric and Operational Considerations .......... 98

5.2.3 Secondary Heat Exchanger for Desalinated Water

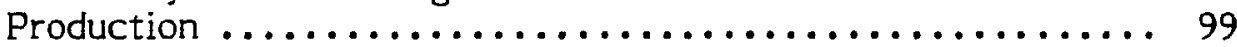

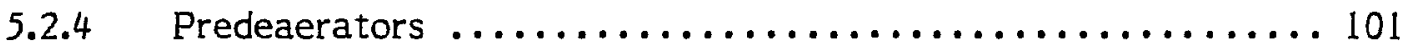

5.3 Conceptual Design of Heat Exchanger Components $\ldots \ldots \ldots \ldots \ldots \ldots 102$

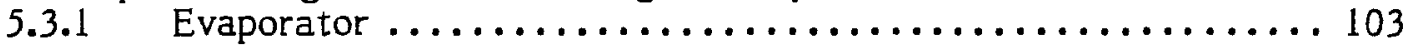

5.3.1.1 Evaporator Planform Area and Loading......... 103

5.3.1.2 Evaporator Spouts .................... 106

5.3.1.3 Evaporator Water Supply and Distribution ....... 106

5.3.1.4 Flow Variation in the Evaporator

Distributor ........................... 107

5.3.1.5 Evaporator Discharge Plenum .............. 107

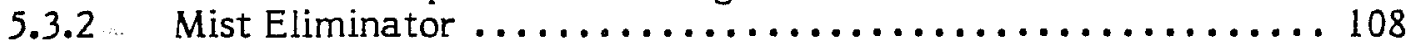

5.3.3 Direct-Contact Condenser (DCC).................. 108

5.3.3.1 DCC Planform Area and Required Loadings ....... 110

5.3.3.2 Structured Packing and Condenser Heights........ 111

5.3.3.3 Water Distributors for the DCC ............. 112

5.3.3.4 Control of Water Flow ..................113

5.3.3.5 Discharge Plenum of the Direct-Contact

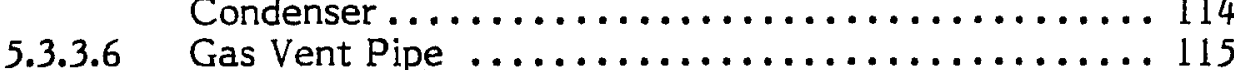

5.3.4 Hydraulic Losses of Main Heat Exchangers ............. 115

5.3.5 Surface Condenser for Desalinated Water Production........ 116

5.4 Design Performance and Uncertainties . . . . . . . . . . . . . . . . . 116

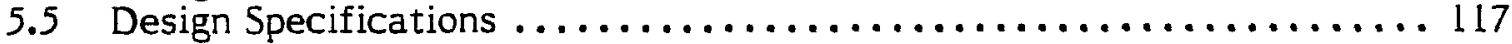

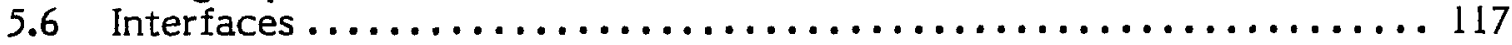

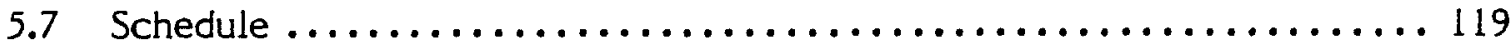

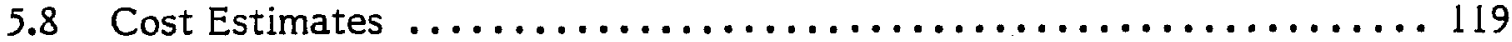

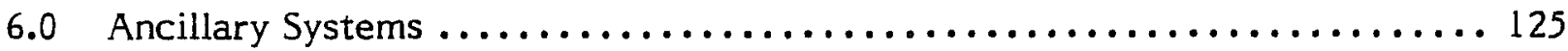

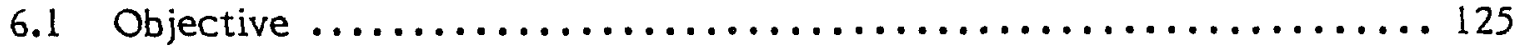

6.2 Goal............................................. 125

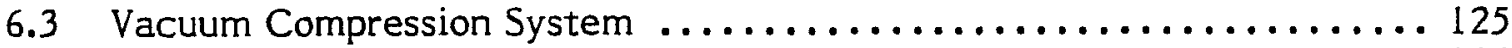

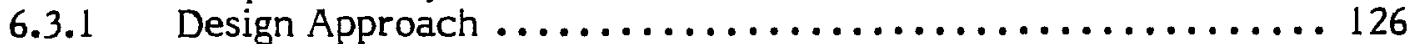

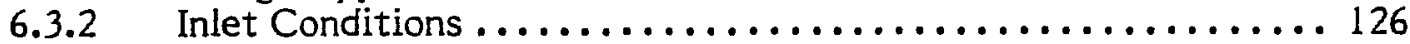

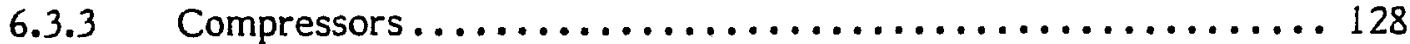

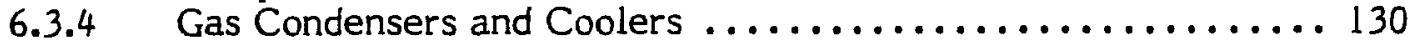

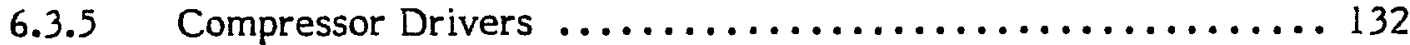

6.3.6 Other Vacuum Compressor Support Equipment $\ldots \ldots \ldots \ldots \ldots 133$

6.3.7 Conceptual Design Performance Prediction $\ldots \ldots \ldots \ldots \ldots \ldots 133$ 
TABLE OF CONTENTS (Concluded)

Page

6.3.8 Preliminary Design Contract.................... 135

6.3.9 Remaining Issues and Uncertainties ................. 135

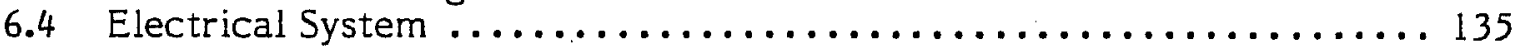

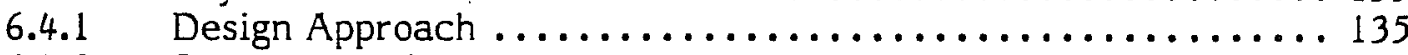

6.4.2 System Requirements and Options .................. 135

6.4 .3 Cost Estimates ............................... 137

6.4.4 Remaining Issues and Uncertainties ................. 137

6.5 Instrumentation and Control Systems $\ldots \ldots \ldots \ldots \ldots \ldots \ldots \ldots \ldots \ldots \ldots \ldots \ldots \ldots \ldots \ldots \ldots \ldots \ldots$

6.5.1 Design Approach . ........................... 137

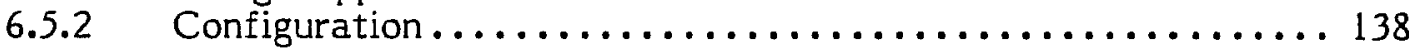

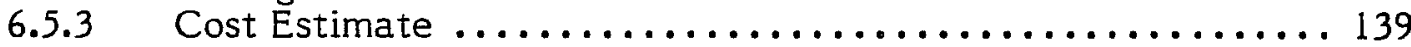

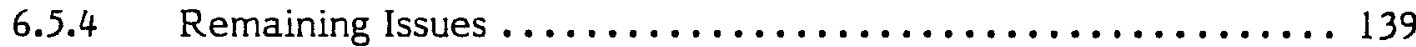

6.6 Miscellaneous Ancillary Systems $\ldots \ldots \ldots \ldots \ldots \ldots \ldots \ldots \ldots \ldots \ldots \ldots \ldots \ldots$

$6.6 .1 \quad$ Design Approach .............................. 140

6.6 .2 Cooling-Water Circulation ...................... 140

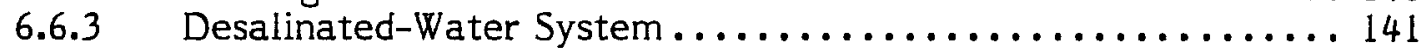

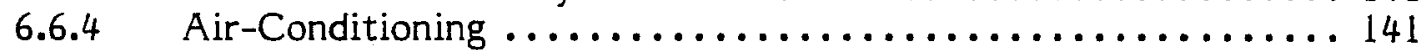

6.6.5 Other Miscellaneous Items......................... 141

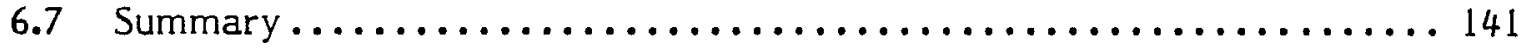

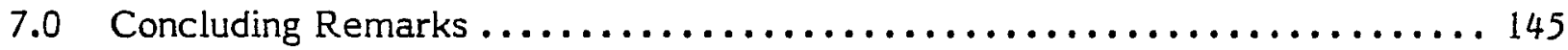

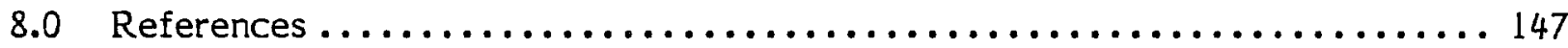

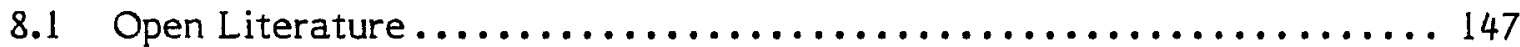

8.2 Internal Documents................................. 149

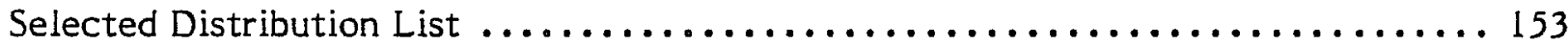




\section{LIST OF FIGURES}

$\underline{\text { Page }}$

1-1 Work breakdown structure for the development of HMTEA/NPPE $\ldots \ldots \ldots \ldots \quad 7$

1-2 Research activities and plan for the development of HMTEA/NPPE ...... 8

1-3 Schedule for design and developmental activities for HMTEA/NPPE ...... 9

2-1 Variation of gross power vs. steam flow for the net power-producing

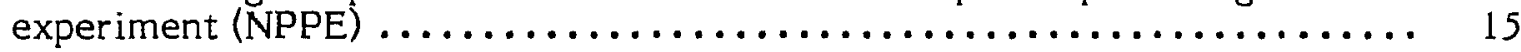

2-2 Variations of HMTEA/NPPE system net power with resource-seawater

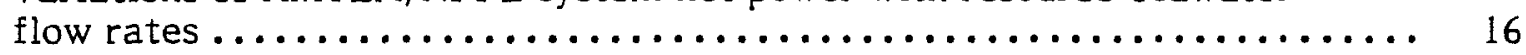

2-3 Sketches of "telephone" and "dome" configurations for HMTEA/NPPE ..... 27

2-4 General arrangement of components in "telephone" configuration

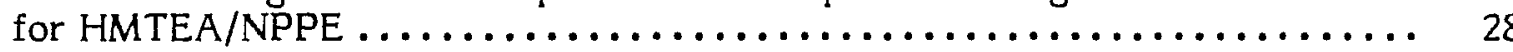

2-5 General arrangement of components in "dome" configuration for HMTEA/NPPE

2-6 Engineering sketch of HMTEA/NPPE

2-7 Process flow diagram for HMTEA/NPPE, with critical interfaces identified

2-8 Photograph of vacuum structure showing internal arrangement of

HMTEA/NPPE system components .........................

2-9 Site plan for HMTEA/NPPE at the DOE Seacoast Test Facility,

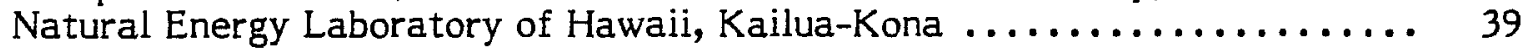

3-1 Approach to turbine development $\ldots \ldots \ldots \ldots \ldots \ldots \ldots \ldots \ldots \ldots \ldots, 50$

3-2 Operating conditions for system and turbine $\ldots \ldots \ldots \ldots \ldots \ldots \ldots \ldots \ldots, 53$

3-3 Turbine off-design performance characteristics $\ldots \ldots \ldots \ldots \ldots \ldots \ldots \ldots .64$

3-4 Design concept for the turbine/generator $\ldots \ldots \ldots \ldots \ldots \ldots \ldots \ldots \ldots \ldots, 56$

3-5 Physical interface between turbine and structure $\ldots \ldots \ldots \ldots \ldots \ldots \ldots \ldots .57$

3-6 Diagram of principal interfaces, NPPE turbine $\ldots \ldots \ldots \ldots \ldots \ldots \ldots \ldots \ldots . . \ldots 9$

3-7 A partial representation of Dillingham design of the HMTEA $\ldots \ldots \ldots \ldots \ldots .61$

3-8 Steel wall option for vacuum vessel $\ldots \ldots \ldots \ldots \ldots \ldots \ldots \ldots \ldots \ldots \ldots \ldots, 63$

3-9 Platform layout (a) and penetration layout (b) of vacuum vessel......... 66 


\section{LIST OF FIGURES (Concluded)}

Page

3-10 Layout of control building and associated structures $\ldots \ldots \ldots \ldots \ldots \ldots \ldots 68$

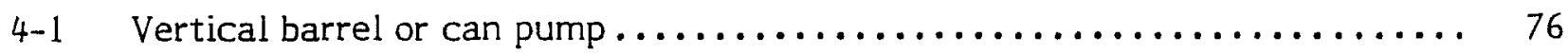

4-2 Vertical wet pit pump installation in the pump station $\ldots \ldots \ldots \ldots \ldots \ldots \ldots$. 77

4-3 Sample warm-seawater pump curves $\ldots \ldots \ldots \ldots \ldots \ldots \ldots \ldots \ldots \ldots \ldots .79$

4-4a Sample cold-seawater pump curves $\ldots \ldots \ldots \ldots \ldots \ldots \ldots \ldots \ldots \ldots \ldots .60$

4-4b Sample cold-seawater pump curves $\ldots \ldots \ldots \ldots \ldots \ldots \ldots \ldots \ldots \ldots \ldots . \quad 80$

4-5 Concrete sump and 1.22-m (48-in) discharge pipe with spool piece (R.M. Towill 1989)...................................... 84

4-6 Warm-seawater system heads and elevations, draft, $9 / 22 / 89 \ldots \ldots \ldots \ldots \ldots 86$

4-7 Cold-seawater system heads and elevations, draft, $11 / 08 / 89 \ldots \ldots \ldots \ldots . \quad 87$

4-8 Seawater systems interface diagram, $12 / 6 / 89 \ldots \ldots \ldots \ldots \ldots \ldots \ldots \ldots . . \ldots 1$

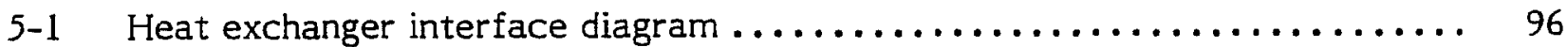

5-2a Plan view of heat exchangers and evaporator distributor $\ldots \ldots \ldots \ldots \ldots \ldots .104$

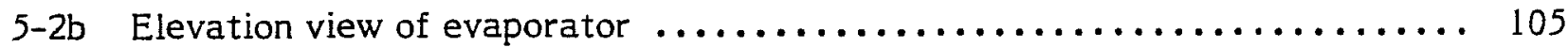

5-3 Influence of liquid loading on seawater spout evaporator $\ldots \ldots \ldots \ldots \ldots \ldots 106$

5-4 Elevation view of direct-contact condenser $\ldots \ldots \ldots \ldots \ldots \ldots \ldots \ldots \ldots . .109$

5-5 Model parametric runs for NPPE, packing and freefall heights .......... 112

5-6 Elemental section of test unit $\ldots \ldots \ldots \ldots \ldots \ldots \ldots \ldots \ldots \ldots \ldots \ldots \ldots, 117$

5-7 Overall view of condenser test unit $\ldots \ldots \ldots \ldots \ldots \ldots \ldots \ldots \ldots \ldots \ldots \ldots, 118$

6-1 Conceptual design of vacuum compressor system $\ldots \ldots \ldots \ldots \ldots \ldots \ldots \ldots, 126$

6-2 Pressure-volume diagram for centrifugal and positive-displacement types of machines $\ldots \ldots \ldots \ldots \ldots \ldots \ldots \ldots \ldots \ldots \ldots \ldots \ldots \ldots, 134$ 


\section{LIST OF TABLES}

$\underline{\text { Page }}$

2-1 HMTEA/NPPE Seawater System Design Conditions as of

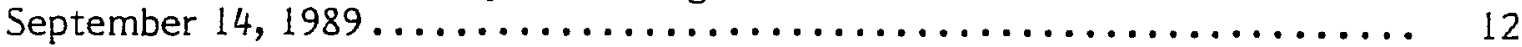

2-2 Power Budget Distribution and Design Projections $\ldots \ldots \ldots \ldots \ldots \ldots \ldots .14$

2-3 Nominal Design Conditions for the NPPE System

(Projections at Nov. 1989) .............................. 17

2-4 NPPE System Net Power Sensitivities ....................... 19

2-5 Systems Code Benchmark Comparison of NPPE Design Conditions ....... 22

2-6 HMTEA/NPPE System Specifications $\ldots \ldots \ldots \ldots \ldots \ldots \ldots \ldots \ldots \ldots \ldots . . \ldots \ldots$

2-7 List of Critical System Interfaces $\ldots \ldots \ldots \ldots \ldots \ldots \ldots \ldots \ldots \ldots . .40$

2-8 HMTEA/NPPE Project Costs at Nov. $1989 \ldots \ldots \ldots \ldots \ldots \ldots \ldots \ldots \ldots . \ldots 4$

3-1 Preliminary Design Evaluation for Turbine $. . \ldots \ldots \ldots \ldots \ldots \ldots \ldots \ldots . . \ldots 1$

3-2 Steam Inlet and Outlet Conditions for the NPPE Turbine $\ldots \ldots \ldots \ldots \ldots \ldots$..... 52

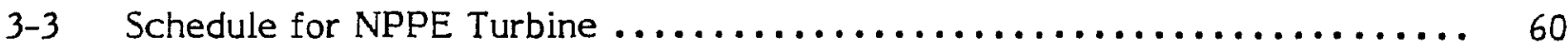

3-4 NPPE Turbine Costs $\ldots \ldots \ldots \ldots \ldots \ldots \ldots \ldots \ldots \ldots \ldots \ldots \ldots \ldots \ldots \ldots, 60$

3-5 Schedule for NPPE Structures Task $\ldots \ldots \ldots \ldots \ldots \ldots \ldots \ldots \ldots \ldots \ldots \ldots, 71$

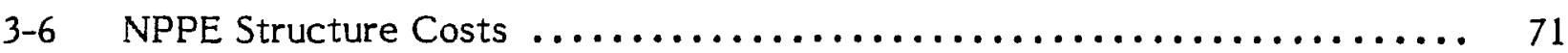

4-1 NPPE Seawater Systems Performance Summary (as of 11-15-89) ........ 89

4-2 Seawater Systems Specifications as of $11-15-89 \ldots \ldots \ldots \ldots \ldots \ldots \ldots .90$

4-3 Seawater Systems Schedule (as of $11-15-89) \ldots \ldots \ldots \ldots \ldots \ldots \ldots \ldots . \ldots . \ldots 1$

4-4 Cost Estimate for the HMTEA/NPPE Seawater Systems . ............ 92

5-1 Options for Secondary Condensers--Desalinated Water Production ....... 100

5-2 Performance Predictions at Nominal Conditions (Summary) ........... 119

5-3 Heat Exchangers: Specifications and Related Parameters ............ 120

5-4 Projected Schedule for Heat Exchangers ..................... 122

5-5 Breakdown of Heat Exchanger Costs $\ldots \ldots \ldots \ldots \ldots \ldots \ldots \ldots \ldots \ldots \ldots . . . \ldots \ldots$

6-1 Key Performance Parameters for a VCS $\ldots \ldots \ldots \ldots \ldots \ldots \ldots \ldots \ldots \ldots .127$ 


\section{LIST OF TABLES (Concluded)}

$\underline{\text { Page }}$

6-2 Basis for Defining the Requirements for the VCS Design . . . . . . . ... 127

6-3 Inlet NPPE Operating Requirements for the Preliminary VCS . . . . . . . . 128 Design Contract

6-4 Compression System Power Projection Using Existing Positive-

Displacement Compressor Hardware at Standard Pressure Ratios . . . . . . . 129

6-5 Compression System Power Projection Using Existing Positive-

Displacement Compressor Hardware at Lower-Than-Standard

Pressure Ratios .................................. 130

6-6 Summary of Gas Condenser/Cooler Types Considered for the

Precooler and Intercooler Designs of the HMTEA/NPPE VCS . . . . . . . . 131

6-7 Cost Estimate for Ancillary Electric System . . . . . . . . . . . . . . 137

6-8 Instrumentation and Controls Needed for the HMTEA/NPPE $\ldots \ldots \ldots \ldots \ldots$

6-9 Power Consumption Estimate for Ancillary Systems . . . . . . . . . . . . 142

6-10 Cost Estimate for Ancillary Systems ....................... 142

6-11 Summary Schedule for Ancillary Systems . . . . . . . . . . . . . . . . . 142 


\section{CHAPTER 1.0}

\section{INTRODUCTION}

Ocean thermal energy conversion (OTEC) technology is based on the principle that energy can be extracted from two reservoirs if they are different temperatures. A temperature difference of about $20^{\circ} \mathrm{C}$ can be exploited effectively to produce usable energy. Temperature differences of this magnitude exist between ocean waters at the surface and at depths up to $1000 \mathrm{~m}$ in many areas of the world, in tropical latitudes between 24 deg north and south of the equator. Here, surface water temperatures typically range from $24^{\circ} \mathrm{C}$ to $29^{\circ} \mathrm{C}$, and temperatures at a depth of $1000 \mathrm{~m}$ typically range from $4^{\circ} \mathrm{C}$ to $6^{\circ} \mathrm{C}$. This constitutes a vast, renewable resource for baseload power generation.

The U.S. Department of Energy (DOE) has concentrated on two OTEC power cycles for converting this thermal energy to electrical energy, namely, closed cycle and open cycle. In a closed-cycle system, warm seawater is used to vaporize a working fluid, such as ammonia, flowing through an evaporator. The vapor expands at moderate pressures and turns a turbine. The vapor is condensed in a condenser using cold seawater pumped from the ocean's depth through a cold-water pipe. The condensed working fluid is recirculated to the evaporator to repeat the cycle.

In an open-cycle system, steam generated from the warm seawater is the working fluid. A small portion of the warm seawater is flash-evaporated in a vacuum chamber at an absolute pressure of about $2.4 \mathrm{kPa}(0.34 \mathrm{psia})$ to produce steam. The steam expands through a low-pressure turbine coupled to a generator to produce electricity. The steam exiting the turbine is condensed using the cold seawater in a direct-contact condenser. If a surface condenser is used, the condensed steam provides desalinated water as well.

Open-cycle research is based on the projected advantages of water production and of completely or partially eliminating conventional heat exchangers in the cycle and the penalties of performance and cost associated with them. Whether the full potential for this approach can be realized depends on achieving acceptable levels of power-conversion efficiency and on reducing parasitic losses in the highly coupled process in systems of sufficiently large scale.

Analytical efforts coupled with experimental verification on components have indicated that open-cycle systems appear promising. These results lead to experimentally investigating the feasibility of this to validate the analytical projections on a system level. Combining experimental efforts for the open-cycle heat exchangers with those of the turbine subsystem will result in a validated technical data base for the open-cycle power system. System-level experiments will be carried out through design, construction, and operation of the Heat- and Mass-Transfer Experimental Apparatus (HMTEA) and the net power-producing experiment (NPPE).

The purpose of the present investigation is to determine the interaction among the various components, to determine the net-to-gross power output, and to validate and refine analytical models. Practical experience gained in these experiments will provide a basis for substantiating and modifying the assumptions used in the analyses. A second outcome of the research will be the verification of the technical feasibility of the opencycle (OC) OTEC process, over an extended period of time, at a precommercial scale. 


\subsection{Background on Open-Cycle Development}

In 1979, Westinghouse Corporation, with DOE funding, completed design studies for a $100-\mathrm{MW}$ OC-OTEC plant (Westinghouse 1979). A design was developed for a floating system that used a large vertical-axis turbine, a channel flash evaporator, and a surface condenser enclosed in a reinforced concrete vacuum vessel. This design described a castconcrete containment structure that combined multiple structural functions with an axisymmetric layout for the major system components. The study concluded that an open-cycle plant could be a cost-effective alternative to the closed-cycle designs. It identified flash evaporation, direct-contact condensation, and use of innovative materials for the turbine and structural elements as ways to further reduce costs significantly.

A study in 1985 completed by a team from the Florida Solar Energy Center (FSEC) and Creare R\&D, Inc., explored the economic and technical viability of OC-OTEC for producing electricity and desalinated water based on hardware reflecting the current state of the art (Block and Valenzuela 1985). FSEC and Creare concluded that such plants could deliver desalinated water and electricity at a competitive cost to many island markets, with plant sizes of less than $20 \mathrm{MW} e$ and, in many cases, with plants in the $2-10 \mathrm{MW}$ e size range.

The FY 1985-1989 federal Ocean Energy Technology (OET) Multiyear Program Plan (issued in December 1985) defined the long-range mission for the program as follows:

to develop ocean energy technology to a point where the commercial sector can make competent assessments of whether applications of the technology are viable energy conversion alternatives, or supplements, to systems presently in use (U.S. DOE 1985).

This mission would be accomplished by researching components and modeling systems.

A fresh-water direct-contact heat- and mass-transfer laboratory was designed and built at the Solar Energy Research Institute (SERI) to study and improve methods for transferring heat and mass under small driving forces at low operating pressures. A number of evaporator geometries were tested in this facility. These tests led to the definition and experimental evaluation of a vertical-spout evaporator, which has a thermal effectiveness ranging from $90 \%$ to $97 \%$ with a spout head loss of approximately $0.7 \mathrm{~m}$ (Bharathan and Penney 1983).

Extensive experiments were carried out on various configurations of contacting media suitable for condensing steam at the low pressures applicable for OC-OTEC. These experiments identified condensers using structured packing to yield an effectiveness in the $86 \%$ to $90 \%$ range with minimal vapor pressure loss and a water head loss of less than $2.0 \mathrm{~m}$ (Bharathan, Parsons, and Althof 1988).

The data from these experiments were used to validate detailed analytical models describing the performance of the direct-contact condensers (Bharathan, Parsons, and Althof 1988). The development of this analytical capability and the definition of hardware concepts that achieve the performance potential inherent in the direct-contact processes were significant steps in the OET program.

Most recent research efforts in the OET program were to scale up the experimental apparatus to a thermal capacity of over $1 \mathrm{MW}$ using seawater as the process fluid. This apparatus, called the Heat- and Mass-Transfer Scoping Test Apparatus (HMTSTA), was designed and built cooperatively by the Argonne National Laboratory (ANL) and SERI and 
is installed at the Seacoast Test Facility (STF) at the Natural Energy Laboratory of Hawaii (NELH) (Parsons et al. 1989).

Tests in the HMTSTA confirmed the heat- and mass-transfer performance of spout evaporators and structured packing condensers observed in fresh-water experiments and predicted by analytical models (Zangrando et al. 1989). Data on the performance of surface condensers and on seawater deaeration also were obtained in HMTSTA experiments.

Over the past decade, sufficient data and operational experience have been gathered to permit the OET program to undertake the next step with confidence, namely, designing a larger system, the HMTEA/NPPE.

A parallel set of activities toward developing a suitable turbine for the NPPE began in October 1987 with a workshop held at the Pacific International Center for High Technology Research (PICHTR). The outcome of the workshop led to two approaches, namely, using existing hardware and pursuing existing technology to develop the turbine. PICHTR investigated a variety of existing rotor stages for their potential use. In March 1988 SERI released a Request for Proposal to turbine manufacturers for developing a turbine. Preliminary designs were pursued using both approaches; they were evaluated in July 1989. The evaluations led to the choice of a newly designed turbine, primarily to minimize the technical risk. The early start of these activities in turbine development resulted in the most complete design to date of any of the major components for the NPPE.

\subsubsection{Background on the Seawater Systems}

In 1987, the warm and cold resource seawater at the STF at the NELH became more available. In a joint effort by DOE, the State of Hawaii, and PICHTR, a state-of-the-art cold-water pipe was installed. This polyethylene pipe is $1 \mathrm{~m}$ in diameter and $2060 \mathrm{~m}$ long and is deployed to a water depth of $675 \mathrm{~m}$, with the deeper section in an inverted buoyant catenary configuration (Lewis, Van Ryzin, and Vega 1988). Along with an upgraded warm-seawater intake system, the facility çan now deliver volume flows of cold and warm seawater of $0.41 \mathrm{~m}^{3} / \mathrm{s}$ and $0.61 \mathrm{~m}^{3} / \mathrm{s}$, respectively, to the OTEC facilities. Another $0.43 \mathrm{~m}^{3} / \mathrm{s}$ of cold water is delivered to other NELH experiments, primarily in mariculture, A cooperative agreement between DOE and the State of Hawaii stipulates that $0.41 \mathrm{~m}^{3} / \mathrm{s}$ of the total cold water will be available to the continuing research activities in the OET program.

\subsubsection{Summary}

The sequence of steps followed over the past decade in developing the OC-OTEC technology and installing a seawater system at the NELH has led to the conceptual design of the HMTEA/NPPE described in the remainder of this report. This design, based on an extensive array of analytical tools and experimental data, permits the OET program to proceed with confidence to a net-power-generating system for performance studies and verification.

\subsection{HMTEA/NPPE Overview}

\subsubsection{Summary}

The design of the HMTEA/NPPE builds on performance data obtained on heat exchangers using seawater at the HMTSTA (Zangrando et al. 1989), turbine design studies (Mechanical Technology Inc. 1989; Fong, Masutani, and Neill 1989), and HMTEA design studies by 
industry teams (Dillingham 1987a; PICHTR 1988). The apparatus will be designed and built in phases. The HMTEA will permit a sixfold scale-up from the HMTSTA of heatand mass-transfer hardware to validate predictive codes at a scale consistent with resource water availability. The HMTEA will also provide data that will facilitate effective operation of the NPPE with minimum technical risk for producing net power. The NPPE will be complete when a turbine/generator unit is integrated into the HMTEA.

The experimental testing of this system will meet the OET program goals when net power is produced at a design goal of $40 \mathrm{~kW}$. The data gathered with the HMTEA/NPPE will augment the technical data base to validate system performance predictive codes and to understand the system component interactions and stability and control characteristics of a power-producing system. The operational experience will generate insights into the dynamic stability; transient response; and the long-term reliability, availability, performance, and maintainability of the system.

\subsubsection{Task Areas}

The design of the HMTEA/NPPE is organized into five major technical areas for managing the design effort:

- Systems integration

- Turbine/structures

- Seawater systems

- Heat exchangers

- Ancillary systems.

The systems integration task provides overall guidance to the HMTEA/NPPE development. Setting directions and goals, planning, and managing all aspects of the development fall under this task.

The turbine/structures task carries forward the designs for the turbine and structures within the general framework established by the design team. Development of all support facilities is included in this task.

The seawater systems task addresses issues related to the supply and discharge of the seawater to and from the facility. Other areas under this task include safety, permits, and environmental issues.

The heat exchanger task addresses the design and development of the direct-contact and surface heat exchangers. Other areas included under this task are predeaeration and activities related to heat- and mass-transfer tests.

The ancillary systems task addresses issues related to the development of all remaining components and systems. Specifically these areas include the development of the vacuum system, electrical systems, miscellaneous cooling systems, instrumentation and control, and data-acquisition systems.

For the conceptual design, the systems integration analysis treats the other four tasks representing the major subsystems as "black boxes" with a projected practical performance. This analysis defines the design and operating parameters to achieve the required system performance and establishes the design interfaces among the components. The details of the analyses, designs, and specifications that describe the systems integration effort and each of the major subsystems are presented in subsequent chapters of this report. The system analysis and physical integration design presented in 
Chapter 2.0 establishes the design parameters for each of the components and is a necessary precursor to the detailed design work. Descriptions of the design effort carried out in the other four task areas follow in the subsequent chapters.

\subsubsection{Technical Approach}

The technical approach to developing the HMTEA/NPPE is to complete a three-phase design--conceptual, preliminary, and engineering--before constructing the experiment. In each phase of the design, all aspects of the system should be addressed, with increasing detail as the design progresses. The products of all phases of the design will be in the form of drawings and specifications, performance analyses and projections, cost estimates, schedules, and status reports of progress.

The following defines the differences in the products for each of these cycles.

Conceptual Design. The purpose of the conceptual design is to identify and evaluate an experimental concept that can most effectively meet the research goal for the project. In the conceptual design, investigators must emphasize the performance analysis using the best tools available to identify the mix and arrangement of subsystems and components that can best achieve the stated goal. The drawings developed are engineering sketches to define the overall configuration and arrangement of key components and subassemblies. Cost estimates will be provided to assess that the experiment can be completed within the overall program budget. At this time these costs must be considered rough-order-of-magnitude estimates.

At the end of the conceptual design, the type, specifications, and arrangement of the major subassemblies to achieve the experimental objectives will be established.

Preliminary Design. The purpose of the preliminary design is to establish the engineering and economic feasibility of the experimental concept (established earlier) by identifying the engineering design and reconfirming the performance projections of the concept.

The mix between the drawings and analysis shifts toward design and cost activities; the level of analytical efforts increases in an attempt to reduce the technical and cost uncertainties to less than 25\%. This implies that the analytical models and assumptions need to be rigorously justified, and the drawings need to provide sufficient details that engineering realities are reflected in the cost and performance projections.

At the end of the preliminary design, the system design and detailed subassembly specifications will be established.

Engineering Design. The purpose of the final engineering design is to produce the design and documentation necessary to build and install the experiment. Thus, the emphasis shifts almost entirely to the design of subassemblies and components. The only analysis required is to evaluate such changes in subsystem performance arising out of detailed engineering design and to develop the detailed test program.

\subsection{Management Approach}

\subsubsection{Organizational Roles and Responsibilities}

The management approach for the HMTEA/NPPE project is built around implementing a cooperative team effort involving SERI, ANL, and PICHTR working under DOE direction. The management process was initiated in a planning session involving the first 
working group of the three participating organizations on February 22-23, 1989 (Presentation Packages 1989). In this session and the plan that resulted from it, five task teams were formed that included members from each laboratory and a representative from DOE. A task leader was identified for each area. SERI was given the lead role for HMTEA/NPPE system development in the conceptual design; ANL and PICHTR were given supporting roles. All organizations will participate in the design and implementation. PICHTR will assume lead responsibility in the later design stages and implementation.

\subsubsection{Planning}

The first working group reviewed and clarified the HMTEA/NPPE plans that were developed, established teams for completing the project, defined operational and review procedures, and established a baseline configuration for the HMTEA/NPPE that would form the point of departure for all future design work. Out of this planning activity, a system development management plan (First Working Group 1989) was developed on the basis that

- The NPPE would be ready for testing in the first quarter of 1993.

- The needed resources in terms of labor and dollars were available.

- The defined "baseline" configuration would remain the concept from which further variations would occur.

The management plan organizes the project according to the system skeleton work breakdown structure shown in Figure $1-1$. This structure follows a detailed structure developed specifically for OTEC systems (Value Engineering 1979).

The HMTEA/NPPE project is scheduled in the time frame indicated on the OET program activities chart shown in Figure 1-2.

A detailed Gantt chart for the project is shown in Figure 1-3. Major milestones in the project are completing the three stages of design, the construction and installation of the system, and the performance tests in the HMTEA and the NPPE. The items on the critical path toward the project completion are the development of the turbine for the NPPE and the structure and vacuum exhaust systems for the HMTEA. Further assessments of the schedule during the conceptual design stages indicate that with an accelerated effort, the HMTEA will be operational in mid-1991 and the NPPE in mid-1992, provided the current levels of effort can be maintained.

The NPPE systems team is responsible for reviewing and updating all elements of the management plan.

\subsubsection{Project Review and Control}

In addition to the normal program control exercised by DOE through the annual operating plan and field work proposals, the HMTEA/NPPE project will incorporate formal review procedures that will provide for consulting, evaluation, and recommendation services to each of the task areas.

The individual task teams are responsible for resolving technical issues. If an issue cannot be resolved at the task level, it will be referred to the systems team for resolution. If resolution does not occur at that level, it will be carried forward to DOE for final resolution. 
At the end of each phase, DOE, SERI, ANL, and PICHTR, with provision made for independent evaluations by selected expert(s) from outside the program, will review the project before it moves to the next development phase. The form for this review will be a formal presentation of project results, status, and unresolved issues documented in a technical report similar to this conceptual design report.

The individual task leader is the communication facilitator, keeping the systems integrations task leader informed through weekly highlights and direct and special communication. In writing to the systems integration task leader, the individual task leader documents specific work assignments, specific conclusions or recommendations made by the team, unresolvable issues, or factors affecting other tasks. The individual task leader is reponsible for maintaining communication and information flow among his or her task team members.

The primary task control vehicle is a task plan produced by the task leader and approved by the systems integration team. The plan will communicate task objectives, strategy, and tactics. The technical milestones for the organization's annual plan will be incorporated into the project plan and will be meaningful measurements of the percentage of completion of a given task. The milestones will be used by the systems integration task leader to evaluate progress against the goal and to recommend corrective or preventive action as required.

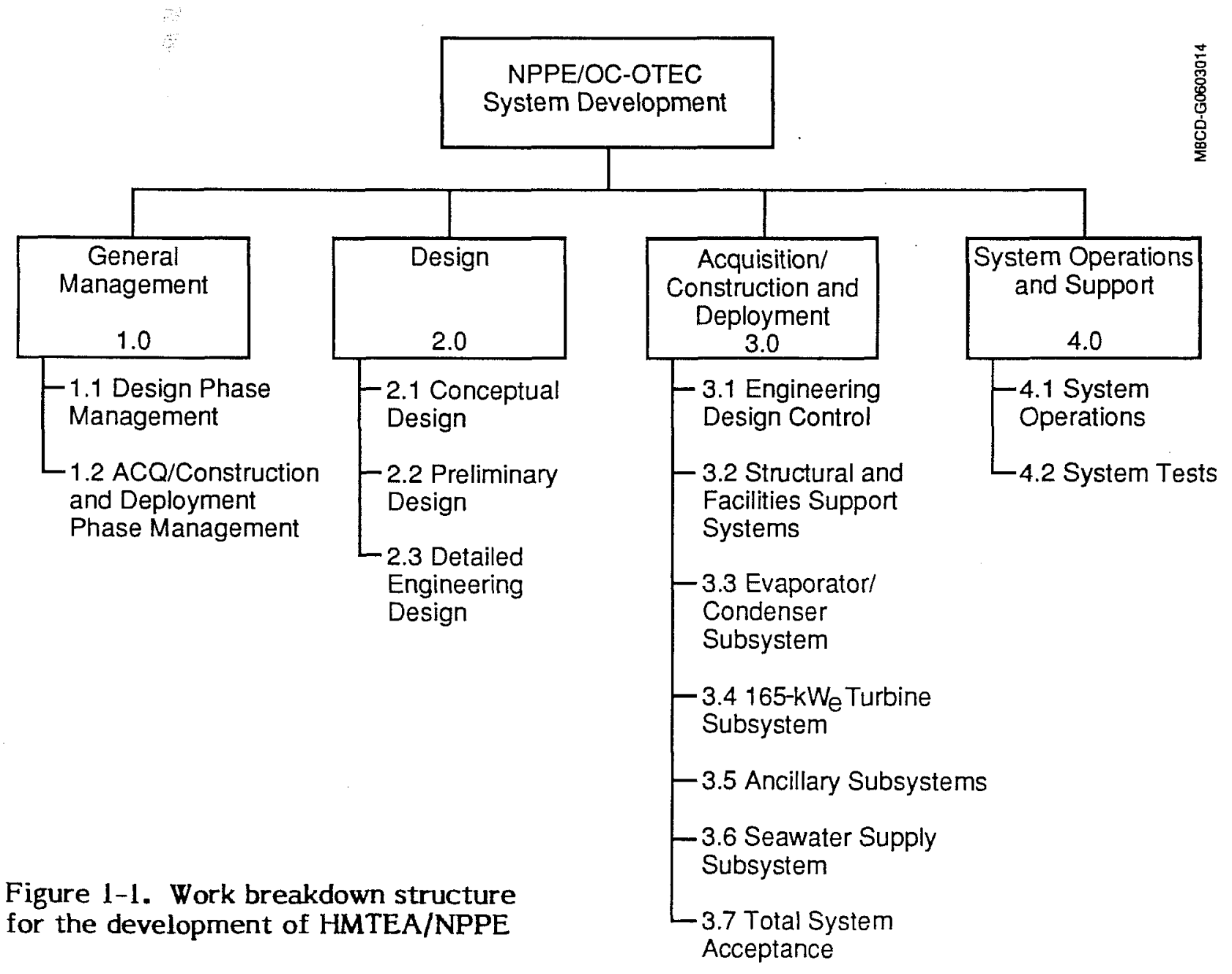


M7-G0540201

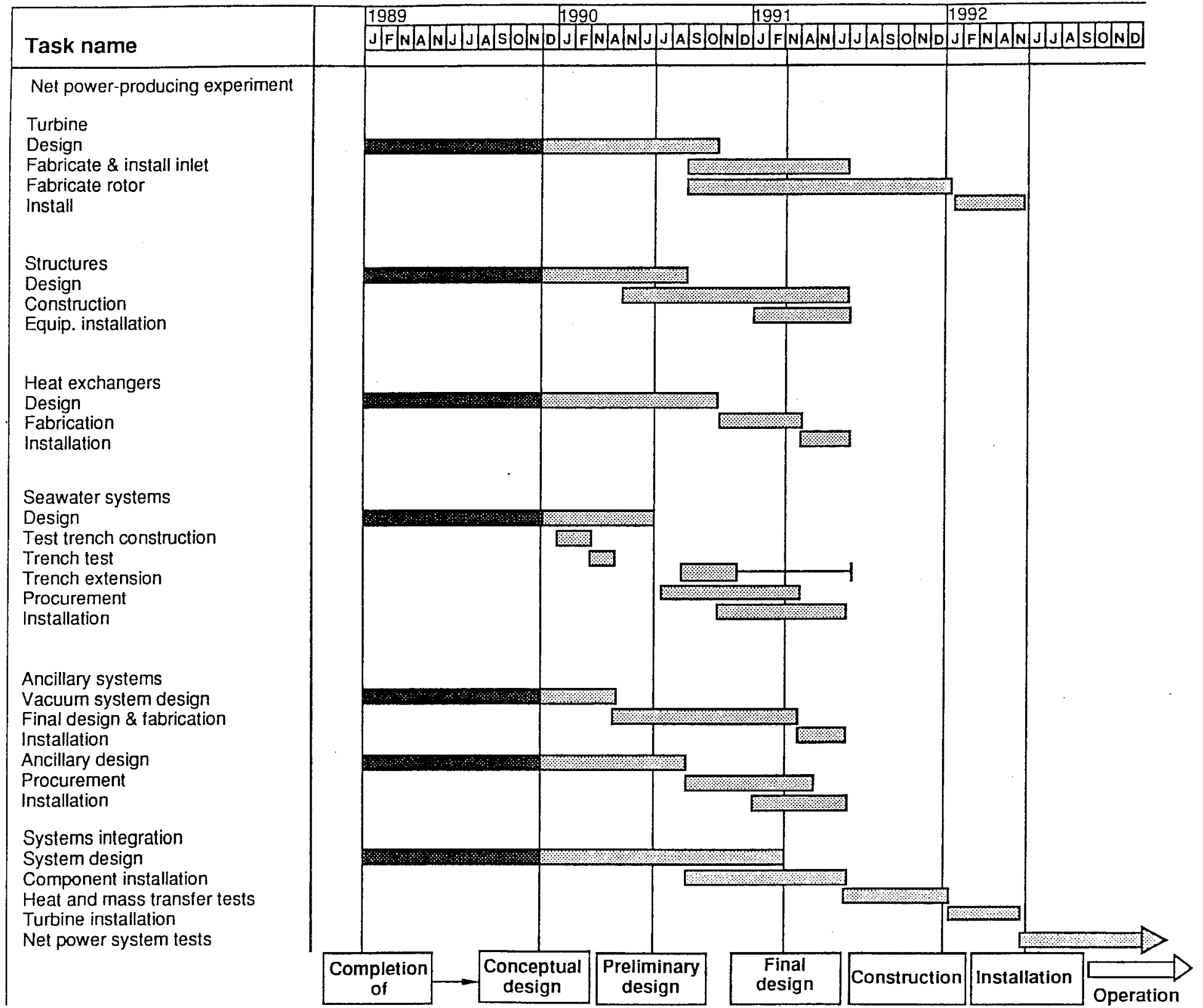

Figure 1-3.

Schedule for

design and

developmental

activities for

HMTEA/NPPE 
The task leader is responsible for assigning all task activities and communicating task status and issues to the systems integration team through the systems integration task leader.

\subsection{Experiment Constraints}

The baseline HMTEA/NPPE design is defined by technical, budget, and other factors. A major constraint is the capability of the seawater systems at NELH to deliver cold and warm water to the experiment. Because of a cooperative agreement between DOE and the State of Hawaii, resulting from their cost shares in constructing the present seawater system at the NELH, federal projects have priority in using $0.61 \mathrm{~m}^{3} / \mathrm{s}(9600 \mathrm{gal} / \mathrm{min})$ of warm surface seawater and $0.41 \mathrm{~m} / \mathrm{s}(6500 \mathrm{gal} / \mathrm{min})$ of deep-ocean cold seawater. Water temperature is in the range of $24.5^{\circ} \mathrm{C}$ to $28^{\circ} \mathrm{C}$ for the surface water (depending on the time of the year) and remains at $6.1^{\circ} \mathrm{C}$ for the cold water. Environmental permits have also been obtained for disposal of the seawater at these stated volume flows on an experimental basis.

The ground level at the proposed experiment site is $4 \mathrm{~m}(13 \mathrm{ft}$ ) above mean sea level. Existing onshore piping at NELH supplying the seawater to the HMTEA/NPPE site is $0.61 \mathrm{~m}(2 \mathrm{ft})$ in diameter and is projected to cause more hydraulic losses than are acceptable for assuring net power production. Thus the piping must be enlarged.

Early projections of power consumption within the system indicated that up to $75 \%$ of the generated power will be used for the system operation with the earlier constraints. The small fraction of gross power available makes the technical objective of demonstrating net power production more demanding than in the case of a larger plant, where the net power fraction may approach 70\% (Parsons, Bharathan, and Althof 1985).

Scaling the experiment from $1.2 \mathrm{MW}_{t}$ for the HMTSTA to $7.0 \mathrm{MW}_{t}$ for the HMTEA/NPPE represents a significant extension in the technology data base. In addition to the limited water available to the DOE project, the budget, schedule, and other external constraints argue in favor of the current scale--called the $165-\mathrm{kW}_{\mathrm{e}}\left(7.0-\mathrm{MW}_{\mathrm{t}}\right)$ experiment--for the HMTEA/NPPE project.

Given the combination of constraints, analytical studies of various experimental options have supported the selection of the baseline experimental system summarized in this report (Shelpuk 1985; Link and Parsons 1986; Lewis, Trimble, and Bowers 1987; PICHTR 1988). 


\section{CHAPTER 2.0}

\section{SYSTEM INTEGRATION}

This chapter describes the status of the project at the end of the conceptual design. The design effort was carried out from January through October 1989.

\subsection{Goals and Objectives}

The NPPE will be developed in two steps: the HMTEA and the NPPE. To assure compatibility, it is important to define the goals and objectives in terms of both of these steps. The first step will be to construct the HMTEA.

The goal in developing the HMTEA is to design, build, and operate an experimental system capable of performing OC-OTEC evaporator and condenser tests at a scale required for the NPPE. The purpose of these tests will be limited to verifying the design performance and assuring the reliable operation of the heat exchangers. Another goal is to have the HMTEA function as a development facility for full-scale evaporator and condenser components after the primary goal for the NPPE is attained.

The goal of the NPPE is to experimentally verify the feasibility of OC-OTEC through validating power-generation techniques by producing at least $40 \mathrm{~kW}$ of net power with a minimum risk of failure. The intermediate completion of the HMTEA directly supports the minimum risk requirements for achieving the NPPE goal.

To meet the NPPE system goal, the following objectives were established (OET System Team Meeting Minutes 1989):

- Obtain data on subsystem and system performance using seawater in the HMTSTA/ HMTEA/NPPE.

- Develop and validate necessary predictive codes.

- Obtain system control data and operational experience.

- Evaluate dynamic stability and transient responses of the system.

- Begin considering scaling issues.

\subsection{Design Requirements}

The design of the HMTEA/NPPE is established by combining requirements of the project goals and objectives and the resource water availability at the test site at the NELH. The baseline system design conditions are in Table 2-1.

The design requirements for the HMTEA/NPPE are then described in the following areas: function, reliability, operation and maintenance, safety, cost, and aesthetics.

The function of the NPPE is to produce net power at the stated level to evaluate the feasibility of the open-cycle concept. Analysis has shown that a minimum $200 \mathrm{~kW}$ of gross power must be generated to meet the project goal of $40 \mathrm{~kW}$ net power availability. Another functional requirement is that the system be fully controllable with built-in stability. The design should also provide for adequate performance margins so the system will operate satisfactorily during the off-design conditions expected during most of the testing period.

The generated electrical energy will be dissipated in controlled resistive loads or delivered to the utility grid. A functional requirement important to the designer is that the 
Table 2-1. HMTEA/NPPE Seawater System Design Conditions as of September 14, 1989 (units revised 12-5-89)

\begin{tabular}{|c|c|c|c|c|}
\hline & & Nominal & High & Low \\
\hline \multicolumn{5}{|l|}{ WARM SEAWATER: } \\
\hline \multirow{2}{*}{ Flow rate } & $\mathrm{kg} / \mathrm{s}$ & 620 & 680 & 310 \\
\hline & $\mathrm{gpm}$ & 9,600 & 10,560 & 4,800 \\
\hline \multirow[t]{2}{*}{ Temperature } & ${ }^{\circ} \mathrm{C}$ & 26.0 & 27.5 & 24.5 \\
\hline & ${ }^{\circ} \mathrm{F}$ & 78.8 & 81.5 & 76.1 \\
\hline \multirow[t]{2}{*}{ Density } & $\mathrm{kg} / \mathrm{m}^{3}$ & $1,022.9$ & $1,022.6$ & $1,023.5$ \\
\hline & $\mathrm{lb} / \mathrm{ft}^{3}$ & 63.86 & 63.84 & 63.90 \\
\hline \multirow[t]{2}{*}{ Barometric head } & $\mathrm{m}$ & 9.88 & 10.00 & 9.66 \\
\hline & $\mathrm{ft}$ & 32.4 & 32.8 & 31.7 \\
\hline \multicolumn{5}{|l|}{ COLD SEAWATER: } \\
\hline \multirow[t]{2}{*}{ Flow rate } & $\mathrm{kg} / \mathrm{s}$ & 420 & 460 & 210 \\
\hline & gpm & 6,500 & 7,150 & 3,250 \\
\hline \multirow{2}{*}{$\begin{array}{l}\text { Offshore } \mathrm{CW} \text { pipe total } \\
\text { flow rate }\end{array}$} & $\mathrm{kg} / \mathrm{s}$ & 860 & 860 & 420 \\
\hline & $\mathrm{gpm}$ & 13,300 & 13,300 & 6,500 \\
\hline \multirow[t]{2}{*}{ Temperature } & ${ }^{\circ} \mathrm{C}$ & 6.1 & 6.1 & $<6.0 ?$ \\
\hline & ${ }^{0} \mathrm{~F} / \mathrm{m}^{3}$ & $\begin{array}{r}43 \\
10769\end{array}$ & 43 & $<42.8 ?$ \\
\hline Density & $\mathrm{lb} / \mathrm{ft}^{3}$ & $\begin{array}{r}1,026.9 \\
64.11\end{array}$ & $\begin{array}{r}1,026.9 \\
64.11\end{array}$ & - \\
\hline \multirow[t]{2}{*}{ Barometric head } & $\mathrm{m}$ & 9.97 & 10.09 & 9.78 \\
\hline & $\mathrm{ft}$ & 32.7 & 33.1 & 32.1 \\
\hline \multirow[t]{2}{*}{ CW pipe density head loss } & $\mathrm{m}$ & 1.00 & - & -- \\
\hline & $\mathrm{ft}$ & 3.3 & $-\infty$ & -- \\
\hline \multicolumn{5}{|l|}{ MIXED DISCHARGE: } \\
\hline \multirow[t]{2}{*}{ Flow rate } & $\mathrm{kg} / \mathrm{s}$ & 1,040 & 1,140 & 520 \\
\hline & $\mathrm{gPm}$ & 16,100 & 17,710 & 8,050 \\
\hline \multirow[t]{2}{*}{ Temperature } & ${ }^{\circ} \mathrm{C}$ & 18.0 & 18.9 & - \\
\hline & & 64.4 & 66.0 & - \\
\hline \multirow[t]{2}{*}{ Density } & $\mathrm{kg} / \mathrm{m}_{3}^{3}$ & $1,024.8$ & $1,024.4$ & - \\
\hline \multirow{2}{*}{\multicolumn{5}{|c|}{ OTHER: }} \\
\hline & & & & \\
\hline \multirow[t]{2}{*}{ Tide } & $\mathrm{m}$ & 0 & +0.61 & -0.37 \\
\hline & $\mathrm{ft}$ & 0 & +2.0 & -1.2 \\
\hline \multirow[t]{2}{*}{ Barometric pressure } & mbar & 1,015 & 1,026 & 995 \\
\hline & psi & 14.72 & 14.88 & 14.43 \\
\hline
\end{tabular}

Acceleration of gravity at 20 deg latitude: $9.786 \mathrm{~m} / \mathrm{s}^{2}\left(32.11 \mathrm{ft} / \mathrm{s}^{2}\right)$

Grade elevation at the NPPE: $4 \mathrm{~m}$ (13 ft) 
latter be done safely and within specifications and tolerances acceptable to the local utility company, especially when the NPPE is operating as a test bed for new and innovative components.

Finally, although the net power criterion for the experiment will be applied in a powerproducing configuration, the system will be designed so $10 \%$ of the design steam flow can be condensed in a surface condenser to produce desalinated water.

Reliability considerations are driven by a stated requirement that the system have a useful life of two years of intermittent operation, with a planned continuous operation for up to six months. Although no specific availability has been stated as a requirement, certain guidelines on the reliability were put forth at the first systems team meeting. No redundancies for major equipment are required; however, all components are to be chosen within the state of the art, with considerations given to reliability and field maintainability. One of the purposes of the planned long-term NPPE tests will be to evaluate the reliability and availability of the system.

The system should be designed to require a minimum of down time for either scheduled or unscheduled maintenance, with no more than two persons needed for routine operation and maintenance.

Safety is the highest priority item, with adequate design margins applied throughout. Control redundancy with built-in safety sensors and controls and annunciators will be required. A detailed safe operating procedure will be developed, maintained, and followed throughout the functional period of the HMTEA/NPPE. Accompanying detailed analyses of the failure modes and operators' actions for the system will be developed during the design process.

The cost of the project must be compatible with anticipated funding levels, which can vary but are now estimated at $\$ 15 \mathrm{M}$ over the three-year development period.

Finally, aesthetic design will be used throughout, with emphasis on simplicity, accessibility, and interchangeability. Attractive use of simple but functional components and subsystems will be emphasized during design.

\subsection{System Analysis}

\subsubsection{Analysis Method}

System analysis identifies the component operating conditions and specifications (constrained within an overall physical concept for the system) that will satisfy the system's technical and functional requirements at the minimum first cost and operating cost. For the NPPE a higher priority has been placed on minimizing the risk associated with producing net power than on achieving the minimum cost. The cost must be kept within the budget constraints, however.

Validating system feasibility and analysis codes is also a prime objective of the experiments to be carried out with the HMTEA/NPPE. The NPPE tests will provide data to upgrade the design codes for use in optimizing the systems for a minimum cost in commercial installations.

The design was initiated by completing several system analyses, which were used to eliminate unreasonable designs based on the criterion of maximum net power from a fixed quantity and quality of cold water. Early system analyses identified the sensitivity 
Table 2-2. Power Budget Distribution and Design Projections

\begin{tabular}{|c|c|c|c|c|}
\hline & Task & $\begin{array}{l}\text { Description of } \\
\text { Power Use }\end{array}$ & $\begin{array}{c}\text { Power Budget } \\
\text { Goal } \\
\left(k W_{e}\right)\end{array}$ & $\begin{array}{l}\text { Design } \\
\text { Projections } \\
\left(k W_{e}\right)\end{array}$ \\
\hline A. & Turbine/structures & $\begin{array}{l}\text { Generator output } \\
\text { gross (minimum) } \\
\text { less oil system }\end{array}$ & 165 & 213 \\
\hline B. & Seawater systems & $\begin{array}{l}\text { Supply/discharge } \\
\text { pumping (maximum) }\end{array}$ & 81 & 71 \\
\hline C. & Heat exchangers & $\begin{array}{l}\text { Parasitic water } \\
\text { pumping (maximum) }\end{array}$ & 20 & 20 \\
\hline \multirow[t]{2}{*}{ D. } & Ancillary systems & $\begin{array}{l}\text { Vacuum, control, } \\
\text { and intercoolers } \\
\text { (maximum) }\end{array}$ & 24 & 38 \\
\hline & System integration & NET POWER $=A-(B+C+D)$ & 40 & 84 \\
\hline
\end{tabular}

of system performance to the various design and operating parameters and established the boundaries of the experimental test envelope used in the HMTSTA tests (Zangrando et al. 1989). The results of the HMTSTA experiments were then used to establish nominal NPPE component specifications. These design performance estimates incorporated into a first-cut system definition are bracketed by experimental test results for the direct-contact heat exchangers, projected performance of the low-pressure turbines based on design studies (Mechanical Technology Inc. 1989; Fong, Masutani, and Neill 1989), and documented performance in the case of other commercially available equipment.

The subsystem performance goals for the NPPE were developed based on the operating conditions that can be expected in a typical OC-OTEC plant. These goals (shown in the third column of Table 2-2) guided the first cycle of the design. An original assumption of cold-seawater temperature of $7^{\circ} \mathrm{C}$ was used in developing this table. Operational experiences with the upgraded seawater system at the NELH have resulted in updating the available cold-seawater temperature to $6.1^{\circ} \mathrm{C}$. A detailed systems analysis effort described in Section 2.3.2 provides the next-level update of the subsystem performance projections (see Table 2-2, fourth column).

\subsubsection{Analysis Results}

A system performance analysis was then completed to establish the preferred steam flow through the turbine (Figure 2-1) and water flow through the flash evaporator (Figure 2-2). Figure 2-1 plots the projected gross power vs. steam flow through the turbine. Because gross power is proportional to the product of the steam flow and its temperature drop across the turbine, this figure shows that there is a specific steam flow rate that maximizes the power. Losses in warm-seawater pumping are less than in cold, so the temperature distribution in the power-maximizing system shifts toward a lesser 


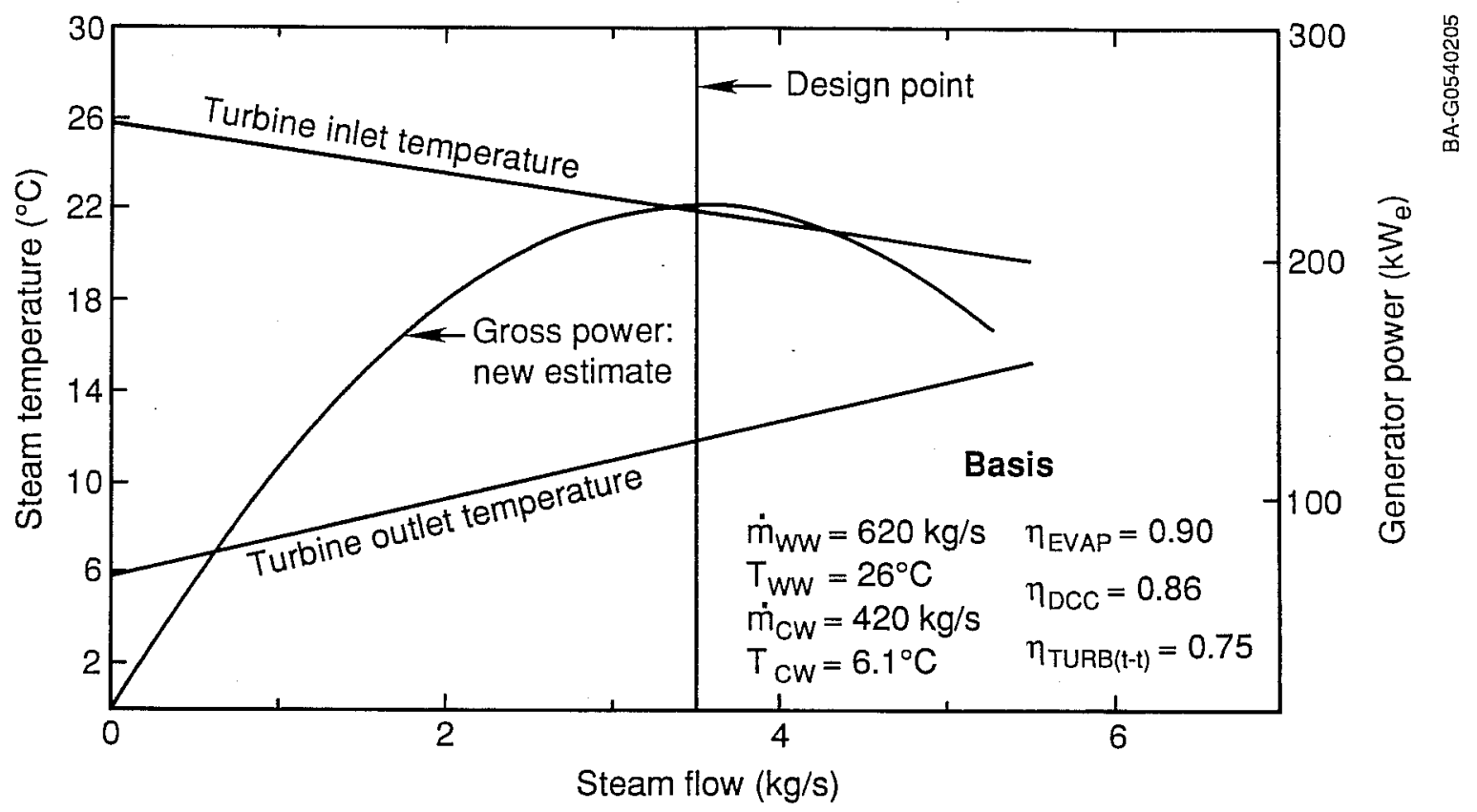

Figure 2-1. Variation of gross power vs. steam flow for the net power-producing experiment (NPPE)

temperature difference across the evaporator than in the condenser; i.e., more warm water is used than cold. The chosen value of $3.5 \mathrm{~kg} / \mathrm{s}$ for the steam flow will accommodate reduced resource-water temperature differences (caused by seasonal variations in the ocean temperature), and/or less-than-expected heat-exchanger effectiveness with minimum decrease in the power output. The design value also will handle increased resource-water temperature differences or improved heat-exchanger effectiveness, or both, which would call for a higher value of steam flow through the turbine for maximum power.

The exact value of turbine inlet and outlet temperatures is determined by heatexchanger design and performance. The results of the HMTSTA experiments on the direct-contact heat exchangers have guided the selection of the design performance goals for the system. Confirmation of the design in the planned HMTEA experiments is important to the success of the NPPE.

Figure 2-2 shows the effect of water flow rate variation on system net power output. Increasing cold-water flow rate increases the net power and vice versa. However, the available cold-water flow rate is fixed for this project. To achieve maximum net power, all of the available cold water must be used.

Figure 2-2 is also used to identify a warm-water flow rate of $0.61 \mathrm{~m}^{3} / \mathrm{s}(9600 \mathrm{gal} / \mathrm{min})$ as a preferred design value. A set of assumptions with respect to the onshore seawater supply piping has been made (for details see Chapter 4.0). Careful design of the onshore piping is necessary to preserve the performance gains identified in this analysis.

Table 2-2 summarizes the nominal design conditions for the NPPE facility as established by the assumptions and the foregoing analysis. This table also compares the design projections against the initial goals set for the various tasks. The design results are the basis for the component specifications and hardware designs presented in the following 
chapters. Based on the results of these analyses, the original design goals can be compared with the present design projections. At this stage of the design, the gross power projection increased to 213 $\mathrm{kW}$, and the net power increased to 84 $\mathrm{kW}$. Most of these increases stem from updating the cold-water temperature from $7^{\circ} \mathrm{C}$ to $6.1^{\circ} \mathrm{C}$.

Potentials exist for an increase of up to $40 \mathrm{~kW}$ in the system parasitic losses because of uncertainties in the performances of the seawater system and vacuum exhaust system. To assure a net power of 40 $\mathrm{kW}$, the power output of the turbine/ generator unit must be maintained at over $200 \mathrm{~kW}$ e.

Table 2-3 provides a detailed set of performance projections for the various major components and subsystems of the NPPE (updated November 15, 1989).

\subsubsection{Sensitivity Analysis}

A sensitivity analysis was completed to establish the influence of the expected bands of uncertainty associated with the key variables in the design. Table 2-4 provides a summary of the results. The major variables are categorized broadly as the component performance, resource variability, and control variables.

Shown first are the sensitivities to uncertainties in the projected heat-exchanger performance. For the evaporator, the design effectiveness is 0.90 . Variations in its effectiveness of +0.05 and -0.03 are realistic and yield changes in the net power of $+3 \mathrm{~kW}$ and $-4 \mathrm{~kW} e$, respectively. The performance variations in the direct-contact condenser result in the net power variation of $+3 \mathrm{~kW}$ to $-6 \mathrm{~kW}$. Other uncertainties in the components permit the determination of an average net power of $82 \mathrm{~kW}$, with a standard deviation of $+5 \mathrm{~kW}$. At this stage of the design, based on a statistical approach (Kline and Mc $\bar{C}$ lintock 1953), the average net power of $75 \mathrm{~kW}$ is assured at $67 \%$ confidence level, and a minimum net power of $67 \mathrm{~kW}$ is assured at a $99 \%$ confidence level at the design resource-water temperatures and flow availability. Validated experimental data on the seawater supply systems and performance projections of the vacuum exhaust system will affect these projections up or down as the design progresses.

A major uncertainty currently is the projected performance level of the disposal trench. The projections call for discharge of $1.02 \mathrm{~m}^{3} / \mathrm{s}(16,100 \mathrm{gal} / \mathrm{min})$ of spent water at a discharge pool elevation of $0.9 \mathrm{~m}(3 \mathrm{ft}$ ) above sea level. An elevation of $3 \mathrm{~m}(10 \mathrm{ft})$ to discharge this water will reduce the net power by $30 \mathrm{~kW}$, as shown in the second category. 
Table 2-3. Nominal Design Conditions for the NPPE System (Projections at Nov. 1989)

\begin{tabular}{|c|c|c|}
\hline \multicolumn{3}{|l|}{ Component Description } \\
\hline \multicolumn{3}{|l|}{ Turbine } \\
\hline Generated power & 217 & $k W_{e}$ \\
\hline Generator efficiency & 0.92 & -- \\
\hline Turbine efficiency & 0.85 & -- \\
\hline Steam inlet temperature & 21.8 & ${ }^{\circ} \mathrm{C}$ \\
\hline Steam outlet temperature & 11.3 & ${ }^{\circ} \mathrm{C}$ \\
\hline Steam iniet velocity & 60 & $\mathrm{~m} / \mathrm{s}$ \\
\hline Steam outlet velocity & 117 & $\mathrm{~m} / \mathrm{s}$ \\
\hline Steam enthalpy drop (total to total) & 84 & $\mathrm{~kJ} / \mathrm{kg}$ \\
\hline Steam flow rate & 3.5 & $\mathrm{~kg} / \mathrm{s}$ \\
\hline Maximum tip speed & 275 & $\mathrm{~m} / \mathrm{s}$ \\
\hline Rotor outside diameter & 2.9 & $\mathrm{~m}$ \\
\hline Rotational speed & 1800 & rpm \\
\hline \multicolumn{3}{|l|}{ Diffuser } \\
\hline Recovery factor & 0.65 & -- \\
\hline Outlet steam velocity & 59 & $\mathrm{~m} / \mathrm{s}$ \\
\hline Steam outlet temperature & 11.8 & ${ }^{\circ} \mathrm{C}$ \\
\hline \multicolumn{3}{|l|}{ Evaporator } \\
\hline Mist-removal pressure loss coefficient & 10 & -- \\
\hline Mist-removal steam velocity & 7 & $\mathrm{~m} / \mathrm{s}$ \\
\hline Mist-removal pressure drop & 4 & $\mathrm{~Pa}$ \\
\hline Evaporator-mist pressure loss coefficient & 0.5 & - \\
\hline Steam generation velocity & 10 & $\mathrm{~m} / \mathrm{s}$ \\
\hline Evaporator-mist pressure drop & $<1$ & $\mathrm{~Pa}$ \\
\hline Liquid loading & 35 & $\mathrm{~kg} / \mathrm{m}^{2}$ \\
\hline Steam generation temperature & 21.8 & ${ }^{\circ} \mathrm{C}$ \\
\hline Evaporator effectiveness & 0.9 & - \\
\hline Warm-seawater inlet temperature & 26.0 & ${ }^{\circ} \mathrm{C}$ \\
\hline Warm-seawater outlet temperature & 22.5 & ${ }^{\circ} \mathrm{C}$ \\
\hline Warm-seawater flow rate & 620 & $\mathrm{~kg} / \mathrm{s}$ \\
\hline Fraction of equilibrium gas release & 100 & $\%$ \\
\hline Noncondensable gas evolution & 0.012 & $\mathrm{~kg} / \mathrm{s}$ \\
\hline Air leakage rate & 0.0005 & $\mathrm{~kg} / \mathrm{s}$ \\
\hline Spout-seawater velocity & 1 & $\mathrm{~m} / \mathrm{s}$ \\
\hline Evaporator platform area & 18 & $\mathrm{~m}_{2}^{2}$ \\
\hline Mist removal area & 28 & $\mathrm{~m}^{2}$ \\
\hline \multicolumn{3}{|l|}{ Direct-Contact Condenser } \\
\hline Diffuser/condenser pressure loss coefficient & 1 & -- \\
\hline Diffuser/condenser pressure loss & 2 & $\mathrm{~Pa}$ \\
\hline Cocurrent pressure loss & $<45$ & $\mathrm{~Pa}$ \\
\hline Countercurrent pressure loss & $<75$ & $\mathrm{~Pa}$ \\
\hline Cold-seawater inlet temperature & 6.1 & ${ }^{\circ} \mathrm{C}$ \\
\hline Cold-seawater outlet temperature & 11.2 & ${ }^{\circ} \mathrm{C}$ \\
\hline Steam/gas outlet temperature & 6 & ${ }^{\circ} \mathrm{C}$ \\
\hline Outlet steam flow rate & 0.033 & $\mathrm{~kg} / \mathrm{s}$ \\
\hline Cocurrent gas loading & 0.4 & $\mathrm{~kg} / \mathrm{m}^{2} \mathrm{~s}$ \\
\hline Cold-seawater flow rate & 420 & $\mathrm{~kg} / \mathrm{s}$ \\
\hline Equilibrium gas release & 100 & $\%$ \\
\hline Noncondensable gas evolution & 0.008 & $\mathrm{~kg} / \mathrm{s}$ \\
\hline Air leakage rate & 0.0005 & $\mathrm{~kg} / \mathrm{s}$ \\
\hline Water loading & $<40$ & $\mathrm{~kg} / \mathrm{m}^{2} \mathrm{~s}$ \\
\hline
\end{tabular}


Table 2-3. Nominal Design Conditions for the NPPE System (Concluded)

Component Description

\section{Condenser Exhaust Compressor Train}

Number of compression stages

Intercooler/precooler pressure drop

Compressor stage pressure ratio

Intercooler gas exit temperature

Motor/compressor efficiency

Power requirement

$\begin{array}{cc}4 & -- \\ 50 & \mathrm{~Pa} \\ 3.1 & -- \\ 6.5,13.5 & { }^{\circ} \mathrm{C} \\ 0.6 & -- \\ 30 & \mathrm{~kW}\end{array}$

Warm-Seawater Flow System

Onshore supply pipe, nominal diameter

0.9

Supply pipe head loss

2.2

Overall pumping efficiency

Supply pump power

66

Evaporator static loss

13

Evaporator dynamic loss

0.5

Discharge pipe head loss

Discharge trench head loss

Total warm-water head loss

Supply pump head

Overall pumping efficiency

Supply pump power

Discharge pump head

0.5

0.5

0.9

4.6

1.4

66

13

Overall pumping efficiency

3.2

Discharge pump power

72

27

Total warm-water pumping power

40

m

m

$\%$

$\mathrm{kW}$

$\mathrm{m}^{\mathrm{e}}$

$\mathrm{m}$

$\mathrm{m}$

$\mathrm{m}$

$\mathrm{m}$

$\mathrm{m}$

$\%$

$\mathrm{kW}$

$\mathrm{m}^{\mathrm{e}}$

$\%$

$\mathrm{kW}$

Cold-Seawater Flow System

Onshore supply pipe, nominal diameter

0.6

$k W_{e}^{e}$

Total supply head loss

Density head loss

Condenser static loss

Condenser dynamic loss

Discharge pipe head loss

Discharge trench head loss

Total cold-water head loss

4.4

$\mathrm{m}$

1.0

$m$

1.5

$m$

0.5

$\mathrm{m}$

0.6

$\mathrm{m}$

0.9

$\mathrm{m}$

9.0

Supply pump head

Overall pumping efficiency

3.6

Supply pump power

72

21

Discharge pump head

5.4

Overall pumping efficiency

72

Discharge pump power

31

Total cold-water pumping power

52

$\mathrm{m}$

$\mathrm{m}$

$\mathrm{m}$

$\%$

$\mathrm{kW}$

$\mathrm{m}$

$\%$

$\mathrm{kW}$

$k W_{e}^{e}$

\section{Miscellaneous Equipment}

Lube oil pumps

Oil cooling system

Plant control system

Intercooler water pumps

$k W$

$\mathrm{kW} e$

$\mathrm{kW}$

$k W_{e}^{e}$

System

Total parasitic power requirement

133

Net power production

$\mathrm{kW}$

$k W_{e}^{e}$ 
Table 2-4. NPPE System Net Power Sensitivities

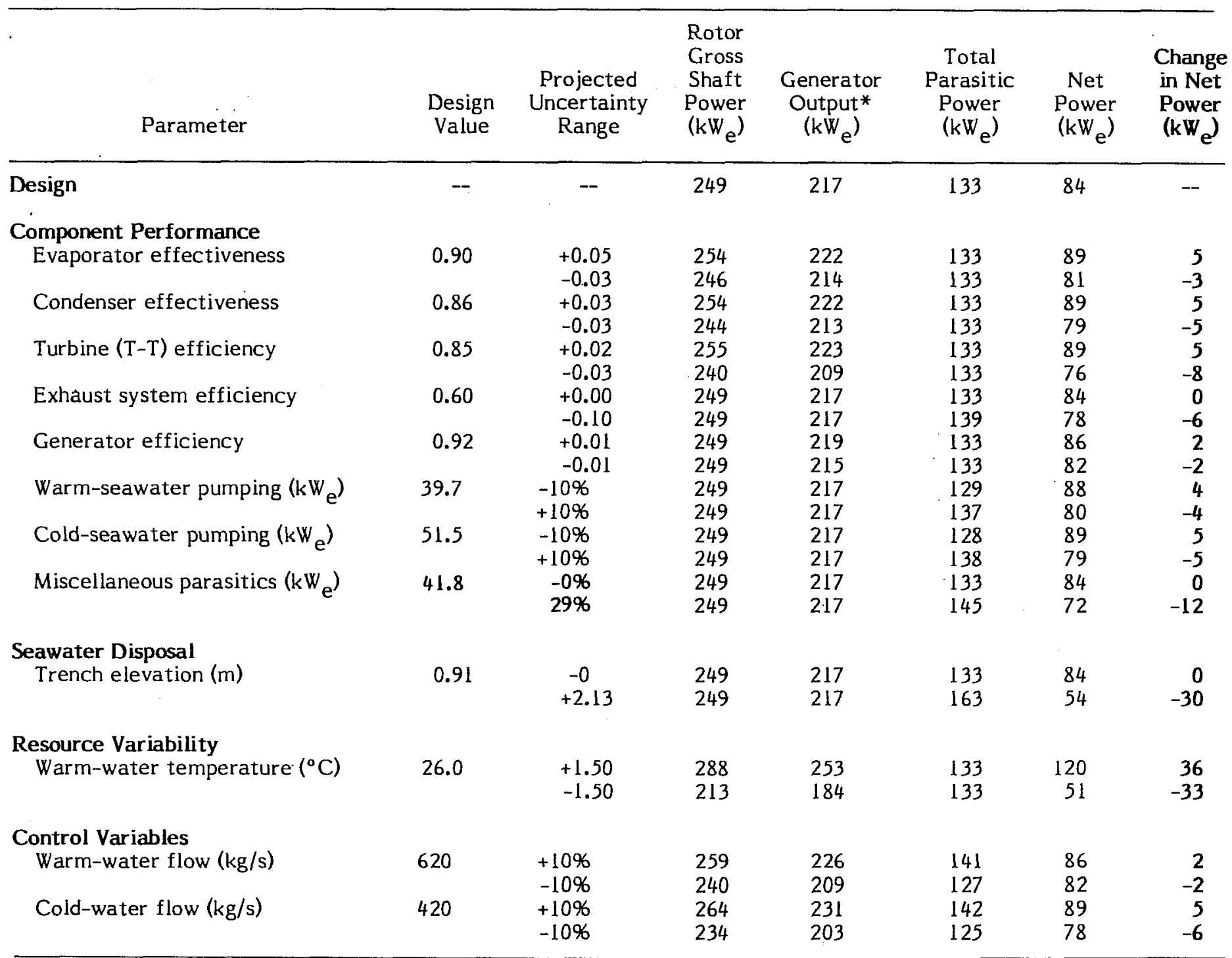

* Generator output is (rotor gross power minus bearing loss) times generator efficiency. 
A third category for the sensitivity analyses is the resource variability. The influence of a variation in the warm-seawater temperature is projected to be the greatest, causing a net power change of $-33 \mathrm{~kW}$ at a low temperature of $24.5^{\circ} \mathrm{C}$ to $+36 \mathrm{~kW}$ at a high temperature of $27.5^{\circ} \mathrm{C}$. Tides are not expected to influence the net power, because the level of cold seawater in the supply system rises and falls with the tide. Another variable is the cold-seawater temperature; however, this temperature is not projected to vary significantly as compared with that of the warm seawater.

A fourth category shown in Table $2-4$ is the resource-water flow rates, which can be used to control the system operation within a limited range. A range of $10 \%$ (increase and decrease) in the warm and cold water flow rates yields roughly a $1-\mathrm{kW}_{\mathrm{e}}$ and $4-\mathrm{kW}$ (increase and decrease) change in net power, respectively.

Demand for cold seawater from other users (such as the Hawaii Ocean Science and Technology [HOST] park) at the NELH will influence the parasitic losses associated with the offshore section of the water intake pipe. When only $0.41 \mathrm{~m} / \mathrm{s}(6500 \mathrm{gal} / \mathrm{min})$ of cold seawater is drawn through the offshore pipe (as opposed to the design draw of $0.61 \mathrm{~m}^{3} / \mathrm{s}$ ), the net power yield from the NPPE system will increase by roughly $10 \mathrm{~kW}$ above the design value, because the supply pump efficiency does not deteriorate at low heads.

The variability in the warm-water temperature previously considered covers a range encountered in field measurements at the NELH over the past several years. This range of variability falls within the plateau of system performance described in Figure 2-1 and indicates a variation of steam flow rate from 3.2 to $3.7 \mathrm{~kg} / \mathrm{s}$ of steam. Projected variation in the turbine efficiency over this range of steam flow is minimal. It is thus reasonable to expect a minimum of $40 \mathrm{~kW}$ e out of the plant at any time of the year.

The projected variations in the design efficiency for the turbine are based on an extensive data base on which the turbine design is founded. It is expected that the stated turbine design efficiency goal will readily be met or surpassed. Thus, the technical objective of achieving a net power production of $40 \mathrm{~kW} e$ remains well in reach.

\subsubsection{Code Benchmark Comparisons}

Two types of mathematical codes were used for system analysis. A detailed code entitled OC-OTEC-SYS was developed at SERI and extensively used at SERI and at PICHTR. This code accepts the basic operating parameters for the system as inputs along with limited component design assumptions. This code exercises all of the design variables to arrive at complete system and component designs that maximize power output or minimize system cost, depending on the chosen criterion.

Early heat-exchanger and turbine development studies have shown that these components can be designed for high performance over a wide range of operating conditions. It is not necessary to complete a design analysis of each component every time a system analysis effort is undertaken. Rather, the key components can be described as black boxes in the system analysis (using a given efficiency) with resource-water flow rates and temperatures as the input parameters. The output defines the system operating conditions, intercomponent flow rates, temperatures, and power. This simple second model can also be installed in a spreadsheet format; the results of varying the key parameters are then obtained quickly, with preferred operating conditions arrived at by observing trends.

The results reported in this section were obtained using the simple model. The results were then compared with those obtained from OC-OTEC-SYS on several benchmark runs, 
one of which is reported in Table 2-5 (projections as of September 18, 1989). The correlation between the two methods is sufficiently close that the results are indistinguishable.

The chosen design for the NPPE conservatively defines components for the critical systems. Any design margin caused by this approach will provide for unanticipated performance shortfalls caused by factors not modeled.

The first cycle of the design was completed by projecting the performance of critical components based on experimental data. The performance requirements then permitted the sizing and assembly of those and other components in a manner to maximize net power.

\subsubsection{System Control}

Control of an OC-OTEC system has not been analyzed in detail; however, it appears not to be a significant issue. There are four control requirements: long-term control to accommodate seasonal temperature variations, component performance changes, and tidal influences; short-term control to handle sudden load or water flow variations resulting from HOST park operations; normal system start/stop sequences; and emergency shutdown.

Long-Term Control. Variations that occur over periods of days or weeks are readily accommodated by this system. It may not be necessary to provide active controls because the expected fluctuations will not drive the operation of all components and the system far from their design point. Resource-water flow rates will be regulated by variable-speed drives on the supply system. Discharge water pumps will be controlled using water discharge pool levels in the heat exchangers to maintain those levels within specified limits. Such a system will be self-adjusting and deliver more or less power, depending on the nature of the variation. Further analysis will be carried out during the preliminary design stages to assure stable system operation.

Short-Term Control. Short-term control presents a different type of problem. Load variations are likely; power output fluctuations from the generator should be accommodated by corresponding variations to the load bank using the electrical switching circuitry. Sudden load losses or gains are typical requirements for power plants of all types, and standard switchgear is well able to handle the requirement.

Sudden fluctuations of water flow, however, would cause a different type of situation. Because the NPPE will share the water flow from the NELH cold-water system with the HOST park facility, fluctuating demands from HOST users would set up water flow oscillations in the experiment. Preliminary assessments indicate that these oscillations occur over time periods of 5 to 10 minutes and are well damped at startup or gradual shutdown. Some overshoots in the pump-sump pool depression would occur. Head variations in the supply sumps may lead to possible unstable pump operation, pump cavitation, and potential trapping of air bubbles in the offshore pipe. The implications of the shortterm sump oscillations will have to be assessed during the preliminary design.

Wave action may not affect the supply of cold water but may influence the supply of warm water. The high flow resistance through the warm-water supply system in comparison with the wave excursions should mitigate the potential problems.

The short-term fluctuations in the flow of warm or cold water should not affect the rotational speed of the turbine rotor because of its large inertia; however, further 
Table 2-5. Systems Code Benchmark Comparison of NPPE Design Conditions

\begin{tabular}{|c|c|c|c|}
\hline & $\begin{array}{l}\text { Projec } \\
\text { SERI } \\
(9 / 18 / 89)\end{array}$ & $\begin{array}{l}\text { ions by } \\
\text { PICHTR } \\
(9 / 13 / 89)\end{array}$ & $\begin{array}{l}\text { Systems } \\
\text { Analysis } \\
\text { Basis }\end{array}$ \\
\hline \multicolumn{4}{|l|}{ Turbine and Generator } \\
\hline Generated power & $217 \mathrm{~kW} e$ & 211 & $\begin{array}{l}\text { Model with radial } \\
\text { turb., } 9 / 13 / 89\end{array}$ \\
\hline Generator efficiency & 0.92 & 0.92 & H. Link $8 / 89$ \\
\hline Turbine efficiency & 0.85 & 0.85 & $\begin{array}{l}\text { D. Bharathan } \\
5 / 8 / 89\end{array}$ \\
\hline Steam inlet temperature & $21.8^{\circ} \mathrm{C}$ & 21.8 & $\begin{array}{l}\text { Computer model } \\
9 / 13 / 89\end{array}$ \\
\hline Steam outlet temperature & $11.5^{\circ} \mathrm{C}$ & 11.4 & $\begin{array}{l}\text { Computer model } \\
9 / 13 / 89\end{array}$ \\
\hline Steam inlet velocity & $60.1 \mathrm{~m} / \mathrm{s}$ & 53 & $\begin{array}{l}\text { Computer model } \\
9 / 13 / 89\end{array}$ \\
\hline Steam outlet velocity & $127 \mathrm{~m} / \mathrm{s}$ & 97.3 & $\begin{array}{l}\text { Computer model } \\
9 / 13 / 89\end{array}$ \\
\hline $\begin{array}{l}\text { Steam enthalpy drop } \\
\text { (total to total) }\end{array}$ & $83.8 \mathrm{~kJ} / \mathrm{kg}$ & ??? & \\
\hline Steam flow rate & $3.5 \mathrm{~kg} / \mathrm{s}$ & 3.44 & $\begin{array}{l}\text { Computer model } \\
9 / 13 / 89\end{array}$ \\
\hline Maximum tip speed & $275 \mathrm{~m} / \mathrm{s}$ & & \\
\hline $\begin{array}{l}\text { Rotor outside diameter } \\
\text { Rotational speed }\end{array}$ & $\begin{array}{c}2.9 \mathrm{~m} \\
1800 \mathrm{rpm}\end{array}$ & $\begin{array}{c}? ? ? \\
1800\end{array}$ & H. Link 8/89 \\
\hline \multicolumn{4}{|l|}{ Diffuser } \\
\hline $\begin{array}{l}\text { Pressure recovery factor } \\
\left(2\left(p_{2}-p_{1}\right) / \rho_{1} v_{1}\right)\end{array}$ & 0.65 & 0.65 & $\begin{array}{l}\text { D. Bharathan } \\
5 / 8 / 89 \\
\text { Eff }=0.87\end{array}$ \\
\hline Inlet steam velocity & $127 \mathrm{~m} / \mathrm{s}$ & 97.3 & $\begin{array}{l}\text { Computer model } \\
9 / 13 / 89\end{array}$ \\
\hline Outlet steam velocity & $58.5 \mathrm{~m} / \mathrm{s}$ & 48.7 & $\begin{array}{l}\text { Computer model } \\
9 / 13 / 89\end{array}$ \\
\hline Steam inlet temperature & $11.5^{\circ} \mathrm{C}$ & 11.4 & $\begin{array}{l}\text { Computer model } \\
9 / 13 / 89\end{array}$ \\
\hline Steam outlet temperature & $11.8^{\circ} \mathrm{C}$ & 11.76 & $\begin{array}{l}\text { Computer model } \\
9 / 13 / 89\end{array}$ \\
\hline \multicolumn{4}{|l|}{ Evaporator } \\
\hline $\begin{array}{l}\text { Mist removal pressure loss } \\
\text { coefficient }\left(2 \Delta \mathrm{p} / \rho \mathrm{v}^{2}\right)\end{array}$ & 10 & 4 & $\begin{array}{l}\text { TRC 非3 } \\
4 / 12-4 / 13 / 89\end{array}$ \\
\hline Mist removal steam velocity & $6.5 \mathrm{~m} / \mathrm{s}$ & 6.2 & $\begin{array}{l}\text { Computer model } \\
9 / 13 / 89\end{array}$ \\
\hline Mist removal pressure drop & $4 \mathrm{~Pa}$ & 1.5 & $\begin{array}{l}\text { Computer model } \\
9 / 13 / 89\end{array}$ \\
\hline $\begin{array}{l}\text { Evaporator/mist eliminator pressure } \\
\text { loss coefficient }\left(2 \Delta \mathrm{p} / \mathrm{\rho v}^{2}\right)\end{array}$ & 0.5 & ??? & \\
\hline Steam generation velocity & $10 \mathrm{~m} / \mathrm{s}$ & 10 & $\begin{array}{l}\text { D. Bharathan } \\
5 / 8 / 89\end{array}$ \\
\hline
\end{tabular}


Table 2-5. Systems Code Benchmark Comparison of NPPE Design Conditions (Cont'd)

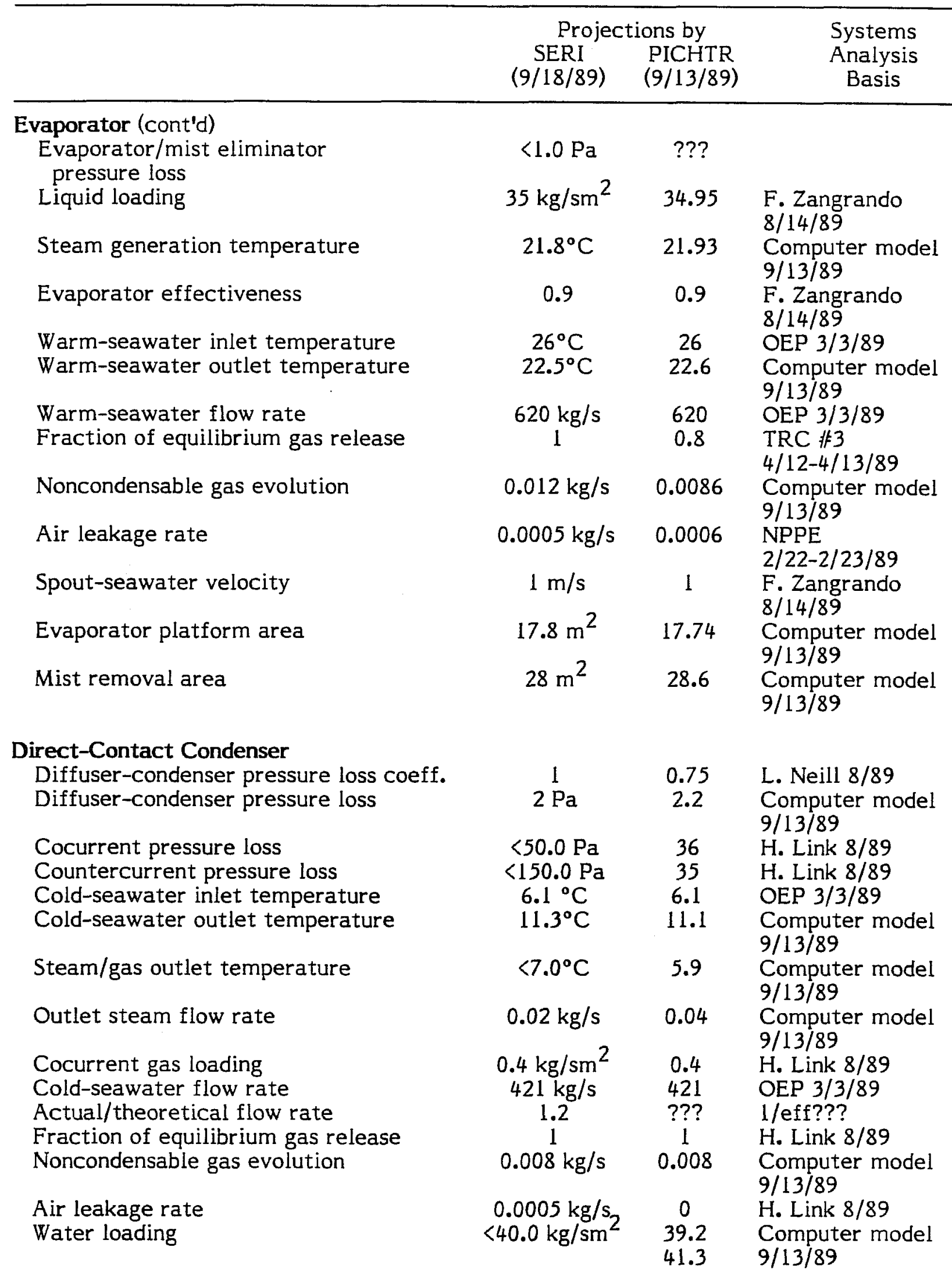


Table 2-5. Systems Code Benchmark Comparison of NPPE Design Conditions (Cont'd)

\begin{tabular}{|c|c|c|c|}
\hline & $\begin{array}{l}\text { Projec } \\
\text { SERI } \\
(9 / 18 / 89)\end{array}$ & $\begin{array}{l}\text { ons by } \\
\text { PICHTR } \\
(9 / 13 / 89)\end{array}$ & $\begin{array}{l}\text { Systems } \\
\text { Analysis } \\
\text { Basis }\end{array}$ \\
\hline \multicolumn{4}{|l|}{ Condenser/Exhaust Compressor Train } \\
\hline Number of compressor stages & 4 & 4 & $\begin{array}{l}\text { B. Parsons } \\
8 / 11 / 89\end{array}$ \\
\hline Intercooler/precooler pressure drop & $50 \mathrm{~Pa}$ & 50 & $\begin{array}{l}\text { B. Parsons } \\
8 / 11 / 89\end{array}$ \\
\hline Compressor stage pressure ratio & 3.1 & 3 & $\begin{array}{l}\text { Computer model } \\
9 / 13 / 89\end{array}$ \\
\hline Intercooler gas exit temperature & $\begin{array}{l}6.5^{\circ} \mathrm{C} \\
13.5^{\circ} \mathrm{C}\end{array}$ & $? ? ?$ & Not part of model \\
\hline Motor/compressor efficiency & 0.6 & 0.6 & $\begin{array}{l}\text { B. Parsons } \\
8 / 11 / 89\end{array}$ \\
\hline Power requirement & $30 \mathrm{kWe}$ & 30 & $\begin{array}{l}\text { B. Nichols } \\
\text { not modeled }\end{array}$ \\
\hline \multicolumn{4}{|l|}{ Warm-Seawater Flow System } \\
\hline $\begin{array}{l}\text { Onshore supply pipe, nominal } \\
\text { diameter }\end{array}$ & $0.91 \mathrm{~m}$ & 0.91 & $\begin{array}{l}\text { H.J. Green } \\
8 / 22 / 89,36 " \text { steel }\end{array}$ \\
\hline Supply pipe head loss & $2.2 \mathrm{~m}$ & 2.23 & $\begin{array}{l}\text { H.J. Green } \\
8 / 22 / 89 \\
\text { vertical wet pit }\end{array}$ \\
\hline Evaporator static loss & $0.52 \mathrm{~m}$ & 1.01 & $\begin{array}{l}\text { H.J. Green, } \\
\text { stat. + dynam. }\end{array}$ \\
\hline Evaporator dynamic loss & $0.49 \mathrm{~m}$ & & incl. above \\
\hline Discharge pipe head loss & $0.49 \mathrm{~m}$ & 0.78 & $\begin{array}{l}\text { H.J. Green } \\
8 / 22 / 89 \text { sep. } \\
\text { disch. }\end{array}$ \\
\hline Discharge trench head loss & $0.91 \mathrm{~m}$ & 0.91 & $\begin{array}{l}\text { H.J. Green } \\
7 / 13 / 89\end{array}$ \\
\hline Total warm-water head loss & $4.6 \mathrm{~m}$ & 4.93 & $\begin{array}{l}\text { Computer model } \\
9 / 13 / 89\end{array}$ \\
\hline Supply pump head & $1.4 \mathrm{~m}$ & $? ? ?$ & \\
\hline $\begin{array}{l}\text { Overall pumping efficiency, } \\
\text { supply pump }\end{array}$ & $66 \%$ & 72 & $\begin{array}{l}\text { H.J. Green } \\
7 / 13 / 89\end{array}$ \\
\hline $\begin{array}{l}\text { Supply pump power } \\
\text { Discharge pump head }\end{array}$ & $\begin{array}{l}12.6 \mathrm{~kW} \mathrm{e} \\
3.2 \mathrm{~m}\end{array}$ & $\begin{array}{l}\text { ??? } \\
\text { ??? }\end{array}$ & \\
\hline $\begin{array}{l}\text { Overall pumping efficiency, } \\
\text { discharge pump }\end{array}$ & $72 \%$ & 72 & $\begin{array}{l}\text { H.J. Green } \\
7 / 13 / 89\end{array}$ \\
\hline Discharge pump power & $27.1 \mathrm{~kW} e$ & $? ? ?$ & \\
\hline Total warm-water pumping power & $39.7 \mathrm{~kW} e$ & 42 & $\begin{array}{l}\text { Computer model } \\
9 / 13 / 89\end{array}$ \\
\hline \multicolumn{4}{|l|}{ Cold-Seawater Flow System } \\
\hline $\begin{array}{l}\text { Onshore supply pipe, nominal } \\
\text { diameter }\end{array}$ & $0.61 \mathrm{~m}$ & 0.61 & $\begin{array}{l}\text { H.J. Green } \\
\text { 8/22/89 } \\
\text { 24" HDP DR26 }\end{array}$ \\
\hline Total supply head loss & $4.6 \mathrm{~m}$ & 4.17 & $\begin{array}{l}\text { H.J. Green } \\
8 / 22 / 89 \\
\text { vertical wet pit }\end{array}$ \\
\hline
\end{tabular}


Table 2-5. Systems Code Benchmark Comparison of NPPE Design Conditions (Concluded)

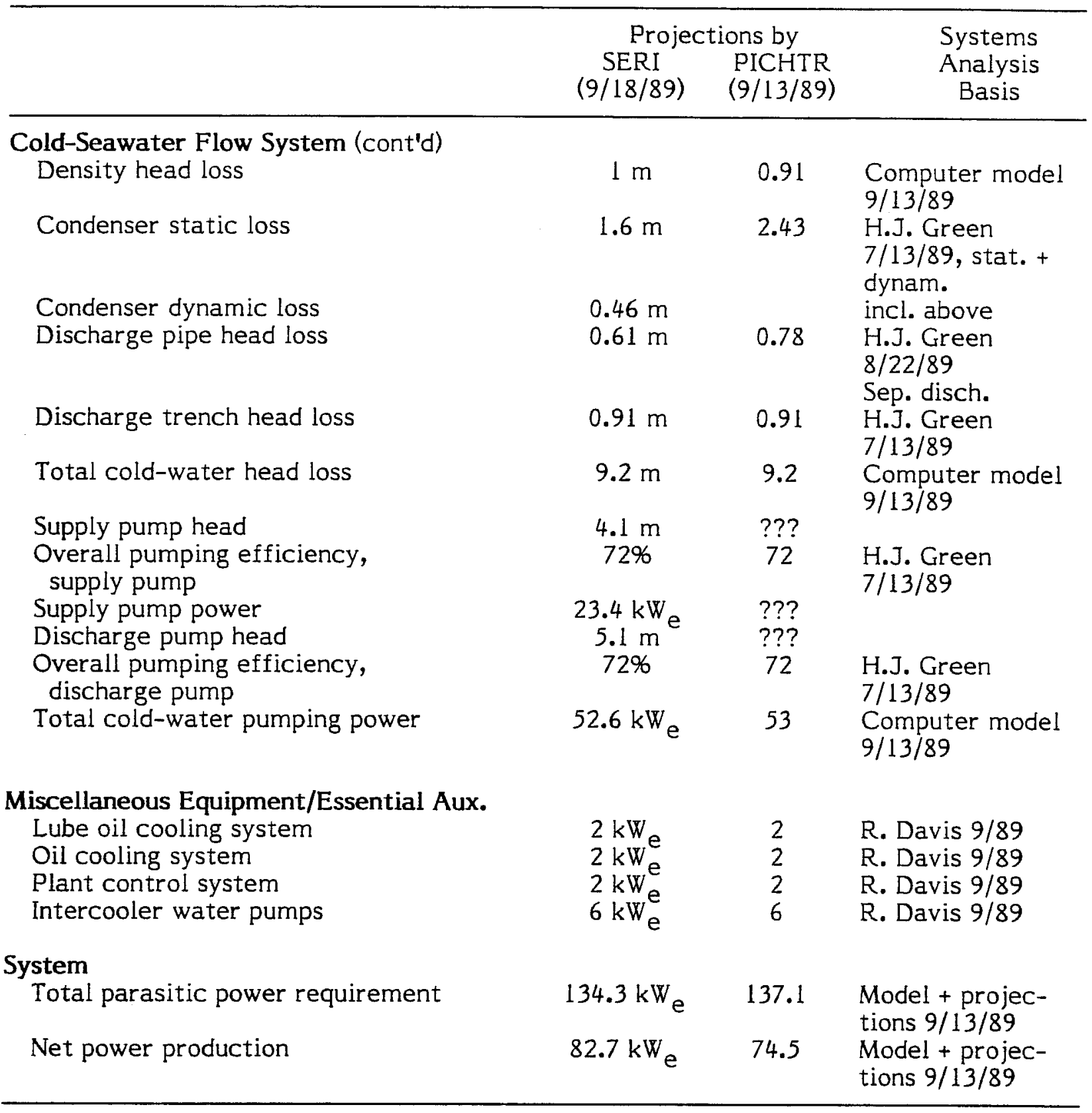

analysis must be carried out to determine the effects on the turbine efficiency caused by changes in steam velocity from such fluctuations.

Short-term control requires a detailed analysis to ascertain the control requirements and means for implementation. Proper management of the total NELH water delivery system is required. Special attention should be paid to a quantitative analysis of the shortterm control aspects during preliminary design. 
Start/Stop Control. The startup and shutdown of the HMTEA will follow procedures similar to those used at the HMTSTA (Parsons et al. 1989), and no specific additional control requirements are foreseen. For the NPPE, however, start-up and shutdown involve synchronizing the turbine/generator. Details of the control requirements are discussed in Chapter 3.0.

Emergency Control. The NPPE can be shut down in an emergency by venting (by breaking the vacuum) the working fluid space to atmospheric pressure at a controlled rate. No detailed calculations have been made on the spin-down time of the turbine rotor nor the aerodynamic heating that will occur as the turbine alters function from an expander to a compressor. However, given the kinetic energy of the rotor at the operating speed, preliminary calculations indicate that spin-down will occur in 10 to 20 minutes. Spraycooling may be needed to prevent significant temperature rise and damage to the internal system from frictional heating. A positive stop valve is not planned in the steam supply line because of the large size required and the flow losses it might introduce. A complete safety analysis, during normal operation and shutdown and in emergency situations, will be necessary to determine the extent of shutdown controls required.

The controls and safety issues were considered in a qualitative fashion during conceptual design and do not appear to be of any real concern. A priority activity for preliminary design will be to complete a quantitative analysis of these issues and to initiate an analysis of major transients that might affect either the performance or reliability of the NPPE components.

\subsection{Physical Integration}

\subsubsection{Integration Options}

The first iteration of the design assumed no component interface losses. With the low steam pressure used in this cycle and the large volume of the process steam and water flows, careful attention is necessary to the physical arrangement of the components and definition of the flow path. Two basic configurations for the overall system were considered. The first involves a horizontal orientation for the turbine axis of rotation with the evaporator and condenser located on either side of the turbine. The second option is defined with a vertical-axis turbine with the condenser located below and directly on the axis of the turbine. The evaporator is located in an axisymmetric annular cylindrical space with its inside diameter in line with the turbine inlet perimeter and its outer diameter extending to the outer wall of the vacuum enclosure. Figure 2-3 provides illustrations of the two options.

\subsubsection{Selection Criteria and Rationale}

The design choices of all of the HMTEA/NPPE components are based on their performance, technical risk, schedule, and cost in the given order of importance. The following discusses the relative merits of the choices in the physical integration of the system.

Performance. System analysis has shown that the proof of the feasibility (for producing net power at the stated power levels possible with the resource seawater flow available at $\mathrm{NELH}$ ) requires near-peak performance from all subsystems used in the experiment. The operating margin for achieving the net power goal of $40 \mathrm{~kW}$ is, at best, $25 \%$ of the gross power under an optimistic scenario and zero with conservative projections of component performances. The requirement for minimal performance losses is a key consideration for the physical system arrangement. 

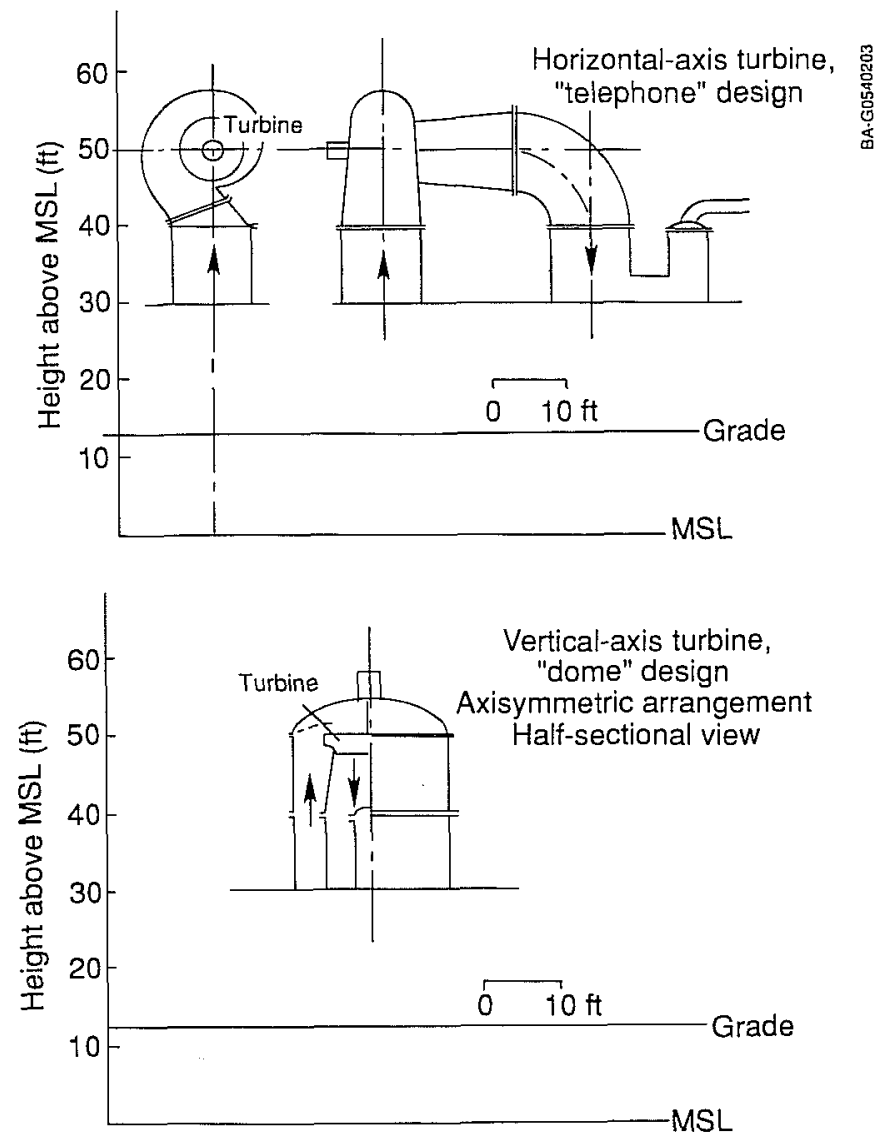

Figure 2-3. Sketches of "telephone" and "dome" configurations for HMTEA/NPPE
Technical Risk. Falling short of the predicted performance goal is the major risk factor and is also considered in the performance category in assessment; so the technical risk carries double weight as used. Under this category, the possibility is considered that the experiment will not work at all or will fail prematurely. Experimental research completed to date provides high confidence that the system will operate as projected in either configuration. Therefore, consideration of the technical risk is confined to evaluating the possibility of system or component failure or degradation over the useful life of the experiment.

Schedule. Consistent with the research agenda outlined in the OET Multiyear Program Plan (U.S. DOE 1985), the NPPE project should be completed within the time frame of the schedule as presented in Figure $1-3$, with an acceleration of that schedule being desirable. Any slippage of schedule will also affect overall system cost.

Cost. Developmental cost for the experiment should be consistent with the projected federal and PICHTR budgets, a requirement which appears feasible at this point. Any cost increase from the baseline projection could put the project at risk. The ability to raise additional funds, however, is perceived possible; a potential increase in cost would be less risky to the project than would its failure to achieve either the stated performance or reliable operation. Project cost details are discussed in Section 2.5.

\subsubsection{Configuration Options}

The two options considered for physically integrating the HMTEA/NPPE are described below:

Telephone. The telephone configuration is based on an extension of the HMTEA design studied by an industrial design team (Dillingham 1987b). The concept is based on expanding the existing HMTSTA design to a larger size and mounting it on a fabricated steel tower. To accommodate a turbine/generator for an NPPE, the side-by-side heat exchangers need to be separated horizontally to locate the turbine between them. The ducting space must be adequate to assure proper steam flow distribution across the face of the turbine and to allow for low-loss steam exit from the evaporator and entrance to 


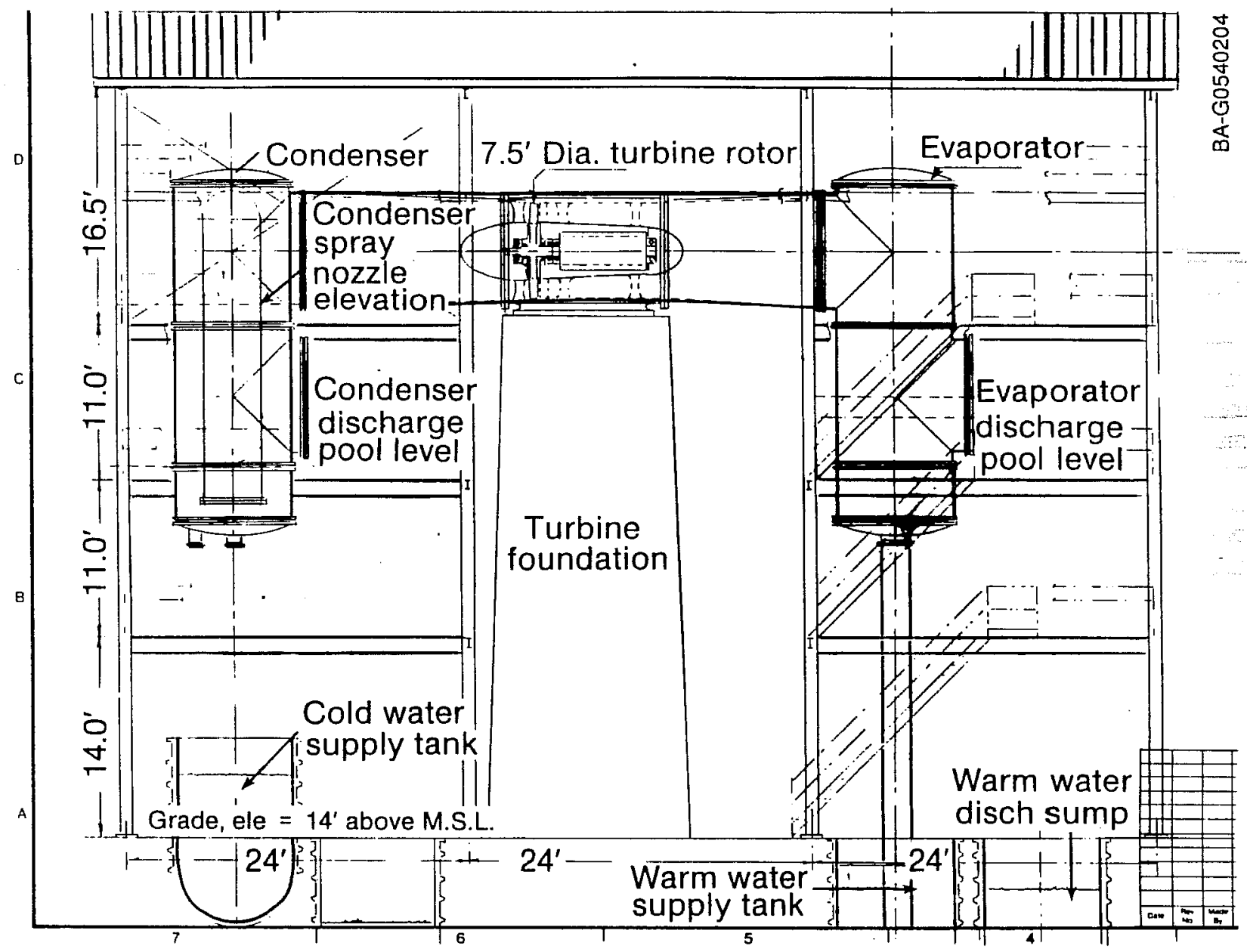

Figure 2-4. General arrangement of components in "telephone" configuration for HMTEA/NPPE

the condenser. These considerations result in a structure schematically shown in Figure 2-4. The advantages of this approach are as follows:

- The heat exchangers reflect the construction and configurations previously built and tested.

- Vacuum containment made of steel should be reliable and easy to maintain for extended periods.

- The arrangement provides flexibility for any potential future modifications.

The disadvantages are as follows:

- The structure is large, requiring a minimum footprint area of $14 \times 5 \mathrm{~m}(42 \times 15 \mathrm{ft}$ ).

- To provide for adequate seismic protection, the turbine foundation needs to be extended directly to bedrock.

- No overhung design (bearings located only on one end) exists of a single-rotor turbine of about $5000 \mathrm{~kg}(11,000 \mathrm{lb})$ with a horizontal axis of rotation; such a design may cause 
a significant imbalance in bearing load and is a departure from standard engineering practice.

- A horizontal-axis single-rotor design that is overhung represents a departure from all prior open-cycle designs, which use a balanced double-rotor horizontal-axis design or a single-rotor vertical-axis design.

- To ensure uniform flow distribution to and from the turbine, two large volutes to guide the steam flow are needed. Each volute is estimated to weigh $10,000 \mathrm{~kg}(22,000 \mathrm{lb})$.

- Evaporator and condenser vessels are roughly $4.6 \mathrm{~m}(15 \mathrm{ft})$ in diameter, approaching the diameter of the dome. The evaporator poses difficulties in arranging the multiple spouts; the condenser requires a separate countercurrent vessel(s).

- All vessel walls and steam piping must withstand full internal vacuum, requiring stiffened steel wall construction.

Dome. This concept is based on a vertical-axis turbine and a concrete vacuum enclosure proposed and studied in earlier open-cycle OTEC design efforts (Westinghouse 1979; Block and Valenzuela 1985; Valenzuela et al. 1988; Penney et al. 1984; Ludke and Chow 1984). In this concept, the system is built around the vertical axis of the turbine with all of the major components contained within a reinforced-concrete cylindrical enclosure that also acts as the mounting pedestal for the turbine. (Designs by Valenzuela et al. and Ludke and Chow use a double-rotor horizontal-axis turbine enclosed in the dome structure.) The concept is defined in the artist's sketch shown in Figure 2-5.

The advantages of this concept are

- It is a compact arrangement, sharing several structural functions in a single structure and simplifying the on-site assembly construction.

- The straight in-line exhaust of steam from the turbine to the condenser minimizes flow losses, provides excellent steam distribution to the condenser, and facilitates the integration of a diffuser.

- Heavy rotors of large sizes (such as in hydraulic machines) are typically arranged with a vertical axis to minimize radial bearing-load imbalances.

- The vertical shaft allows preloads on the radial bearings to be adjusted in the field to achieve the most effective rotor dynamic performance.

- Diffuser and other steam piping needs to withstand only the pressure corresponding to that between the evaporator and the condenser; they can be made of lightweight plastic materials and can readily be modified.

- The water distribution manifolds can be integrated readily within the vacuum structure using plastic plumbing.

The disadvantages are

- The vacuum containment, if made of concrete, requires special coatings to prevent air permeation and seawater leaching.

- Access to internal parts in a larger system may require heavy equipment and complicated procedures.

Based on a qualitative comparative evaluation of the two options at the first working group meeting (SERI 1989), the systems team selected the dome configuration as the prime configuration for the NPPE system with both steel and concrete as candidate materials. Further design work was directed to proceed with the dome configuration. The telephone configuration was to be maintained as a backup option in the event that future work reveals serious technical or cost issues related to the dome's further development. 
2.4.4 The Integrated NPPE System Design

System Description. The conceptual design of the NPPE is defined in the overall system drawing shown in Figure $2-6$, the process flow diagram in Figure $2-7$, and the system specification summarized in Table 2-6. A photograph of a scaled model of the vacuum structure and internals is shown in Figure 2-8.

The system is built around a verticalaxis, mixed-flow turbine rotor $2.9 \mathrm{~m}$ $(9.5 \mathrm{ft})$ in diameter supported by a 7.3-m (24-ft) outside-diameter vacuum housing that also acts as the structural backbone of the system. An exhaust diffuser is incorporated into the turbine design to recover most of the kinetic energy of the discharge. This diffuser, with a conical center body, is $2 \mathrm{~m}(6.6 \mathrm{ft})$ in diameter at the turbine exhaust and $3.65 \mathrm{~m}(12 \mathrm{ft})$ long and forms an annular entry to the cocurrent condenser section that is $4.1 \mathrm{~m}(13.5 \mathrm{ft})$ outside diameter and $2.4 \mathrm{~m}(8 \mathrm{ft})$ inside diameter. The diffuser is contained within the vacuum enclosure and, thus, is required to withstand the minimal pressure drop across the turbine and to support its own weight. It can be fabricated from light-gauge steel or possibly a plastic composite.

The electrical generator is located above the turbine assembly and outside the vacuum enclosure. It is an air-cooled, 4-pole, 1800-rpm synchronous generator with a brushless exciter. Further details on the turbine/generator are found in Chapter 3.0.

The turbine is supplied with low-pressure steam from an arrangement of 12 vertical spouts, each $0.24 \mathrm{~m}$ (10 in.) in diameter and located so the spout exit is $4.6 \mathrm{~m}$ ( $15 \mathrm{ft}$ ) above grade level. The spout evaporator occupies an annular cylindrical space bounded by the vacuum enclosure and an annular inner wall that separates the evaporator and the condenser. Warm seawater is brought to the evaporator by a single pipe $0.76 \mathrm{~m}$ (30 in.) in diameter that penetrates the vacuum enclosure at the bottom and rises in the vacuum space to an evaporator water manifold located just below the spouts. $A$ chevron-type mist eliminator is located above the evaporator to assure that moisture impingement is not a problem for the turbine rotor.

The condenser is direct contact with coaxial cocurrent and countercurrent stages fabricated and filled with a cooling tower packing (Munters Plasdek CF-25060 fill or equivalent). The first stage of the condenser occupies the outer annular cylindrical space connected to the diffuser exit and operates in a cocurrent flow of steam and water vertically down. Cold seawater is supplied to the condenser packing from a series of radial water manifolds equally spaced around the perimeter of the condenser space. A cold-water supply pipe $0.6 \mathrm{~m}(24 \mathrm{in}$.) in diameter penetrates the vacuum enclosure at the bottom and delivers the water for both condenser stages. The distribution manifold located on the centerline of the system is sized to distribute appropriate flows to the two stages. The second stage of the condenser is centrally located within the first stage. It 


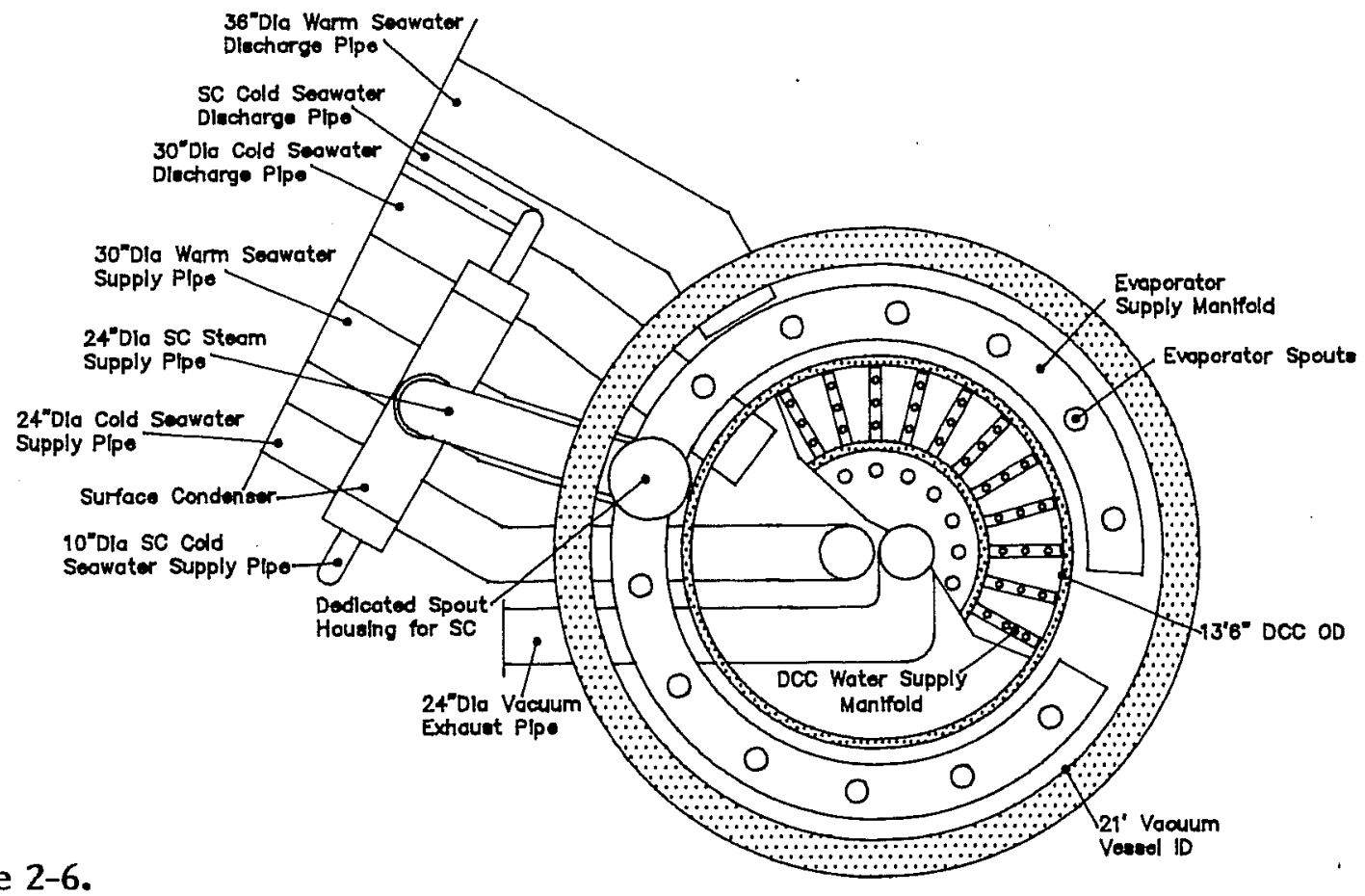

Figure 2-6.

Engineering sketch of HMTEA/NPPE. Sections shown are at varied levels to illustrate details

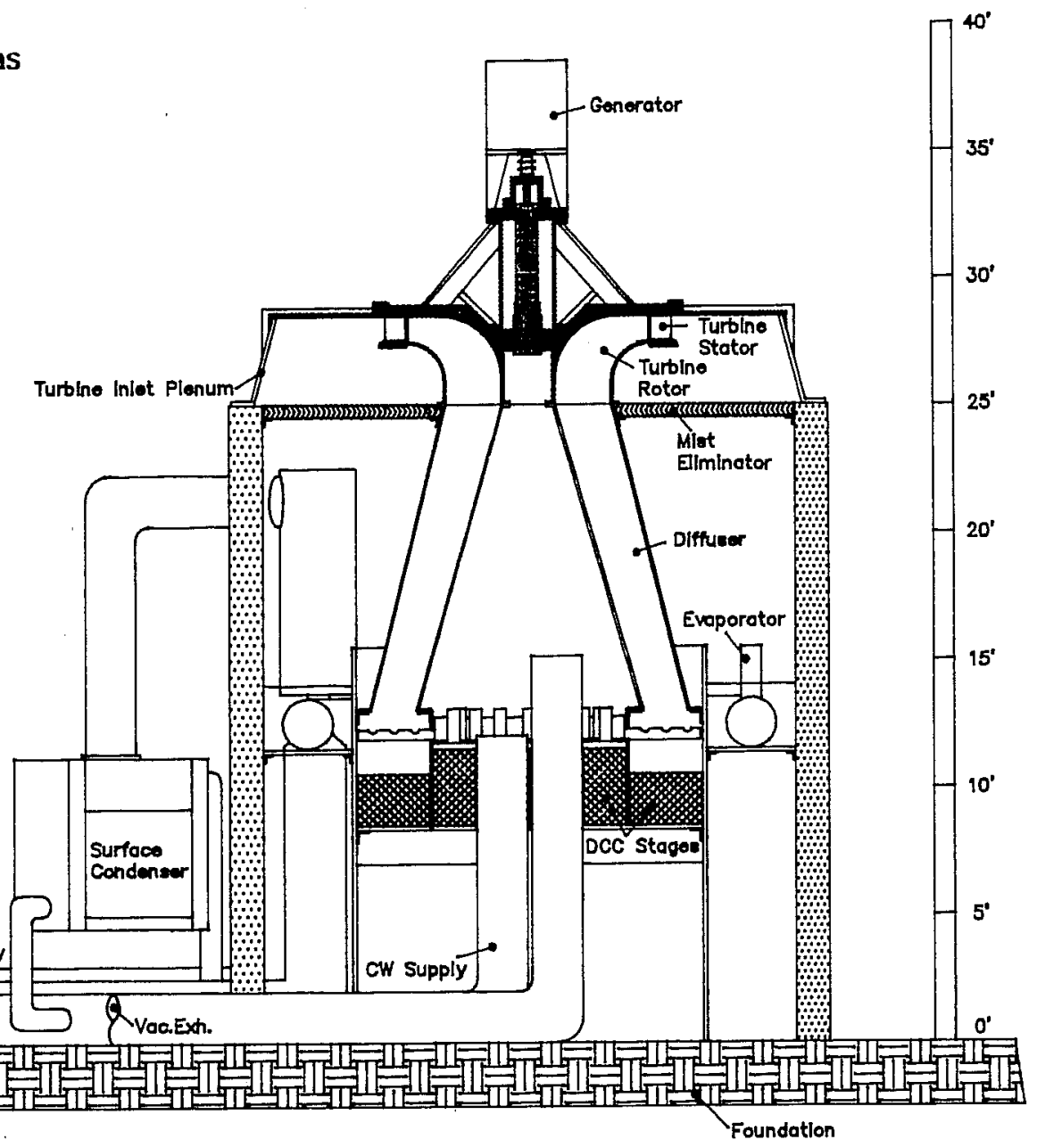




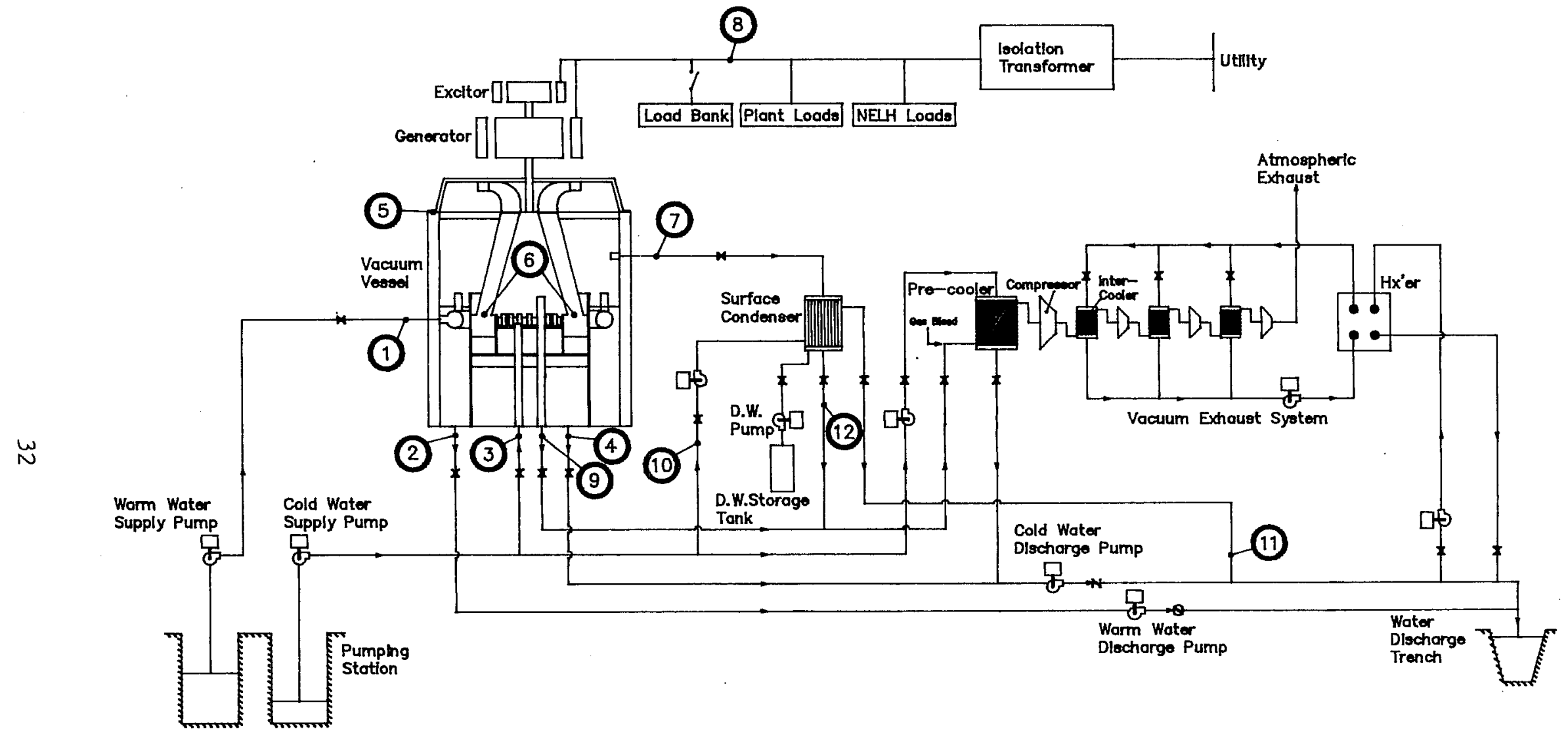

Figure 2-7. Process flow diagram for HMTEA/NPPE, with critical interfaces identified 


\section{Turbine/Generator}

Radial inflow, single stage

Steam consumption

Steam inlet temperature

Steam exhaust pressure

Turbine speed

Rated power

Generator design output

Voltage/phase/cycles

Shaft seal leakage

Heat Exchangers

Evaporator

Type

Seawater flow

Seawater temperature

Steam generation rate

Steam temperature

Design effectiveness

\section{Direct Contact Condenser}

Type

Seawater flow

Seawater temperature

Steam consumption rate

Steam inlet temperature

Inert gas content in steam

Design water effectiveness

\section{Surface Condenser}

Type

Seawater flow

Seawater temperature

Steam consumption rate

Steam inlet temperature

Inert gas content in steam

Design water effectiveness
$3.5 \mathrm{~kg} / \mathrm{s}$

$21.8^{\circ} \mathrm{C}$

$1.38 \mathrm{kPa}$

$1800 \mathrm{rpm}$

$300 \mathrm{~kW}$

$220 \mathrm{~kW}$

$480 \mathrm{~V} / 3 \mathrm{ph} \mathrm{AC} / 60 \mathrm{~Hz}$

$\leq 0.0005 \mathrm{~kg} / \mathrm{s}$

Vertical Spout

$620 \mathrm{~kg} / \mathrm{s}$

$26^{\circ} \mathrm{C}$

$3.5 \mathrm{~kg} / \mathrm{s}$

$21.8^{\circ} \mathrm{C}$

0.9

Packed Column

$420 \mathrm{~kg} / \mathrm{s}$

$6.1^{\circ} \mathrm{C}$

$3.5 \mathrm{~kg} / \mathrm{s}$

$11.8^{\circ} \mathrm{C}$

$0.013 \mathrm{~kg} / \mathrm{s}$

0.86

Plate-Fin

$42 \mathrm{~kg} / \mathrm{s}$

$6.1^{\circ} \mathrm{C}$

$0.35 \mathrm{~kg} / \mathrm{s}$

$11.8^{\circ} \mathrm{C}$

$0.0013 \mathrm{~kg} / \mathrm{s}$

0.9

Seawater Pumps

Function

Warm-

Cold-

Water Water

Warm-

Cold-

Supply

Supply

Water

Water

Discharge

Discharge

Number

Flow rate $(\mathrm{kg} / \mathrm{s})$

Total head $(\mathrm{m})$

Efficiency (\%)

Voltage/phase

\begin{tabular}{cccc}
1 & 1 & 1 & 1 \\
620 & 420 & 620 & 420 \\
1.4 & 3.6 & 3.2 & 5.4 \\
66 & 72 & 72 & 72 \\
\hline & - & $-480 \mathrm{~V} / 34 \mathrm{Ph}-$
\end{tabular}


Table 2-6. HMTEA/NPPE System Specifications (Concluded)

\begin{tabular}{lc}
\hline Ancillary Systems & \\
Vacuum Exhaust Compressors & \\
Type: Centrifugal and/or positive-displacement compressors, & \\
\multicolumn{1}{c}{4 stages, with precooler and interstage coolers } & 6.9 \\
Inlet flow rate $(\mathrm{m} / \mathrm{s})$ & 1.2 \\
Inlet pressure $(\mathrm{kPa})$ & 101 \\
Discharge pressure $(\mathrm{kPa})$ & 40 \\
Maximum power $(\mathrm{kW})$ & TBD \\
Instrumentation & \multicolumn{1}{c}{ TBD } \\
Control System Specifications & \\
Vacuum Structure & \\
Size & $6.4 \mathrm{~m}$ ID x 7.6 m height \\
Material & Coated reinforced concrete \\
Leak rate & $0.0005 \mathrm{~kg} / \mathrm{s}$ \\
Internal pressure & $1 \mathrm{kPa}$ (absolute) \\
External loading & 40 tons (vertical) \\
Design requirement & Seismic zone 3 \\
\hline
\end{tabular}

operates in countercurrent flow to condense additional leftover steam in the exhaust so the pumping requirement for the vacuum vent system is minimized. The countercurrent stage is constructed of the same material as the cocurrent stage but is longer with an overall packing height of $0.91 \mathrm{~m}(3 \mathrm{ft})$.

A surface condenser is used in the system to condense up to $10 \%$ of the steam flow to produce desalinated water as a by-product of power generation. The surface condenser will be developed as a test article to acquire performance data. The condenser is fabricated as a brazed aluminum structure, with extruded channels forming the seawater passages and offset finstock acting as the enhanced condensing surface in the vapor stream (Panchal and Genens 1989). This surface condenser is located outside but next to the vacuum enclosure. It is supplied with cold seawater tapped from the main condenser coolant supply and uses separate water circulation pumps on the desalinated water and seawater streams. Chapter 5.0 provides further details on the heat exchangers.

The seawater systems consist of supply, discharge, and distribution portions for the warm and cold waters. The distribution system to the evaporator and condenser was described earlier. The major part of the supply system already exists at NELH. This existing supply system will be modified by adding onshore piping and replacing existing pumps with a complement of high-efficiency pumps. One supply pump will be used in each of the warm and cold water streams. The supply pumps will be located at the intake sump and will be of a vertical wet-pit construction using mixed-flow impellers. The housings will be coated cast iron with yet-to-be-chosen impeller and shaft materials. Another pair of pumps will provide for the discharge and will be barrel-type pumps located near but outside the vacuum enclosure. All pumps will use variable-frequency drives for flow control. 


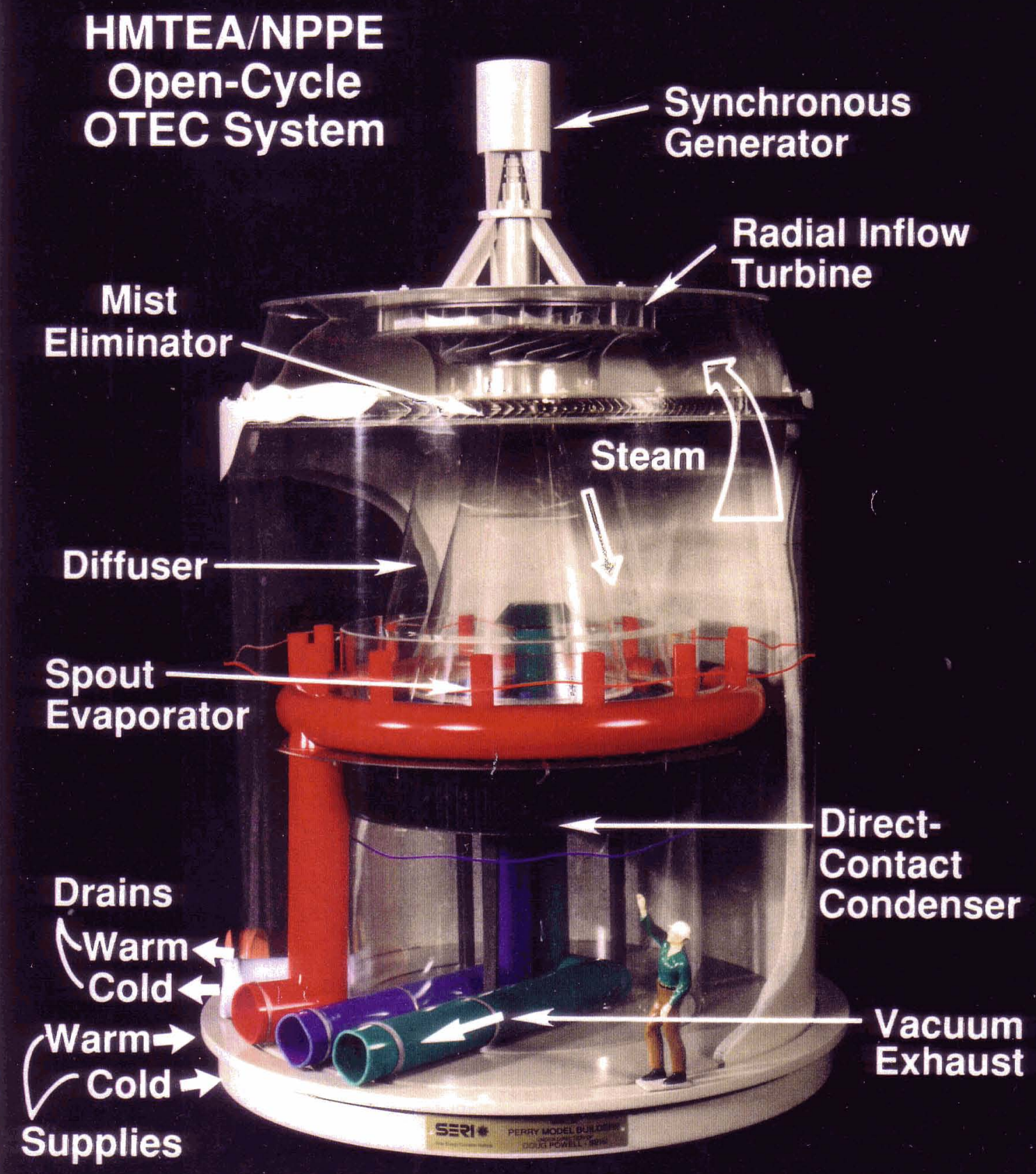

Figure 2-8. Photograph of vacuum structure showing internal arrangement of HMTEA/NPPE system components 
Warm-water onshore piping will be $0.91 \mathrm{~m}$ (36 in.) in diameter; cold-water onshore piping will be $0.61 \mathrm{~m}(24 \mathrm{in}$.) in diameter. The material for these pipes is unspecified at this stage. On the discharge side, the water streams will be combined downstream of the pumps into a 1.22-m- (48-in.)-diameter polyethylene pipe, which will be buried and will end in a percolation discharge trench. A proposed test trench on the site is $3.05 \times 3.05 \times$ $30.5 \mathrm{~m}(10 \times 10 \times 100 \mathrm{ft})$ in its excavated dimensions to discharge nominally $0.19 \mathrm{~m} / \mathrm{s}$ (3000 gal/min.). This trench is expected to be operational in early 1990 . The size of the trench needed for the HMTEA/NPPE discharge will not be determined until construction and testing are completed on the performance of the test trench. An existing water disposal sump on the site will not be used. For further details on the pump designs and other remaining open issues, see Chapter 4.0.

The most important ancillary equipment in the HMTEA/NPPE is the vacuum compression system. The design established for the HMTEA/NPPE uses a high-efficiency, multiplestage, intercooled compressor. The system will use a precooler and direct-contact or surface-type interstage coolers with four compression stages, operating with nearly a $3: 1$ compression ratio and projected $60 \%$ design efficiency in each stage. Potential suppliers for the vacuum compressors were identified during the conceptual design. Resolution on the type of compressors to be used was achieved. However, assessment of off-the-shelf machines suggested that to maintain low power consumption, the compressor(s) will be an engineered product and will use positive-displacement and/or centrifugal machine(s). A high-priority effort during the preliminary design is warranted to finalize the vacuum system. More details on the vacuum system and other ancillary systems are provided in Chapter 6.0.

For increased safety, the physical locations of the critical high-speed rotating machines, namely the turbine and vacuum pumps, will be higher than $6.4 \mathrm{~m}(21 \mathrm{ft}$ ) above grade level to ensure that no seawater damage could occur during any unanticipated operating conditions.

Process Description. Surface seawater enters the evaporator held at an absolute pressure of about $2.6 \mathrm{kPa}$, where it generates low-pressure steam by flash evaporation. Nearly $0.6 \%$ of the incoming water is converted to steam. The spent water is drained from a pool below. Dissolved gases, mostly oxygen and nitrogen, also evolve from the seawater. Almost $100 \%$ of these gases are projected to be released from the seawater. The mixture of these gases and steam flows upward, carrying some seawater droplets generated during evaporation.

A mist eliminator located directly above the evaporator allows water droplets of over 40-micrometer diameter to be removed from the steam. Steam then enters the stator of the turbine where it is accelerated to match its exit tangential velocity to the tip speed of the rotor. Thus, the steam enters the rotor radially and exits the rotor vertically downward. The power imparted by the steam to the rotor is transmitted to the generator via a flexible coupling.

A diffuser located below the rotor allows partial recovery of the kinetic energy of the spent steam. Below the diffuser, the steam contacts cold seawater distributed over packings in the cocurrent section of the condenser. Nearly $80 \%$ of the steam is condensed here, causing the water temperature to rise about $5^{\circ} \mathrm{C}$. The remaining steam is collected centrally and flows upward through a countercurrent section of the condenser. This section is also provided with cold seawater from above, distributed over packings. Up to $98 \%$ of the remaining steam is condensed in this section. The spent water from both sections of the condenser is collected in a pool below and discharged from the vacuum vessel. 
Dissolved gases are also released from the cold seawater. The remainder of the steam, together with the noncondensable gases (released from both seawater streams and leaked into the vessel), is removed through a central pipe connected to the vacuum exhaust compressors located outside but adjacent to the vacuum vessel.

The power generated is distributed to water pumps, vacuum pumps, other ancillary equipment, and essential control elements. Excess power from the system will be dissipated in a load bank or fed into the local utility grid.

\subsubsection{Site Plan}

The site plan for the HMTEA/NPPE involves three primary locations. The pump station for the existing seawater systems is located approximately $70 \mathrm{~m}(200 \mathrm{ft}$ ) from the shoreline and currently contains 12 pumps in two sumps. The low-head system that will be used for the HMTEA/NPPE contains three pumps to supply the cold-water flow and four pumps to provide the warm-water flow in a separate sump. As was discussed earlier, this arrangement will be reviewed in the later design phases to achieve higher pump efficiency and reduced piping losses. Although the final decision has not been made, the new supply pumps will be located in or near the present sumps.

The main experiment location is between the NELH administration building and the site of the HMTSTA, as shown on the plot plan in Figure 2-9. The domed cylindrical apparatus and a HMTEA/NPPE control building will be installed on a pad at this location. The seawater supply piping from the pump station to the experiment is $200 \mathrm{~m}$ (650 ft) long and will be buried.

The piping run from the experiment to the third HMTEA/NPPE site, namely the discharge trench, is $1.22 \mathrm{~m}$ (48 in.) in diameter and $215 \mathrm{~m}(700 \mathrm{ft}$ ) long. The discharge pipe will also be buried until it emerges in the trench. The trench site is north of the other facilities at the NELH; the tests at the test trench will allow determination of the ultimate trench size.

\subsubsection{System Interfaces}

A vital function of the systems integration task is to establish and manage the interfaces among all the components and subassemblies that make up the experiment. These interfaces include size and location of physical connections, flow rates, electrical power, instrumentation, and utility hookups. Key interfaces among the various tasks as outlined in the work breakdown structure are identified in Table 2-7 and are noted in the accompanying process flow diagram shown in Figure 2-7. This list is by no means complete. Early in the preliminary design, closure points on all of these interfaces are compatible and realistic. Once a closure occurs, changes in interfaces will only be possible through a prescribed formal procedure. Such a procedure will assure the various designers that unknown or arbitrary changes in their interface requirements will not occur. As the design proceeds, requirements may arise on both sides of an interface that are incompatible or that compromise safety, reliability, accessibility, or maintainability. In those cases, the system integrator will define, document, and control the alterations in the interfaces.

\subsection{Cost Projections}

The objective of a conceptual design is to develop data such that a skilled reviewer can assess the project's technical merit and potential risks and can roughly estimate the cost of turning the concept into hardware. At the present level of the HMTEA/NPPE design, 


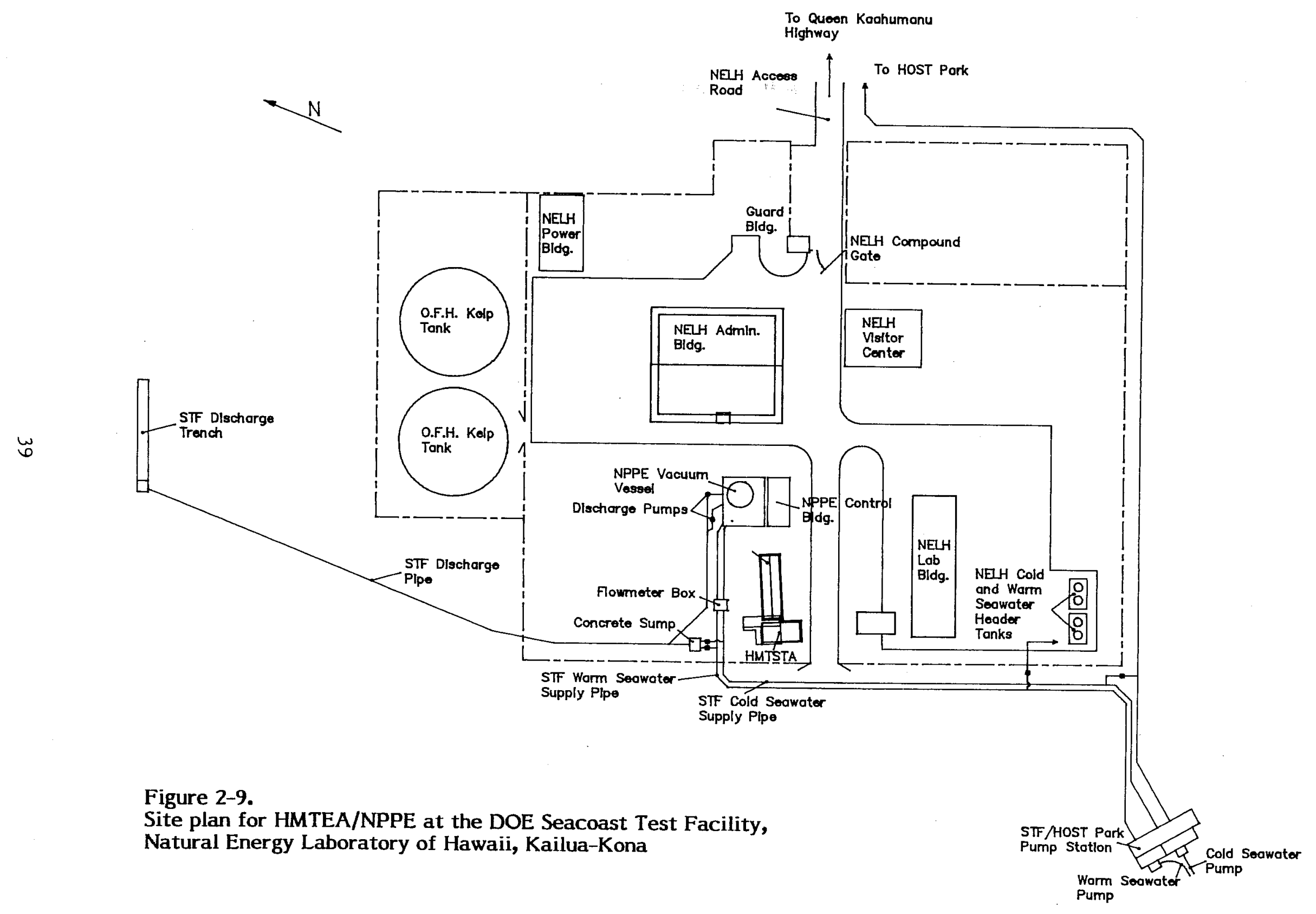


Table 2-7. List of Critical System Interfaces

\begin{tabular}{|c|c|c|c|c|c|}
\hline From* & To* & Number* & Medium* & $\begin{array}{l}\text { Qualitative } \\
\text { Description }\end{array}$ & $\begin{array}{l}\text { Quantitative } \\
\text { Description }\end{array}$ \\
\hline$S$ & $\mathrm{H}$ & 1 & $W W$ & $\begin{array}{l}\text { Warm seawater } \\
\text { supply to } \\
\text { evaporator }\end{array}$ & $\begin{array}{l}\text { Vacuum-rated flange, } 30 " \\
\text { dia., to handle up to } \\
10,600 \mathrm{gal} / \mathrm{min}\end{array}$ \\
\hline $\mathrm{H}$ & $S$ & 2 & $W W$ & $\begin{array}{l}\text { Warm seawater } \\
\text { drain from } \\
\text { the evaporator }\end{array}$ & $\begin{array}{l}\text { Vacuum-rated flange, 36" } \\
\text { dia., to handle up to } \\
10,600 \mathrm{gal} / \mathrm{min}\end{array}$ \\
\hline$S$ & $\mathrm{H}$ & 3 & $\mathrm{CW}$ & $\begin{array}{l}\text { Cold seawater } \\
\text { supply to } \\
\text { condenser }\end{array}$ & $\begin{array}{l}\text { Vacuum-rated flange, } 24 " \\
\text { dia., to handle up to } \\
7,150 \mathrm{gal} / \mathrm{min}\end{array}$ \\
\hline $\mathrm{H}$ & $S$ & 4 & $\mathrm{CW}$ & $\begin{array}{l}\text { Cold seawater } \\
\text { drain from } \\
\text { condenser }\end{array}$ & $\begin{array}{l}\text { Vacuum-rated flange, } 30 " \\
\text { dia., to handle up to } \\
7,150 \mathrm{gal} / \mathrm{min}\end{array}$ \\
\hline $\mathrm{H}$ & $\mathrm{T}$ & 5 & LS & $\begin{array}{l}\text { "Mist-free" steam } \\
\text { supply to turbine }\end{array}$ & $\begin{array}{l}\text { Vacuum-rated horizontal } \\
\text { flange, } 21^{\prime} \text { dia., to } \\
\text { handle up to } 3.9 \mathrm{~kg} / \mathrm{s} \\
\text { steam flow at a pressure } \\
\text { of nominally } 2.4 \mathrm{kPa} \text {. } \\
\text { Physically located } 25^{\prime} \\
\text { above grade }\end{array}$ \\
\hline $\mathrm{T}$ & $\mathrm{H}$ & 6 & LS & $\begin{array}{l}\text { Spent steam from } \\
\text { turbine to first- } \\
\text { stage condenser }\end{array}$ & $\begin{array}{l}\text { Vacuum-rated horizontal } \\
\text { double flange, } 8^{\prime} \\
\mathrm{ID} \text { on inner; } 13.5^{\prime} \\
\text { OD* on outer, to } \\
\text { handle up to } 3.9 \mathrm{~kg} / \mathrm{s} \\
\text { steam at nominal pressure } \\
1.4 \mathrm{kPa} \text {. Physically } \\
\text { located } 13^{\prime} \text { above grade }\end{array}$ \\
\hline $\mathrm{H}$ & $\mathrm{H}$ & 7 & LS & $\begin{array}{l}\text { "Mist-free" ? } \\
\text { low-pressure steam } \\
\text { supply to surface } \\
\text { condenser }\end{array}$ & $\begin{array}{l}\text { Vacuum rated vertical } \\
\text { flange, } 24 " \text { dia., to handle } \\
0.35 \mathrm{~kg} / \mathrm{s} \text { steam flow at } \\
\text { pressure } 1.4 \mathrm{kPa} \text {. } \\
\text { Physically located at } \\
21^{\prime} \text { elevation }\end{array}$ \\
\hline$T$ & A & 8 & E3 & $\begin{array}{l}\text { Three-phase } \\
\text { electrical output } \\
\text { from generator }\end{array}$ & $\begin{array}{l}\text { Rating } 300 \mathrm{~kW} \\
3 \text { phase, } 60 \mathrm{~Hz} A 80 \mathrm{~V} \text {, }\end{array}$ \\
\hline
\end{tabular}


Table 2-7. List of Critical System Interfaces (Concluded)

\begin{tabular}{cccccc}
\hline From* & To* & Number* & Medium* & $\begin{array}{c}\text { Qualitative } \\
\text { Description }\end{array}$ & \multicolumn{1}{c}{$\begin{array}{c}\text { Quantitative } \\
\text { Description }\end{array}$} \\
\hline H & A & 9 & LS & $\begin{array}{l}\text { Exhaust from } \\
\text { condenser }\end{array}$ & $\begin{array}{l}\text { Vacuum-rated horizontal } \\
\text { flange } 24^{\prime \prime} \text { dia., to handle } \\
\text { up to } 3.8 \mathrm{~m}^{3} / \mathrm{s} \text { of low- } \\
\text { pressure steam inert } \\
\text { mixture }\end{array}$ \\
$\mathrm{S}$ & $\mathrm{H}$ & 10 & $\mathrm{CW}$ & $\begin{array}{l}\text { Cold-water supply } \\
\text { to surface } \\
\text { condenser }\end{array}$ & $\begin{array}{l}\text { Vacuum-rated flange, } \\
10^{\prime \prime} \text { dia., to handle up to } \\
750 \text { gal/min cold seawater }\end{array}$ \\
$\mathrm{H}$ & $\mathrm{S}$ & 11 & $\mathrm{CW}$ & $\begin{array}{l}\text { Cold-water drain } \\
\text { from surface } \\
\text { condenser }\end{array}$ & $\begin{array}{l}\text { Vacuum-rated flange, } \\
10^{\prime \prime} \text { dia., to handle } \\
\text { up to } 750 \text { gal/min cold } \\
\text { seawater }\end{array}$ \\
$\mathrm{H}$ & $\mathrm{A}$ & 12 & $\mathrm{LS}$ & $\begin{array}{l}\text { Exhaust from } \\
\text { surface condenser }\end{array}$ & $\begin{array}{l}\text { Vacuum-rated vertical } \\
\text { flange to handle steam } \\
\text { and noncondensable } \\
\text { flow, 8" diameter }\end{array}$ \\
\hline
\end{tabular}

* See below for explanation of abbreviations

$I$ = System integration

$(000)$

$\mathrm{H}=$ Heat exchanger

$(100)$

$T=$ Turbine

(200)

$S=$ Seawater system (300)

$A=$ Ancillary system

(400)

$W W=$ warm seawater

LS $=$ low-pressure steam

$\mathrm{CW}=$ cold seawater

$\mathrm{DW}=$ desalinated water

$\mathrm{CS}=$ control signal

$\mathrm{E} 3=3$ phase, $480 \mathrm{~V}$, electrical supply

IN = instrumentation signal

$E I=1$ phase, $120 \mathrm{~V}$, electrical supply

$\mathrm{CA}=$ compressed air

$O D=$ outer diameter

$\mathrm{LO}=$ lube oil

ID = inner diameter

a number of alternatives remain to be decided upon for several components. Details of possible interrelational aspects among the various components have not been thoroughly considered. Possible cost premiums associated with site-related special requirements, and the details of the civil structures needed, have not been considered. This lack of detail makes a comprehensive cost estimate impractical.

A detailed analysis of the design and cost of the major components in the NPPE has been completed and is documented in this report. Some costs were established by parametric relationships or analogy. Because the costs of major components (which form the bulk of the system cost) were evaluated closely, even though others are estimated roughly or overlooked altogether, the total cost is adequately defined for budgetary planning. 
The following cost estimate is broken down into two categories: the cost of design and construction, and the extent of project management support necessary to complete the intermediate research experiments and analysis and to establish the management basis for constructing and operating the experiment.

\subsubsection{Design and Construction}

Table 2-8 on pages 44 and 45 summarizes the estimated cost of completing the design and construction of the NPPE. The costs are organized according to the major component and subsystem categories discussed in this report. Each category is broken down into three cost elements: equipment purchases; contracts for design, installation, and repair or modification; and consultants to provide expert assistance in specifying and evaluating the HMTEA/NPPE and its elements as well as analyzing and troubleshooting the equipment and experimental results. As is apparent in this report, the design and cost are most thoroughly defined for the turbine, ancillary systems, seawater systems, and heat exchangers. Because these elements account for more than $75 \%$ of the total cost, a contingency fund of approximately $15 \%$ of the total cost is applied that could cover an uncertainty of up to $100 \%$ in the cost of the structure and the projected extension to the disposal trench (the major uncertainties at this point).

\subsubsection{Technical Management}

Because the HMTEA/NPPE is an ongoing research experiment with intermediate experiments to be completed with the HMTEA, "technical management" may be a misnomer for the supporting technical effort that must be provided. Some of the activities that must be completed by the design team for the NPPE to be successful are as follows:

Studies and Analyses. At the end of conceptual design, numerous choices need to be made regarding component specifications, materials, operating parameters, and so on. As the design and interfaces begin to solidify, conflict and compromises that arise can only be resolved through objective analysis. Such studies and analyses will have to be undertaken as required on a continuing basis.

Subcontract Management. The technical, coordinating, and administrative functions for each subcontract will involve one or more team members.

Configuration Management and Interface Control. The chief engineer will formalize and manage the documentation of the design and assume that all interfaces are compatible.

Project Management and Review. Overall coordination and control of budget and schedule will have to be maintained. Timely reports to DOE will be required on the progress of the project and any corrective or preventive actions needed.

Test Plan Development. A comprehensive HMTEA test plan will be developed and test results will be evaluated before the NPPE test plan is finalized. However, an early draft of the NPPE test plan will be made available to guide the design team on the NPPE testing requirements.

Other HMTEA/NPPE Plans and Documentation. The following plans and documentation will be developed and managed in the course of the project:

- Work breakdown structure

- Reporting procedures for cost and schedule 
- Procurement plan, including inspection, quality control procedures, and acceptance procedures and criteria

- Permits and licensing plan, including environmental monitoring and reporting

- Safe procedures and operating plan that will include analyses of component failures and recommended actions under unusual or emergency situations

- Construction methods and equipment plan that will assure that the HMTEA/NPPE will meet standards of quality, aesthetics, and safety appropriate at the NELH

- Operation and maintenance plan that assures that procedures necessary for safe operation and maintenance of the useful life of the system will be followed

- Equipment disposition plan for continued use or disposition of HMTEA/NPPE hardware and associated systems and equipment.

Other activities that may arise in the course of the project development and that are appropriate for the OTEC project team will be completed within the technical management function.

It is estimated that a full-time force of 12 workers, distributed among the three cooperating organizations, will be needed to carry out these various activities. This estimate contains a contingency of $50 \%$.

\subsection{Remaining Issues and Future Work}

\subsubsection{Technical Issues}

The objective of the system analysis and integration task is to provide the analysis, engineering, planning, and direction to address the following specific issues of the HMTEA/NPPE:

- System performance

- Component interfaces

- System control

- System stability and dynamics

- Hardware design and integration.

All of these issues were considered in varying levels of detail during the conceptual design. System stability and control were examined mostly qualitatively. Definition and analysis of the control schemes remain as outstanding issues at this stage.

The compatibility of component interfaces was examined, and all interfaces appear to be satisfactory for good performance and reliable operation. The beginning of preliminary design is the appropriate time to clearly define and document all of the interfaces and to begin to formalize the procedures for their management.

Performance of Developmental Items. The structural design of the vacuum containment vessel needs further definition, particularly regarding air leakage and impact of seismic activity. The vessel serves the dual function of vacuum containment and structural support of the turbine. Adequacy of the structure for both of these requirements will have to be evaluated in the light of a possible seismic event.

The planned tests to evaluate the permeability of the trench that is under development will provide data on the extension required to discharge the entire HMTEA/NPPE water stream and on the associated parasitic power penalties for the system. Should the permeability prove to be unacceptable, alternative methods for disposing of the discharge streams need to evaluated and ranked and assessments made of potential environmental effects and costs. 
Table 2-8. HMTEA/NPPE Project Costs at Nov. 1989

\begin{tabular}{|c|c|c|c|c|}
\hline Task & Equipment & Contracts & Consultants & Totals \\
\hline \multicolumn{5}{|l|}{ System Integration } \\
\hline Documentation & & 150 & & 150 \\
\hline Reviews & & & 30 & 30 \\
\hline Failure mode analyses & & & 30 & 30 \\
\hline Total & 0 & 150 & 60 & $210 \$ \mathrm{~K}$ \\
\hline \multicolumn{5}{|l|}{$\begin{array}{l}\text { Turbine/Structures } \\
\text { Turbine }\end{array}$} \\
\hline Turbine & 1600 & & & 1600 \\
\hline Phase I turbine design & & 280 & & 280 \\
\hline Phase II turbine design & & 600 & & 600 \\
\hline Turbine-related electrical items & 210 & & & 210 \\
\hline Consultants & & & 250 & 250 \\
\hline Total & 1810 & 880 & 250 & $2940 \$ K$ \\
\hline Structure & & & & \\
\hline Site preparation & 100 & & & 100 \\
\hline $\begin{array}{l}\text { Vacuum vessel ( } 21^{\prime} \text { inner diameter } \\
\text { by } 25^{\prime} \text { high) }\end{array}$ & 300 & & & 300 \\
\hline Instrument house (1200 sq ft) & 100 & & & 100 \\
\hline Miscellaneous & 30 & & & 30 \\
\hline Equipment installation & 150 & & & 150 \\
\hline Design and specifications & & 170 & & 170 \\
\hline Structure consultants & & & 30 & 30 \\
\hline Total & 680 & 170 & 30 & $880 \$ \mathrm{~K}$ \\
\hline
\end{tabular}

\section{Heat Exchangers}

Fabricated equipment

Evaporator (distributor, mist elim.) 60

DCC (packing, walls, distributor) 115

Surface condenser

Drawings/installation

30

Test instrumentation 
Table 2-8. HMTEA/NPPE Project Costs at Nov. 1989 (Concluded)

\begin{tabular}{|c|c|c|c|c|}
\hline Task & Equipment & Contracts & Consultants & Totals \\
\hline \multicolumn{5}{|l|}{ Ancillary Systems } \\
\hline \multicolumn{5}{|l|}{ Vacuum compression system } \\
\hline Preliminary design & & 30 & 10 & 40 \\
\hline Final design and construction & 210 & 50 & 10 & 270 \\
\hline \multicolumn{5}{|l|}{ Controls and instrumentation } \\
\hline Dynamic analysis & & & 10 & 10 \\
\hline Final control/DAS design & & 50 & 20 & 70 \\
\hline Purchases & 250 & 85 & & 335 \\
\hline \multicolumn{5}{|l|}{ Electrical } \\
\hline Preliminary design completion & & 20 & & 20 \\
\hline Final design & & 60 & & 60 \\
\hline Wiring, MCC, etc., purchase & 290 & & & 290 \\
\hline \multicolumn{5}{|l|}{ Miscellaneous ancillary } \\
\hline Cooling/fresh water/AC & 35 & & & 35 \\
\hline Other & 100 & & & 100 \\
\hline Total & 885 & 295 & 50 & $1230 \$ K$ \\
\hline \multicolumn{5}{|l|}{ Seawater Systems } \\
\hline SWS flow tests & 5 & & & 5 \\
\hline A\&E, consulting firm & & & 20 & 20 \\
\hline Safety consultant & & & 15 & 15 \\
\hline Trench extension (100') & & 110 & & 110 \\
\hline Onshore piping & 200 & 290 & & 490 \\
\hline Seawater pumps & 170 & 160 & & 330 \\
\hline Instrumentation & 10 & & & 10 \\
\hline Total & 385 & 560 & 35 & $980 \$ \mathrm{~K}$ \\
\hline Subtotal & 4030 & 2085 & 425 & $6540 \$ \mathrm{~K}$ \\
\hline Contingency (Approx. 15\%) & & & & $950 \$ \mathrm{~K}$ \\
\hline Contractor Fees \& Handling (Approx. 12\%) & & & & $800 \$ \mathrm{~K}$ \\
\hline HMTEA/NPPE Total Project Cost (ROM) & & & & $8290 \$ K$ \\
\hline
\end{tabular}


The preliminary design and development of the vacuum exhaust system must be monitored closely to ensure its acceptability for parasitic power consumption and timely delivery at or below the projected cost.

The design of the advanced plate-fin surface condenser for producing desalinated water must be evaluated. Close attention should be paid to the compatibility of the material with seawater, the potential for corrosion and pitting, and the projected life expectancy.

The effects of these developmental items on performance, technical risk, cost, and schedule of the system must be monitored especially carefully throughout their developmental period.

Other Critical Areas. Other areas of concern lie in the projected off-design performance of the power generating system, the potential effects of critical component failures on safety of personnel and integrity of the system, the effect of seismic action and tsunamis, and other environmental causes and issues. All of these areas require detailed evaluation during the next stage of the HMTEA/NPPE design.

\subsubsection{Preliminary Design}

The next step in the project is to proceed to preliminary design and to put in place the described technical management activities.

The objective of preliminary design is to obtain adequate data with supporting drawings and analyses to establish the engineering and economic feasibility of the concept and to accommodate all technical uncertainties through alternative engineering approaches. The design will be sufficiently detailed that cost and schedules can be established to within $25 \%$.

To achieve the objective, the following activities and documentation are required:

- A drawing of the preliminary site plan that shows the experiment's location at the $\mathrm{NELH}$, establishes all utility interface requirements, defines all future expansions (if required), and shows access to workshops, offices, storage, and sanitary and other facilities that may be required

- A final drawing of the overall layout of the system showing size and location of all major subsystems drawn to scale and showing major dimensions

- A preliminary piping and instrumentation drawing providing an engineering estimate of the amount, type, and cost of the plumbing, electrical, and instrumentation and control components

- Final system performance specifications defined as major subassemblies. These specifications will establish operating parameters (e.g., temperatures, flow rates, pressures, and levels), minimum performance measures, and outline drawings for each major subassembly.

- An analysis of the system performance at the design point and over a range of expected operating conditions. This analysis will use validated or consensus models and methods with all critical performance assumptions traceable to manufacturers' data or valid experimental research results.

- An analysis of safety, expected life, reliability, and maintenance requirements for the system operating continuously or intermittently at NELH over a period of two years

- An analysis of system control, performance, stability, and data-acquisition requirements, with special attention paid to off-design and emergency conditions

- An itemized construction cost estimate accurate to within $25 \%$ for the system as installed and ready to run 
- A preliminary test plan that meets the basic objectives of the project and allows for additional testing that can provide data for understanding the system's operation and designing future systems if they are perceived as being valuable.

\subsubsection{Final Design}

The design cycle will be completed with the final engineering design and specification for the HMTEA/NPPE.

The objective of this phase is to produce design and construction drawings and specifications so the schedule and cost for procuring, building, installing, and operating the HMTEA/NPPE hardware can be quoted on a firm fixed-price basis.

The design and documentation package that will permit procuring, constructing, and successfully operating the experiment will include

- A final approved drawing package providing adequate detail that every hardware item in the system may be purchased or built. The package will include all drawings necessary for site preparation, utility interfaces, component and subsystem subassembly and installation, and assembled system checkout.

- Final specifications and data sheets for all system components and instrumentation

- A detailed safe operating procedure

- A fixed-price cost estimate and construction bid package

- A system acceptance procedure that defines criteria by which the DOE and its costsharing partners will accept ownership of the system. The procedure will specify the responsibilities of all parties and make provisions for resolving any disagreements that may arise.

- A final test plan that will identify data, instruments, test procedures, and data analysis methods suggested for the experiment

- A detailed technical report that addresses the analyses used as the basis for the design, with particular emphasis on areas that needed supplementation or modification from the preliminary design results

- A final data package reflecting the as-built key system parameters.

It is recommended that the final design package be reviewed by a competent architectural and engineering firm with established expertise in developing systems of similar complexity before the sponsors formally approve it. When the final design and approvals are completed, construction and installation can begin. 


\section{CHAPTER 3.0}

\section{TURBINE AND STRUCTURES}

\subsection{Development of the Turbine}

\subsubsection{Goal and Objective}

The objective of the NPPE turbine task is to develop a turbine/generator unit that will ensure net power production with minimum technical risk.

The performance goal is generation of at least $165 \mathrm{~kW}$. Given improved operating conditions when $6.1^{\circ} \mathrm{C}$ cold seawater is used (earlier estimates were for $7^{\circ} \mathrm{C}$ cold seawater) and projected high thermodynamic efficiency for the turbine configuration chosen, the turbine/generator should be capable of exceeding its performance goal by as much as $40 \mathrm{~kW}_{\mathrm{e}}$.

\subsubsection{Approach}

The approach for this task (shown in Figure 3-1) is as follows:

- Evaluate the potential of existing turbine hardware for meeting the task goal at a lower cost or in less procurement time than a new design would require.

- Evaluate the expected performance of a turbine/generator unit using existing technology but new hardware.

- Choose the most appropriate turbine/generator option (existing hardware or existing technology) for procurement.

- Complete a detailed design of the turbine/generator, ensuring that it is physically and operationally integrated with the rest of the NPPE system.

- Fabricate the turbine/generator and perform factory tests so that required on-site assembly and checkout activities are minimal.

- Ship the unit to the test site, erect it on the NPPE structure, and make final adjustments.

- Validate performance with comprehensive acceptance tests.

To ensure timely completion of this work, a turbine design team was formed. At the time of writing, members are H. Link, SERI; K. Fong, PICHTR; T. Rabas, ANL; and C. Castellano, U.S. DOE. Others who have contributed to the effort include T. Penney, B. Shelpuk, and D. Bharathan of SERI and S. Masutani of PICHTR.

Consultants from the turbine industry have also played key roles in writing the specifications and statements of work for the Phase I and Phase II design contracts. Helpful evaluations of Phase I designs of existing hardware and technology were given by William Steltz, William Sanders of Turbo Technic Services, Inc., and Neville Rieger of Stress Technology Incorporated. Dr. Taher Schobeiri of Texas A\&M University reviewed thermodynamic performance of radial-inflow and axial machines for this application.

\subsubsection{Options Considered and Eliminated}

\subsubsection{Existing Hardware vs. Existing Technology}

The primary consideration was whether to procure a turbine that uses existing components such as blades or to build a new one based on new knowledge about design. A parallel-path development plan was enacted to assist in evaluating these two options. 


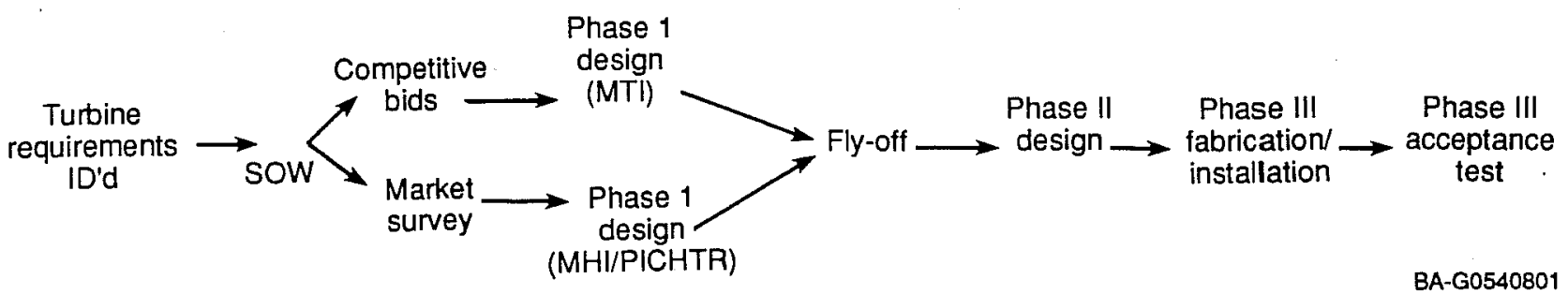

Figure 3-1. Approach to turbine development

SERI staff members and a team of turbine consultants prepared a Request for Proposal in which commercial firms were asked to bid on a three-phase turbine development program. Approaches for both existing hardware and existing technology were available to the bidders. Two proposals were received for the existing-technology approach, and a subcontract was awarded to Mechanical Technology Inc. (MTI), for Phase I design. MTI proposed the use of a radial-inflow turbine--a configuration with which the company has had considerable experience.

PICHTR investigated the existing-hardware option more fully so that a tradeoff evaluation could be made after Phase I design was complete. After investigating a number of options, PICHTR determined that Mitsubishi Heavy Industries (MHI) would best meet the the NPPE turbine requirements with existing hardware. MHI recommended use of blades from an axial-flow machine which had been designed for geothermal applications.

Details of the two designs are contained in two Phase I design reports (MTI 1989; Fong, Masutani, and Neill 1989), which were reviewed by the turbine task team, the turbine consultants, and T. Schobeiri (1989). The turbine team and consultants met at SERI in July 1989 for a final evaluation and selection. Results of the evaluation are summarized in Table 3-1.

The probability for net power was the deciding factor in the evaluation. The turbine consultants judged that MHI's efficiency prediction was overly optimistic, considering that the blades would be subjected to high incidence angles and negative reaction at the root. Design conditions for the MHI blades deviate significantly from standard designs, in which incidence is normally less than $10^{\circ}$ and reaction is not permitted below $+15 \%$. MHI based its predictions regarding efficiency on existing performance data but, for proprietary reasons, would not present parts of that data for review.

The MTI design was judged to have a good probability of achieving total-to-total isentropic efficiencies of $85 \%$ to $90 \%$, which would result in a power output of 183 to 195 $\mathrm{kW}_{\mathrm{e}}$ under steam conditions used in the Phase I design.

\subsubsection{Horizontal vs. Vertical Axis}

A second consideration was whether the turbine should have a vertical or horizontal axis orientation. This issue is not limited solely to turbines; axis orientation significantly affects structural design and could also influence design of the heat exchangers. 
Table 3-1. Preliminary Design Evaluation for Turbine

\begin{tabular}{|c|c|c|}
\hline & $\begin{array}{c}\text { Existing } \\
\text { Technology }\end{array}$ & $\begin{array}{c}\text { Existing } \\
\text { Hardware } \\
\end{array}$ \\
\hline Design team & MTI & MHI/PICHTR \\
\hline Configuration & Radial-inflow & Axial \\
\hline $\begin{array}{l}\text { Projected cost } \\
\text { (Phase II and } \\
\text { Phase III) }\end{array}$ & $\$ 2.2 \mathrm{M}$ & $\$ 2.0 \mathrm{M}$ \\
\hline Delivery & 36 months & 19 months \\
\hline $\begin{array}{l}\text { Assessment of probability } \\
\text { of net power }\end{array}$ & High & Low \\
\hline $\begin{array}{l}\text { Recommended for Phase II } \\
\text { design }\end{array}$ & $X$ & \\
\hline
\end{tabular}

A decision was made at the first working group meeting to proceed with the design of a "dome" structure rather than the "telephone" structure. More discussion of the implications of this decision is provided in Chapter 2.0 of this report. Briefly, its effect on turbine design was to increase the desirability of a vertical-axis orientation, which integrates well with a dome structure.

Structural integration issues aside, MTI and others identified other advantages of the vertical-axis turbine. First, the journal bearings do not have to support the weight of the turbine wheel and thus can be adjusted to meet rotordynamic requirements. Second, both journal bearings can be located on one end of the wheel in an "overhung" configuration without significantly increasing bearing loss. The overhung configuration eliminates the need for bearing support struts at the turbine exducer (outlet), which would impede steam flow and reduce efficiency of the diffuser.

A disadvantage is that a larger thrust bearing is necessary to support the weight of the rotor and the aerodynamic thrust of the blades. Friction in this larger bearing consumes more energy than is required for the thrust bearing in a horizontal-axis machine.

\subsubsection{Other Major Considerations}

\subsubsection{Radial-Inflow vs. Axial Configuration}

Both radial-inflow and axial configurations were considered for this turbine. Either configuration can be used to obtain high thermodynamic efficiency under the steam conditions expected for the NPPE. MTI, the winner of the turbine development contract, selected radial inflow for one or more of the following advantages:

- Under the specified steam conditions, Reynolds numbers in the radial machine tend to be higher, reducing skin friction losses and slightly increasing efficiency.

- Loading on radial blades is less, because the pressure drop is distributed over a larger area of the blade.

- Blade-root connections are much larger and therefore not as susceptible to failure from fatigue or corrosion or both. 


\subsubsection{Modified Steam Conditions}

Steam conditions for the turbine were modified twice from those first specified in the Request for Proposal, reflecting new information developed during conceptual design. The first modification (Table 3-2) increased the pressure drop across the turbine and slightly decreased steam flow. This change centered the nominal operating conditions within the range of uncertainty in performance of the heat exchanger.

Table 3-2. Steam Inlet and Outlet Conditions for the NPPE Turbine

\begin{tabular}{lccr}
\hline \multicolumn{1}{c}{ Property } & $\begin{array}{c}\text { Request for } \\
\text { Proposal }\end{array}$ & $\begin{array}{c}\text { Phase I } \\
\text { Design }\end{array}$ & $\begin{array}{c}\text { Phase II } \\
\text { Design }\end{array}$ \\
\hline Inlet Conditions & 2573 & $2637^{*}$ & 2613 \\
\hline Pressure (Pa) & $21.55^{*}$ & 21.95 & 21.80 \\
Saturation temp. $\left({ }^{\circ} \mathrm{C}\right)$ & 3.40 & 3.35 & 3.50 \\
Steam flow $(\mathrm{kg} / \mathrm{s})$ & 0.0 & 0.0 & 0.0 \\
Moisture content $(\%)$ & $\mathrm{n} / \mathrm{s}^{* *}$ & $\mathrm{n} / \mathrm{s}$ & 0.35 \\
Air content $(\%)$ & 2541 & 2542 & 2541 \\
Enthalpy (kJ/kg) & & & \\
Outlet Conditions & 1517 & $1443 *$ & 1384 \\
\hline Pressure (Pa) & $13.20 *$ & 12.44 & 11.8 \\
Saturation temp. & $\left({ }^{\circ} \mathrm{C}\right)$ & &
\end{tabular}

* Calculated for this table--not originally specified.

**n/s: not specified.

The second modification was made after the Phase I turbine design was completed. It increased both pressure drop and steam flow to reflect new estimates of the temperature of the cold-water resource. Earlier estimates of $7.0^{\circ} \mathrm{C}$ were based on NELH records of water supplied by the $0.30-\mathrm{m}(12$-in.) cold-water pipe. With higher flows through the new 1.0-m (40-in.) pipe, temperatures measured at the HMTSTA averaged about $6.1^{\circ} \mathrm{C}$. Figure 3-2 shows gross power output from the generator as a function of steam flow rate. The new cold-water inlet temperature increases the power output at all steam flows and shifts the maximum power output, resulting in a slightly higher rate of steam flow.

The turbine designer, MTI, has stated that the new steam conditions can be accommodated without resizing the turbine; however, detailed analysis may indicate a potential $1 \%$ increase in turbine efficiency if the rotor wheel were slightly enlarged.

\subsubsection{Speed Control}

Speed control for steam turbines normally consists of both a stop valve and a bypass valve. In OC-OTEC, both valves would need to be quite large to be effective or to prevent excessive loss of pressure. Analysis of the turbine's transient response indicated that adequate speed control can be provided by controlling water flow rate, changing vent compressor flow, bleeding air into the evaporator or condenser, or changing electrical load. These indirect methods can be considered in lieu of steam control valves because the turbine's rotational inertia is very large compared to the driving force of the steam. MTI estimates that 30 seconds would elapse before a $20 \%$ change in load (or 


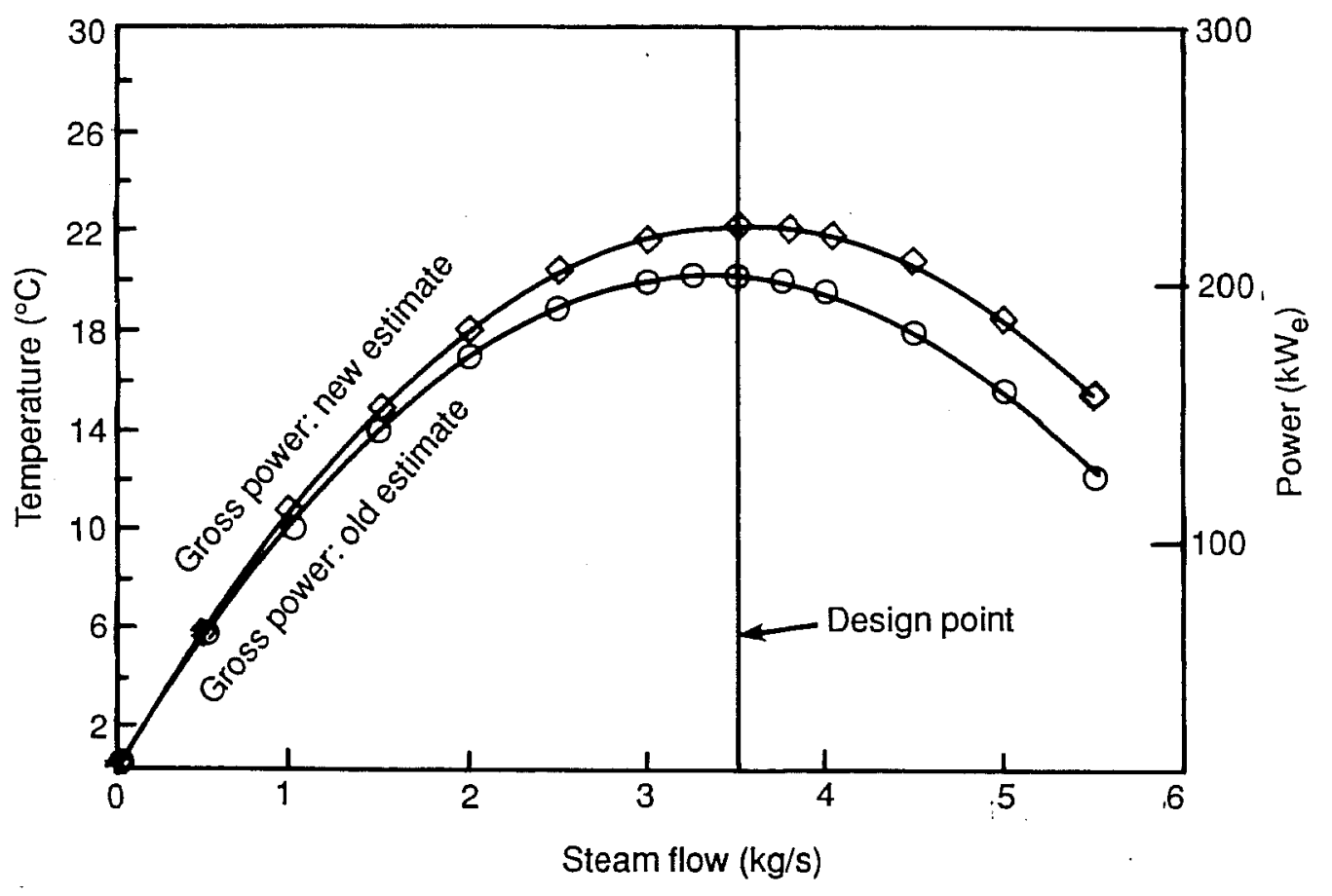

Basis: $\begin{array}{lll}M_{W W} & =620 \mathrm{~kg} / \mathrm{s} & \eta_{\text {EVAP }}=0.90 \\ T_{W W}=26^{\circ} \mathrm{C} & \eta_{\mathrm{DCC}}=0.86 \\ \mathrm{~m}_{\mathrm{CW}}=420 \mathrm{~kg} / \mathrm{s} & \eta_{\mathrm{TGU}}=0.75 \\ \mathrm{~T}_{\mathrm{CW}}=6.1^{\circ} \mathrm{C}\left(\mathrm{vs} .7^{\circ} \mathrm{C}\right) & \end{array}$

Figure 3-2. Operating conditions for system and turbine

steam driving force) would cause the turbine to deviate $1 \%$ from its design speed. This very slow response is relatively easy to control, based on measurement of the phase angle between the generator electro-motive force (emf) and power grid voltage.

\subsubsection{Variable-Position Stator Vanes}

Hydraulic control of stator vanes is another means of speed control. In addition, it permits adjustment of the angle of the stator vane to maximize performance over a relatively wide range of steam conditions. This feature is attractive in an experimental system. However, the option was rejected because of added cost (about $\$ 500,000$ ) and reduced performance caused by leakage around the stator blades.

\subsubsection{Design Performance and Uncertainties}

Total-to-total isenthalpic efficiency--a key performance parameter for the turbine/generator unit--describes the ratio of the work obtained from the turbine (not counting bearing and seal losses) to the amount that would be obtained if the turbine had no aerodynamic losses and all kinetic energy in the exhaust gas were recovered. 
MTI estimated that the turbine's total-to-total aerodynamic efficiency would be between $85 \%$ and $90 \%$ based on the performance of similar turbines. Their loss analysis indicated $85.3 \%$ to $86.8 \%$ total-to-total efficiency with a $7-\mathrm{m}$-long diffuser. They estimate other losses as follows: bearing and seal friction, $12.6 \mathrm{~kW}$; generator efficiency, $92 \%$; and electrical parasitics for equipment such as the lubricating oil pump, $1 \mathrm{~kW}$. These estimates result in gross power output of 183 to $195 \mathrm{~kW}_{\mathrm{e}}$ and an overall (not totalto-total) efficiency of $74 \%$.

Since MTI's Phase I design was completed, SERI has estimated that the turbine system would produce about $217 \mathrm{~kW}$, based on

- the revised steam conditions given in Table 3-2

- total-to-total efficiency of $85 \%$

- a shorter (4-m-long) diffuser (preferred because it reduces overall height of the vacuum vessel)

- bearing and seal losses equal to those estimated by MTI

- a $92 \%$ efficient generator.

As noted above, MTI estimates that total-to-total efficiency could drop by $1 \%$ if the turbine is not resized for the new steam conditions (see Figure 3-3). The shorter diffuser is likely to exhibit a lower pressure-recovery factor (0.65 vs. MTI's 0.78$)$, which would decrease total-to-total efficiency by $0.9 \%$. The combined effect of these two changes would be to reduce estimated total-to-total efficiency to between $83 \%$ and $88 \%$. SERI's estimate falls in the middle of this range.

Bearing and seal losses should remain the same if the turbine shaft is not resized. Although the generator's efficiency is likely to increase as its capacity is increased, no allowance for such an increase was included in the estimate. Electrical parasitics will be higher than estimated by MTI when effects are included of cooling water pump power and maintenance of buffer seal pressure. SERI increased the estimate of electrical parasitics from 1 to $2.5 \mathrm{~kW}_{\mathrm{e}}$.

The uncertainty in SERI's estimate of $217 \mathrm{~kW}$ is on the order of $\pm 5 \%$, which translates to a gross power from the turbine/

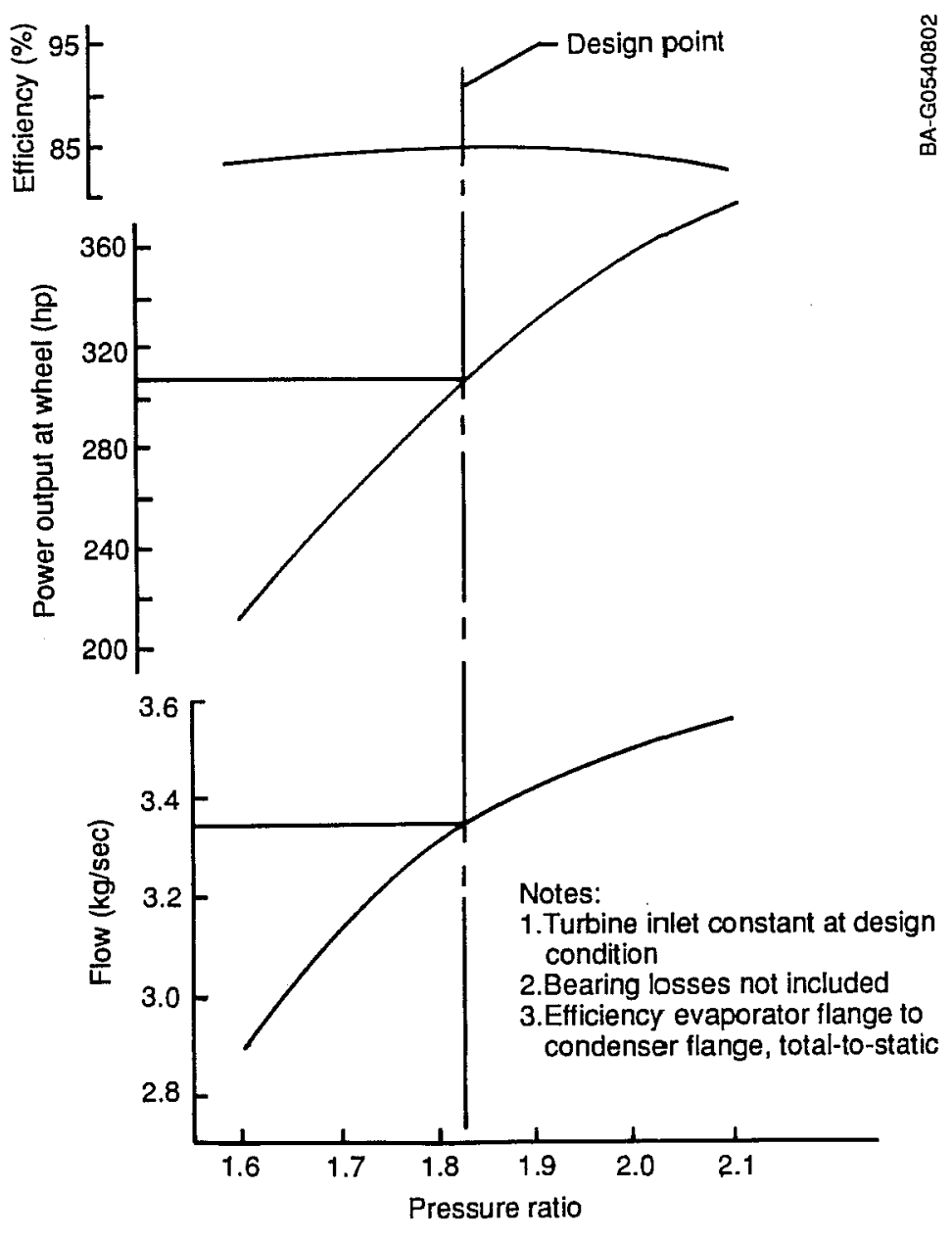

Figure 3-3. Turbine off-design performance characteristics 
generator unit ranging from 204 to $225 \mathrm{~kW}$. The draft specification written for Phase II and Phase III of the turbine procurement contract requires an output of $215 \mathrm{~kW}$ to provide a small margin below SERI's estimated performance. This specification may be revised during contract negotiations.

\subsubsection{Design Specifications}

The original technical specifications in the Request for Proposal for the turbine development contract were the basis for the full specifications for the Phase II turbine design (Appendix A of MTI 1989). MTI modified them to reflect improved knowledge of the turbine design that resulted from their Phase I design effort. The turbine task team further modified them to reflect new steam conditions and to identify performance requirements rather than physical configurations where appropriate. A final specification will be developed as part of the detailed design effort for use in procuring and testing the hardware.

\subsubsection{Layouts}

Figure 3-4 shows the main features of the turbine/generator unit. Standard commercially available components are used wherever possible. The rotor is made up of 26 $13-\mathrm{mm}(0.5$-in.) steel vanes welded to a steel hub. The hub is bolted to a $304-\mathrm{mm}$ (12-in.) cantilevered vertical shaft. The shaft is supported by two sets of self-acting (i.e., hydrodynamic), oil-lubricated, tilting-pad journal bearings and a rolling-element thrust bearing. The shaft is sealed against air infiltration by a labyrinth seal and a double circumferential floating ring seal.

A flexible-disk coupling between the turbine and the generator requires no maintenance and can be disassembled without removing the generator. The generator is a salientpole, synchronous machine that is directly driven by the turbine shaft. The generator can act as a motor when operated below synchronous speed to help speed up the turbine during start-up operations.

The inlet plenum for the turbine occupies most of the dome of the vacuum vessel and transmits the turbine's weight to the outer walls of the structure. It has been configured from 25-mm (1-in.) steel plate with reinforcement ribs added at various positions. The fixed-blade assembly (stator) has 23 blades set to a nominal $20^{\circ}$ angle, which can be adjusted during final checkout to maximize performance for the achieved steam flow conditions.

The rotor casing and diffuser resist small loads caused by pressure differences between evaporator and condenser steam. The rotor casing will be constructed of steel plate and machined to provide a close clearance to the rotor vane. The diffuser can be constructed of light $(6-\mathrm{mm})$ steel plate or composite plastic materials.

\subsubsection{Interfaces}

The turbine interfaces with the structure at three flange connections (Figure 3-5)--one between the turbine inlet plenum and the structure's outer wall, and two between the diffuser outlet and the direct-contact condenser. The turbine manufacturer will fabricate the lower flange on the outer wall to mate with the flange at the inlet plenum to ensure a leak-tight seal.

The transition is abrupt between the diffuser outlet and the cocurrent stage of the direct-contact condenser because the diffuser is short, a desirable feature which 


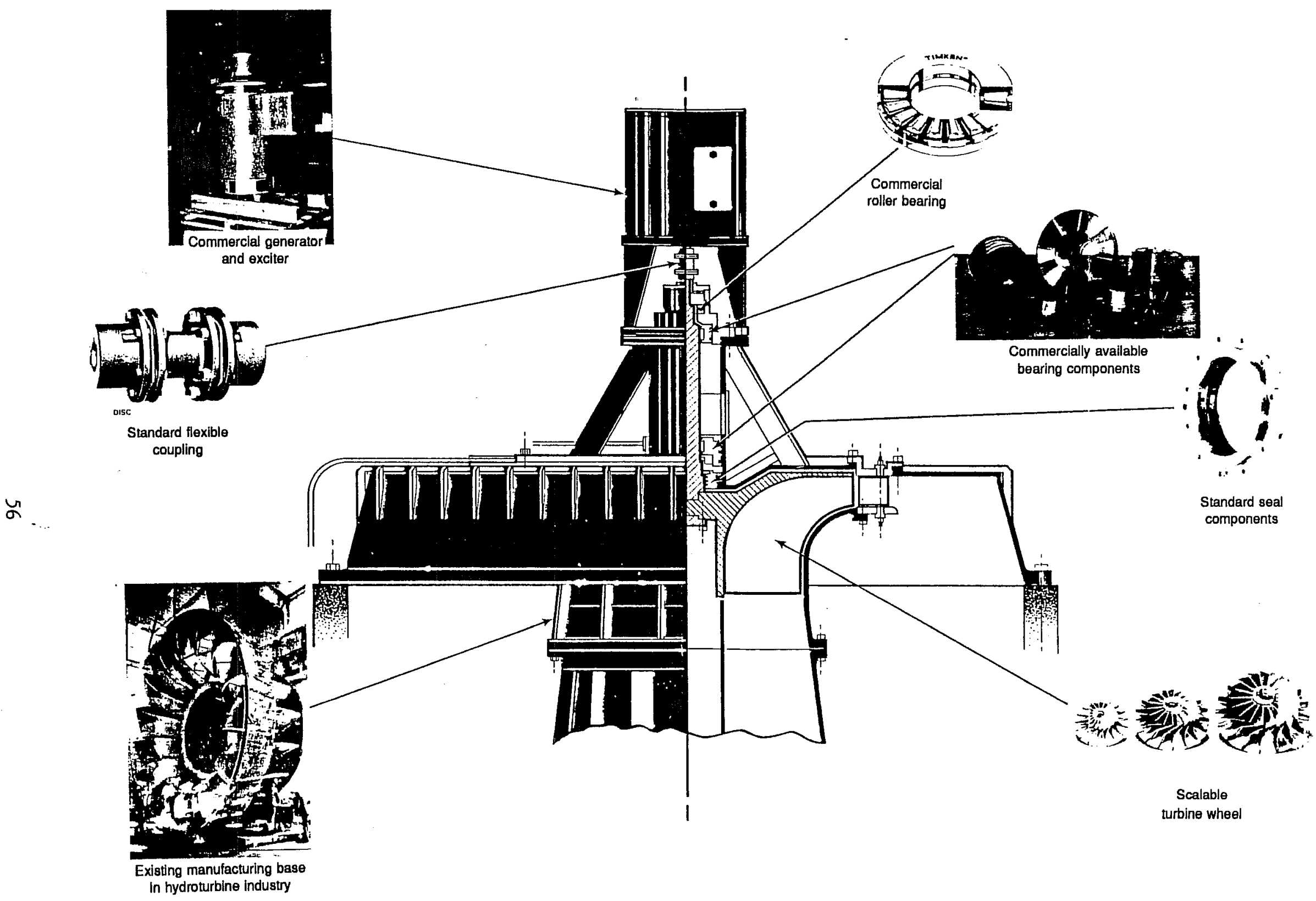

Figure 3-4. Design concept for the turbine/generator 


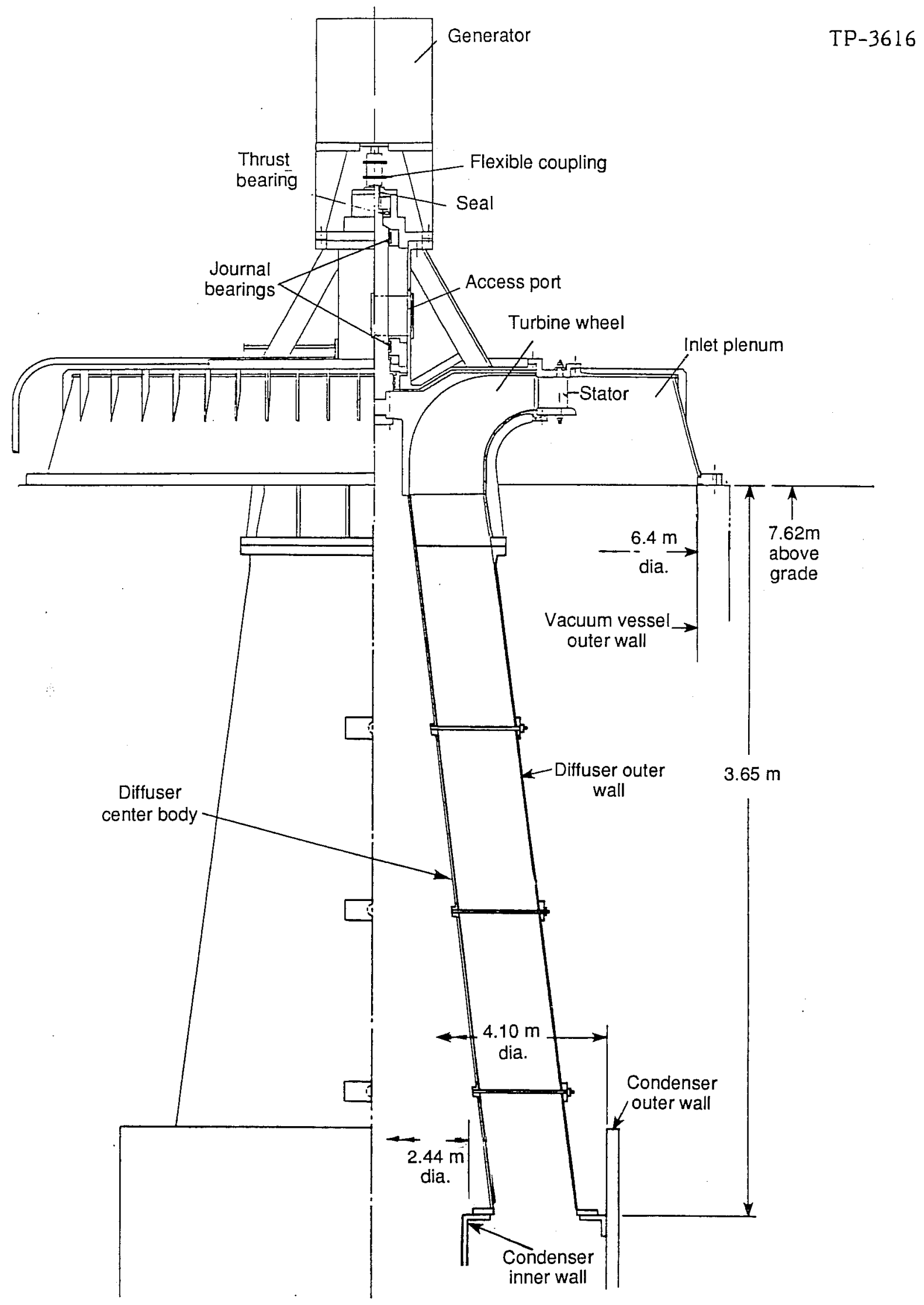

Figure 3-5. Physical interface between turbine and structure 
minimizes the overall height of the vacuum structure. It has been estimated that the transition will cause very small pressure losses and will not significantly affect steam distribution in the condenser. In later design efforts, the turbine and heat exchanger teams will consider adding fairings to smooth the transition.

Functional interfaces are shown in Figure 3-6. The sections entitled "Resistive Load Bank" and "System Switchgear and Protective Relays" were considered to be outside the scope of the original turbine/generator system. However, because of the numerous control and power interconnections required, the turbine team judged that risk could be reduced by combining these sections into the turbine/generator system.

\subsubsection{Schedule}

Timely procurement of the turbine is critical for completion of the NPPE on schedule. Various ways of accelerating the procurement schedule were considered, including negotiating the construction subcontract simultaneously with Phase II design. The approach that seems to combine the earliest delivery of the turbine with the lowest risk of major price increases is to combine Phase II design with construction, installation, and acceptance testing activities and to provide incentives for early completion. Table 3-3 shows the anticipated schedule at the time of writing.

\subsubsection{Cost and Uncertainties}

The Phase I design contract was $\$ 240 \mathrm{~K}$ for the existing-technology option. The design team of MHI and PICHTR accomplished the Phase I design of the existing-equipment option for $\$ 40 \mathrm{~K}$.

MTI estimated a cost of $\$ 2,400 \mathrm{~K} \pm 20 \%$ for a contract that combines Phase II design with construction, installation, and acceptance test activities. The design part of this amount is $\$ 600 \mathrm{~K}$.

Other costs primarily support the consultant team. In-house labor for monitoring of the subcontracts and other activities is not included in the breakdown that is presented in Table 3-4.

\subsection{Structures}

\subsubsection{Goal and Objective}

The objective of the structures task is to design and construct the vacuum vessel and support facilities for the HMTEA/NPPE.

The vacuum vessel affects system performance by permitting air to leak into the vacuum system. This process adds to the noncondensable gases desorbed from seawater, increases vacuum compressor power, and decreases the system's net power. The goal of the design is that leakage into the vacuum structure add no more than $0.5 \mathrm{~g} / \mathrm{s}$ of air to the vacuum system. If this goal is met, net power production will be reduced only $0.5 \mathrm{~kW}$ from a case in which the vessel is leak tight.

Besides preventing air from entering the system, the vacuum vessel houses the directcontact heat exchangers and supports the turbine. It must provide for internal water supply manifolds and seawater discharge pools for the evaporator, the direct-contact condenser, the mist eliminator, and the turbine exhaust diffuser. 

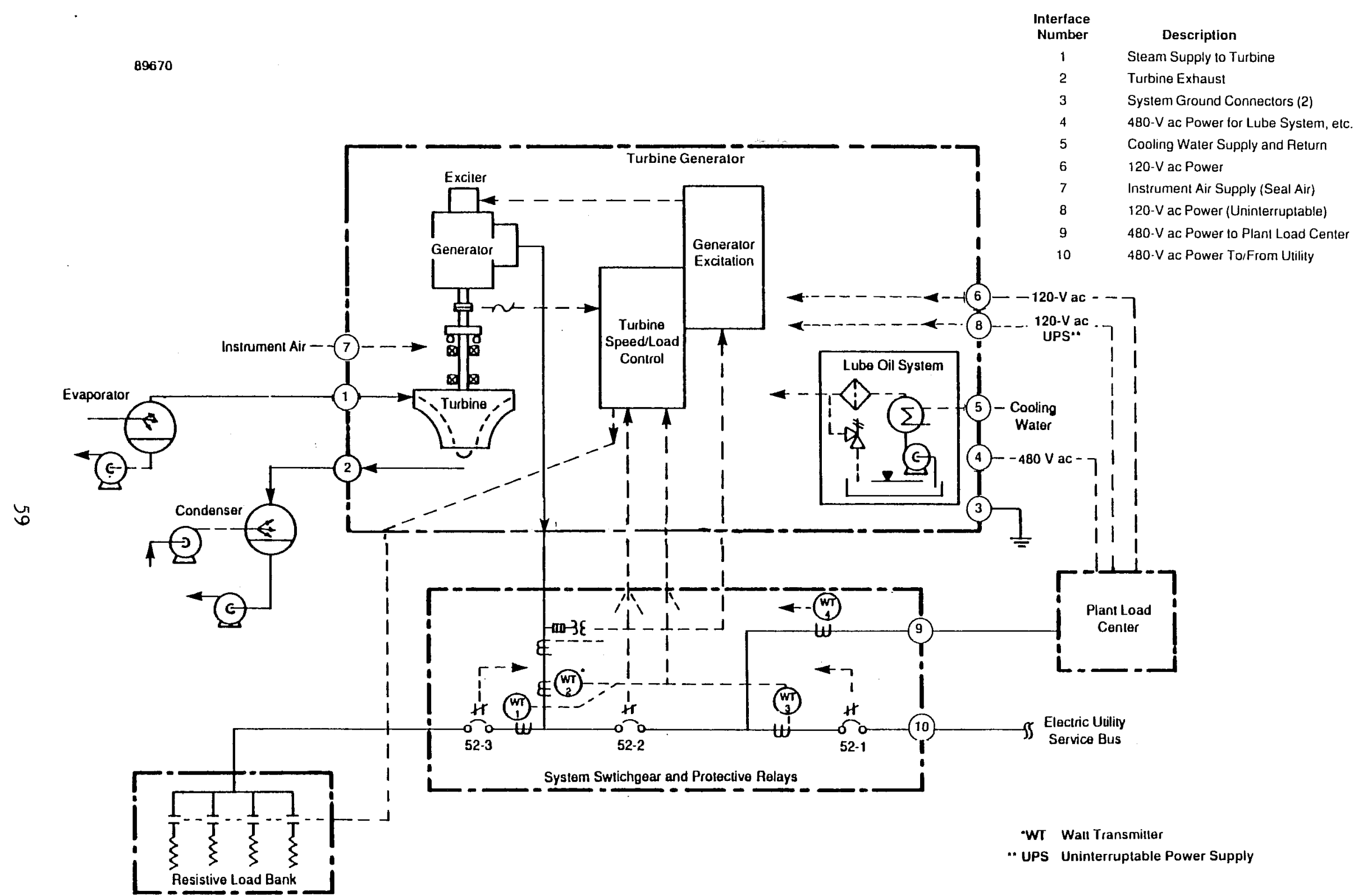

Figure 3-6. Diagram of principal interfaces, NPPE turbine 
Table 3-3. Schedule for NPPE Turbine

\begin{tabular}{|c|c|}
\hline Phase I design & October 1,1988 - August 1,1989 \\
\hline $\begin{array}{l}\text { Phase II design } \\
\text { Prepare Statement of Work } \\
\text { Negotiate Phase II } \\
\text { and Phase III } \\
\text { Engineering design }\end{array}$ & $\begin{array}{l}\text { August } 1,1989 \text { - November 15, } 1989 \\
\text { November 15, } 1989 \text { - January } 1,1990\end{array}$ \\
\hline $\begin{array}{l}\text { Phase III fabrication } \\
\text { Purchase long-lead items } \\
\text { Fabrication and assembly } \\
\text { Factory tests } \\
\text { Ship and install } \\
\text { On-site tests } \\
\text { Turbine ready }\end{array}$ & $\begin{array}{l}\text { August } 1,1990 \text { - September } 1,1990 \\
\text { September } 1,1990 \text { - June } 1,1991 \\
\text { June } 1,1991 \text { - September } 1,1991 \\
\text { September } 1,1991 \text { - January } 1,1992 \\
\text { January } 1,1992 \text { - June } 1,1992 \\
\text { June } 1,1992\end{array}$ \\
\hline
\end{tabular}

Table 3-4. NPPE Turbine Costs (in \$K)

\begin{tabular}{lcccr}
\hline \multicolumn{1}{c}{ Task } & Equipment & Contracts & Consultation & Total \\
\hline Phase I design & 0 & 280 & 100 & 380 \\
Phase II design & 0 & 600 & 50 & 650 \\
Fabrication/testing & 1,600 & 0 & 100 & 1,700 \\
Turbine-related & $\underline{210}$ & - & - & \\
electrical items & 1,810 & 880 & 250 & 2,940 \\
$\quad$ Total & & & & \\
\hline
\end{tabular}

The control building houses instrumentation and control functions, electrical power distribution cabinets, offices, and a visitors' center.

\subsubsection{Approach}

The approach for this task is as follows:

- Determine the applicability of Dillingham Construction's (1987b) existing HMTEA design (Figure 3-7) to current NPPE requirements.

- Choose the general configuration for the vacuum structure (dome or telephone) and develop specifications for diameter, height, internal features, and penetration.

- Award a subcontract for design of the vacuum vessel.

- Determine requirements for the control building and other structures.

- Design the control building and other structures.

- Determine whether needs for lifting equipment can be met using NELH equipment, renting local equipment, or purchasing new equipment.

- Award subcontracts to construct the vacuum vessel, control building, and other structures.

A team of staff members from SERI, ANL, and PICHTR was formed to accomplish this work. This report summarizes their work during the conceptual design stage of 
Figure 3-7. A partial representation of Dillingham design of the HMTEA

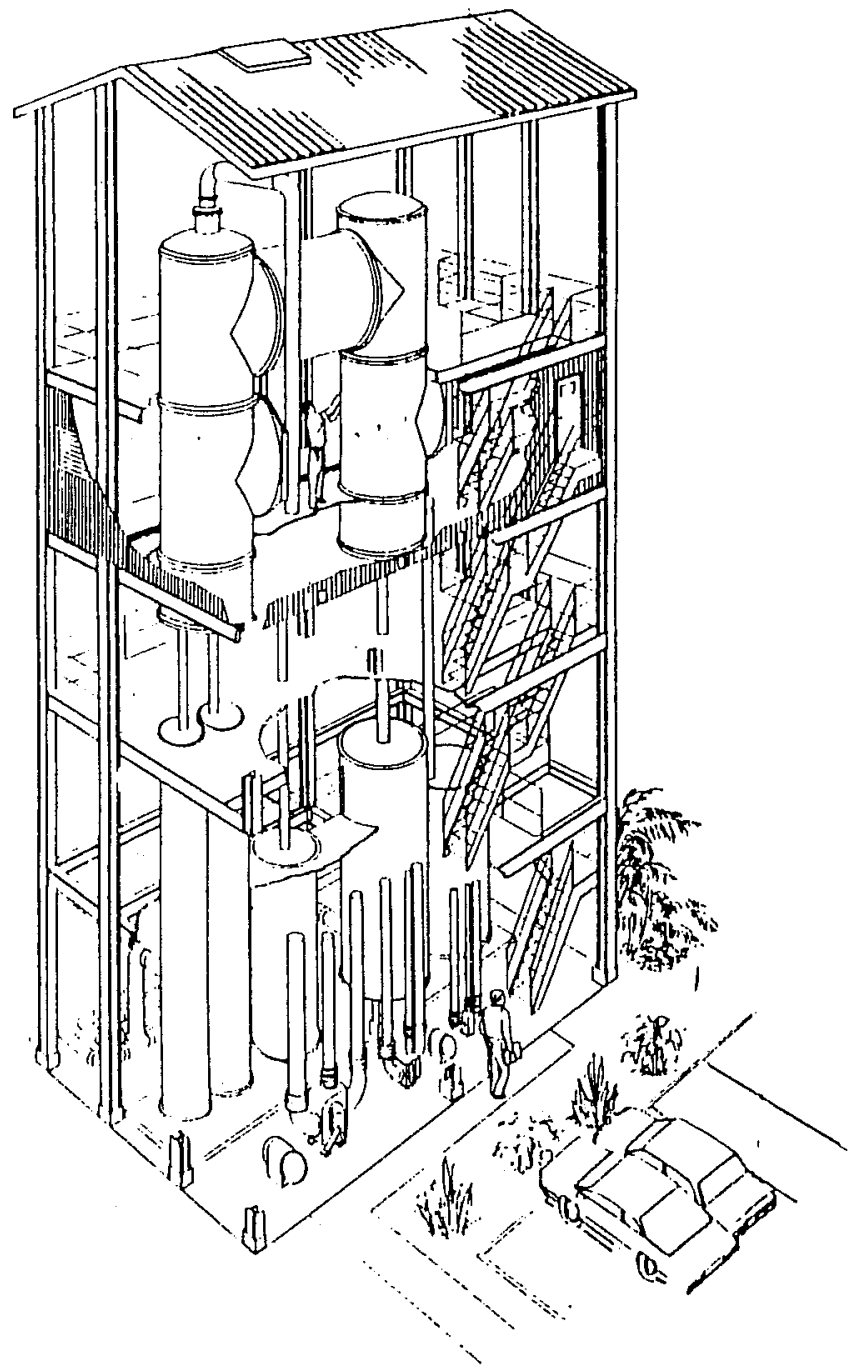

the structures' development. Team members at the time of this writing are H. Link, SERI; K. Fong, PICHTR; and L. Genens, ANL. Previous team members who contributed to this conceptual design are D. Bharathan of SERI and S. Masutani of PICHTR.

\subsubsection{Options Considered and Eliminated}

\subsubsection{Dome vs. Telephone Configuration}

The most significant consideration was the choice between a dome or telephone configuration for the vacuum vessel. The telephone configuration features separate vessels for the evaporator and direct-contact condenser with the turbine located in a connecting pipe between the two. The present HMTSTA is an example of a telephone configuration. The recently designed HMTEA (Dillingham Construction 1987b) is a second example. SERI proposals made in 1987 (Trenka 1987) for the HMTEA showed that the Dillingham design could be modified to operate as a NPPE.

The dome configuration encloses the evaporator and direct-contact condenser coaxially within one structure. Westinghouse (1979) de-

signed a $100-\mathrm{MW}$ floating plant based on a dome configuration. This configuration was also suggested by Creare, Inc. (Valenzuela et al. 1988) for a $10-\mathrm{MW}$ land-based plant and by T.Y. Lin and SERI (Penney et al. 1984) for a $1-\mathrm{MW}$ OC-OTEC experiment. The systems team chose the dome configuration for continued development at the first working group meeting in February 1989. Additional analysis by the heat-exchanger team (and documented in Chapter 5.0 of this report) provided additional support for the dome configuration.

Structurally, the primary advantage of the dome configuration is that the surface area for the vacuum barrier is minimized. Using the most recent numbers for heat-exchanger planform areas and heights, the dome configuration would use almost $30 \%$ less surface area than the telephone configuration. This minimizes cost and reduces potential for air leakage. A second advantage is the elimination of two external elbows (or involutes) and an external diffuser. These components are complexly shaped and would be costly to fabricate. They also require large flange connections to the heat-exchanger vessels, which could increase air leakage. 
The primary advantage of the telephone configuration is easier access to the evaporator or condenser to replace major components. With the dome, the turbine and its inlet plenum must be removed to install or remove major components inside the vessel. With the telephone configuration, only the overhead elbow would require removal.

\subsubsection{Materials for Vacuum Vessel Walls}

Three options were considered for the vacuum vessel walls: steel only, reinforced concrete only, and a combination of the two. Steel provides an excellent barrier to air leakage and is thus the most common material for small vacuum vessels. For larger sizes, the combination has been used; concrete provides the strength and steel the impermeability required for high-vacuum vessels. The largest known vacuum vessel in the United States is the $4,000-\mathrm{m}^{3}$ pentagonal Planetary Aeolian Laboratory at the Ames Research Center (a NASA research center in Ames, California), which features concrete-only walls. Any of the three options could be considered for the HMTEA/NPPE.

In the NPPE, the vacuum vessel must support not only dead weight and vacuum loads, but also the large rotating mass of the turbine. It is critical, therefore, that the vessel not exhibit resonant vibration frequencies around the $30-\mathrm{Hz}(1,800-\mathrm{rpm})$ rotational frequency of the turbine. Although steel-only walls withstand other structural loads with a plate thickness of $28 \mathrm{~mm}$ (1.125 in.), finite-element analysis indicated that the vessel would have a resonant frequency close to $30 \mathrm{~Hz}$. To increase the stiffness sufficiently to ensure a resonant frequency of at least $110 \%$ of the turbine excitation, a plate thickness of $44 \mathrm{~mm}(1.75 \mathrm{in.})$ is required. ANL directed the design and analysis of this steel-only vessel (Figure 3-8). They estimated the cost to be $\$ 294,000$. The high cost and difficult on-site assembly of such thick steel plates reduce the attractiveness of this option. With the low cost of reinforced-concrete construction, the vacuum vessel walls could be constructed as thick as 18 in. and still cost significantly less than steel walls. Estimates for cost of a concrete-walled vessel range from $\$ 120,000$ to $\$ 180,000$ (Oswald 1989; Bharathan memorandum 1989; Flug 1989).

Although a finite-element analysis of concrete walls has not been completed, calculations indicate that 18 -in. walls would have natural frequencies over $40 \mathrm{~Hz}$--well past the frequency range of concern. In addition, the added mass and higher damping characteristics of concrete minimize vibration and noise at all excitation frequencies, so the vessel would seem more "solid."

Regarding concrete, the two biggest concerns are ease of modification and susceptibility to increased leakage. Although steel would probably be easier and less expensive to modify than concrete, major changes are not anticipated for this apparatus.

Penetrations have been configured and located to facilitate a variety of modifications without requiring new penetrations. For example, the access penetrations are configured to double as possible ventilation ports, observation ports, or feedthroughs for instrumentation wiring. Should a new large penetration be required, methods and equipment have been identified (Stallman 1989) to permit such a modification without major cost.

Brackets and fixtures can be securely mounted on a concrete wall with anchor bolts. Such mountings do not present much more difficulty than the required cleaning, welding, and repainting associated with attachment of brackets to a steel wall. 


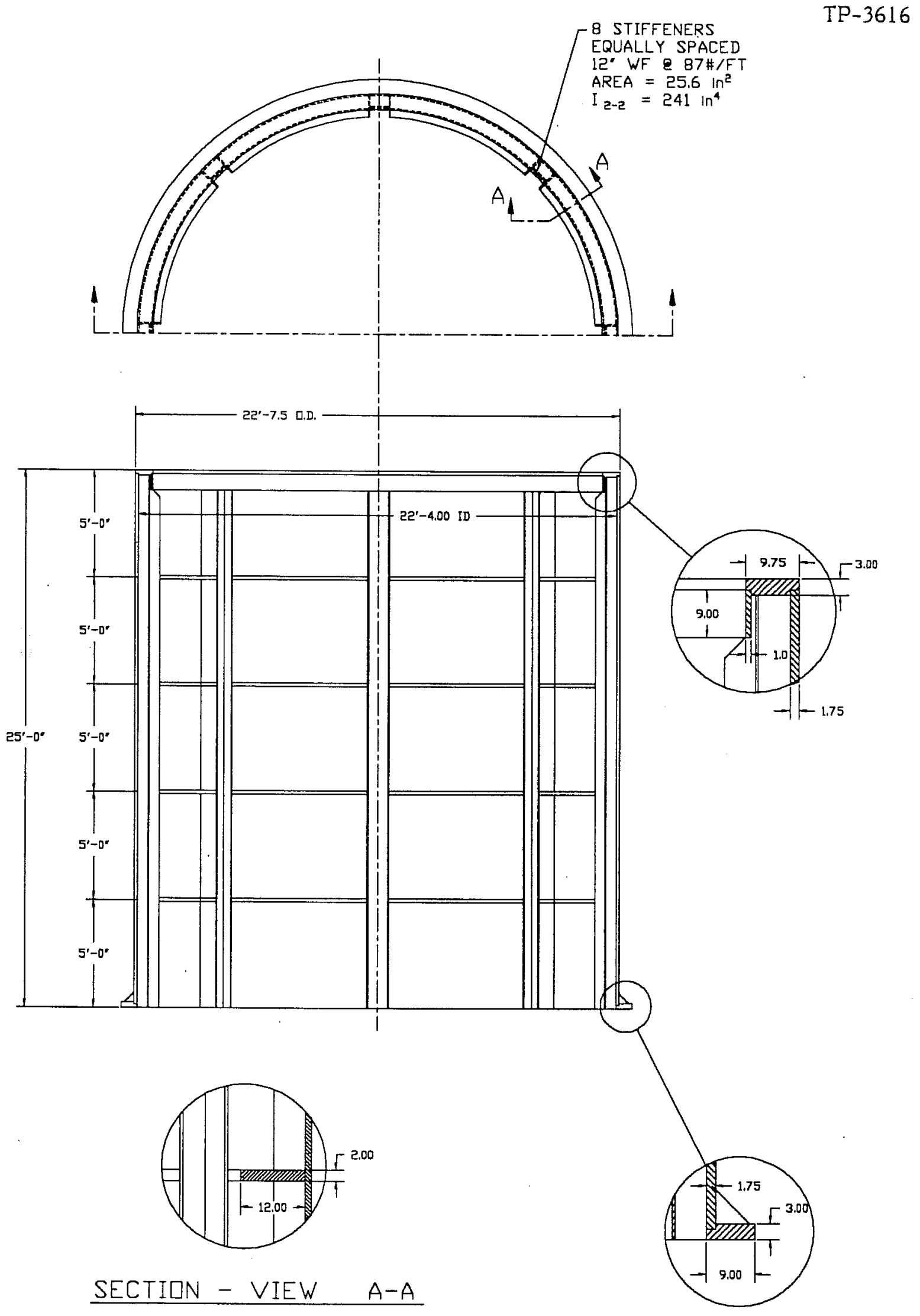

Figure 3-8. Steel wall option for vacuum vessel 
The second concern with concrete, rate of leakage, is affected by

- Permeability

- Leakage through construction joints and around penetration inserts

- Leakage through seals

- Leakage through small cracks.

Studies (Westinghouse 1979; Valenzuela et al. 1988) have indicated that, although concrete is permeable, permeation through structural walls would be insignificant compared to the rate at which noncondensable gases evolve from seawater in an OC-OTEC plant. In addition, permeation can be reduced to negligible levels if inexpensive coatings are applied to the outside of the vessel.

Experts from structural engineering companies (Stallman 1989; Stinnett 1989) have indicated that leakage around penetrations and through construction joints can be controlled with standard methods used in concrete water tanks, including elastomeric water stops and sealants.

Seals are likely to be the biggest cause of air leakage. However, the choice of wall material probably will not affect leakage through seals, because it is expected that metal inserts will be used for penetrations and for the flange at the connection to the turbine.

A significant concern is that cracks may form as a result of shrinkage or one of the seismic tremors that occur frequently on the big island of Hawaii. Depending upon the construction details, such a crack is not likely to result in leakage if it does not extend completely through the wall. If it does, the reinforcing steel bars should prevent it from widening beyond a hairline. Low stresses and natural compressive loads tend to limit width of cracks. Any one of a number of coating materials, including those used for roofing, should be sufficiently flexible and impervious to prevent leakage through such a small crack.

Nonetheless, if leakage were to occur through such a crack, it might be difficult to identify the crack's location on the outside of the vessel, where it would be easiest to fix. It is conceivable that a leak around a penetration insert, for example, could connect to a crack remotely located on the inner surface of the wall. Such a situation would be similar to a roof leak, in which the location of the drip provides only a rough guide for location and repair of the failure in the roof.

The structures team has considered several possible solutions for this issue. Low leakage could be assured by jacketing the concrete walls with thin $(6-\mathrm{mm})$ steel plates. The plates would be supported by the concrete wall, and any possibility of unidentifiable or nonrepairable leaks would be eliminated. Simple designs are available that permit the welding of plates to each other and to all penetrations. Some or all of the jacket could be applied at any time after construction of the vessel if tests for leakage indicate that performance of coated concrete is inadequate. However, this adds an estimated $\$ 50,000$ to the cost and may not be necessary.

Because no single solution has yet been selected, the team has decided to pursue preliminary design of a concrete vessel through a subcontract to an experienced structural engineering firm. As part of the design, the subcontractor will assess risks of leakage through the concrete walls and will recommend design and operating procedures that could ensure low rates of leakage. 


\subsubsection{Other Major Considerations}

\subsubsection{Position of the Condenser}

In the dome configuration, it is necessary to decide whether the evaporator should be located outside the condenser or vice versa. Both the radial-inflow and the axial-flow turbines considered for this experiment undergo lower losses of pressure when turns in the high-velocity steam at the turbine outlet are avoided. Thus, it is preferable to locate the condenser directly beneath the turbine outlet in the center of the vessel. The evaporator is best configured as an annular planform area outside of the condenser.

\subsubsection{Diameter of the Vacuum Vessel}

The vessel's diameter was determined primarily by the required planform area of the evaporator and direct-contact condenser. Limited additional area was provided for partitions, water manifolding, and access. The evaporator area was increased from the required minimum to provide ample clearance between the inner and outer walls of its partition. Additional information on heat-exchanger configuration is provided in Chapter 5.0 of this report.

\subsubsection{Height of the Vacuum Vessel}

The height of the vessel's dome was determined from the sum of four components: the turbine/generator unit, the turbine exhaust diffuser, the direct-contact condenser, and the discharge pool for the direct-contact condenser. The preliminary design for the turbine/generator unit established the distance between its mounting flange and the top of the dome at about $1.2 \mathrm{~m}(4 \mathrm{ft})$.

The diffuser was originally specified to be $6.9 \mathrm{~m}(22.8 \mathrm{ft})$ long. Although such a long diffuser offers potentially good recovery of the energy contained in the turbine's outlet velocity head, it places the turbine much higher than is practical. A SERI analysis (Bharathan memorandum 1989) indicated that use of a diffuser $3.7 \mathrm{~m}(12 \mathrm{ft}$ ) long would reduce performance by only $2 \mathrm{~kW}$. This minimal penalty is justified by the lower cost of the structure and diffuser, improved access to the turbine, reduced requirements for crane reach, and improved frequency response of the vessel.

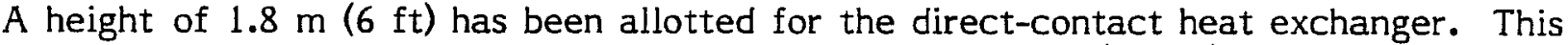
provides a $0.15-\mathrm{m}$ margin over the presently specified $0.5-\mathrm{m}(1.5-\mathrm{ft})$ clearance between the bottom of the condenser packing and the discharge pool level, 0.9-m- $(3-\mathrm{ft})$-high packing, and $0.3 \mathrm{~m}(1 \mathrm{ft})$ for water distribution manifolding above the packing. During conceptual design, designers recognized that the condenser's height could be reduced slightly by eliminating the margin and by positioning some of the water manifolding in the volume inside the inner wall of the diffuser. However, the $1.8-\mathrm{m}$ height was maintained to provide flexibility for design modifications, should they be necessary for efficient operation of the condenser.

The height of the discharge pool was fixed at $2.1 \mathrm{~m}(7 \mathrm{ft})$ based on the following considerations:

- Height is sufficient above the top of the cold-water discharge pipe that entrained gas bubbles separate from the discharge water before it enters the pipe. The pipe diameter is nominally $0.75 \mathrm{~m}(30 \mathrm{in}$.) and the pipe is located just above the foundation pad.

- Supply water for the condenser enters at grade level and turns $90^{\circ}$ to flow upward to the supply manifolds above the packing. The elbow and flanges required for this turn 
must not extend above the water level of the discharge pool to ensure an unobstructed path for steam entering the countercurrent condenser stage.

- The cold-water discharge pump is expected to have a net positive suction head between 3.7 and $6.1 \mathrm{~m}$. It is preferable not to locate the inlet to this pump below the water table at the NPPE site (about $4 \mathrm{~m}$ below grade level) because excavation costs increase significantly below water level.

- Some flexibility in maintaining water level in this pool is desirable.

These combined requirements fixed the overall height of the vessel's dome at $8.8 \mathrm{~m}$ (39 ft) and of the wall at $7.6 \mathrm{~m}(25 \mathrm{ft})$.

\subsubsection{Design Performance and Uncertainties}

The only factor in the structures design that affects performance of the HMTEA/NPPE is the rate at which air leaks into the vacuum vessel. Assuming an efficiency of $60 \%$ for the vent compressor, net power is decreased by about $1 \mathrm{~kW}$ for each gram per second of leakage. Currently it is estimated that the combined leakage of the turbine shaft seal, the vacuum vessel, and all exterior piping will not exceed $1 \mathrm{~g} / \mathrm{s}$. Of this combined rate, leakage through the vessel should be less than $0.5 \mathrm{~g} / \mathrm{s}$. This estimate was arrived at in part by scaling up the HMTSTA's typical rate of leakage of $0.05 \mathrm{~g} / \mathrm{s}$.

The uncertainty regarding this rate is based primarily on the potential for leakage around penetrations and through construction joints and cracks. Flexible exterior coatings and a steel jacket will ensure that the goal of $0.5 \mathrm{~g} / \mathrm{s}$ can be achieved.

Figure 3-9. Platform layout ( $a$, this page) and penetration layout (b, opposite page) of vacuum vessel.
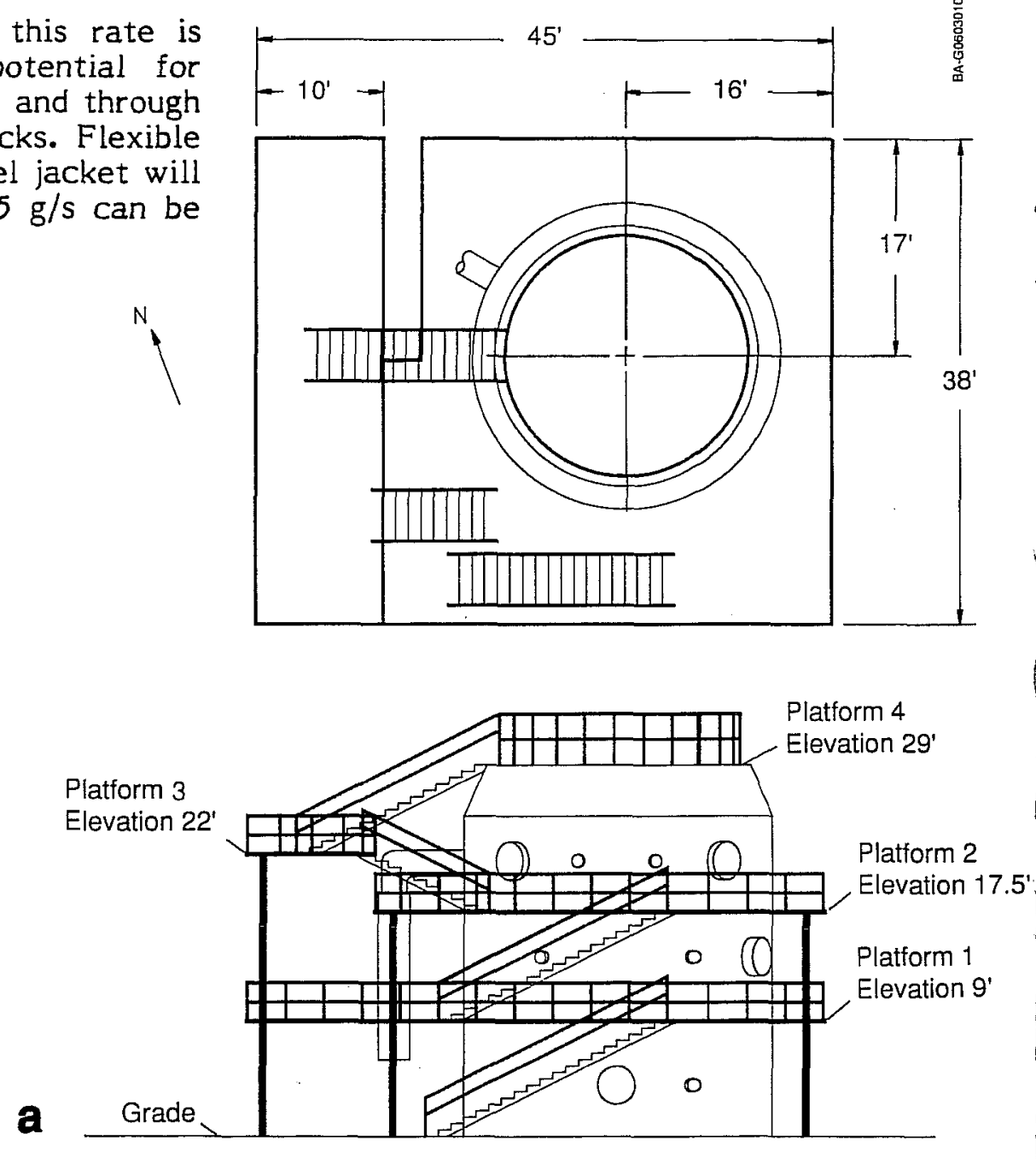


\subsubsection{Design Specifications}

\subsubsection{Vacuum Vessel}

Design of the HMTEA/NPPE vacuum vessel must ensure that it meets the requirements of other components of the apparatus. Thus, the vacuum vessel must house the heat exchangers, their supply manifolds and discharge pools, and the diffuser. It must support the turbine and some internal components and resist vacuum loads, dead weight, and seismic loads. It must provide access, ventilation, lighting, external viewing, and feedthroughs for water, pressure, power, and instrumentation wiring. Finally, it must limit leakage of air to less than $0.5 \mathrm{~g} / \mathrm{s}$ while operating.

The vessel achieves its size requirements by having a $6.4-\mathrm{m}$ inside diameter and a $7.6-\mathrm{m}$ height to the turbine inlet plenum flange, as shown in Figure 2-6 on page 31 . Requirements for piping, access, and instrumentation are met by platforms (Figure 3-9a) and penetrations (Figure 3-9b). The turbine/generator unit (including the inlet plenum that comprises much of the vessel's dome) is expected to weigh 36 metric tons. The vacuum load that the dome exerts on the vessel's walls will be 333 metric tons at minimum internal and maximum atmospheric pressures.
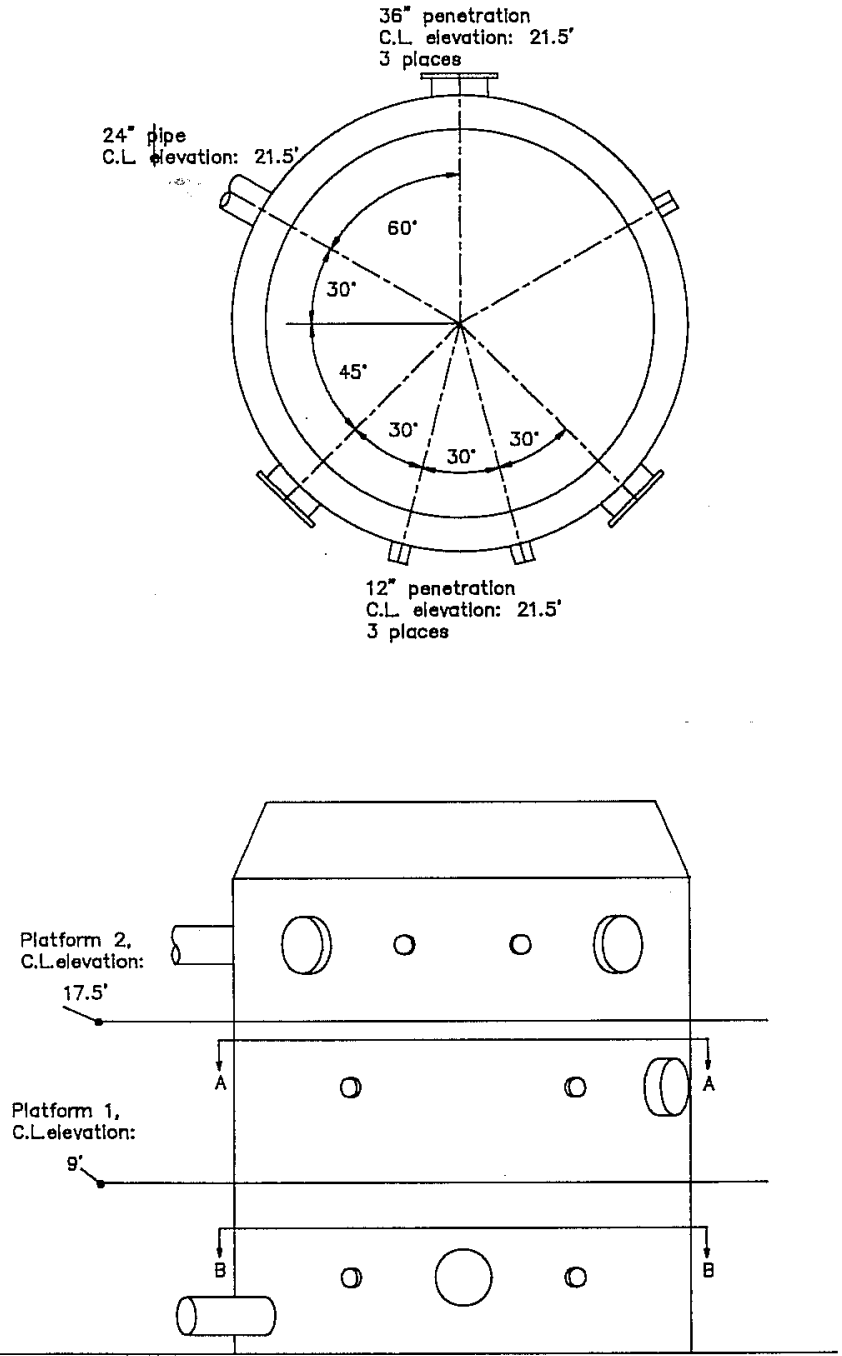

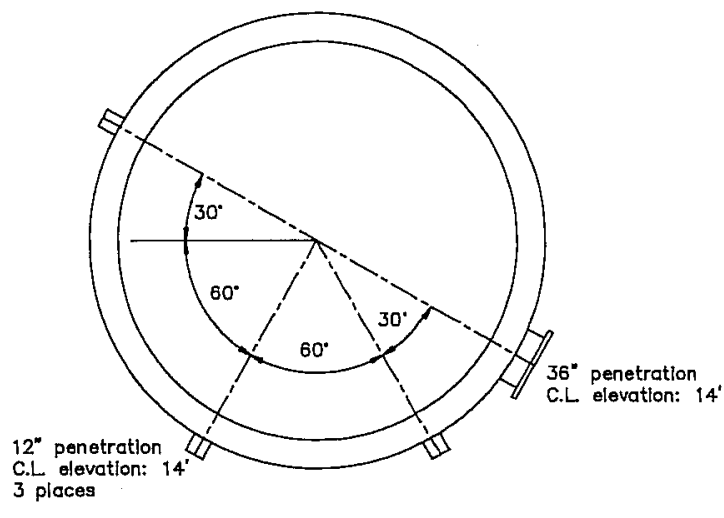

Section A-A

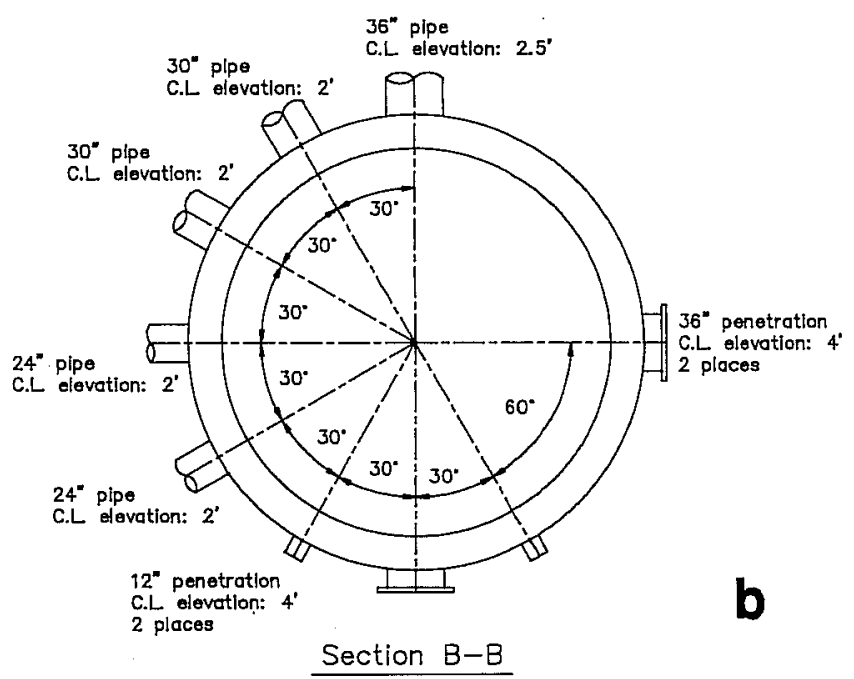




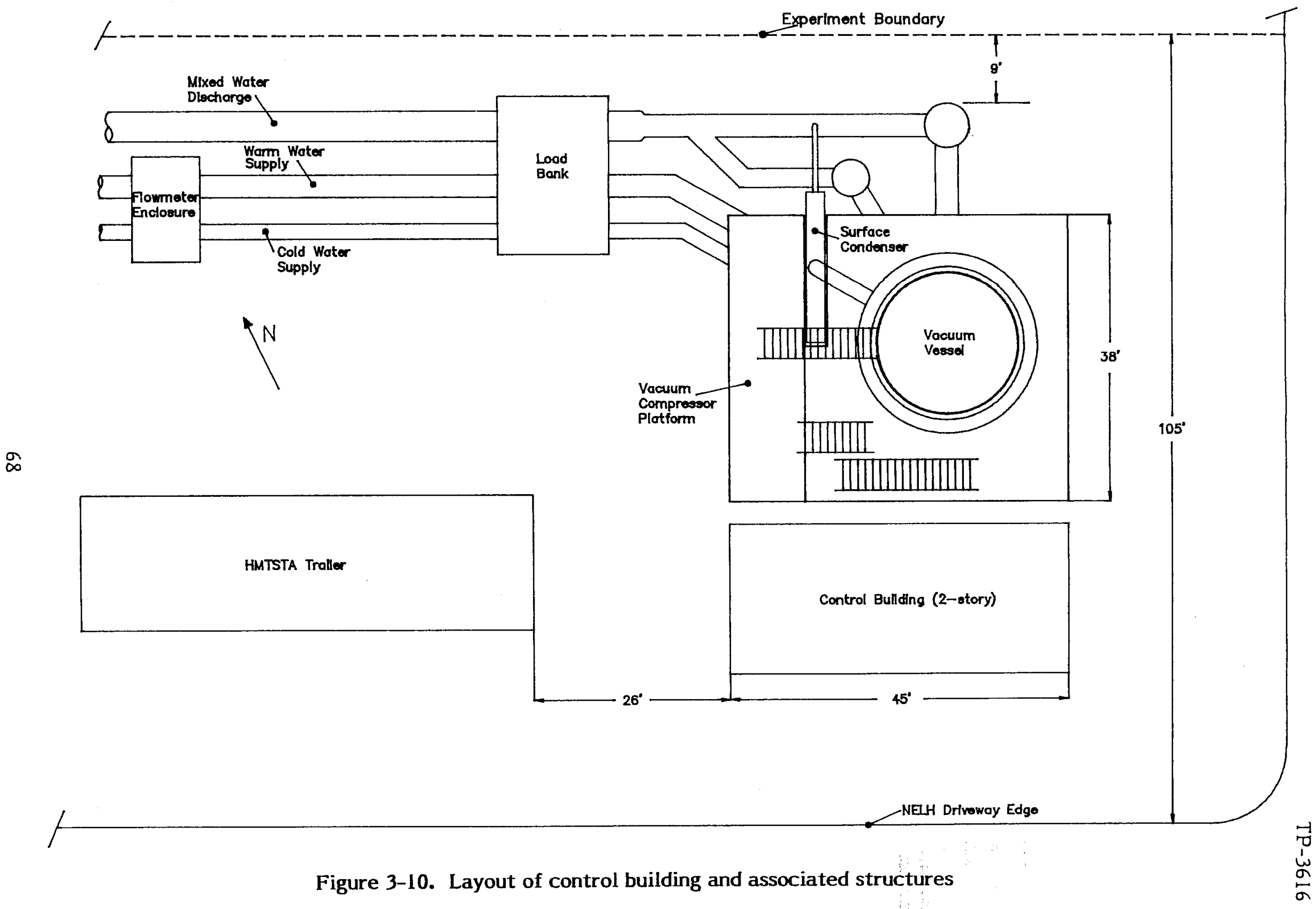


The vessel will be designed to withstand a horizontal seismic load corresponding to the response spectrum given in the Uniform Building Code (1988) with a peak ordinate of $0.100 \mathrm{~g}$ and zero period acceleration of $0.040 \mathrm{~g}$, where $\mathrm{g}$ is the acceleration of gravity. A geotechnical survey will be conducted to provide information needed to confirm or change the current choice of soil type 1 for the site. The vessel will also be designed to withstand vertical loads corresponding to the same response spectrum but with peak and zero period accelerations reduced to 0.067 and $0.027 \mathrm{~g}$, respectively. The vertical and horizontal response spectra will not be applied concurrently. These specifications meet the general requirements for Category I (normal use) facilities.

\subsubsection{Control and Auxiliary Buildings}

The control building provides room and shelter for control functions, data acquisition, electrical switchgear, offices, and public relations. The present control building for the HMTSTA will provide room for extra offices, storage, and a small workshop/calibration area. Adjacent buildings or simple roofed structures will shelter equipment such as the vacuum compressor, instrument air compressor, and oil lubrication pump systems. NELH facilities will be available for restrooms and some inside storage.

\subsubsection{Crane}

In some early conceptual design work, provisions were made for a crane to be permanently installed on the site. Such a crane would be used to install and remove the steam turbine, the turbine inlet plenum, and equipment located inside the vacuum vessel. $A$ mobile crane, column-jib crane, gantry crane, and overhead traveling crane were considered. Of these, the overhead crane was the least expensive at a cost of between $\$ 75,000$ and $\$ 125,000$ (Stinnett 1989). The overhead rails could add another $\$ 50,000$ to $\$ 100,000$.

An attractive alternative is to rely on mobile cranes available from local or Honolulubased construction or equipment rental companies. Although the heaviest turbine component is expected to weigh less than 15 tons, a mobile crane cannot be positioned closer than about $8 \mathrm{~m}$ from the centerline of the turbine. Thus the mobile crane would need to have a capacity of between 50 and 100 tons.

Such cranes are available; one was on site for more than a year during installation of the $1-m(40-i n$.$) cold-water pipe system. Rental rates should not exceed \$ 1,000$ per day, including labor and insurance. Although the savings are significant, delays of up to one week might be expected before test personnel could remove the vacuum vessel's dome if unscheduled maintenance were required.

During the preliminary design phase, this issue should be investigated further. Specific data on cost and availability should be obtained for leased, new, and surplus cranes.

\subsubsection{Layouts}

Figure 3-10 shows the general layout of the HMTEA/NPPE vacuum vessel, control building, and auxiliary structures. Pending approval from NELH, they will be located between the HMTSTA and NELH's administration building. Choice of this position is based, in part, on the presence of portions of the onshore seawater supply pipes. Aligning the vessel and control buildings with the south walls of the HMTSTA trailer and the NELH administration building rather than with the existing pipes is an efficient and aesthetically pleasing arrangement. 
The seawater supply and discharge pipes are in a corridor that permits access to HMTEA/NPPE and HMTSTA components by forklifts and cranes. The control building adjacent to the vacuum vessel provides easy access for observation, wiring, and entry. $\AA$ mobile crane can be positioned in an adjacent area to install and remove the turbine.

The turbine, exterior wall, and foundation are the major components of the vacuum vessel (Figure 2-6). An interior wall will separate the evaporator from the condenser, including their respective discharge water pools. It will also support the outer wall of the diffuser. A grating mounted on the inner partition will support the condenser packing, the partition between the cocurrent and countercurrent stages of the condenser, and the inner wall of the diffuser. Columns will reinforce the grating of the condenser. Brackets on the inner surface of the vessel's outer wall will support the evaporator supply manifold and a grating in the evaporator spout area. They will also hold instruments and help to support the mist eliminator.

The 1,200-sq-ft control building (Figure 3-10) houses the control room, signal wiring/ computer room, offices, visitors' center, electrical switchgear room, and restrooms. Specific construction methods and physical arrangements will be identified in the preliminary design stage. However, the building can probably be economically constructed using a pre-engineered (Butler-type) design.

\subsubsection{Interfaces}

The principal interfaces between the vacuum vessel and the turbine are the physical dimensions and loads at the turbine inlet and outlet flanges. Between the vacuum vessel and the seawater systems, the interfaces are the seawater pipe sizes and positions and the discharge pool levels. The interfaces between the vessel and the heat exchangers are the required planform areas, heights, and manifolding supports. In addition, steam piping to the surface condenser and vacuum compressor requires interfaces with the vacuum vessel.

An additional "interface" between the vacuum vessel and the turbine is necessary because of the desirability of completing heat- and mass-transfer tests before the turbine arrives. Because the turbine inlet plenum and rotor assembly form the vessel's dome, it will be necessary to ensure that parts of the turbine are delivered before the turbine rotor is, or that a suitable blank is available to close the top of the vacuum vessel. It now appears that the inlet plenum can be fabricated and delivered earlier than other parts of the turbine system. The rotor assembly requires the most time for fabrication and factory testing, and it is not likely to be available until after heat- and mass-transfer tests are complete. Therefore, the structures team is designing and planning to fabricate a suitable blank to cover the opening for the turbine rotor.

Besides the interfaces described above between the vacuum vessel and other components of the HMTEA/NPPE system, additional interfaces exist between other structures and other components. For example, platforms will be required to support the vacuum compressor, the surface condenser, and the turbine's resistive load bank. Such platforms will be designed to provide stable support for and adequate access to these components. Piping routes and supports, instrumentation and power cableways, and provisions for access of personnel and cranes require a careful interfacing between the applicable component design group and the structures team. 
Table 3-5. Schedule for NPPE Structures Task

\begin{tabular}{ll}
\hline Conceptual design & Jan. 1, 1989-Oct. 31, 1989 \\
Preliminary design & Nov. 1, 1989-Mar. 31, 1990 \\
Final design & April 1, 1990 - Aug. 15, 1990 \\
$\begin{array}{l}\text { Construction } \\
\text { Leak detection }\end{array}$ & July 1, 1990 - June 31, 1991 \\
and elimination & July 1, 1991 - Sept. 30, 1991 \\
\hline
\end{tabular}

Table 3-6. NPPE Structure Costs (in \$K)

\begin{tabular}{lcccc}
\hline \multicolumn{1}{c}{ Task } & Equipment & Contracts & Consultants & Total \\
\hline Preliminary design & 0 & 75 & 20 & 95 \\
Final design & 0 & 75 & 10 & 85 \\
Construction/testing & $\underline{680}$ & $\underline{20}$ & $\underline{0}$ & $\underline{700}$ \\
& 680 & 170 & 30 & 880 \\
\hline
\end{tabular}

\subsubsection{Schedule}

The schedule for design and construction of the vacuum vessel and control building at the time of writing is shown in Table 3-5. Unless unforeseen problems arise, the structures should be ready for installation of equipment by January 1991 and for heatand mass-transfer tests by July 1991.

\subsubsection{Cost and Uncertainties}

Table 3-6 summarizes estimated costs. Equipment costs include costs for site preparation $(\$ 100 \mathrm{~K})$ and for construction of the vacuum vessel $(\$ 300 \mathrm{~K})$, the control building $(\$ 100 \mathrm{~K})$, and miscellaneous structures $(\$ 30 \mathrm{~K})$. Equipment installation will cost $\$ 150 \mathrm{~K}$. The contract for construction and testing covers an on-site quality assurance inspector to test and approve forming, concrete mixture and placement, and coatings. 
TP-3616

\section{CHAPTER 4.0}

\section{SEAWATER SYSTEMS}

\subsection{Objective}

The objective of the seawater systems task is to develop the seawater systems for the HMTEA/NPPE at the STF, to manage environmental issues related to HMTEA/NPPE operation, and to ensure safe operation of the facility.

\subsection{Goal}

The goal of the task is to develop seawater systems for the NPPE which will consume no more than $81 \mathrm{~kW}$ of power at the design point. Including $20 \mathrm{~kW}$ of power consumed in the NPPE heat exchangers, the goal for total pumping power is $\mathrm{fOI} \mathrm{kW}_{\mathrm{e}}$. The seawater pumps will be the largest users of parasitic power in the system.

\subsection{Approach}

The U.S. DOE has cooperated with the State of Hawaii to upgrade the capacities of the seawater systems serving the STF to $620 \mathrm{~kg} / \mathrm{s}$ (9600 gal/min) warm seawater and $420 \mathrm{~kg} / \mathrm{s}$ (6500 gal/min) cold seawater (DOE 1986). The seawater supply portion of this effort was completed and placed in limited service in July 1988. A seawater disposal trench is nearing construction. The upgrade will be the basis for the HMTEA/NPPE seawater systems. The existing portions of the upgrade are documented by Lewis, Van Ryzin, and Vega (1988), by Daniel (1989), and by construction blueprints from the Department of Accounting and General Services of the State of Hawaii (DAGS 1986).

Adapting the STF upgrade to the needs of the HMTEA/NPPE requires engineering design that emphasizes performance, cost, and reliability. No new research or development is required. During the conceptual design, the upgrade was evaluated and the potential was assessed for producing net power from the NPPE using the present system. It was determined that the existing system is inadequate to meet the goal for total pumping power. Design changes which will reduce the pumping power and meet the NPPE goal have been determined. Approaches to individual design issues are discussed below. Options considered and eliminated are presented, and other major considerations are discussed.

Members of the seawater system team at the time of writing are Ron Davis of PICHTR, Lyle Genens of ANL, Herbert J. Green of SERI, and Lloyd Lewis of DOE. Ken Fong of PICHTR has also contributed to the conceptual design.

\subsubsection{Design Conditions}

Design conditions for the HMTEA/NPPE seawater systems (Table 2-1, p. 12) were continuously updated and expanded during conceptual design. A complete discussion of these data and their sources is found in Document No. 2.1.3.6.14.

The nominal flow rates of $620 \mathrm{~kg} / \mathrm{s}(9600 \mathrm{gal} / \mathrm{min})$ warm seawater and $420 \mathrm{~kg} / \mathrm{s}(6500$ $\mathrm{gal} / \mathrm{min}$ ) cold seawater have been dictated by design parameters of the existing STF upgrade and by related environmental permits. The low and high flow rates are $50 \%$ and $110 \%$, respectively, of the nominal flow rates. These are the projected requirements of the HMTEA experiments and the turbine checkout tests. The total flow rate in the offshore cold-water pipe, $860 \mathrm{~kg} / \mathrm{s}(13,300 \mathrm{gal} / \mathrm{min})$, includes the cold-water allocation for the HOST Park, $440 \mathrm{~kg} / \mathrm{s}$ ( $6800 \mathrm{gal} / \mathrm{min})$, as well as the HMTEA/NPPE flow rate. 
The seawater temperatures, $26^{\circ} \mathrm{C}\left(78.8^{\circ} \mathrm{F}\right)$ warm and $6.1^{\circ} \mathrm{C}\left(43.0^{\circ} \mathrm{F}\right) \mathrm{cold}$, are based on measurements made at the HMTSTA early in 1989. The range of the warm-seawater temperature is the seasonal variation recorded by the NELH. The cold-seawater low temperature will not be known until the system can be operated at full capacity, $860 \mathrm{~kg} / \mathrm{s}$ $(13,300 \mathrm{gal} / \mathrm{min})$, and the temperature is measured on shore. Data indicate that the temperature at $675 \mathrm{~m}(2,215 \mathrm{ft})$, the depth of the inlet, may actually be as low as $5.3^{\circ}$ $5.8^{\circ} \mathrm{C}\left(41.5^{\circ}-42.4^{\circ} \mathrm{F}\right)$ (Ocean Data Systems 1977). Even if the cold seawater is below $6.1^{\circ} \mathrm{C}\left(43.0^{\circ} \mathrm{F}\right)$, the remaining uncertainty is much smaller than the seasonal variation in the warm seawater. Thus, the nominal temperature difference, $19.9^{\circ} \mathrm{C}\left(35.8^{\circ} \mathrm{F}\right)$, is a reasonable design point. It is well within the range of temperature differences that will be available to the NPPE in the course of a year. If slightly lower cold-seawater temperatures are available, they will have the beneficial effect of increasing turbine shaft power without increasing parasitic power of the system.

Data on seawater density are taken from measurements off Kahe Point, Oahu. Less than $0.5 \%$ difference exists between the densities of the warm and cold seawater. The barometric head calculations accounted for the local barometric pressure and the NPPE operating pressures as well as the seawater densities. The variation of the force of gravity as a function of latitude was also considered. The supply and discharge barometric heights are essentially the same, because the change in density of seawater within the NPPE is quite small. The cold-water pipe density head loss of $1.0 \mathrm{~m}(3.3 \mathrm{ft})$ is from an experiment performed at the STF in August 1989. Previous estimates of this head loss ranged from $0.88 \mathrm{~m}(2.9 \mathrm{ft})$ to $1.07 \mathrm{~m}(3.5 \mathrm{ft})$ based on various projections of the seawater density vs. depth. The tides were determined from 1990 and 1991 tide tables for Kailua Kona harbor (NOAA 1989).

\subsubsection{Pump Configuration}

One of the most important design issues for NPPE seawater systems is configuration of the pump. Pump configuration refers to the location of the pumps in the system as well as the type of pump (e.g., submersible, vertical wet pit). The pump configuration is closely coupled with other design parameters. such as the head losses in the supply and discharge pipes and the elevations of the heat exchangers. These are discussed in Sections 4.4 and 4.5. Several configurations for supply and discharge pumps were identified and their relative merits evaluated. Some were less attractive and were set aside.

A key decision reached during the first working group meeting in February 1989 was to use both supply and discharge pumps in the design of systems for both warm and cold seawater (Green Feb. 1989). This has the important advantage of allowing the heat exchangers to be located relatively close to grade, thus reducing overall height of the structure and keeping costs down. Another advantage is that net power production will be substantially disconnected from the tide and from variations in barometric pressure. For instance, the increase in pumping power of the seawater supply at low tide will be accompanied by a decrease in discharge pumping power. At high tide, just the opposite will occur. In either case, little change in net power will occur. (Observations at the pump station indicate that the cold-seawater sump is subject to tidal fluctuations just as is the warm-seawater sump. The disposal trench is also expected to respond to the tides.)

Placing pumps in each supply and discharge pipe also provides the operational flexibility to adjust to uncertainties in head loss estimates or changes in head resulting from fouling of the pipes, changes in the experiment, or other causes. The result is a system capable of delivering the required flow rates with minimal risk. For the warm-seawater supply, a pump with a very low head, $1.37 \mathrm{~m}(4.5 \mathrm{ft})$, will be used so that the elevation of the 
evaporator discharge pool will be minimized (Document No. 2.1.3.6.16). A higher elevation would reduce the space above the evaporator needed for separation of seawater droplets from the steam before it enters the turbine. Because this pump will operate at such a low head, it will have a somewhat lower efficiency than the other pumps. However, the resulting increase in pumping power is less than $1 \mathrm{~kW}$.

The impeller of the NPPE discharge pumps must be located below grade to have sufficient net positive suction head (NPSH). The configuration chosen for the discharge is the vertical barrel pump (Figure 4-1). The barrel provides an enclosure that operates at line rather than atmospheric pressure. The electric motor and the suction and discharge flanges all can be located above grade. Only the barrel and impeller are below grade, so that excavation is minimal. Location of these pumps near the HMTEA/NPPE structure will be convenient for both construction and maintenance. It will also minimize the length of the suction pipe to the pumps, thus maximizing the available NPSH.

The configuration chosen for the supply pumps is vertical wet pit pumps located in the pump station sumps (Figure 4-2). This type of pump is installed in the HMTSTA seawater discharge sumps and is the configuration used for the OTEC-1 seawater pumps. The pumps have performed well in both applications. Also, this configuration has ample NPSH for the pumps. The cost of modifying the pump station to accommodate vertical wet pit pumps as shown in Figure 4-2 is reasonable, about $\$ 40 \mathrm{~K}$ per pump (Fong Oct. 1989). These proposed modifications will require the approval of NELH.

A disadvantage of this configuration is the possibility that the electric motors will be flooded. This could result from storm surge. In the case of the cold-seawater sump, flooding also could be caused by the large momentum of seawater in the offshore pipe following a sudden loss of pumping power or shutdown of the HOST Park pumps. For this reason, two backup configurations for supply pumps have been identified--submersible and vertical-barrel pumps. Further analysis will determine which configuration will be used.

The submersible pump is the existing STF upgrade configuration. However, the existing pumps are too inefficient and deliver heads much too high for the NPPE. Further, their demonstrated reliability is currently inadequate for the needs of the NPPE. Progress at the STF with cast-iron submersible pumps and impressed current galvanic protection is being closely monitored. If they demonstrate improved reliability and adequate performance, they could be reconsidered as a good alternative.

Vertical-barrel pumps can be installed in the supply pipes near the vacuum vessel. The potential disadvantage of this configuration is that performance of the pumps would degrade in response to air leakage or deaeration of noncondensable gases in the supply pipe coming from the pump station. This is possible because the entire pipe will be below atmospheric pressure while the system is operating.

As for other configurations, vertical dry pit pumps were rejected because of the extensive modifications that would be required in the pump station. Placement of verticalbarrel pumps in the supply pipes just above the pump station was rejected because they could be vulnerable to high surf and would not be readily accessible for maintenance. Additional information about all of the pump configurations can be found in Documents 2.1.3.6.8 and 2.1.3.6.16.

Redundancy within the seawater systems to increase reliability also has been considered. For the conceptual design, single pumps have been used. The additional cost of installing 
BA.G0539205

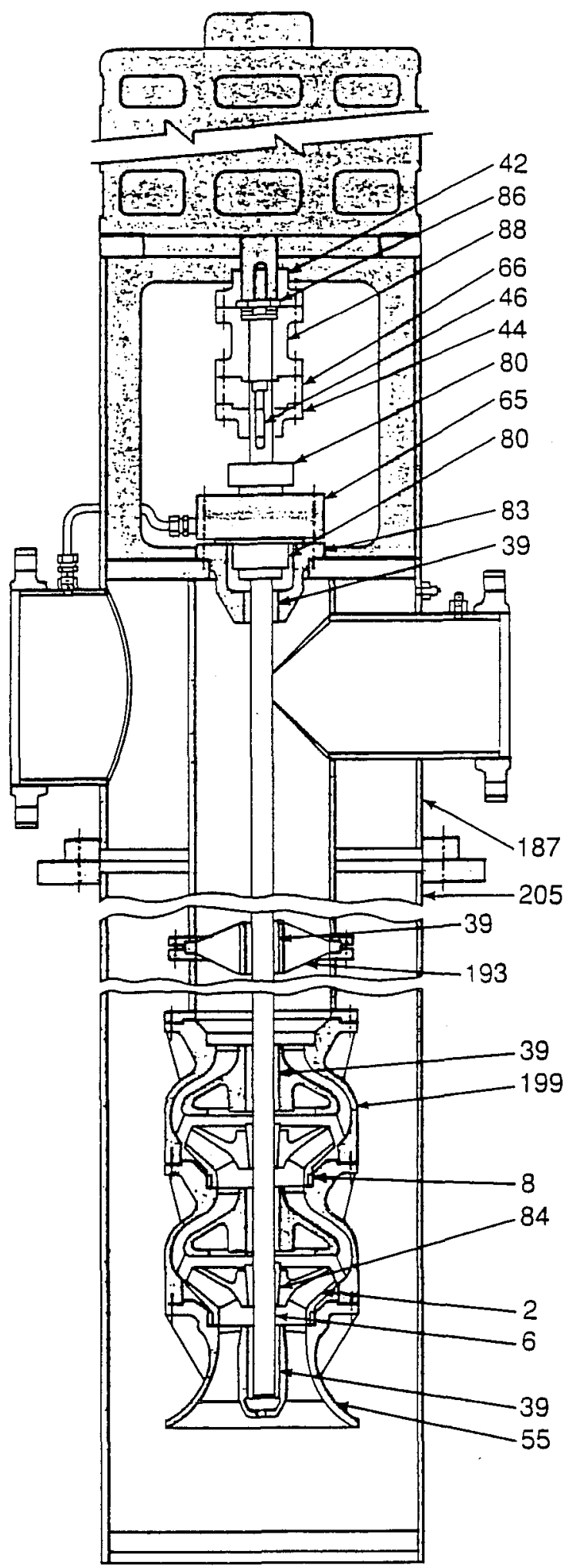

unused pumps is not warranted for an experiment. During the preliminary design, three redundancy options will be assessed. The first will be the use of multiple pumps of smaller capacity, e.g., two half-capacity pumps or three one-third-capacity pumps. If one should fail, the system at least could continue to operate although at a reduced level of performance. The second option will be an on-site stock of spare parts, perhaps including spare motors. The third will be backup pumps stored on site but not installed. Costs and effects on reliability of the system will be assessed for the three options" and recommendation will be made to the system team during the course of the preliminary design.

\subsubsection{Pump Bids}

One of the first activities for the conceptual design was to evaluate the possibility of using the existing Flygt pumps. They were found to be well oversized for the HMTEA/NPPE. They are rated to deliver $18.9 . \mathrm{m}$ $(62 \mathrm{ft})$ of head, whereas the requirements for the NPPE are $3.60 \mathrm{~m}(11.8 \mathrm{ft})$ and $1.37 \mathrm{~m}(4.5 \mathrm{ft})$ for the cold- and warm-seawater pumps, respectively (see Section 4.4). This evaluation also revealed that the impeller and motor efficiencies for submersible pumps are somewhat lower than those for available vertical

Figure 4-1. Vertical barrel or can pump
Impeller
Shaft, Pump
Ring, Impeller
Bushing, Bearing
Coupling Half, Driver
Coupling Half, Pump
Key, Coupling
Bell, Suction
Seal, Mechanical, Stationary Element
66 Nut, Shaft Adjusting Seal, Mechanical, Rotating Element Stuffing Box Collet, Impeller Lock Ring, Thrust, Split Spacer, Coupling Head, Surface Discharge
Retainer, Bearing, Open Lineshaft
Bowl, Intermediate
Barrel or Can Suction

80

83

84

86

88

187

193

199

205 


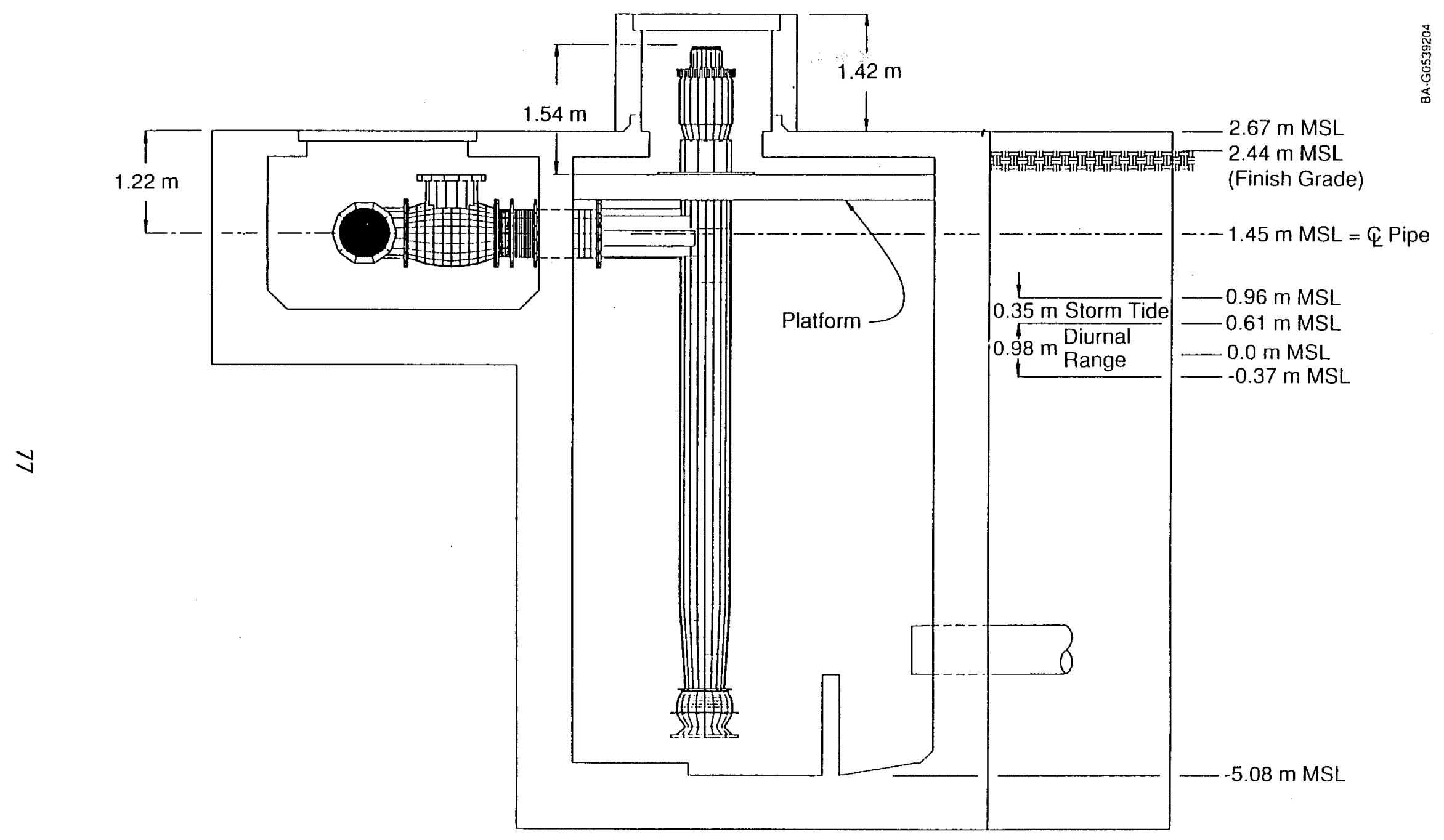

Figure 4-2. Vertical wet pit pump installation in the pump station 
wet pit pumps. Submersible pump impellers are typically designed with high clearances for wastewater service resulting in efficiencies less than $80 \%$. The motor efficiencies are usually less than $90 \%$ because they are completely enclosed and must expend additional power to reject heat.

An assessment of the system's performance using the existing Flygt pumps was made by PICHTR (June 1989). Replacing the impeller and using variable-frequency drives (VFDs) were investigated as means of adapting the Flygt pumps to the needs of the NPPE. The best combination, the existing pumps with VFD, would consume more than $101 \mathrm{~kW}$ of power, the task goal. This assessment was based on an early configuration of the HMTEA/NPPE. Subsequent changes have only decreased the suitability of the existing pumps.

Bids were solicited from pump vendors to obtain cost and performance data for pumps better suited to the needs of the NPPE. Specifications for the supply and discharge pumps were written based on the seawater system layout as of March 1989 (Document No. 2.1.3.6.11). The specifications included warm- and cold-seawater supply pumps and mixed-discharge pumps. The three pump configurations specified were vertical wet pit, vertical barrel, and submersible. Three capacities were also included: 100\%, 50\%, and $33 \%$ of the rated flow rates for both warm and cold seawater. Together, the specifications included 30 different pumps incorporating all the options under consideration at the time and called for cast iron or equivalent material for construction. This is the type of construction used for the OTEC-1 and HMTSTA seawater pumps, all of which have performed well.

Bids from at least 14 manufacturers were accumulated over several months. They have been compiled and summarized (PICHTR Sept. 1989) to provide a valuable data base of pump options for the NPPE. Although the seawater system layout has changed since the specifications were written in March, the bids indicate the prices and performance expected from the pumps that eventually will be purchased. Many were quoted with high impeller efficiencies of $80 \%$ to $89 \%$. Several brands of barrel pumps are available that have the required NPSH between 1.8 and $6.1 \mathrm{~m}$ (6 and $20 \mathrm{ft}$ ). This is an important characteristic for the discharge pumps, as noted previously. Prices for the 100\%-capacity pumps were generally between $\$ 20 \mathrm{~K}$ and $\$ 40 \mathrm{~K}$ per pump for the sizes appropriate to the current configuration of the system. Curves shown in Figures 4-3 and 4-4 are examples of the performance of the pumps. Operating points for all four pumps are noted on the curves. Efficiencies range from $76.5 \%$ for the warm-seawater supply pump to $85.5 \%$ for the cold-seawater supply pumps.

Most of the bids were for pumps with mixed-flow or axial-flow impellers. They have two inherent characteristics that set them apart from most centrifugal pumps. The shutoff head is usually significantly higher than the head at the design point, which creates the possibility of overloading the motor. They would require safety features such as alarms for high motor temperature, high current draw, or high discharge pressure. In addition, they typically have areas of unstable operation at low rates of flow. The preliminary design will include careful evaluation whether operating conditions might occur in which potential exists for these instabilities.

\subsubsection{Electric Motors}

In vertical-shaft pumps, the thrust bearings are generally put in the electric motor. The pumps themselves have only shaft bearings, so that the weight and thrust loads of the 


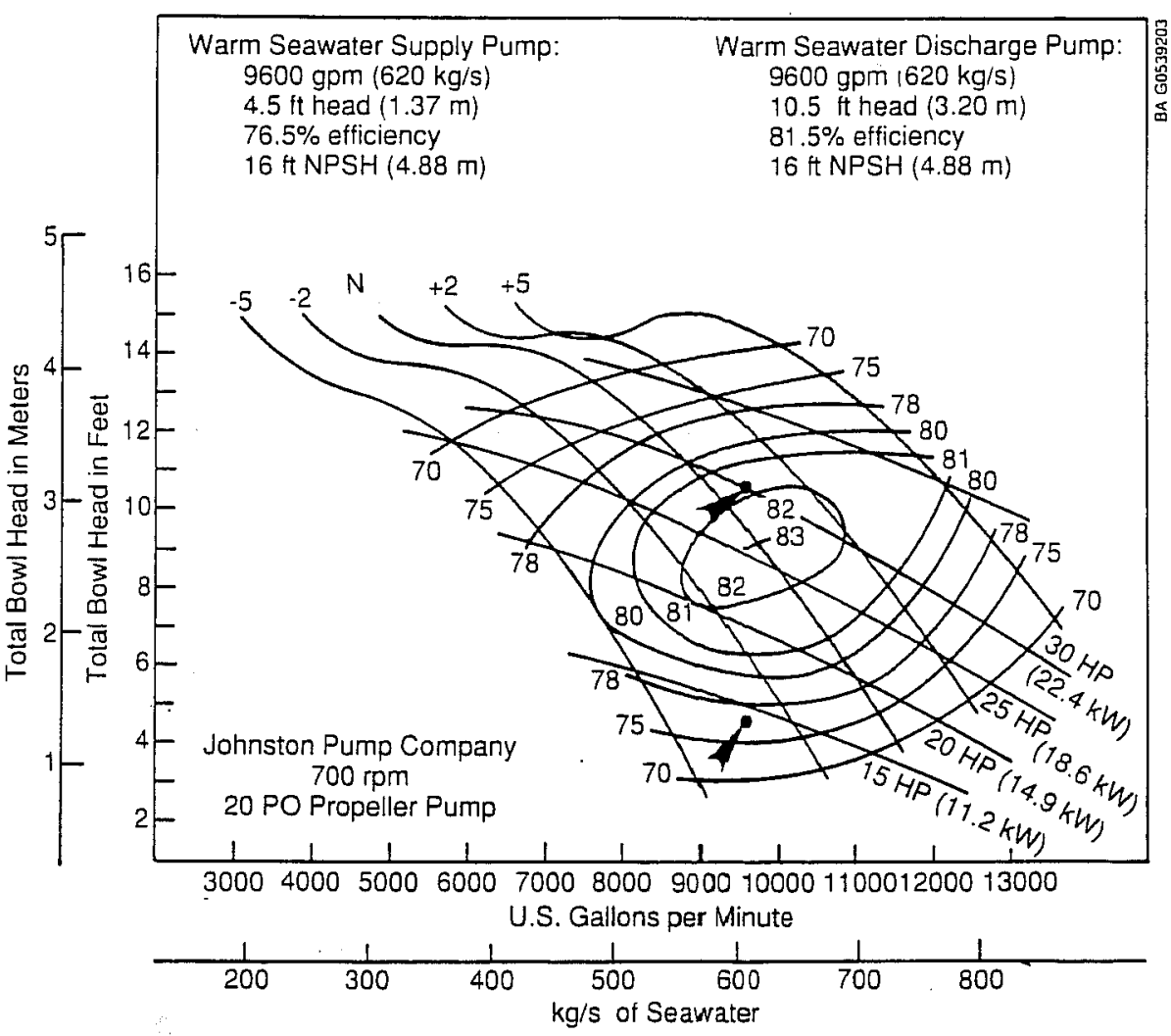

Figure 4-3.

Sample warm-seawater pump curves

shaft and impeller are suspended from the motor thrust bearing. The height of the impeller in the bowl is determined by an adjustment in the coupling between pump and motor shafts. Typically, the pump and motor are shipped to the site separately because of the weight of the motor. The unit is assembled on site and the impeller height is then adjusted.

High-thrust vertical motors have two configurations: solid shaft and hollow shaft. In vertical hollow-shaft motors, the pump shaft extends through the motor and is coupled to the motor shaft on top. In vertical solid-shaft motors, the shaft coupling is below the motor. The two domestic suppliers of high-thrust vertical electric motors are General Electric and U.S. Motors.

Performance of electric motors is affected by the type of enclosure. The more completely enclosed and weatherproof a motor is, the less effectively it rejects heat. Totally enclosed fan-cooled (TEFC) motors require a fan for cooling, which reduces efficiency. Open drip-proof motors may be $1 \%$ or $2 \%$ more efficient than comparable TEFC motors. For outdoor installation, TEFC motors are recommended. General Electric offers premium-efficiency TEFC motors with efficiencies between $90 \%$ and $94 \%$ in the sizes of interest for the HMTEA/NPPE, 15 to $37 \mathrm{~kW}$ (20 to $50 \mathrm{hp}$ ). Certification of performance by factory testing is available for an additional fee.

The motor specifications should include materials and coatings appropriate for a nearocean location (severe duty). Auxiliary heaters inside the motor to keep it dry should also be specified. Such heaters have effectively prevented condensation of atmospheric moisture inside motors used in humid environments. For applications with VFDs, highertemperature insulation such as Class $\mathbf{F}$ is recommended, because a motor rejects heat 

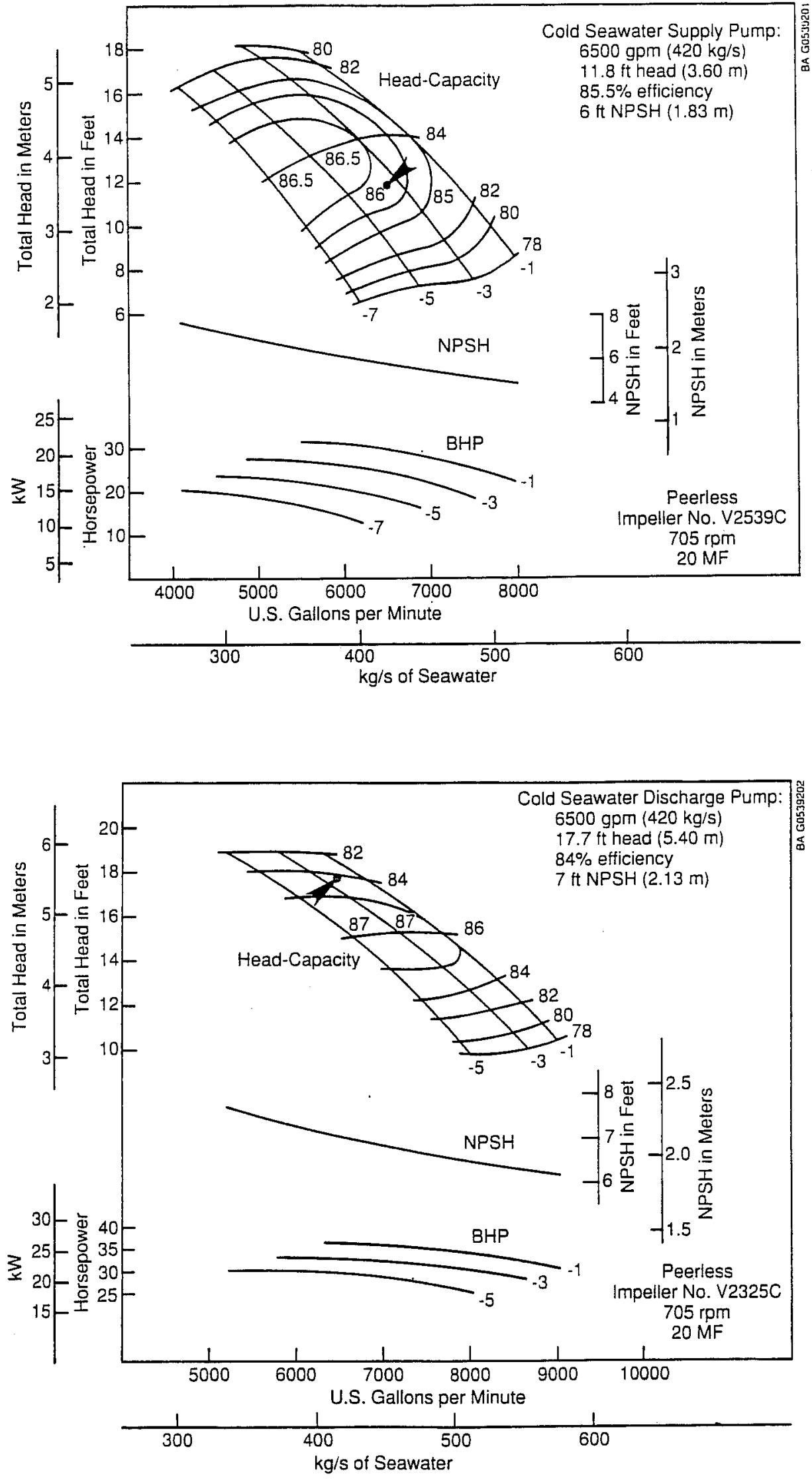

Figure 4-4a. Sample cold-seawater pump curves
Figure 4-4b. Sample cold-seawater pump curves 
less effectively as it is slowed down. Class B is adequate for single-speed motors. Purchasing the pump, motor, and VFD as a package may be advantageous because it centralizes responsibility for performance and service.

Motors are rated for the power required by the pump and must not overload over the full operating range of the pump. Motors are rated for an altitude of $1000 \mathrm{~m}(3300 \mathrm{ft})$. At sea level, a given motor will cool itself more efficiently which, in effect, provides some factor of safety above its nameplate power rating. Motors typically come with 1.0 or 1.15 service factors. A service factor of 1.15 is equivalent to excess rating of $15 \%$. For a power system with nominal voltage of 480 volts, the motor nameplate voltage will be 460.

\subsubsection{Control of Flow Rate}

Variable-frequency drive (VFD) has been selected to control the flow rates in the NPPE seawater systems. VFD is typically more energy efficient than a throttling valve or a bypass loop for controlling flow over a range of flow rates and heads. The change in head or flow need only be greater than the drop in efficiency caused by addition of the VFD to the electrical circuit. Typical VFD electrical efficiencies are about 95\%, so any change in either flow or head or both that is greater than $5 \%$ will make VFD the most energy efficient method. When operating at synchronous speed (e.g., $60 \mathrm{hz}$ ), the rectifiers in the VFD can be bypassed so that it is virtually $100 \%$ efficient.

VFD also offers greater operating flexibility than throttling valves. The seawater systems design requires a range of flow rates from $50 \%$ to $110 \%$ of the nominal flow rate and a range of tides of $-0.37 \mathrm{~m}(-1.2 \mathrm{ft})$ and $+0.61 \mathrm{~m}(+2.0 \mathrm{ft})$. The discharge pumps may operate against a head that increases with time if degradation should occur in disposal trench performance. Furthermore, the estimates of the head losses in the piping runs have some uncertainty. A pump controlled with a VFD can adjust to these kinds of changes. The VFD can drive the pump above the synchronous speed of the electric motor, allowing the pump to deliver heads, flow rates, or combinations of the two that are greater than those originally specified. It is only necessary that the VFD and the motor be sized for the increased electrical loads.

Another advantage of VFD control of flow rate is that pumps may be soft started, allowing operators to start the seawater flow in a gradual, controlled manner. This will be especially helpful because levels of seawater at the pump station and disposal trench are functions of the flow rates through them. As those levels change during start-up, shutdown, or other operational transients, the required pump heads will also be changing. Finally, soft starts prevent large inrush of current to the electric motors. The selection of VFD to control flow rate is discussed in Document No. 2.1.3.6.12.

\subsubsection{Supply and Discharge Pipes}

Onshore supply pipes for both warm and cold seawater were installed between the pump station and NELH during construction of the STF upgrade. Both pipes are 0.61-m (24-in.) high-density polyethylene (HDPE) pipe about $180 \mathrm{~m}(600 \mathrm{ft})$ long. Sections of these pipes are fully buried to prevent damage from high surf and to pass beneath roadways. For most of their length, however, the pipes are buried only to their centerline. Their layout is described in Section 4.4 .

Because HDPE is flexible, the pipes are subject to collapse under internal vacuum. Analysis of the STF supply pipes, performed with the assistance of the manufacturer, determined that the buried sections would withstand the vacuum that would exist during 
operation but the half-buried sections would not. The buried pipe performs better because the backfill around it helps to maintains its circular cross section. This analysis is presented in detail in Document No. 2.1.3.6.9. For the HMTEA/NPPE, the supply pipes must either be replaced or modified with some type of mechanical restraint. Suitable restraints might include a gravel berm over the pipe, a poured concrete cover, or steel reinforcing bands.

During the first working group meeting in February 1989, it was decided that the existing warm-seawater supply pipe would be replaced with pipe of larger diameter to reduce the head loss (SERI March 1989). A $0.91-\mathrm{m}$ (36-in.) pipe is recommended which will reduce the head loss about $1.68 \mathrm{~m}(5.5 \mathrm{ft})$ at $640 \mathrm{~kg} / \mathrm{s}(9600 \mathrm{gal} / \mathrm{min})$ which in turn will reduce

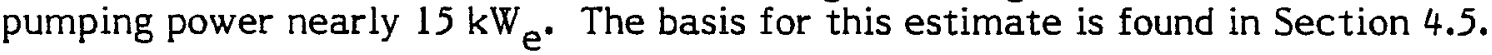

Alternative materials that have been suggested for the new pipe are buried HDPE, fiberreinforced plastic, PVC, coated steel, concrete-lined steel, and uncoated steel. These materials are being evaluated. The important criteria are capability to withstand vacuum, leaktight joints, resistance to corrosion, and installed cost. Selecting the material is a top priority for the seawater systems team during the preliminary design. A route for installation of the pipe must also be determined. The option of removing the existing $0.61-\mathrm{m}$ (24-in.) pipe and replacing it with the $0.91-\mathrm{m}$ (36-in.) pipe is under consideration and must be approved by NELH.

A decision is also pending on the cold-seawater supply pipe. The existing 0.61-m (24-in.) pipe will have head losses of only $0.98 \mathrm{~m}(3.2 \mathrm{ft})$ at $420 \mathrm{~kg} / \mathrm{s}(6500 \mathrm{gal} / \mathrm{min})$, requiring pumping power of $5.4 \mathrm{~kW}$. Thus, the incentive is only moderate to replace the pipe simply to increase the diameter. If the pipe is replaced, a $0.76-\mathrm{m}$ (30-in.) pipe would be adequate, reducing the pumping power to $1.4 \mathrm{~kW} \mathrm{e}^{\text {. }}$

The existing pipe could be modified to withstand vacuum as previously noted. There are concerns, however, about the integrity of numerous flanged joints in the pipe run, many of them buried and therefore inaccessible. Each is a potential source of leaks. A leak check has not yet been done because an NELH tenant, Ocean Farms Hawaii, is continuously dependent on this pipe for cold water. Additional sources of supply may make this pipe available for DOE use during 1990. Further analysis and testing will be done to enable a decision about this pipe during the preliminary design.

Pipes will be needed to connect the HMTEA/NPPE to the discharge pumps and the 1.2-m (48-in.) discharge pipe. The material chosen for the warm-seawater pipe will also be used for these. A $1.2-\mathrm{m}$ (36-in.) warm and $0.76-\mathrm{m}(30$-in.) cold discharge pipe from the HMTEA/NPPE vacuum vessel to the discharge pumps will be located about $12.2 \mathrm{~m}(40 \mathrm{ft}$ ) away. A $0.91-\mathrm{m}$ (36-in.) mixed-discharge pipe will run about $36.6 \mathrm{~m}(120 \mathrm{ft})$ from the pumps to connect to the $1.2-\mathrm{m}(48$-in.) pipe that runs to the trench.

\subsubsection{Concrete Sump}

A concrete disposal sump was included in the STF upgrade completed in 1988. Its purpose was to mix seawater discharged from the STF with seawater bypassed from the supply pipes going to the STF. This sump has been carefully evaluated and found to be inadequate for use in the HMTEA/NPPE.

For the HMTEA/NPPE, the sump would be required to operate at a pressure of one-half atmosphere. Structural analysis showed that the sump's flat cover would not bear the loads imposed by this internal vacuum. In addition, the 1.2-m (48-in.) pipe penetrations to the sump probably are not currently vacuum tight and cannot be easily modified to be 
so. Using the sump in the discharge system would add a source of leaks as well as a high point which would require venting with a vacuum pump. Additional head losses would also occur in the seawater flow into and out of the sump.

Finally, the possibility was investigated of using the sump as a bypass between the HMTEA/NPPE supply and discharge pipes. It was found that pressure in the sump will be higher than that in the seawater supply pipes. If the bypass valves to the sump were opened, seawater would flow the wrong direction, from the sump into the low-pressure supply lines. Given all of these findings, the concrete sump was eliminated from the NPPE design.

To provide the capability of bypassing the sump, an additional pair of flanges will be

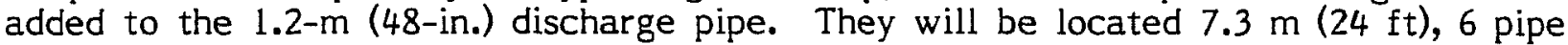
diameters, from the first flange at the concrete sump. This will create a spool piece that will later be removed (Figure 4-5) for making the connection to the HMTEA/NPPE. In the interim, the concrete sump will be available for flowing seawater to the disposal trench for tests.

\subsubsection{Disposal Trench}

The State of Hawaii, through its contractor R. M. Towill Corporation, is responsible for design and construction of the disposal trench and 1.2-m (48-in.) HDPE discharge pipe. In July 1989, Towill submitted a final design in the form of a Prefinal Bid Document for DOE review. It covers the first phase of construction, $30.5 \mathrm{~m}$ (100 ft) of trench, and installation of the 1.2-m (48-in.) pipe. Towill incorporated review comments into a Revised Prefinal Bid Document submitted in September. This document, with minor modifications, was promptly approved by DOE as the final design of the trench. The seawater systems team supported DOE throughout this process by writing design specifications and providing technical review of the bid documents. The state is proceeding to award a construction contract. The trench should be complete and ready for testing by mid-1990.

Complete details of the final design are available from the bid document (R. M. Towill 1989). The locations of the pipe and trench can be seen in the site layout, Figure 2-9 (p. 39). Numerous features have been incorporated to meet HMTEA/NPPE requirements. The 1.2-m (48-in.) pipe will slope continuously down to the trench. No sharp turns or fittings will create additional pressure drop or trap air bubbles. A spool piece added to the pipe as noted above (Figure 4-5) will accommodate bypass of the concrete sump. The entire pipe will be buried $1.2 \mathrm{~m}(4 \mathrm{ft})$ deep. Thus constrained, it will be able to withstand internal vacuum without collapse. The heavy-walled HDPE pipe available at NELH, DR21, will be used, which will also provide greater resistance to collapse. The top of pipe will be at least $0.3 \mathrm{~m}(1 \mathrm{ft})$ below the lowest tide as it enters the trench. The elevation of the bottom of the trench will be surveyed to expedite measurements of the water level.

Geolabs-Hawaii, designer of the trench, estimated a capacity between 65 and $260 \mathrm{~kg} / \mathrm{s}$ $(1000$ and $4000 \mathrm{gal} / \mathrm{min})$ for the first $30.5 \mathrm{~m}$ (100 ft) of trench based on permeability tests done in 15-cm (6-in.) wells drilled at the trench site. Their estimate allowed for $3.0 \mathrm{~m}$ (10 ft) of head in the trench. Given that the discharge flow rate from the HMTEA/NPPE is $1040 \mathrm{~kg} / \mathrm{s}(16,100 \mathrm{gal} / \mathrm{min})$, more than $122 \mathrm{~m}(400 \mathrm{ft})$ of trench may by needed. Furthermore, a $3.0-\mathrm{m}(10-\mathrm{ft})$ head in the trench would consume more than $40 \mathrm{~kW}$ of pumping power, which would seriously affect net power production. (See Section 4.5 for details of performance projections.) Because of the characteristic inhomogeneities of the lava rock at Keahole Point, the actual performance of the disposal trench could be 


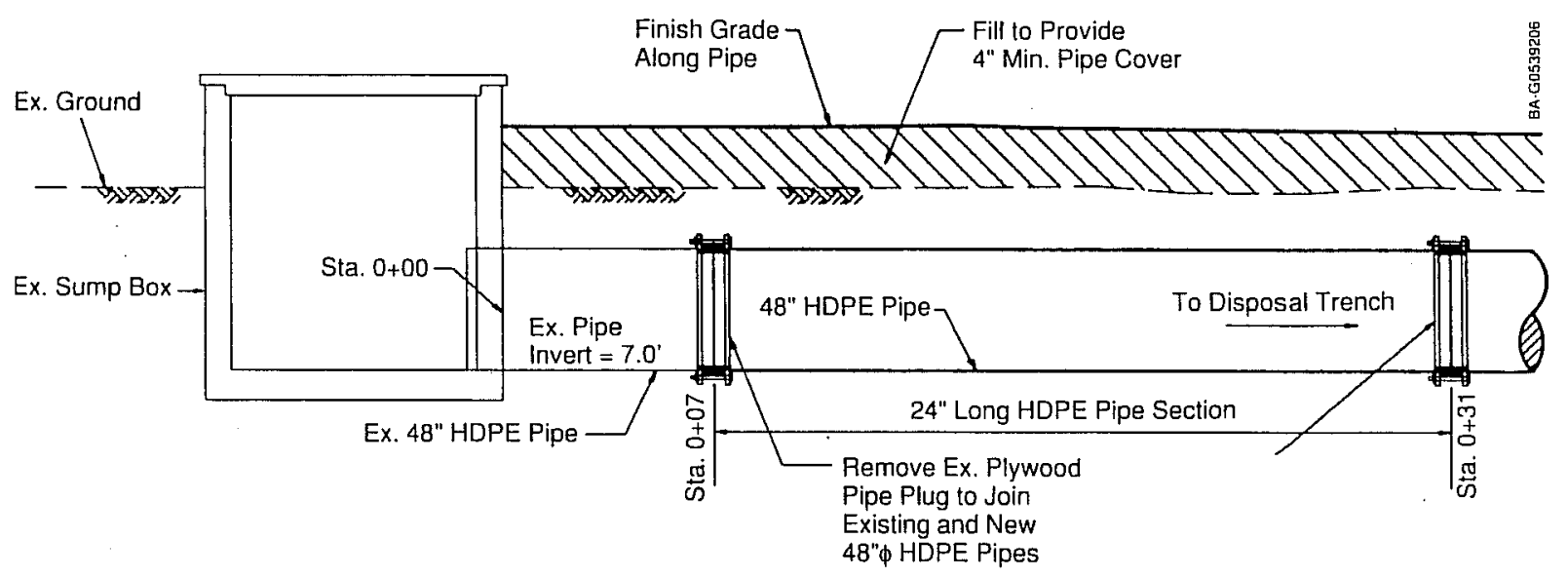

Figure 4-5. Concrete sump and 1.22-m (48-in.) discharge pipe with spool piece (R.M. Towill 1989)

significantly different than Geolabs has estimated. When the first $30.5 \mathrm{~m}$ (100 ft) of trench is in and tested, better estimates of its performance and of net power production will be made.

During the conceptual design, no other disposal methods have been investigated. During the preliminary design, alternatives to trench disposal should be assessed, taking into account both cost and environmental regulations.

The NPPE baseline design from 1987 specified a 1.8-m (6-ft) discharge head dictated by a weir in the trench. During the first working group meeting in February 1989, the weir was eliminated. Subsequently, the seawater systems team has used an optimistic goal of $0.9 \mathrm{~m}(3 \mathrm{ft})$ of head in the trench as a basis for obtaining bids from pump vendors and estimating performance of seawater systems. Net power production will decrease about $4.3 \mathrm{~kW}$ for each additional foot of head.

\subsubsection{Seawater System Tests}

Flow tests are planned for the STF upgrade of the seawater systems including the disposal trench. The data from these tests will be considered in the design of the seawater systems for the HMTEA/NPPE. The data are especially important because the seawater systems will be the major consumer of parasitic power.

The goal of the flow tests is to measure the hydraulic performance of the seawater systems over a range of operating conditions. Characteristics to be measured include head losses in both the onshore and offshore pipes, sump operating levels at the pump station, seawater temperatures, and elevation of the disposal trench pool. These data are particularly critical for selecting pumps for the NPPE that have appropriate head-vs.-flow characteristics, sufficiently low NPSH requirements, and high operating efficiency.

These tests have not yet been performed because an adequate disposal system for the seawater is lacking and because of use of the cold-seawater pumps and supply pipe by Ocean Farms Hawaii, as noted previously. Limited tests were performed in August 1989, when NELH provided an hour during which the cold-seawater flow rate could be varied and head losses measured. Similar additional tests and flowmeter calibrations are pending. 
A draft test plan for a full set of seawater system tests has been written during the conceptual design. This plan will be promptly completed during the preliminary design, so that instruments can be obtained and calibrated and testing can begin as soon as the disposal trench and cold-seawater supply pipe become available. The discharge trench and associated 1.2-m (48-in.) discharge pipe are currently scheduled for construction in early 1990 (see Section 4.3.8). The tests are also contingent on environmental monitoring that is already under way (see Section 4.3.10). For these tests, seawater will be pumped from the pump station through the existing $0.61-\mathrm{m}$ (24-in.) pipes to the concrete disposal sump and on to the disposal trench. Construction of the trench and completion of the subsequent flow tests is critical for the final design. The preliminary design can proceed based on head-loss calculations alone.

\subsubsection{Environmental Issues}

Environmental impact statements were prepared by the High Technology Development Corporation (1985) and the Natural Energy Laboratory of Hawaii (NELH 1987) for the STF seawater system upgrade. DOE (1988) has completed a "finding of no significant impact" for the system. These documents allow construction and operation of the system to proceed. The potential impacts of disposing seawater into the trench were found to be either reversible or readily mitigated. Environmental monitoring is mandated to enable early detection of any unacceptable impacts. If such impacts are detected, appropriate corrective action will be taken. Reaeration of the discharged seawater will be investigated as a means of mitigating potential impacts of discharging oxygen-depleted seawater.

The monitoring will be part of a broader program developed to meet the needs of all users of seawater at NELH and the HOST Park. A draft plan for this program, called the Cooperative Environmental Monitoring Program (CEMP), was circulated to interested parties for review in April 1989. The seawater systems team, through DOE, provided comment to NELH. The team found that the CEMP was adequate to provide monitoring before and during operation of the disposal trench and the HMTEA/NPPE. DOE is one source of funds for this program.

Although the CEMP has not been completed and published, NELH has begun sampling the groundwater, the near-shore seawater, and the anchialine ponds. These samples will provide the baseline data against which future data will be compared when the trench is operating. By the time the trench is completed in 1990, sufficient baseline data should be available so that testing and operation will not be delayed.

\subsubsection{Plant Safety}

In keeping with the task plan, no formal activities with regard to plant safety were conducted during the conceptual design. However, plant safety and the possibility of failures have been considered by all of the design teams. Structured activities regarding plant safety will begin during the preliminary design phase, and analysis of failure modes and their effects for the entire HMTEA/NPPE system will be completed. Safe operating procedures will be drafted to provide specific guidance for the final design.

\subsection{Layout}

A process flow sheet for the NPPE including the seawater systems is found in Figure 2-7 (p. 32). The site plan in Figure 2-9 (p. 39) shows the overall layout for the onshore sections of the seawater systems, including routes of the existing $0.61-\mathrm{m}$ (24-in.) supply pipes and the future locations of the 1.2-m (48-in.) discharge pipe and disposal trench. 
The route for the replacement $0.91-\mathrm{m}$ (36-in.) warm-seawater supply pipe will be determined during the preliminary design. The supply pipes are shown passing through the existing flowmeter enclosure and on to the HMTEA/NPPE. Use of these flowmeters also will be evaluated during the preliminary design.

Design of the seawater systems has been coordinated with that of the HMTEA/NPPE structure to determine the elevations of the evaporator and direct-contact condenser. These elevations, with the relevant heads and barometric heights for the seawater systems, are shown schematically in Figures 4-6 and 4-7. Discharge pumps have been incorporated into the design so that the heat exchangers can be located relatively close to grade rather than at the barometric height. This reduces the overall height of the HMTEA/NPPE structure, which will help keep costs down.

The design includes both supply and discharge pumps (see Section 4.3.2). This configuration provides confidence in the system's function and the operating flexibility that is necessary for an experiment. Inclusion of a warm-seawater supply pump places pool elevation of the evaporator $4.1 \mathrm{~m}(13.5 \mathrm{ft})$ above grade. At this elevation, ample headroom is available above the evaporator for droplets to separate from the steam before the steam enters the turbine.

The overall height of the HMTEA/NPPE structure is determined by the elevation of the direct-contact condenser's discharge pool, the height of the direct-contact condenser, and the length of the turbine diffuser. Thus, if the pool elevation can be reduced, the overall height will be reduced. However, the pool must be maintained at an elevation that provides adequate NPSH for the discharge pumps. The vertical-barrel pumps that will be used to discharge seawater will have impellers below grade to gain NPSH. However, construction experience with the HMTSTA sumps and with the STF upgrade pump station indicates that the excavation of pits for these pumps below the

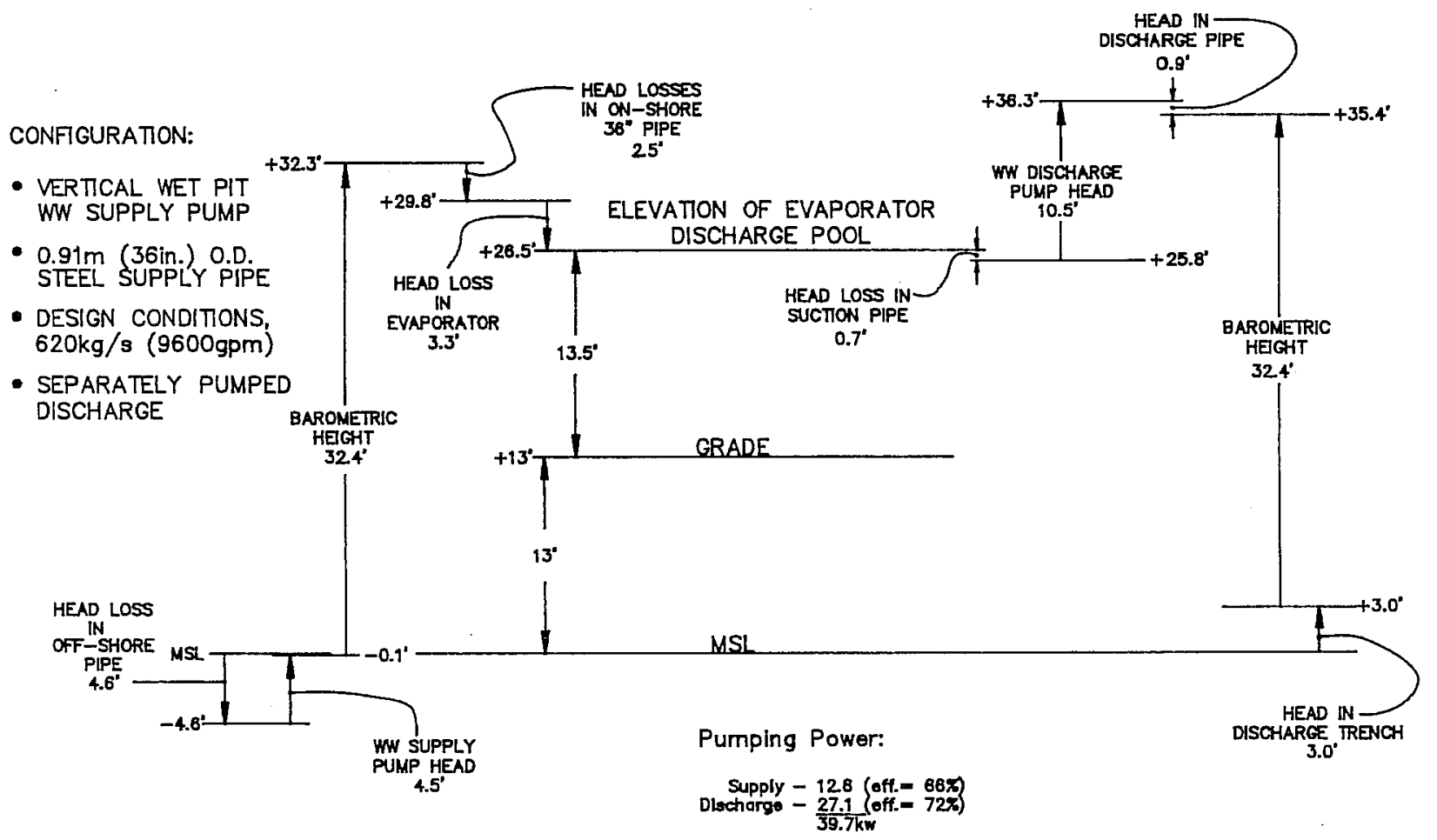

Figure 4-6. Warm-seawater system heads and elevations, draft, $9 / 22 / 89(\mathrm{~m}=\mathrm{ft} \times 0.3048)$ 
CONFIGURATION:

- VertTCAL WeT PIT CW SUPPLY PUMP

- EXISTING $0.61 \mathrm{~m}$ (24in.) SUPPLY PIPE

- DESIGN CONDITIONS $420 \mathrm{~kg} / \mathrm{s}$ (6500gpm)

- SEPARATELY PUMPED DISCHARGE

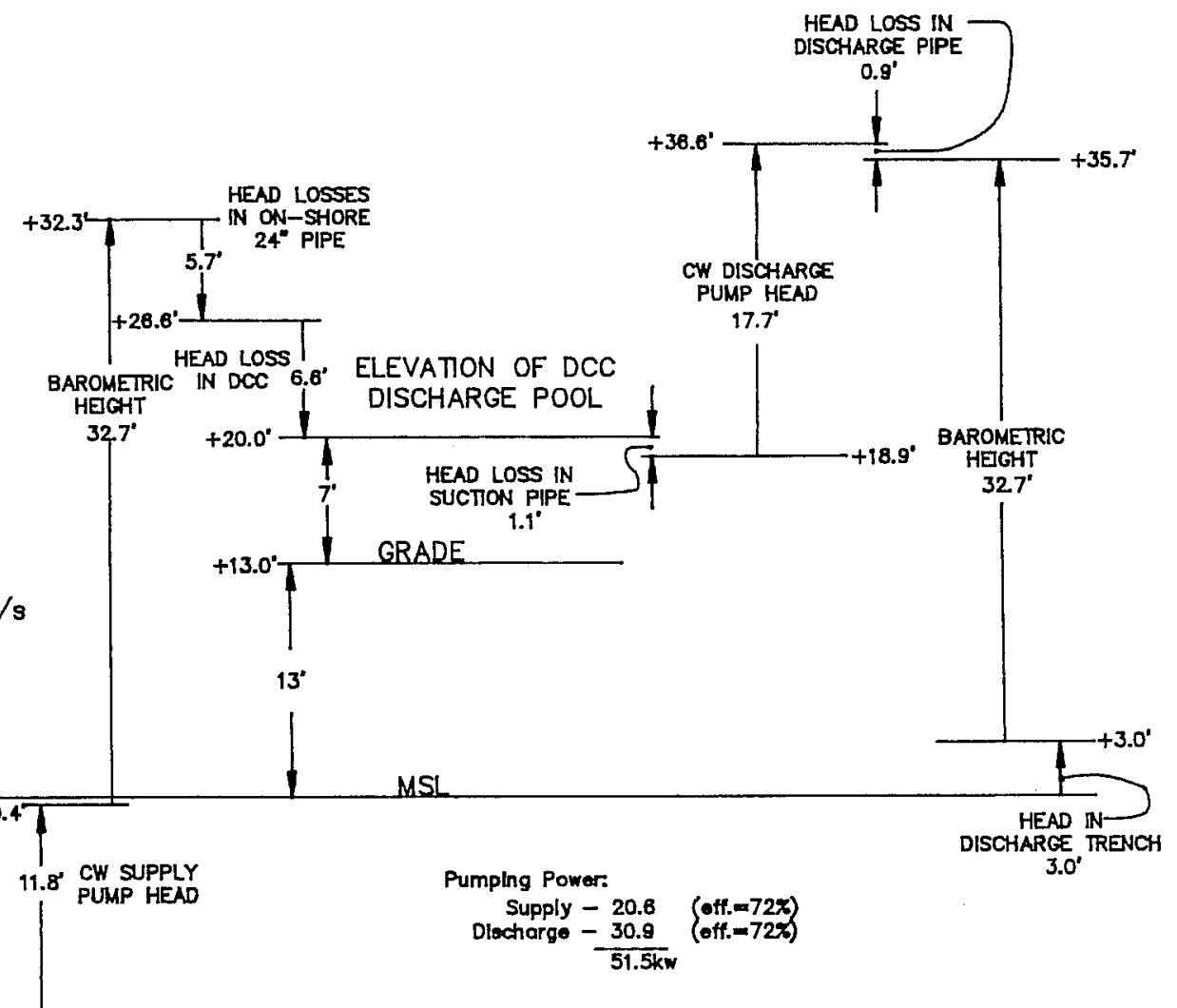

DENSITY HEAD LOSS $3.3^{3}$

Figure 4-7. Cold-seawater system heads and elevations, draft, $11 / 08 / 89(\mathrm{~m}=\mathrm{ft} \times 0.3048)$. Note that static head loss in $\mathrm{DCC}$ is higher than nominal value.

groundwater level is time consuming and expensive. Further, by staying above the groundwater level, the need for a watertight liner for the excavation is avoided and the potential is reduced for corrosion on the pumps' exterior surfaces.

The groundwater levels at the HMTEA/NPPE site are estimated to be between 2.7 and $3.6 \mathrm{~m}$ ( 9 and $11 \mathrm{ft}$ ) below grade at high tide. Additional data will soon be available from groundwater sampling wells monitored by NELH. Allowing for about $0.3 \mathrm{~m}(1 \mathrm{ft})$ head loss in the suction pipe, the direct-contact condenser's discharge pool will be as much as $5.2 \mathrm{~m}$ (17 ft) above the groundwater at high tide. This clearance should be adequate.

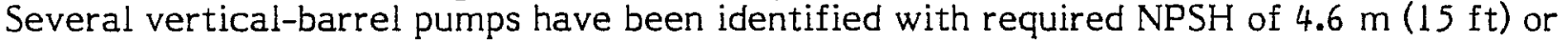
less.

\subsection{Performance}

To predict the performance of the seawater systems, conservative projections for efficiency of the components have been made on the basis of information from vendors. An efficiency of $95 \%$ was estimated for the VFDs and $92 \%$ for the electric motors. An efficiency of $82 \%$ applies to both discharge and cold-seawater supply pumps. A lower efficiency, 75\%, has been projected for the warm-seawater supply pump because it must deliver a very low head and so will operate at less than full efficiency.

Combining projections for pump, motor, and VFDs, the overall efficiency for the three high-efficiency pumps is $72 \%$. The warm-seawater supply pump will operate at $66 \%$ 
overall. Because this pump is delivering a very low head, $1.4 \mathrm{~m}(4.5 \mathrm{ft})$, the penalty for the lower efficiency is less than $1 \mathrm{~kW}$. These efficiencies and other performance parameters are summarized in Table 4- $F$. There are at least two opportunities to get better performance than is projected in the table. First, vendors indicate that efficiencies of $85 \%$ or better may be obtained from the seawater pumps. Second, if the pumps can be operated at $60 \mathrm{~Hz}$, then the VFD can be bypassed so that no decrease in efficiency occurs.

Head losses in the seawater pipes have been estimated using standard methods. Friction factors have been taken from the Moody diagram using pipe roughness of $0.015 \mathrm{~mm}$ $(0.00005 \mathrm{ft})$ for clean pipe as recommended by the manufacturer. K-factors for minor losses in fittings and valves have been taken from Crane (1986). The head loss from the pool elevation in the disposal trench above sea level has been estimated as $0.9 \mathrm{~m}(3 \mathrm{ft}$ ). The uncertainties in this pool elevation are discussed in Section 4.3.8. The head losses in the heat exchangers have been estimated by the heat exchanger team. The head losses calculated for the individual pipe runs are noted in Figures 4-6 and 4-7 and Table 4-1. Details of these calculations are found in Document No. 2.1.3.6.19. The head losses will be measured to add confidence to the design as described previously in Section 4.3.9.

The pumping power is estimated to be $39.7 \mathrm{~kW}$ for warm seawater and $51.5 \mathrm{~kW}$ for cold seawater, for a total of $91.2 \mathrm{~kW}$--almost $10 \mathrm{~kW}$ below the goal of $101 \mathrm{~kW}$ : The sensitivities to changes in head have been estimated by differentiating the expression for pumping power. Additional head will result in an additional $8.5 \mathrm{~kW} / \mathrm{m}(2.6 \mathrm{~kW} / \mathrm{ft})$ of pumping power for warm seawater, $5.6 \mathrm{~kW} / \mathrm{m}(1.7 \mathrm{~kW} / \mathrm{ft})$ for the cold seawater, and $14.1 \mathrm{~kW} / \mathrm{m}(4.3 \mathrm{~kW} / \mathrm{ft})$ for the combined flows. The uncertainty in the pumping power calculation is estimated to be $\pm 10 \%$. A $1 \%$ change in overall pumping efficiency will change the warm-seawater pumping power by $0.54 \mathrm{~kW}$, the cold-seawater pumping power by $0.71 \mathrm{~kW}$, and the combined flows by about $1.25 \mathrm{~kW}$. The seawater system's insensitivity to tides or to changes in barometric pressure was discussed in Section 4.3.2.

\subsection{Specifications}

Specifications for the HMTEA/NPPE seawater systems are summarized in Table 4-2. Supporting information is found in Tables 2-1 and 4-1 and Figures 4-6 and 4-7.

\subsection{Interfaces}

The interfaces between the seawater systems and the rest of the HMTEA/NPPE are shown in Figure 4-8. Various electrical services are required, and compressed air will be used to operate valves. Control signals will be received from the control room, and instrumentation signals will be sent to the control room. The physical interface with the HMTEA/NPPE structure itself will be at flanges outside the vacuum vessel. All plumbing inside the vessel will be designed in the heat exchanger task. The pumps and piping for the miscellaneous cooling loads will be designed in the ancillary systems task. Pumps and piping for the desalinated water condenser will be designed by the heat exchanger team. The seawater supply interface is the ocean, and the seawater discharge interface is the disposal trench.

\subsection{Schedule}

A proposed compressed schedule for the seawater systems task at the time of writing is shown in Table 4-3. This schedule provides for the seawater systems to be operational on July 1, 1991. The first phase of trench construction must be finished before flow tests can proceed. Data from the tests are needed for the final design and to determine what 
Table 4-1. NPPE Seawater Systems Performance Summary (as of 11-15-89)

Warm-Seawater System (at $620 \mathrm{~kg} / \mathrm{s}, 9600 \mathrm{gal} / \mathrm{min}$ )

Offshore pipe head loss

Onshore pipe head loss

Evaporator static loss

Evaporator dynamic loss

Discharge pipe head loss

Discharge trench head loss

Total warm-water head loss

Supply pump head

Overall pumping efficiency

Supply pump power

Discharge pump head

Overall pumping efficiency

Discharge pump power

Total warm-water pumping power

Cold-Seawater System (at $420 \mathrm{~kg} / \mathrm{s}, 6500 \mathrm{gal} / \mathrm{min}$ )

Offshore pipe head loss

Onshore pipe head loss

Cold-water density head loss

Condenser static loss

Condenser dynamic loss

Discharge pipe head loss

Discharge trench head loss

Total cold-water head loss

Cold-water supply pump head

Overall pumping efficiency

Cold-water supply pump power

Cold-water discharge pump head

Overall pumping efficiency

Cold-water discharge pump power

Total cold-water pumping power

Component Efficiencies

Variable-frequency drives

Electric motors

Warm-water supply pump

All other pumps

$\begin{array}{rl}4.6 \mathrm{ft} & 1.4 \mathrm{~m} \\ 2.5 \mathrm{ft} & 0.8 \mathrm{~m} \\ 1.65 \mathrm{ft} & 0.5 \mathrm{~m} \\ 1.65 \mathrm{ft} & 0.5 \mathrm{~m} \\ 1.6 \mathrm{ft} & 0.5 \mathrm{~m} \\ 3.0 \mathrm{ft} & 0.9 \mathrm{~m} \\ 15.0 \mathrm{ft} & 4.6 \mathrm{~m} \\ 4.5 \mathrm{ft} & 1.4 \mathrm{~m} \\ 66 \% & 66 \% \\ 16.9 \mathrm{hp} & 12.6 \mathrm{~kW} \\ 10.5 \mathrm{ft} & 3.2 \mathrm{~m} \\ 72 \% & 72 \% \\ 36.3 \mathrm{hp} & 27.1 \mathrm{~kW} \\ 53.2 \mathrm{hp} & 39.7 \mathrm{~kW} \\ & \end{array}$

$8.9 \mathrm{ft}$

5.7 in

$2.7 \mathrm{~m}$

$3.3 \mathrm{ft}$

$1.7 \mathrm{~m}$

$5.0 \mathrm{ft}$

$1.0 \mathrm{~m}$

$1.6 \mathrm{ft}$

$1.5 \mathrm{~m}$

$2.0 \mathrm{ft}$

$0.5 \mathrm{~m}$

$3.0 \mathrm{ft}$

$0.6 \mathrm{~m}$

$29.5 \mathrm{ft}$

$0.9 \mathrm{~m}$

$11.8 \mathrm{ft}$

$9.0 \mathrm{~m}$

$72 \%$

$3.6 \mathrm{~m}$

$72 \%$

$27.6 \mathrm{hp}$

$17.7 \mathrm{ft}$

$20.6 \mathrm{~kW}_{\mathrm{e}}$

$72 \%$

$5.4 \mathrm{~m}$

$72 \%$

$41.4 \mathrm{hp}$

$30.9 \mathrm{~kW}$

$69.0 \mathrm{hp}$

$51.5 \mathrm{~kW}_{\mathrm{e}}$
$95 \%$

$92 \%$

$75 \%$

$82 \%$ 
Table 4-2. Seawater Systems Specifications as of 11-15-89

\begin{tabular}{|c|c|c|}
\hline & Warm Seawater & Cold Seawater \\
\hline Flow rates & $\begin{array}{c}9600 \mathrm{gal} / \mathrm{min} \\
620 \mathrm{~kg} / \mathrm{s}\end{array}$ & $\begin{array}{c}6500 \mathrm{gal} / \mathrm{min} \\
420 \mathrm{~kg} / \mathrm{s}\end{array}$ \\
\hline Supply pipe size & $\begin{array}{l}36 \mathrm{in} . \\
0.91 \mathrm{~m}\end{array}$ & $\begin{array}{l}24 \mathrm{in} . \\
0.61 \mathrm{~m}\end{array}$ \\
\hline \multicolumn{3}{|l|}{ HMTEA/NPPE flange sizes } \\
\hline Supply & $\begin{array}{l}30 \mathrm{in} . \\
0.76 \mathrm{~m}\end{array}$ & $\begin{array}{l}24 \mathrm{in} . \\
0.61 \mathrm{~m}\end{array}$ \\
\hline Discharge & $\begin{array}{l}36 \mathrm{in} . \\
0.91 \mathrm{~m}\end{array}$ & $\begin{array}{l}30 \mathrm{in.} \\
0.76 \mathrm{~m}\end{array}$ \\
\hline Discharge pipe size & $\begin{array}{l}36 \text { in. } \\
0.91 \mathrm{~m}\end{array}$ & $\begin{array}{l}30 \mathrm{in} . \\
0.76 \mathrm{~m}\end{array}$ \\
\hline Evaporator pool elevation & $\begin{array}{l}13.5 \mathrm{ft} \mathrm{MSL} \\
\text { 4.1 m MSL }\end{array}$ & \\
\hline $\begin{array}{l}\text { Direct-contact condenser } \\
\text { pool elevation }\end{array}$ & & $\begin{array}{l}7.0 \mathrm{ft} \mathrm{MSL} \\
2.1 \mathrm{~m} \mathrm{MSL}\end{array}$ \\
\hline Disposal trench head & $\begin{array}{l}3 \mathrm{ft} \\
0.91 \mathrm{~m}\end{array}$ & $\begin{array}{l}3 \mathrm{ft} \\
0.91 \mathrm{~m}\end{array}$ \\
\hline Mixed-discharge pipe sizes & \multicolumn{2}{|c|}{$\begin{array}{l}36 \mathrm{in} .(0.91 \mathrm{~m}) \text { from discharge } \\
\text { pumps to the STF upgrade } \\
\text { discharge pipe; } 48 \text { in. }(1.2 \mathrm{~m}) \\
\text { to the disposal trench }\end{array}$} \\
\hline
\end{tabular}

additional length of disposal trench is needed. A second phase of trench construction shown on the schedule is less critical.

\subsection{Cost Estimate}

A cost estimate for completion of the HMTEA/NPPE seawater systems is given in Table 4-4. The estimate for onshore piping includes replacing existing warm-seawater supply pipe with a $0.91-\mathrm{m}$ (36-in.) pipe, extension of the existing cold-seawater supply pipe to the HMTEA/NPPE, and discharge pipes to connect the HMTEA/NPPE to the $1.2-\mathrm{m}(48-\mathrm{in}$.$) discharge pipe. The cost to replace the existing 0.61-\mathrm{m}$ (24-in.) coldseawater supply pipe is noted separately because it is only a design option at this time. The cost of the piping is based on quotes for coated steel pipe obtained during the conceptual design. The cost of installation is scaled from the construction cost estimate done by R. M. Towill for the 1.2-m (48-in.) HDPE pipe. 


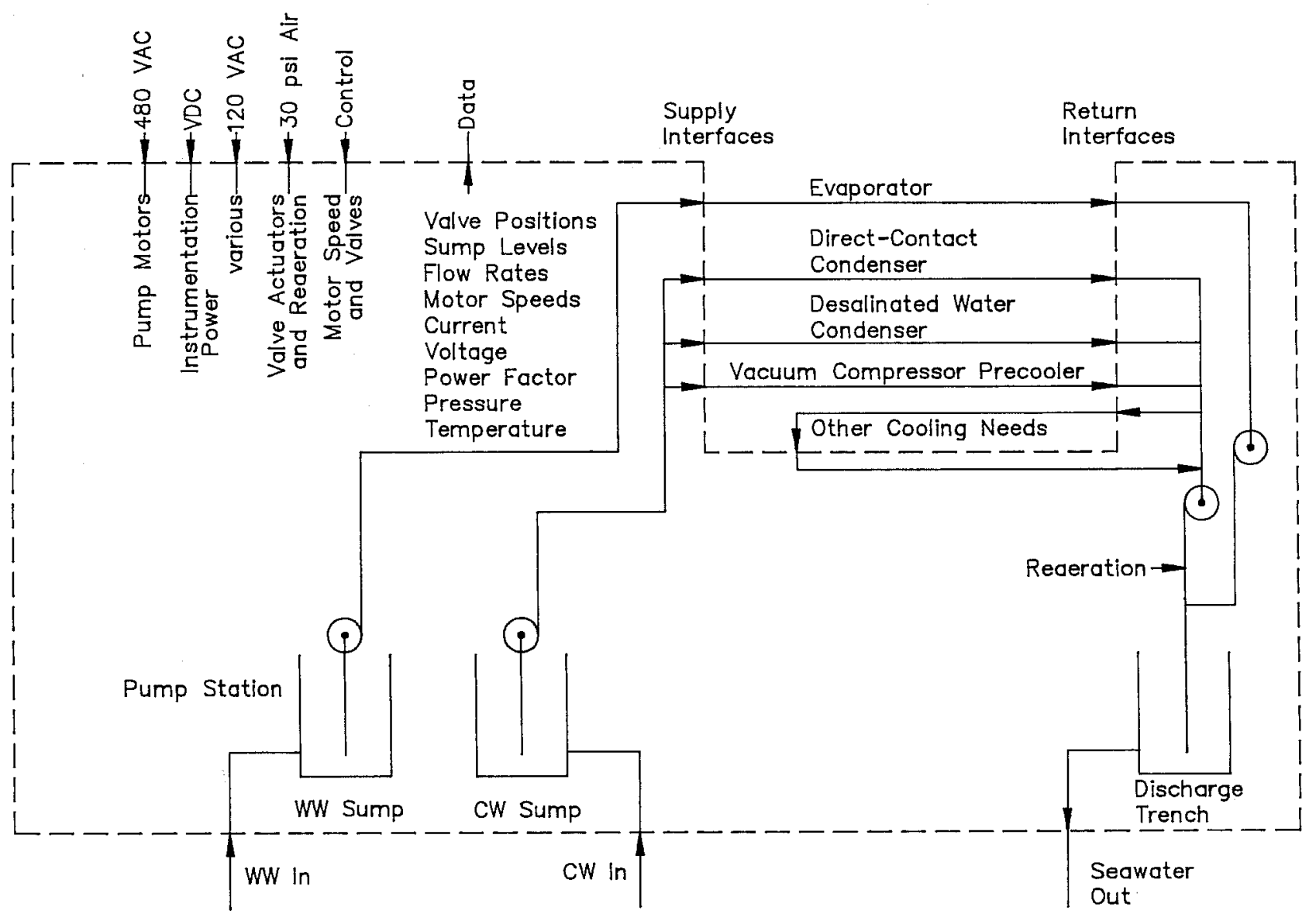

Figure 4-8. Seawater systems interface diagram, 12/6/89

Table 4-3. Seawater Systems Schedule (as of 11-15-89)

Preliminary design

Trench construction (Phase I)

STF flow tests

Final design

Trench construction (Phase II) and testing

Purchase pumps

Install onshore pipes

Install and check out pumps

Seawater systems operational
October 1, 1989 - February 28, 1990

January 1, 1989 - February 28, 1990

March 1, 1989 - March 31, 1989

March 1, 1989 - June 30, 1990

August 1, 1990 - October 31, 1990

July 1, 1990 - March 31, 1991

October 1, 1990 - June 30, 1991

April 1, 1991 - June 30, 1991

July 1,1991 
Table 4-4. Cost Estimate for the HMTEA/NPPE Seawater Systems (\$K) (as of 12-5-89)

\begin{tabular}{|c|c|c|}
\hline & Subtotals & Totals \\
\hline $\begin{array}{l}\text { STF flow tests } \\
\text { - instrumentation }\end{array}$ & & 5 \\
\hline $\begin{array}{l}\text { A\&E consulting firm } \\
\text { - drawing preparation }\end{array}$ & & 20 \\
\hline Safety consultant & & 15 \\
\hline $\begin{array}{l}\text { Warm-seawater supply pipe } \\
\text { (replace existing } 24 \text {-in. pipe) } \\
\text { - purchase } \\
\text { - install }\end{array}$ & $\begin{array}{r}90 \\
130\end{array}$ & 220 \\
\hline $\begin{array}{l}\text { Cold-seawater supply pipe } \\
\text { (extend existing pipe) } \\
\text { - purchase } \\
\text { - install }\end{array}$ & $\begin{array}{l}15 \\
15\end{array}$ & 30 \\
\hline $\begin{array}{l}\text { Discharge pipes } \\
\text { - purchase } \\
\text { install }\end{array}$ & $\begin{array}{l}35 \\
40\end{array}$ & 75 \\
\hline $\begin{array}{l}\text { Seawater pumps } \\
\text { - warm-water supply } \\
\text { - cold-water supply } \\
\text { - warm-water discharge } \\
\text { - cold-water discharge } \\
\text { - installation } \\
\text { (\$40K each) } \\
\text { - VFDs }\end{array}$ & $\begin{array}{r}25 \\
35 \\
40 \\
40 \\
160 \\
30\end{array}$ & 330 \\
\hline Instrumentation & & 10 \\
\hline Task total & & 705 \\
\hline \multicolumn{3}{|l|}{ POTENTIAL ADDITIONAL EXPENSES: } \\
\hline $\begin{array}{l}\text { Disposal trench } \\
\quad \text { - additional } 330 \mathrm{ft} \text {. }\end{array}$ & & 330 \\
\hline $\begin{array}{l}\text { Replace } 24 \text {-in. cold-water supply pipe } \\
\text { purchase } \\
\text { install }\end{array}$ & $\begin{array}{r}65 \\
100\end{array}$ & 165 \\
\hline TOTAL: & & 495 \\
\hline
\end{tabular}


Costs of seawater pumps are based on the bids recently received from vendors for castiron pumps. Installation costs for vertical wet pit supply pumps in the pump station are based on an itemized cost estimate (PICHTR Sept. 1989) that was in good agreement with a similar estimate by $\mathrm{R}$. M. Towill. Installation costs for the discharge pumps were estimated to be the same as those of the supply pumps. More detailed assessment of this cost is needed during the preliminary design.

The cost for the first phase of trench construction is not included in Table 4-4; that money was previously set aside by DOE. The cost of extending the trench is $\$ 110 \mathrm{~K}$ per $30 \mathrm{~m}$ (100 ft), as noted at the bottom of the table. The cost of the extension is projected from R. M. Towill's estimate for the cost of the first $30 \mathrm{~m}(100 \mathrm{ft})$. 


\section{CHAPTER 5.0}

\section{HEAT EXCHANGERS}

\subsection{Objective and Goals}

The objective of the heat exchanger task is to develop the heat exchanger hardware required for the HMTEA/NPPE, including subsystem interfaces to other system components, with minimal technical risk to assure net power production from the overall system.

The components originally assigned to the heat exchangers task are
- Evaporator
- Direct-contact condenser
- Surface condenser
- Containment vessels
- Predeaerators
- Mist eliminator
- Water distributor
- Steam distributor.

The components considered under this task, with the interfaces to other subsystems, are shown in Figure 5-1.

The heat exchanger components developed for the NPPE will be tested during the HMTEA phase of the project to confirm performance predictions and to minimize technical risk for the NPPE tests. Results of the HMTEA tests will also be used to validate the predictive codes developed for the heat exchanger components at a much larger scale than tested in the HMTSTA.

The goals of the task, through the conceptual design phase, were as follows:

1. Complete all tests on the direct-contact condenser at the HMTSTA using seawater, at operating conditions near those originally planned for the NPPE.

2. Analyze the results obtained for direct-contact and surface condensers.

3. Complete comparisons to existing models for the direct-contact and surface condensers and document their verification so that they may be used in the design effort.

4. Complete the conceptual design of heat exchanger components for the HMTEA/NPPE and provide the necessary documentation to proceed with the next step in the design effort.

All goals have been attained; this document summarizes the background of the design, the issues considered and their resolution, and the details of the design that the heat exchanger team developed.

\subsubsection{Composition of the Heat Exchanger Task Team and Documentation}

The heat exchanger team, formed at the inception of the HMTEA/NPPE design effort in February 1989, is composed of Federica Zangrando, SERI, task leader; Steve Masutani, 


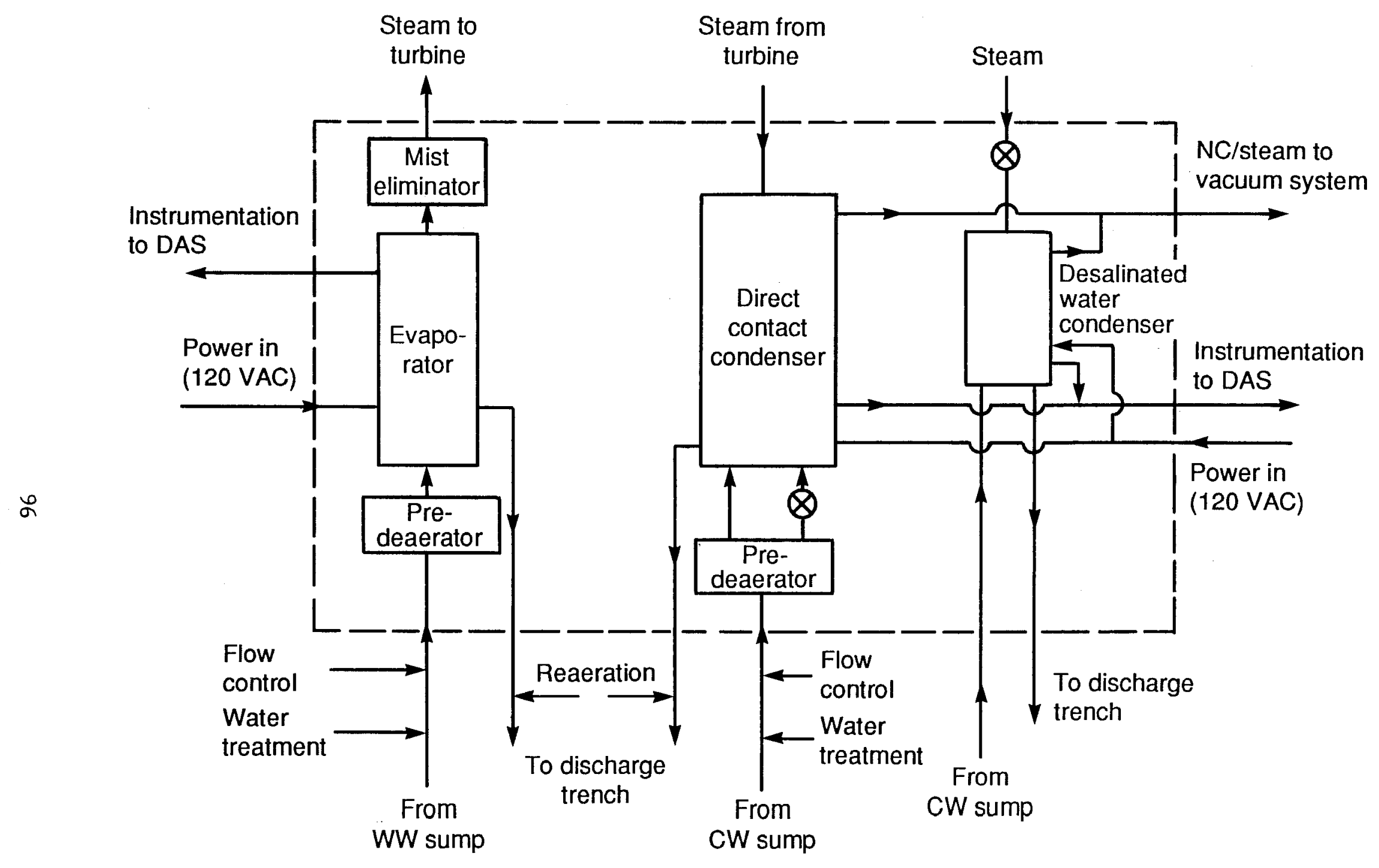

Figure 5-1. Heat exchanger interface diagram 
PICHTR; and C. B. Panchal, ANL. Additional members added to the team during the conceptual design period are Ken Fong of PICHTR and Tom Rabas of ANL.

The task members discussed issues related to the task in meetings held on March 2, 1989 , and April 13, 1989. An additional meeting was held with PICHTR personnel on October 24, 1989. Task members also communicated by telephone and in writing.

The discussions are documented in SERI memoranda (SERI reference document numbers 2.2.3.2, 2.2.3.3, 2.2.3.4, 2.2.3.5, 2.2.3.8, and 2.2.3.9) written between February 28, 1989 and October 26, 1989. Two letters from ANL and two from PICHTR supply additional details regarding options, analyses, and design calculations. These items are available from any task member. Details provided in these internal documents are referred to in the text. The cited documents are listed in the references (Chapter 8.0).

\subsection{Approach to Design}

The major considerations in the design of the HMTEA/NPPE heat exchangers are

- to keep the design structurally and functionally simple

- to provide for minimum maintenance and operational requirements

- to employ demonstrated performance characteristics of the major components.

The design must meet the operational requirements of the NPPE to ensure that net power will be produced. If additional flexibility can be built in that interferes neither with NPPE operation nor with the considerations above, then the design should provide for possible modifications so the HMTEA/NPPE apparatus will be more suitable for additional developmental tests after net power goals have been attained.

\subsubsection{Baseline and Nominal Operating Conditions}

Design conditions for the heat exchangers have been updated since the Dillingham/Lucas design of the HMTEA. The development of the NPPE design and of the operational parameters is discussed in Section 2.3 and summarized in Table 2-3. The parameters pertinent to design of the heat exchangers are summarized here.

Baseline conditions for warm- and cold-seawater flows available for the NPPE have remained $9600 \mathrm{gpm}(620 \mathrm{~kg} / \mathrm{s})$ and $6500 \mathrm{gpm}(421 \mathrm{~kg} / \mathrm{s})$, respectively. The cold-seawater temperature available for the condenser was determined by experiments at the STF to be $T_{C w}=6.1^{\circ} \mathrm{C}$, which is lower than the original baseline value of $7^{\circ} \mathrm{C}$. The nominal warmseawater temperature is $26^{\circ} \mathrm{C}$, and it ranges between $24.5^{\circ} \mathrm{C}$ and $27.5^{\circ} \mathrm{C}$ during the year.

The demonstrated performance of the heat exchangers in fresh water and seawater in the SERI OTEC laboratory and in the HMTSTA gives increased confidence in the following performance characteristics predicted for the NPPE:

Evaporator thermal effectiveness $=$

$$
\frac{T_{\text {in }}-T_{\text {out }}}{T_{\text {in }}-T_{\text {sat }, \text { sw }}\left(P_{\text {evap }}\right)}=0.90
$$


Overall direct-contact condenser thermal effectiveness $=\frac{T_{\text {out }}-T_{\text {in }}}{T_{\text {sat }, \text { sw }}\left(P_{D C C}-T_{\text {in }}\right.}=0.86$.

The thermal effectiveness is the ratio of observed temperature difference in the seawater as it flows through the heat exchanger (the numerator), with respect to the total available temperature driving potential. $T_{\text {sat }, s w}(P)=T_{s}$ is the seawater temperature in equilibrium with the steam, at the respective operating pressures in the evaporator and at the entrance to the direct-contact condenser. Based on these values and on a heat balance of the system, as described in the system performance analysis (Section 2.3), the baseline steam flow was increased from the original baseline of $3.4 \mathrm{~kg} / \mathrm{s}$ to a nominal condition of $3.5 \mathrm{~kg} / \mathrm{s}$.

Concurrently, the steam temperature at the outlet of the diffuser that exhausts gas from the turbine was decreased from $12.4^{\circ} \mathrm{C}$ to $T_{s}=11.8^{\circ} \mathrm{C}$.

These are the given nominal operating conditions at which the heat exchangers were designed.

\subsubsection{Major Geometric and Operational Considerations}

Three key decisions were made at the inception of or during the course of the conceptual design effort which affect the design approach:

1. The HMTEA/NPPE will use a dome configuration.

2. A quantity equivalent to about $10 \%$ of the steam produced under nominal operation will be used to demonstrate the capability of producing desalinated water.

3. Water production will be demonstrated after net power has been produced.

These decisions, although they do not stem from design or performance considerations for the main heat exchangers themselves, do affect the design philosophy.

The first decision was motivated primarily by turbine and structural considerations, as discussed in Section 2.4.3. This decision removed the design of the containment vessels from this task, because the entire HMTEA/NPPE system is integrated into one containment vessel, the dome. The structural requirements to provide a barrier to atmospheric pressure and to support the turbine are discussed in Chapter 3.0. Only the structural requirements to separate the evaporator chamber and the direct-contact condenser (DCC) stages remain in the domain of this task, to be coordinated with the structure team.

The second and third decisions were made during discussions at the First Working Group Meeting (1989) regarding the use of the facility. Because the first priority is to produce net power, it was agreed that production of desalinated water would be a second priority that should not directly affect that goal. A quantity equivalent to $10 \%$ of the steam used for power production is sufficient to show proof of concept for desalinated water production and to significantly advance the technology. After net power is produced, the power requirement for water production will be assessed, as will the impact of using larger quantities of steam to produce desalinated water for larger systems. 


\subsubsection{Secondary Heat Exchanger for Desalinated Water Production}

The type and location of the secondary heat exchanger to demonstrate desalinated water production was assessed early because of the potential impact on geometry, design, construction schedule, and operation of the main NPPE heat exchangers.

Task members compiled a list of options and evaluation criteria (see Table 5-1). Options included designing a new surface condenser, moving existing HMTSTA equipment to the HMTEA/NPPE location, and operating the water production system downstream of the NPPE system by using the seawater discharged from the NPPE into the existing HMTSTA equipment.

A second consideration was whether the steam for water production should be taken from the evaporator before it flowed through the turbine or downstream of the turbine. The effect on performance of the latter was not considered in detail, but it results in a potential decrease of the turbine performance, depending on how the steam would be extracted. These penalties could result from pressure loss and flow separation near the steam removal point on the diffuser, as well as from steam maldistribution to the primary condensers, because of differences in pressure drop between the surface and direct-contact condensers and the difference in condensing temperature seen by the steam in the two cases.

During the discussions, advantages and disadvantages were also identified for the location of the water-producing equipment. Locating the secondary condenser inside the dome may be more representative of larger OTEC systems and would have less visual impact. However, disadvantages include complex design of the main condenser, difficult water and steam routing, and difficult access for people installing or repairing the unit. For a unit outside the dome, the advantages are simple geometry, accessibility, easy water route, and operational flexibility. Disadvantages are the visibility of the external unit and the necessity of sealing one more pipe from the atmosphere.

Based on the discussions, the working group members recommended that a new surface condenser unit be designed specifically for the application, that it be located outside the dome, and that steam be provided to the secondary heat exchanger from the evaporator using a dedicated spout. No provisions were included to route steam from the turbine exhaust diffuser to the surface condenser. The dedicated spout allows production of desalinated water with either the nominal warm-seawater flow rate (and lower than nominal steam flow to turbine) or with nominal steam flow rate (and higher seawater flow).

This option provides for new technical development (a new design of the surface condenser) while minimizing the influence on the design of the primary heat exchangers resulting from geometry restrictions, performance, and development schedule of the secondary heat exchangers. It also eliminates any potential performance penalties on the turbine and main heat exchangers, whether or not fresh water is being produced. If difficulties arise developing or testing the new surface condenser unit, the other options in Table 5-1 could be reassessed and implemented if they necessitated only minimal changes in the design of the main heat exchangers.

Documentation of discussions and ranking of the options is provided in SERI reference documents 2.2.3.2 and 2.2.3.4, two letters from ANL dated March 10 and 24, 1989, and one letter from PICHTR dated March 17, 1989. 
Table 5-1. Options for Secondary Condensers-Desalinated Water Production

\begin{tabular}{|c|c|c|c|c|c|c|}
\hline \multirow{2}{*}{$\begin{array}{c}\text { Options } \\
\frac{\text { Equipment Options }}{\text { Source of steam }}\end{array}$} & \multicolumn{2}{|c|}{ First Option } & \multicolumn{2}{|c|}{$\begin{array}{l}\text { Fallback Option } \\
\text { Move existing equipment to NPPE } \\
\text { Rosenblad }\end{array}$} & \multicolumn{2}{|c|}{$\begin{array}{c}\text { Fallback Option } \\
\text { Existing at HMTSTA }\end{array}$} \\
\hline & NPPE evaporator & After turbine & NPPE evaporator & After turbine & HMTSTA evap. & HMTSTA evap. \\
\hline Schedule & $\begin{array}{l}\text { One year design } \\
\text { One year build }\end{array}$ & $\begin{array}{l}\text { One year design } \\
\text { One year build }\end{array}$ & When applicable & When applicable & $\mathrm{OE}$ & $\mathrm{OE}$ \\
\hline Gas removal & 385 ICFM add. & 3853 ICFM add. & No impact & $\begin{array}{l}\text { Large impact } \\
8503 \text { ICFM add. }\end{array}$ & Existing & Existing \\
\hline Quality of water & $\begin{array}{l}\text { Select } \\
\text { material }\end{array}$ & $\begin{array}{l}\text { Select } \\
\text { material }\end{array}$ & $\begin{array}{l}\text { Change } \\
\text { storage }\end{array}$ & $\begin{array}{l}\text { Change } \\
\text { storage }\end{array}$ & $\begin{array}{l}\text { Filter } \\
\text { water }\end{array}$ & $\begin{array}{l}\text { Filter } \\
\text { water }\end{array}$ \\
\hline Technical gain & $\begin{array}{l}\text { Data on } \\
\text { plate-fin }\end{array}$ & $\begin{array}{l}\text { Data on } \\
\text { plate-fin }\end{array}$ & None & None & Staged OTEC & Staged OTEC \\
\hline Aesthetics & $\begin{array}{l}\text { Visually } \\
\text { best outside } \\
\text { dome }\end{array}$ & Not visible & $\begin{array}{l}\text { Large } \\
\text { condenser } \\
\text { outside dome }\end{array}$ & $\begin{array}{l}\text { Large } \\
\text { condenser } \\
\text { outside dome }\end{array}$ & $\begin{array}{l}\text { Large equip- } \\
\text { ment } \\
\text { Large power use }\end{array}$ & $\begin{array}{l}\text { Large equip- } \\
\text { ment } \\
\text { Large power } \\
\text { use }\end{array}$ \\
\hline $\begin{array}{l}\text { Cost estimate } \\
\text { - Added equipment } \\
\text { - Pipes } \\
\text { - Pumps } \\
\text { - Installation }\end{array}$ & $\begin{array}{l}\$ 50 \mathrm{~K} \\
\text { Steam pipe } \\
2 \text { each } \\
\text { Install new SC }\end{array}$ & $\begin{array}{l}\$ 50 \mathrm{~K} \\
2 \text { each } \\
\text { Integrated }\end{array}$ & $\begin{array}{l}\text { None } \\
\text { Steam pipe } \\
2 \text { each } \\
\text { Move and mount } \\
\$ 2 \mathrm{~K}\end{array}$ & $\begin{array}{l}\text { None } \\
1 \text { each } \\
\text { Move and mount } \\
\$ 2 \mathrm{~K}\end{array}$ & $\begin{array}{l}\text { None } \\
150 \mathrm{ft} \times 2 \\
3 \text { each } \\
\text { None }\end{array}$ & $\begin{array}{l}\$ 12 \mathrm{~K} \\
150 \mathrm{ft} \times 2 \\
3 \text { each } \\
\text { Add plates to } \\
\text { closed-loop } \\
\text { heat exchanger }\end{array}$ \\
\hline
\end{tabular}

Steam flow $=0.35 \mathrm{~kg} / \mathrm{s}$. Drinking water quality required. Power used is to be accounted for in the NPPE balance. No interference with operation/construction schedule of NPPE main exchangers.

DCC = direct-contact condenser; SC = surface condenser; NPPE = net power-producing experiment; HMTSTA = Heat- and Mass-Transfer Scoping Test Apparatus; OTEC = ocean thermal energy conversion 


\subsubsection{Predeaerators}

Predeaeration of the warm and cold seawater has been proposed to reduce parasitic losses in OC-OTEC systems. The net power gain stems from a reduction of pumping power required in the vacuum exhaust system; gas released in the predeaerator would be at a higher pressure than the condenser exhaust pressure, requiring less energy for recompression up to ambient conditions. A secondary gain would be obtained by slightly increased effectiveness in the condenser because of lower noncondensable inlet gas mass fraction and no additional release of noncondensable gases in the stages of the DCC. This would result in a slightly smaller steam flow to the precooler.

The parasitic power consumed in an OC-OTEC plant for compression of all noncondensable gases released during the process has been estimated to be less than $30 \%$ of the overall parasitic losses of the plant (Block and Valenzuela 1985). Taking hydraulic and vacuum system losses into account, the gain potential for predeaeration is on the order of $10 \%$ to $15 \%$ of the parasitic losses of the plant. This amounts to between $3 \%$ and $4.5 \%$ of gross power for a large power-producing system and is clearly a second-order gain.

Analysis indicates that warm seawater predeaeration in the NPPE could contribute a maximum potential gain in net power of $12 \mathrm{~kW} \times \mathrm{F}$, linear in $\mathrm{F}$ where $\mathrm{F}$ is the fraction of the noncondensable gases in the seawater that are liberated in the predeaerator. This assumes that no hydraulic losses are incurred in the predeaeration process and that predeaeration occurs at $11.3 \mathrm{kPa}$ (the inlet pressure of the third stage of the NPPE vacuum system). Predictions for both warm- and cold-seawater predeaeration show that the maximum potential gain is $20 \mathrm{~kW} \times \mathrm{F}$, where $\mathrm{F}$ is the weighted average fraction that is released from both seawater streams.

Warm seawater predeaeration tests conducted at the HMTSTA during Phase I (Zangrando et al. 1990) at liquid loadings equivalent to the NPPE evaporator loading show $F=0.47$, giving a maximum potential gain of $12 \times 0.47=5.6 \mathrm{~kW} e$. When hydraulic losses are taken into account, the net power gain is less than $4 \mathrm{~kW} \mathrm{e}^{\cdot}$

Preliminary tests conducted recently at the HMTSTA indicate that predeaeration levels of $80 \%$ to $90 \%$ may be attainable. If these values could be obtained for higher liquid loadings than tested, and for cold seawater as well as warm seawater, then the maximum potential gain from predeaeration of both streams may be as high as $20 \times 0.85=17 \mathrm{~kW}$, minus hydraulic losses. This is about $10 \%$ of the NPPE overall parasitic losses, in agreement with the estimates made for larger plants.

There remains considerable uncertainty regarding the projected effectiveness of a predeaerator; this results in difficulties in apportioning the noncondensable gas flow to the various stages of the vacuum exhaust system. Should the capacities of the vacuum system stages be mismatched, significant power penalties (i.e., more than what could potentially be gained using a predeaerator) occur. Although a maximum potential gain of $17 \mathrm{~kW}$ from predeaeration is significant, this estimate uses an optimistic projection of the predeaerator performance. The more conservative estimate of $4 \mathrm{~kW}$ potential power saving does not warrant the complications and operational risk of including predeaeration for the NPPE.

In addition to the technical uncertainty and given the existing knowledge of predeaerator performance and operation, serious design complications would be introduced by inclusion of predeaerators, including the following: 
- Probable need for separate, large predeaeration vessels. The low liquid loadings used to obtain high release rates in the HMTSTA require predeaerators with about twice the planform area of the NPPE evaporator.

- Design of the vacuum system to accommodate varied mass flow through the stages. This could seriously affect start-up.

- Additional uncertainty in estimating how the NPPE vacuum pump should be sized. Currently, it is sized for $100 \%$ release at the condenser operating pressure.

- More cumbersome water routing to bring the seawater to and from the predeaerators.

The expected amount of increase in net power is small and does not justify the increased risk, complexity, and cost of hardware. Therefore, no predeaerators (for warm or cold seawater) will be used in the NPPE.

Calculations of net power savings for the NPPE are documented in SERI reference document 2.2.3.9.

\subsection{Conceptual Design of Heat Exchanger Components}

The main heat exchangers consist of a spout evaporator and two DCC stages. The evaporator consists of a cylindrical annulus around the two DCC stages. The DCC stages are coaxial; the first stage is cocurrent, the second countercurrent. The countercurrent stage is at the center. The layout is shown in Figure 2-6.

Because the dome configuration has been selected, the heat exchangers are contained in a single vacuum enclosure. Structural requirements for this enclosure are discussed in Chapter 3.0. The heat exchangers are designed on the basis of results obtained during the HMTSTA tests with seawater. These tests were conducted over a broad test matrix that envelops NPPE nominal operating conditions.

Detailed computer models of heat and mass transfer in DCCs using structured packing have been verified extensively using fresh-water test results obtained at SERI (Bharathan, Parsons, and Althof 1988). These models have been modified for operation with seawater and have been also verified using HMTSTA test results (Zangrando et al. 1990) These results have been used in an overall system model to predict the effect of heat exchanger performance parameters on the NPPE system.

Detailed computer models have been used at NPPE operating conditions for the conceptual design of the condenser and to predict the nominal operating parameters. They will also be used during the preliminary design to fine-tune the geometry and operating conditions of the two stages of the DCC.

The remaining components are the mist eliminator and the water distributors. The turbine diffuser will act as steam distributor to the first stage of the DCC. The small transition in flow area from the base of the diffuser to the first stage will not affect the condition of the steam; it is much smaller than that tested at the HMTSTA, where no measurable effect was observed. Neither warm-nor cold-water predeaeration is planned for the NPPE, as is discussed in Section 5.2.4.

The combined requirements of planform area for the DCC, evaporator, and dividing walls between these heat exchangers define the required inner diameter of the vacuum vessel, $6.4 \mathrm{~m}(21 \mathrm{ft})$. 


\subsubsection{Evaporator}

The proposed conceptual design of the evaporator is shown in Figures $5-2 \mathrm{a}$ and $5-2 \mathrm{~b}$. The evaporator consists of a cylindrical annulus between the dome wall and an internal partition that separates the evaporator from the DCC. Its location in relation to the DCC is selected because of the radial-inflow turbine geometry. A horizontal distribution manifold provides warm seawater to multiple vertical spouts. The warm seawater exiting the spouts flashes and produces steam that rises up toward the inlet to the turbine. The remaining seawater drains into the space around the distribution pipes and exits the drainage plenum through a discharge pipe.

The evaporator receives seawater at nominally $26^{\circ} \mathrm{C}$ and produces steam at $21.8^{\circ} \mathrm{C}$. The nominal evaporator thermal effectiveness is 0.9 ; therefore, the seawater exits at $22.5^{\circ} \mathrm{C}$. The flow rate through the evaporator is $620 \mathrm{~kg} / \mathrm{s}$. Control of warm seawater flow to and from the evaporator occurs outside the dome, as is discussed in Chapter 4.0. The external flow controls are used to adjust the surface level of the drain pool with respect to the tops of the spouts.

The main considerations in evaporator design are liquid loading, active spout height, and homogeneous distribution of water to the spouts. Liquid loading is defined as the mass of warm seawater per second distributed over a unit planform area of the evaporator. The active spout height is the distance between the top of the spout pipe and the surface of the drain pool. These parameters affect the quantity of steam produced, overall thermal effectiveness, and the homogeneity of steam distribution to the turbine.

\subsubsection{Evaporator Planform Area and Loading}

The evaporator's area requirement is governed by considerations of liquid loading and accessibility. In the HMTEA/NPPE dome, accessibility is the more stringent constraint. The evaporator is an annulus that must be wide enough that a person can comfortably enter and work in it.

Tests at the HMTSTA have consistently shown evaporator effectiveness at $\mathrm{g}^{\mathrm{r}}$ above 0.9 , for single as well as multiple spouts, at liquid loadings up to about $50 \mathrm{~kg} / \mathrm{m}^{2} \mathrm{~s}$ and active spout heights of $0.5 \mathrm{~m}$ or more (Figure 5-3). These results agree well with results obtained by French scientists (see discussion in Zangrando et al. 1990 and SERI reference documents 2.2.3.3 and 2.3.3.5). For the same steam loading and water loading the same performance is obtained, regardless of spout size or number of spouts. Both French data sets fall within the error bar of the results obtained at the HMTSTA with seawater. This confirms that high thermal performance is attainable for liquid loading around $50 \mathrm{~kg} / \mathrm{m}^{2} \mathrm{~s}$ from four different test facilities, using both fresh water and seawater.

A liquid loading of $50 \mathrm{~kg} / \mathrm{m}^{2} \mathrm{~s}$ at nominal warm water flow of $620 \mathrm{~kg} / \mathrm{s}$ requires an evaporator area of $12.4 \mathrm{~m}^{2}$. During the first working meeting it was agreed that the design would include a provision to shield each spout at a diameter near $1 \mathrm{~m}$ (the diameter of the HMTSTA is $3.5 \mathrm{ft}$ ), so that each spout could operate in an environment similar to that of the HMTSTA, if needed. Given the inner diameter of the dome wall, $6.4 \mathrm{~m}(21.0 \mathrm{ft})$, and requiring a width of about $12 \mathrm{~m}$ for the annulus, the area of the HMTEA/NPPE evaporator will be about $17.7 \mathrm{~m}^{2}$, for an overall liquid loading of $35 \mathrm{~kg} / \mathrm{m}^{2} \mathrm{~s}$. This liquid loading is quite low, and it should result in a thermal effectiveness higher than 0.9 .

The planform area of the evaporator can be adjusted around the value of $17.7 \mathrm{~m}^{2}$ if construction considerations can benefit from small changes in this area. The width of the 


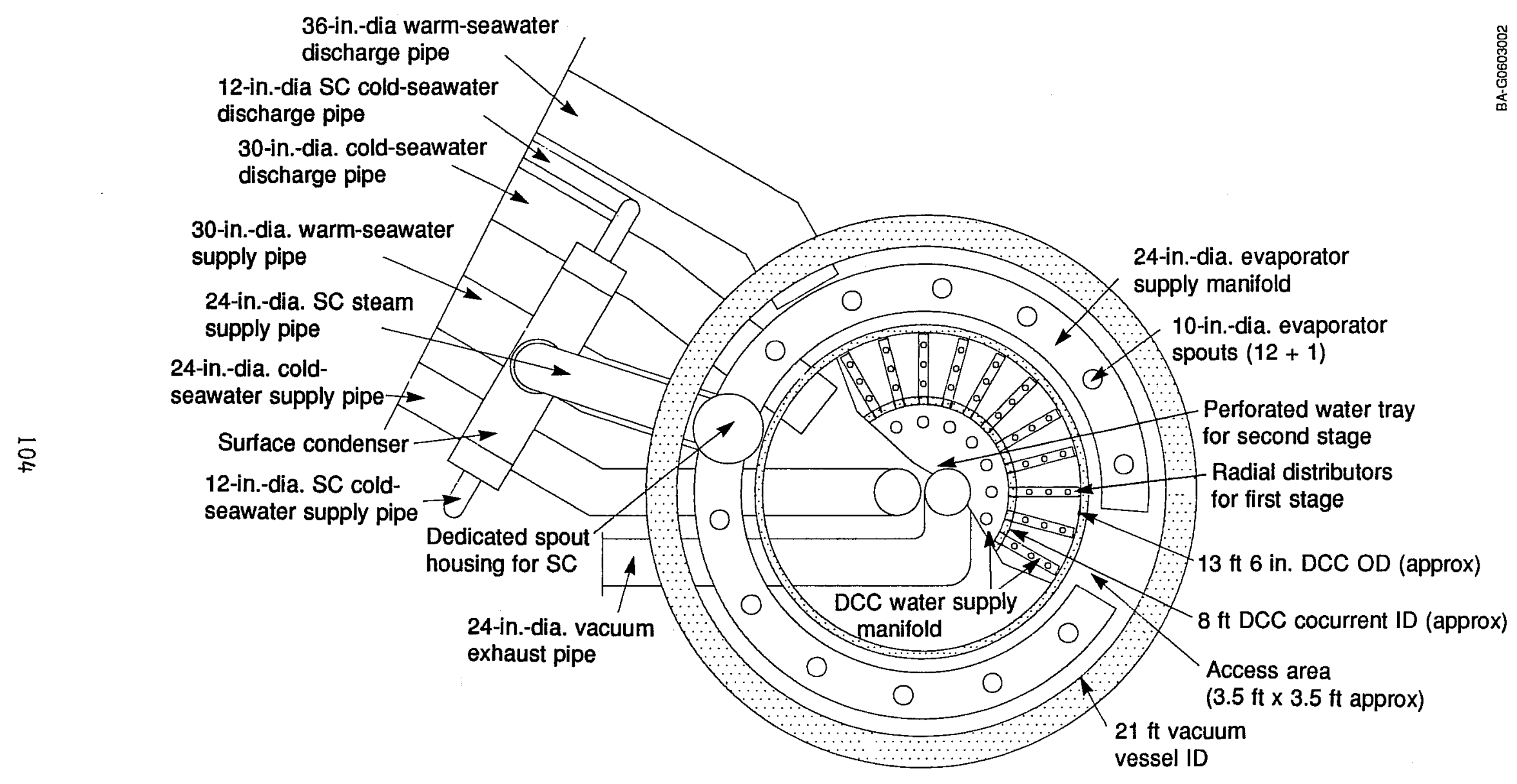

Figure 5-2a. Plan view of heat exchangers and evaporator distributor 


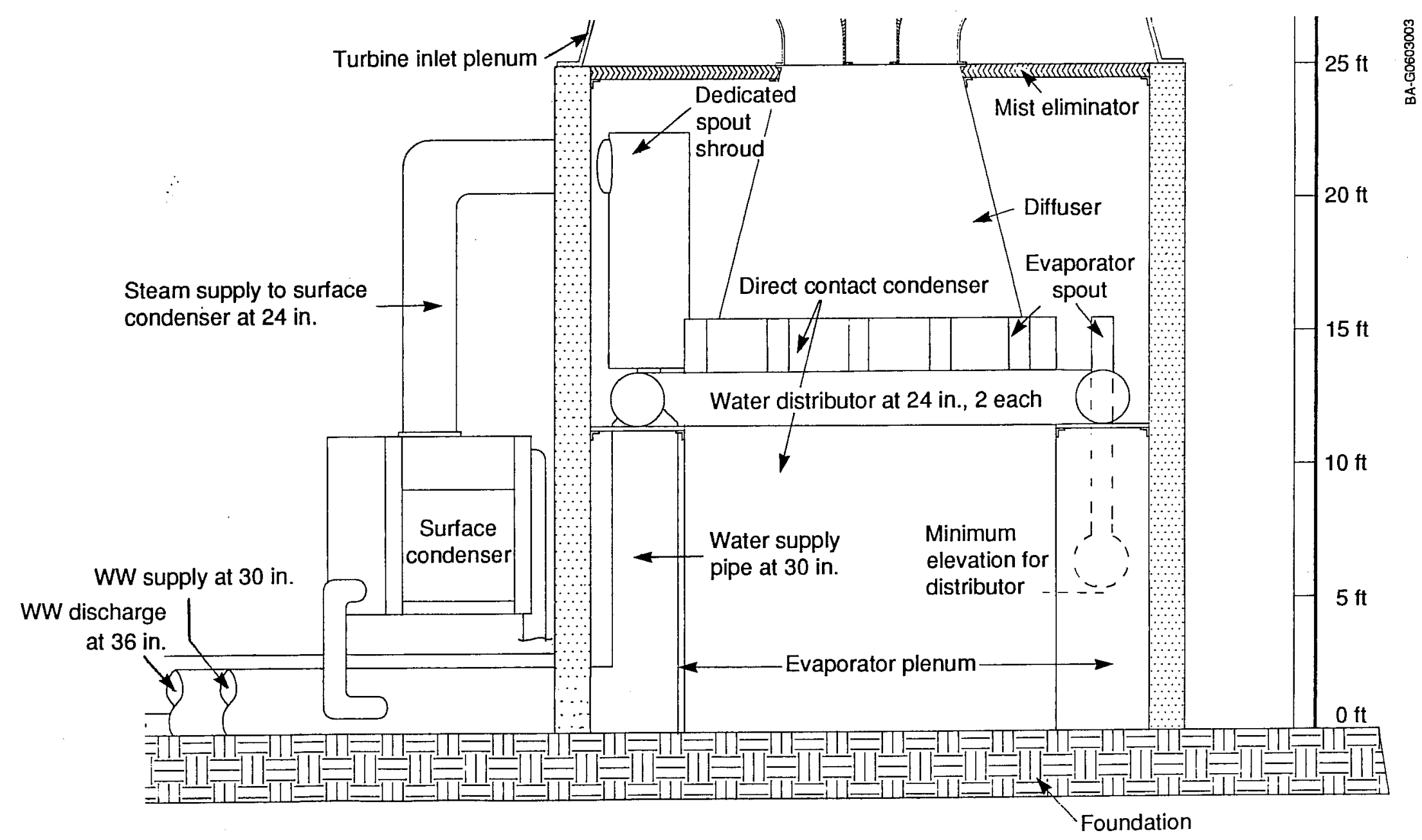

Figure 5-2b. Elevation view of evaporator 


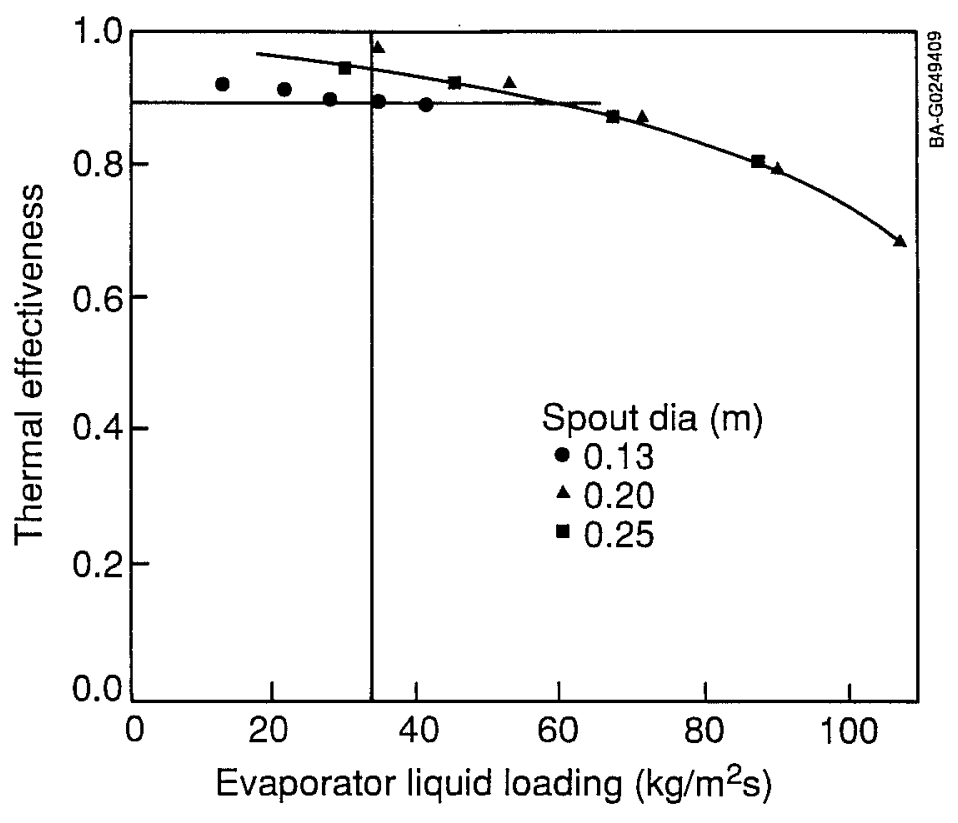

Figure 5-3. Influence of liquid loading on seawater spout evaporator annulus should not be reduced below $1 \mathrm{~m}$--the usual width of corridors--for accessibility and ease of manifold installation. The outer diameter of the evaporator chamber is fixed by the inner diameter of the dome.

\subsubsection{Evaporator Spouts}

Twelve spouts $0.24 \mathrm{~m}$ (10 in.) in diameter satisfy the geometric and loading constraints. Because spout diameter has been shown not to affect the performance of the evaporator (Zangrando et al. 1990), the largest spouts tested at the HMTSTA have been selected for the NPPE, to reduce the hydraulic losses for a given liquid loading. An additional spout dedicated to the surface condenser may be shielded from

the other spouts. The 12 main spouts are distributed symmetrically around the annulus for even distribution of steam. They are placed evenly along the distribution pipes (except along the axis of the main water supply pipe), where they provide sufficient space in the enclosure for easy access from below as well as for side access into the DCC chamber. The configuration provides for balanced flow to the two arms of the warmwater distributor, whether or not the spout dedicated to the surface condenser is active.

The minimum active spout height is $0.5 \mathrm{~m}$. The water distribution pipes may be installed farther below the spouts to provide flexibility in drain-pool level and to accommodate tidal variations, if needed. If the level of the pool's surface needs to be lowered slightly to accommodate unforeseen pump requirements, the spouts can be trimmed appropriately.

The spout dedicated to the surface condenser is mounted directly above the single vertical supply pipe. It is of the same diameter as the other spouts, but it is fitted with a water control valve to regulate the seawater flow for steam production to the surface condenser.

\subsubsection{Evaporator Water Supply and Distribution}

The water distributor requires a single penetration through the dome wall. A pipe of $0.76-\mathrm{m}$ (30-in.) nominal diameter enters horizontally and turns vertically inside the evaporator discharge plenum, as shown in Figures 5-2a and 5-2b. This pipe is connected to the center of a C-shaped horizontal distribution pipe. The nominal diameter of the two branches is $0.61 \mathrm{~m}(24 \mathrm{in.})$. The vertical spouts are mounted at regular intervals on these two branches. The water distributor is supported on a wide-mesh grate mounted on the separating wall and the dome wall. A pipe distributor rather than a supply chamber is chosen for ease of construction and drainage of the spent seawater. Velocities in the NPPE spouts are in the range tested at the HMTSTA. 
Penetrations through the dome walls should be limited to reduce the number of possible sites of leakage. The selection of pipe sizes is such that the area of the two branches is approximately equal to the area of the single vertical supply pipe, for even distribution between the two branches. The vertical pipe size is also selected to facilitate installation in the narrow evaporator plenum. Some balancing of flow rates among spouts can be obtained by trimming the heights of the spouts on site, if necessary.

Other configurations were evaluated but discarded, because analysis of the configuration presented here showed satisfactory results for hydraulic losses and flow homogeneity (see Sections 5.3.1.4 and 5.3.4). A larger pipe for the two branches of the evaporator water distributor was considered but eliminated as unnecessarily large. In addition, increasing the diameter of the branches would restrict drainage from the evaporator because of the narrowness of its chamber.

Tests at the HMTSTA (and at two French research facilities) operating with multiple spouts have shown no spout instabilities, even in the presence of two-phase flow. Hydraulic losses in the spouts have been measured in the HMTSTA for spouts of the same size as those proposed for the NPPE. The differences in design of the water distributor proposed for the NPPE, compared to that tested at the HMTSTA, are not sufficient to result in substantially different behavior, given the low hydraulic losses. Therefore, most task members consider the hydraulic design of the water distributor to be straightforward.

\subsubsection{Flow Variation in the Evaporator Distributor}

PICHTR performed a detailed analysis of the possible variation in flow among the spouts, assuming a constant loss coefficient. Results show that the maximum variation in flow between spouts is within $4 \%$, below the target value of about $5 \%$. Details of the geometry and calculations performed are provided in a PICHTR letter dated November 3, 1989.

\subsubsection{Evaporator Discharge Plenum}

The discharge plenum allows for ease of collection of the spent warm seawater and for possible separation of foam or bubbles before the water is discharged to the drainpipe. It also provides a way of easily controlling surface level of the discharge pool. The plenum fills up from empty to the nominal level in less than two minutes at nominal flow.

The nominal level, governed primarily by seawater systems constraints, is $4.1 \mathrm{~m}$ ( $13.5 \mathrm{ft}$ ) above grade. The constraints from the heat exchangers' point of view are to maintain the required active spout height; to provide sufficient room for installation of the water supply pipe, distributor, and instrumentation; and to allow for easy access to the evaporator chamber.

The spent seawater discharges through a pipe near grade that is $0.91 \mathrm{~m}(36$ in.) in diameter. Access to the evaporator chamber is provided by a hatch through the dome wall near grade level and through the grating that supports the water distributor (see Figure 5-2a), at a position opposite the dedicated spout.

The drain plenum has two walls: the dome wall on the outside, and the cylindrical wall between the evaporator and the DCC. This inner wall must support the load of the diffuser from the turbine as well as the hydrostatic load resulting from the difference between pool surface levels in the evaporator and DCC during operation. Additional strength will be provided for this inner wall because, at start-up, one of the drain 
plenums may be filled before the other. The inner wall also will have three penetrations for the DCC's supply, discharge, and vent pipes. The height of this wall is determined by the highest level the warm seawater is expected to reach. A lightweight deflecting surface placed above the top of this wall ensures that seawater splashing from the spouts will not reach the turbine diffuser walls.

Water leakage between the drain pools should be prevented, but it is not very significant as long as discharge seawater temperatures are monitored upstream of the leak. Leakage of warm seawater into the DCC stages should be prevented, because it would seriously affect the performance of the DCC.

\subsubsection{Mist Eliminator}

The geometry of the evaporator chamber in the HMTEA/NPPE dome configuration provides for very low steam velocities, about $6.2 \mathrm{~m} / \mathrm{s}$, at the flange of the turbine. The distance between the tops of the evaporator spouts and the turbine inlet is also great, about $2.7 \mathrm{~m}$ ( $9 \mathrm{ft}$ ), so that substantial gravitational settling of entrained droplets will occur. In addition, the evaporator liquid loading is low enough that only a small quantity of entrained droplets is introduced into the steam at the level of the evaporator spout. On the basis of data collected at the HMTSTA, a mist eliminator may not be necessary for the NPPE. However, its use is planned because it can be installed readily in the NPPE dome, because of its low cost, and because the dynamic losses are low. The unit may be removed after the HMTEA tests are completed if benefits can be identified.

The mist eliminator tested at the HMTSTA is a Flexi-Chevron Type VIII, made of 304 stainless steel with $25-\mathrm{mm}$ (1-in.) spacing between the chevron passages. The NPPE mist eliminator will be of the same type but made of plastic, which is lighter and less costly. Although it has $19-\mathrm{mm}$ (3/4-in.) passages, the dynamic loss for the NPPE remains small because of the low steam velocity.

The mist eliminator will be installed horizontally between the dome wall and the turbine exhaust diffuser at a height near the turbine flange. The area at this location is about $28 \mathrm{~m}^{2}$. Positioning is not critical, but it should be close to the turbine inlet and should be selected for ease of installation and support.

The pressure loss coefficient for the plastic chevron mist eliminator is 10 (Zangrando et al. 1990). For a steam velocity of $6.5 \mathrm{~m} / \mathrm{s}$ at the height of the mist eliminator, the total pressure drop is $4 \mathrm{~Pa}$.

\subsubsection{Direct-Contact Condenser (DCC)}

The proposed design of the DCC for the NPPE is shown in Figure 5-4. Two levels of the DCC plan view are shown in Figure 5-2a, along with other components. In the first stage of the condenser, the seawater and the steam flow cocurrently. This stage condenses most of the steam exhausted from the turbine. In contrast, the second stage is countercurrent, with seawater flowing down and gas flowing up. This stage condenses the remainder of the steam down to near-equilibrium conditions, and it concentrates the noncondensable gases. The second stage is smaller in diameter than the first stage. It is located at the center of the vessel so that the gas to be exhausted can be collected into a pipe easily and with small pressure drop and routed to the vacuum system. The first stage is an annulus around the second stage. Because the first stage is longer in diameter, the annulus is wide enough to have minimal wall effects. Steam from the turbine is routed to the first stage by a conical diffuser, which acts as a steam distributor. 


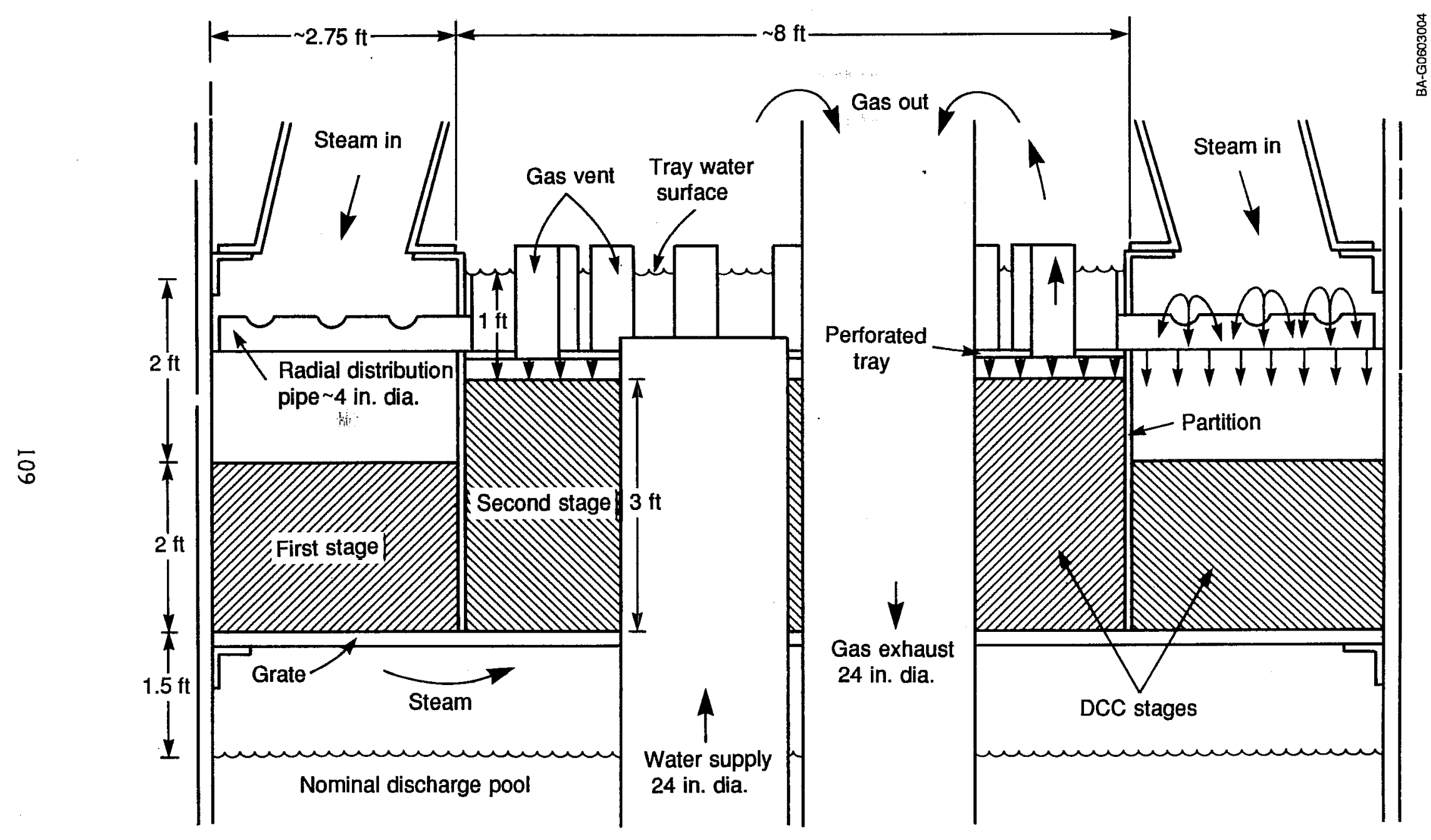

Figure 5-4. Elevation view of direct-contact condenser 
Cold seawater is distributed on top of both stages and spreads through the structured packing in each stage. The spent water is collected below the two stages in a drain plenum common to both and is discharged through a pipe at the bottom.

The area below the structured packing of the two stages, down to the surface of the drain pool, is open to allow passage of the uncondensed steam from the first to the second stage. The flow area between the stages is approximately the same as the planform area of the second stage to minimize gas pressure losses as the uncondensed steam turns around.

The design is virtually the same as that tested in the HMTSTA during the Phase II coaxial tests, except the DCC is proportionally bigger.

The DCC receives cold seawater at nominally $6.1^{\circ} \mathrm{C}$. The total flow to the condenser is $421 \mathrm{~kg} / \mathrm{s}$, split appropriately between the first and second stages. The condenser's overall nominal thermal effectiveness is 0.86; therefore the spent seawater exits at an average temperature of $11.3^{\circ} \mathrm{C}$. At nominal conditions, the condenser exhausts gas at a vent ratio of 0.9 . The vent ratio compares the ideal (smallest) volumetric flow of steam that must be exhausted with the noncondensable gases with the actual volumetric flow rate removed and is defined as

$$
V=\frac{P_{i, 1}-\Sigma \Delta P-P_{s a t}\left(T_{s o}\right)}{P_{i, 1}-P_{s a t}\left(T_{w i, 2}\right)} \cdot \frac{T_{w i}}{T_{s o}} .
$$

A vent ratio of 0.9 implies that the volume of steam exhausted is about $10 \%$ larger than the theoretical minimum.

The main considerations for design of the DCC are steam loading to the first stage, stage area ratio, liquid loadings, packing and freefall height of both stages, interstage gas flow area, and evenness of water distribution to the stages. The steam loading is the mass of steam per second that enters a unit planform area of the condenser stage. The stage area ratio compares the planform areas of the first and second stages. The liquid loading is the mass of seawater per second distributed over a unit planform area of condenser stage. The packing height is the physical height of the structured packing; the freefall height includes the heights above and below the packing at which seawater is in contact with the steam. These parameters affect overall thermal performance, approach to exhaust equilibrium conditions of the steam, and overall pressure losses.

Computer model verification of predicted NPPE performance and a preliminary evaluation of the area ratio and water loading of the DCC stages were obtained with the detailed SERI computer models for each stage (Bharathan, Parsons, and Althof 1988), which have been verified with HMTSTA data for operation with seawater (Zangrando et al. 1990).

\subsubsection{DCC Planform Area and Required Loadings}

On the basis of performance during the HMTSTA tests, the steam loading to the first stage at nominal conditions is $0.4 \mathrm{~kg} / \mathrm{m}^{2} \mathrm{~s}$. For the nominal steam flow of $3.5 \mathrm{~kg} / \mathrm{s}$, this fixes the area of the first stage at $8.75 \mathrm{~m}^{2}$. A preliminary evaluation of the tradeoffs in overall condenser performance with respect to stage area ratio and water loading of the stages indicates that the area ratio of 3 used in the HMTSTA gives good performance. Therefore, the nominal area of the second stage is $2.92 \mathrm{~m}^{2}$. At these conditions, best use of the water is attained with a liquid loading to the first stage of $38 \mathrm{~kg} / \mathrm{m}^{2} \mathrm{~s}$. Given a 
fixed quantity of cold water available, the above parameters fix the liquid loading of the second stage at $30 \mathrm{~kg} / \mathrm{m}^{2} \mathrm{~s}$. The resulting nominal seawater flow rate to the first stage is $333 \mathrm{~kg} / \mathrm{s}$, and to the second stage it is $88 \mathrm{~kg} / \mathrm{s}$.

The outer diameter of the DCC depends slightly on the sizes of pipes at the center of the structure, the area of the two stages, and the thickness of the partition that separates them. This partition must provide an impermeable barrier to steam and water flows in the two stages. It also may need to support the internal cone of the diffuser, if it is not supported by the outer flange of the diffuser or the outer wall of the DCC; guidance from the turbine diffuser's designer will be obtained during the preliminary design. This partition also may support the water tray, if the tray is not installed onto the packing itself. Depending on decisions made during the preliminary design, this partition can be very thin. Sufficient space has been included in the dome's inner diameter for the support walls.

Figure 5-5 shows the predicted overall thermal effectiveness as a function of water loading of the first stage and stage area ratio (indicated by the number used as symbol). These calculations were made for a fixed nominal water flow rate, constant steam loading of $0.4 \mathrm{~kg} / \mathrm{m}^{2} \mathrm{~s}$, and noncondensable-gas mass fraction of $0.3 \%$ at the inlet to the first stage. Results for two heights are shown in the figure: the minimum height of structured packing and the total freefall height of each stage, as discussed below. Some flexibility exists in the actual stage area ratio and related liquid loading if structural considerations indicate a benefit from some small adjustment to the stages' horizontal dimensions. The effects of such modifications need to be modeled during the preliminary design before the modifications are made.

\subsubsection{Structured Packing and Condenser Heights}

The same packing used in the HMTSTA is planned for the NPPE--a Munters ${ }_{3}$ CF-25060 structured packing with effective surface area per unit volume of $98 \mathrm{~m}^{2} / \mathrm{m}^{3}$. Packing heights are $0.61 \mathrm{~m}(2 \mathrm{ft})$ in the cocurrent stage and $0.91 \mathrm{~m}(3 \mathrm{ft})$ in the countercurrent stage. The packing used at the HMTSTA is composed of sections $0.15 \mathrm{~m}$ high that are rotated in the horizontal plane with respect to the neighboring sections to obtain a different orientation of the flow channels. If detailed modeling during the preliminary design shows that a measurable decrease in steam temperature can be obtained at the exit of the countercurrent stage by small modifications of the packing geometry, a single stack of slightly different packing may be substituted at the top of the second stage. This would not affect the stage's overall height.

The total freefall height will be virtually the same for both stages, $1.5 \mathrm{~m}(5 \mathrm{ft})$. The height of the interstage gas passage is controlled by the area selected for the countercurrent stage. At nominal conditions it is $0.47 \mathrm{~m}(1.5 \mathrm{ft})$ high.

Computer model predictions for these heights give a possible overall thermal effectiveness of 0.89 , an overall pressure drop of $83 \mathrm{~Pa}$, and a steam saturation temperature at the exit of the countercurrent stage of $6.0^{\circ} \mathrm{C}$ (the theoretical limit for operation with seawater is $5.82^{\circ} \mathrm{C}$ ). However, the original conservative nominal value of 0.86 for overall thermal effectiveness of the DCC should be used in the conceptual design calculations, because the predicted increase is within the error bars for model and seawater data.

For overall pressure drop, comparison of the model predictions to all coaxial data obtained in the HMTSTA yielded a standard deviation of $\pm 16 \mathrm{~Pa}$ for the cocurrent stage and $\pm 19 \mathrm{~Pa}$ for the countercurrent stage. These are very small pressure variations but 
they amount to a proportionally large error in pressure drop predictions (Zangrando et al. 1990). The gas pressure drop data from the HMTSTA must be sorted, during the preliminary design phase, to isolate those data near the NPPE nominal conditions for which the drift in the pressure drop sensors had been closely monitored. Until this analysis is completed, the entire uncertainty between model and data will be assigned to the model predictions. This conservative approach results in a predicted overall pressure drop of $83+35 \mathrm{~Pa}$ for the NPPE. Therefore, until a more realistic prediction is made, the nominal overall pressure drop will be taken as $<120 \mathrm{~Pa}$. The gas pressure drop affects prediction of the vent performance for the DCC. The net effect of the uncertainty in pressure drop results in a preliminary specification of steam flow to the precooler that is larger than expected during operation, for conservative design.

\subsubsection{Water Distributors for the DCC}

The water distributors should be simply designed on the basis of configurations tested at the HMTSTA. They should occupy a small area and should not interfere with the gas flow to the first stage or with the gas flow between the stages. Because most of the area above the countercurrent condenser is unused except to vent the gas mixture, it is profitable to place the water distributors in this area. Dry water pipes in the cocurrent stage should contribute only a small amount of steam blockage (on the order of $10 \%$ of the area as in the HMTSTA coaxial configuration), so that the steam pressure drop around the pipes remains small. However, if the surface of the pipes is wetted, the proportional area of the pipes can be larger. In this case, the steam condenses onto the cold seawater that emanates from the pipes and this acts as suction to keep the steam flow attached (e.g., Schlichting 1968).

The proposed configuration is to introduce the cold water with a single supply pipe of 0.61-m (24-in.) nominal diameter that penetrates through the dome wall and through the inner wall separating the evaporator from the DCC, as shown in Figures 5-2a and 5-3. In the condenser plenum, this pipe turns vertically at the center of the structure and carries all the cold seawater to just above the second stage, where it is distributed to both stages. Control of water flows is discussed in the next section.

The reason for proposing a combined distribution system from the top of the second stage is its simplicity. It takes advantage of the unused space above the second stage, the low pressure available at the top of the second stage, and the freefall height available above the first stage. In this manner, all the cold water is brought in through a single pipe, and all the water is exposed to the condenser exit pressure. The cold water will be deaerated, slightly improving the DCC's performance. 
Commercial water distributors for cooling towers and packed columns are available that use design concepts similar to those considered here. However, a custom design is preferred to provide greater flexibility, and it may cost less.

The water distribution system to the second stage is well defined and can be scaled up from the geometry successfully used in the HMTSTA. This consists of a perforated drip tray with symmetrically distributed gas standpipes. The holes have 5-mm (13/64-in.) diameters and are evenly spaced in a square pattern at a hole concentration of $6.5 \%$.

The tray is installed directly above the second stage and has the same planform area as this stage. It can be mounted roughly $15 \mathrm{~cm}(6 \mathrm{in}$.) above it. At the liquid loadings required for the NPPE second stage, the water level in a tray configured like the one tested at the HMTSTA is about $40 \mathrm{~mm}(1.5 \mathrm{in}$.$) . If greater levels are needed for the$ first-stage distributor, the number of holes in the tray can be reduced accordingly. Nominal height from above the packing to the surface in the water tray is $0.3 \mathrm{~m}(1 \mathrm{ft})$, to be apportioned as needed.

Water distribution to the first stage is not fully defined, but it will be similar to that used in the HMTSTA coaxial configuration tests, in which the vertical distribution pipes were supplied from a ring distributor installed just below the discharge pool level. This location was selected at the HMTSTA only to ease installation. In the NPPE, the recommended alternative is to build the distributor as an integral part of the second-stage water distributor. Equally spaced pipes protruding radially outward from the edge of the water tray will distribute the cold seawater over the first stage. Thirty-six pipes would sufficiently distribute all the water for the cocurrent stage, maintaining about the same ratio of coverage that was tested at the HMTSTA. The radial distribution pipes will be perforated along their length to offer a wetted surface to the incoming steam, resulting in negligible steam blockage. Details of pipe size, water level in the tray, perforation size and number, and relative elevations will be determined during the preliminary design.

Other alternatives are under consideration and a recommendation will be made during the preliminary design (see SERI reference number 2.2.3.8). One alternative is to separate the flow to the two stages before the cold seawater is introduced into the DCC. In this case, the first-stage water distributor can be installed in the space above the second stage or under the first stage, submerged in the discharge pool. Installation in the evaporator plenum has been considered but leakage is a serious concern.

\subsubsection{Control of Water Flow}

The overall flow rate to the DCC will be controlled outside the vessel on the main supply line from the pump station. Inside the vessel, therefore, it is only necessary to fine-tune the relative amounts of water to the stages. During the HMTEA tests, the design is for a variation of $-50 \%$ to $+10 \%$ of nominal flow, but tests will be conducted at only three or four overall flows. At each setting, the split between the two stages may be changed by about $\pm 10 \%$. During the NPPE tests the overall flow will vary by no more than $\pm 10 \%$. Therefore, HMTEA test requirements should not complicate the design of the seawater systems if satisfactory control of the water flows can be obtained with a single supply pipe for both stages.

Note that during the NPPE tests, it is not necessary to directly measure the flow rate to each stage. Flows can be adjusted by observing the water temperature difference across each stage. During the HMTEA tests, the flow rates can be measured with techniques other than flowmeters in the supply lines. Therefore, from an operational point of view, separate pipes are not required. 
Water flow to each stage can be measured and controlled in several ways. The simplest method in the proposed configuration is to restrict the entrance area of the first-stage distribution pipes from within the water distribution tray, and to monitor surface level of water in the distribution tray and velocity in the radial distribution pipes. This system can be calibrated before tests begin when the countercurrent stage is installed. Details of the control and measurement strategies still need to be defined. Restriction of the second-stage flow has also been considered.

In the recommended design, the flow to the two stages is controlled by the surface level of water in the tray above the second stage and by the hydraulic losses through the tray's bottom and the first-stage radial distribution pipes. These sections can be designed to obtain the desired nominal flow split out of the common tray by selecting proper sizes for the respective flow passages. Trimming of the water split requires a device that slightly modifies the hydraulic losses into one of the two distributor sections by varying the flow-path area. The technique selected must ensure that the control is applied evenly across all openings of either distributor, without significant individual hysteresis, so that even flow is maintained to all sections of each stage for a particular flow rate. Several alternatives are under consideration. Flow to the first-stage radial pipes could be controlled with commercially available pinch valves, short pipe spools with internal flexible sleeves that expand and contract pneumatically from a common air source, or with other inflatable obstructions. V-shaped open distribution channels are also under consideration. A cylindrical ring inside the water tray could be rotated or lowered to block part of the entrance for the radial pipes. Control of flow to the second stage may consist of a plate attached below the water tray, with the same hole pattern as at the base of the tray, mounted on a rotating axis and moved by a gear mechanism. The plate's position would control the available flow area. Recommendations on these alternatives will be made early in the preliminary design.

The use of activated butterfly or ball valves on each radial pipe supplying the first stage was discussed, but that appears to be beyond the level of control required.

\subsubsection{Discharge Plenum of the Direct-Contact Condenser}

The spent seawater from the two stages drains into a common plenum below them and discharges into a common pipe which penetrates two walls: the wall that separates the warm from the cold-water discharge plenums and the dome wall. The diameter of this discharge pipe is planned at $0.76 \mathrm{~m}$ (30 in.) to facilitate discharge of possibly foamy seawater, as was observed in the HMTSTA.

The nominal pool height, $2.1 \mathrm{~m}(7 \mathrm{ft})$, is governed primarily by seawater systems and structure constraints. The constraints from the heat exchangers' point of view are to maintain the required freefall height, to provide sufficient room for installation of the seawater supply pipe and exhaust steam pipe and for instrumentation, and to allow for easy access to the DCC chamber. Such access will be through a hatch in the wall that separates the evaporator from the condenser drain pools. Access to the top of the condenser may be through the central water supply pipe or perhaps through the turbine diffuser walls from the evaporator chamber. In the second case, care must be taken to ensure that steam does not leak through the diffuser openings. Appropriate selection will be made during the preliminary design.

A few supports may be required in the plenum for the wide-mesh grate that supports the packing, the partition between stages, and the water distributor. 


\subsubsection{Gas Vent Pipe}

The second pipe shown in Figures 5-2a and 5-4 near the center of the countercurrent stage removes the exhaust gases to the vacuum system. Its only requirements are that it be high enough to ensure that water cannot be spilled into the vacuum system and large enough to contribute only a very small gas pressure drop between the DCC and the vacuum system. Nominal diameter for this pipe is $0.61 \mathrm{~m}$ (24 in.).

\subsubsection{Hydraulic Losses of Main Heat Exchangers}

The upper estimates for the overall hydraulic losses to be incurred in the evaporator and DCC described above are as follows:

\begin{tabular}{lccc}
\hline & Static & Dynamic & Total \\
\hline $\begin{array}{l}\text { Evaporator } \\
\begin{array}{l}\text { Direct-Contact } \\
\text { Condenser }\end{array}\end{array}$ & $0.5 \mathrm{~m}$ & $0.35-0.5 \mathrm{~m}$ & $1.0 \mathrm{~m}$ \\
\hline
\end{tabular}

These estimates are conservative, and values have been rounded off. The amount of these hydraulic losses attributable to discharge pipes is very small, about $0.05 \mathrm{~m}$ for each of the discharge pipes. This is smaller than the range of uncertainty in the dynamic losses on the supply sides. However, the overall losses in the heat exchangers are so small compared to the overall frictional losses in the other piping that pump selection will not be affected by this uncertainty.

The static losses take into account the height of the water column from the discharge point down to the surface of the drain pool. The estimates assume that four separate pipes are available outside the dome, two for supply and two for discharge of the warm and cold seawater. The estimates incorporate only the losses from just outside the dome through the heat exchangers. The last column assumes worst-case conditions in the pipes, namely some regions of two-phase flow at the lower pressures, as was observed in the HMTSTA.

The range in evaporator dynamic losses depends on the specific location and size of reducers, the fraction of two-phase flow to be encountered in the distribution pipe and spouts, and whether or not the spout base is flared. Results at the HMTSTA have shown hydraulic loss coefficients for the free-standing vertical spout of about 1.9 with bellmouth entrance and about 3 without. It is believed that two-phase flow effects occur only in the upper region of the spout. Therefore, the frictional loss in a large part of the vertical spout may result only from single-flow pipe friction. The HMTSTA spout frictional losses were taken into account in the estimates.

Dynamic losses for the evaporator were calculated independently by PICHTR to be $0.4 \mathrm{~m}$ for the supply side and $0.04 \mathrm{~m}$ for the discharge side, for a total of $0.44 \mathrm{~m}$, as compared to SERI's worst-case estimate of $0.5 \mathrm{~m}$. These are in excellent agreement. The minimum losses for the DCC distributor, assuming single-phase flow, were calculated by PICHTR to be $0.14 \mathrm{~m}$ for supply and $0.04 \mathrm{~m}$ for discharge, for a total of $0.18 \mathrm{~m}$, compared to SERI's calculated minimum of $0.35 \mathrm{~m}$. For two-phase flow conditions near the point of discharge of the cold water, PICHTR estimates dynamic losses of $0.19 \mathrm{~m}$ plus 
$0.04 \mathrm{~m}$ for a total of $0.23 \mathrm{~m}$. The SERI estimate is $0.39 \mathrm{~m}$. These discrepancies appear to stem primarily from slightly different assumptions. Because some details are still to be worked out in the piping to the DCC, a conservative upper limit of $0.5 \mathrm{~m}$ is maintained for the conceptual design. Documentation of the detailed calculations can be found in a PICHTR letter dated November 3, 1989.

\subsubsection{Surface Condenser for Desalinated Water Production}

The proposed secondary condenser for production of desalinated water is an extrudedchannel surface condenser with finned surface on the steam side. The unit is made of brazed aluminum and contains three water passes with cross-flow of steam. The number of fins per unit length is different for each pass, as shown in Figure 5-6. Figure 5-7 shows the unit's dimensions and the required piping connections. This unit is designed on the basis of computer models that have been verified at the HMTSTA for a dimple-plate configuration. The design of this unit is beyond the conceptual stage, and all details are provided in a separate report (Panchal and Genens 1989).

Cold seawater is supplied from a tee in the main supply line to the DCC. Spent seawater is discharged into the main drain pipes. The pipe size for seawater supply and discharge is nominally $0.3 \mathrm{~m}$ (12 in.); the condensate is sent to storage tanks through a $0.1-\mathrm{m}$ (4-in.) pipe. Separate pumps are used in the loops for seawater and desalinated water.

Steam is supplied from the dedicated spout. This spout is similar to the other spouts, but there is a water control valve at the base of the spout and flexible, light shielding around it to isolate it from the evaporator enclosure. This shielding is connected to a $0.61-\mathrm{m}$ (24-in.) penetration in the vessel wall above the evaporator and provides steam to the surface condenser through a valve such as the butterfly valve in the HMTSTA. The uncondensed steam and noncondensable gases are vented to the precooler of the vacuum system through a $0.2-\mathrm{m}$ (8-in.) pipe with a control valve. Capability to control the steam mass flow rate and the steam pressure separately increases the testing range for the unit. As in the HMTSTA, steam to the surface condenser can be controlled by adjusting warm-water flow and pressure drop through the steam valve. If flexible shielding were removed for some tests, evaporator chamber steam would flow to the surface condenser. However, independent control of steam flow rate and pressure would not be possible in this operational mode.

At nominal conditions, the surface condenser receives $0.35 \mathrm{~kg} / \mathrm{s}$ of steam and $10 \%$ of the cold-seawater flow. The unit is predicted to condense $99 \%$ of the steam at these conditions.

\subsection{Design Performance and Uncertainties}

Design performance has been discussed in the text and is summarized in Table 5-2 for the main heat exchangers. The values listed are the conservative estimates for nominal conditions. The values in parentheses are the potential gains that are expected for the NPPE design.

The largest uncertainty is in the expected pressure drop of the DCC. This value is small and difficult to measure. Its effect is seen in the vent ratio and translates into the quantity of steam that is routed to the precooler. Because the highest pressure drop is assumed for conservative design of the vacuum system, a larger quantity of steam is 


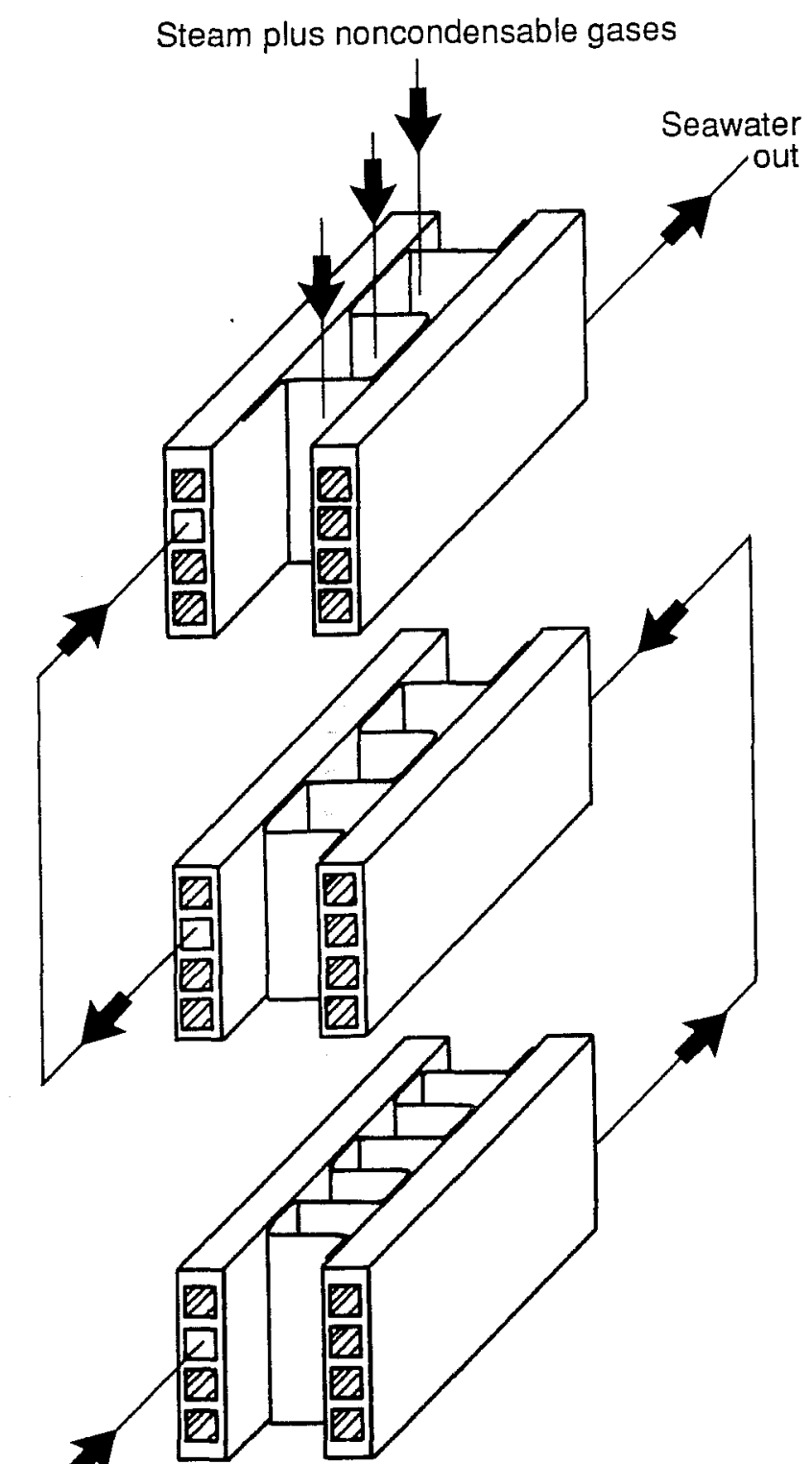

Seawater in

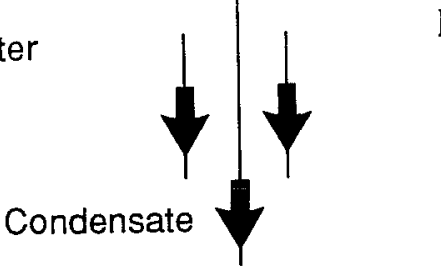

Noncondensable gases

assumed to be exhausted from the condenser at a pressure lower than that actually expected. This penalizes the vacuum system because it requires more work to be done in compressing the gases, resulting in predicted parasitics that are a few percent higher than expected. If the overall pressure drop in the condenser is lower than has been assumed for the nominal design, this penalty may be recovered. When the vacuum system is better defined, this issue will be considered in detail.

\subsection{Design Specifications}

Specifications for the heat exchangers are summarized in Table 5-3. Values of parameters derived from the specifications are added for reference.

\subsection{Interfaces}

The interfaces between the heat exchangers and the rest of the NPPE are shown in Figure 5-1. All penetrations through the vacuum vessel walls and sealing of these penetrations are the responsibility of the structures task. Plumbing on either side of the vacuum vessel will be designed in the respective tasks. The seawater systems task will provide all plumbing for the main heat exchangers up to the flanges on the vacuum vessel walls. Plumbing inside the structure, to distribute and collect the warm and cold seawater and to remove the uncondensed steam and noncondensable gases, will be designed under the heat exchangers task. Steam interfaces inside the vacuum vessel are at the turbine inlet plenum and at the steam diffuser outlet. Seawater and gas

Figure 5-6. Elemental section of test unit

BA-G0603005 plumbing to and from the desalinatedwater condenser will be designed in the heat exchangers task. Control signals will be received from the control room and instrumentation signals will be sent to the control room. Electrical service is necessary inside the vessel mainly for lighting. Compressed air or electrical power will be needed inside the vessel to regulate the water split between condenser stages. 


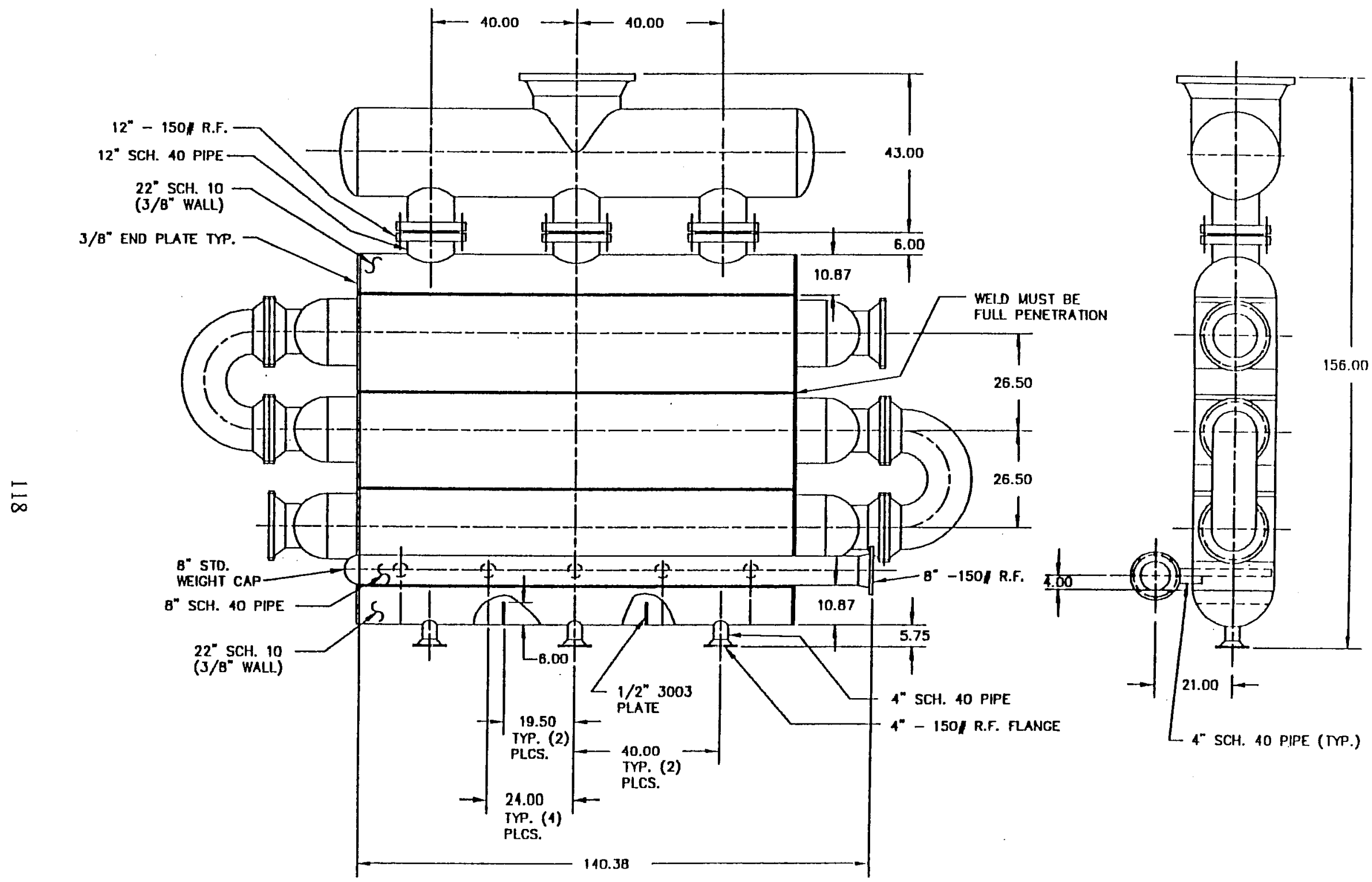

Figure 5-7. Overall view of condenser test unit 


\subsection{Schedule}

The schedule for the heat exchanger task at the time of writing, shown in Table 5-4, is compatible with the summary schedule shown in Figure 1-3. Constraints on the schedule for the heat exchangers stem primarily from the schedule for the vacuum vessel structure, which must be built before heat exchanger components can be installed.

Table 5-2. Performance Predictions at Nominal Conditions (Summary)

\begin{tabular}{ll}
\hline Evaporator & \\
Thermal effectiveness & $0.9(+0.03)$ \\
Mass of steam produced & $3.5 \mathrm{~kg} / \mathrm{s}$ \\
Noncondensable fraction & $0.3 \%$ \\
Seawater-temperature drop & $3.5^{\circ} \mathrm{C}$ \\
Hydraulic losses & \\
- Static & $0.5 \mathrm{~m}$ \\
- Dynamic & $0.5 \mathrm{~m}(-0.15 \mathrm{~m})$ \\
Steam temperature to turbine & $21.8^{\circ} \mathrm{C}$ \\
Mist eliminator pressure drop & $<5 \mathrm{~Pa}$ \\
& \\
Direct-Contact Condenser & \\
Thermal effectiveness & $0.86(+0.03)$ \\
Vent ratio & 0.8 \\
Percent steam uncondensed & $0.8 \%(-0.3 \%)$ \\
Seawater-temperature rise & $5.2^{\circ} \mathrm{C}$ \\
Pressure drop & $120 \mathrm{~Pa}(-37 \mathrm{~Pa})$ \\
Hydraulic losses & \\
- Static & $1.7 \mathrm{~m}(-0.15 \mathrm{~m})$ \\
- Dynamic & $0.5 \mathrm{~m}(-0.15 \mathrm{~m})$ \\
\hline
\end{tabular}

No delays are envisioned because of heat exchanger components, because all supplies and equipment are currently available. The same is true for the water distributors, structured packing sections, and mist eliminator.

\subsection{Cost Estimates}

The estimated cost of specific equipment for the heat exchanger task is summarized in Table 5-5. Costs include purchase of material and labor to build and assemble the components, including piping from the walls of the dome. Costs do not include labor to install the heat exchanger components, because it is assumed that a team will be on site to install the structure.

Developments made during the past decade in direct-contact heat exchangers have reduced not only their performance uncertainty but their cost, especially in the dome configuration. Notice that the cost of the heat exchanger equipment amounts to only $3 \%$ of the total equipment cost estimate for the HMTEA/NPPE. 


\section{Evaporator}

Type

Seawater flow

Inlet-seawater temperature

Steam generation rate

Steam temperature

Liquid loading

Thermal effectiveness

Active spout height

Number of spouts

Diameter of spouts

Spacing between spouts

Chamber width

\section{Related Parameters}

Evaporator planform area

Inside diameter

Outside diameter

Steam generation velocity

Spout-seawater velocity

Outlet-seawater temperature

Supply pipe diameter

Water distribution pipe diameter

Discharge pipe diameter
Vertical spout

$620 \mathrm{~kg} / \mathrm{s}$

$26^{\circ} \mathrm{C}$

$3.5 \mathrm{~kg} / \mathrm{s}$

$21.8^{\circ} \mathrm{C}$

$35 \mathrm{~kg} / \mathrm{m}^{2} \mathrm{~s}$

0.90

$0.5 \mathrm{~m}$

$(12+1)$

$0.24 \mathrm{~m}$ (10 in.)

$\geq 1 \mathrm{~m}$

$\geq 1 \mathrm{~m}$

$17.7 \mathrm{~m}^{2}$

$4.27 \mathrm{~m}(14 \mathrm{ft})$

$6.40 \mathrm{~m}(21 \mathrm{ft})$

$10 \mathrm{~m} / \mathrm{s}$

$1 \mathrm{~m} / \mathrm{s}$

$22.5^{\circ} \mathrm{C}$

$0.76 \mathrm{~m}$ (30 in.)

$0.61 \mathrm{~m}(24 \mathrm{in.})$

$0.91 \mathrm{~m}$ (36 in.)

Munters chevron

Plastic

$19 \mathrm{~mm}(3 / 4$ in.)

$78 \%$

$28 \mathrm{~m}^{2}$

$\geq 2 \mathrm{~m}$

10

$6.2 \mathrm{~m} / \mathrm{s}$

$90 \%$ removal for droplets of diameter greater than $40 \mu \mathrm{m}$

Column, structured packing

2

Munters CF-25060

$421 \mathrm{~kg} / \mathrm{s}$

$6.1^{\circ} \mathrm{C}$

$3.5 \mathrm{~kg} / \mathrm{s}$

$11.8^{\circ} \mathrm{C}$

$0.3 \%$

0.86

$0.4 \mathrm{~kg} / \mathrm{m}^{2} \mathrm{~s}$

$38 \mathrm{~kg} / \mathrm{m}^{2} \mathrm{~s}$

3

$0.61 \mathrm{~m}(2 \mathrm{ft})$ 
Table 5-3. Heat Exchangers: Specifications and Related Parameters (Concluded)

Direct-Contact Condenser (Concluded)

Packing height of second stage

Interstage steam passage height

$0.91 \mathrm{~m}(3 \mathrm{ft})$

$0.47 \mathrm{~m}(1.5 \mathrm{ft})$

Related Parameters

Area of first stage

Area of second stage

Liquid loading of second stage

Overall pressure drop

Steam temperature at outlet

Flow rate to first stage

Flow rate to second stage

Maximum height for water distribution tray

Supply pipe diameter

Discharge pipe diameter

Outside diameter of turbine diffuser exit flange

Inside diameter of turbine diffuser exit flange

$8.75 \mathrm{~m}^{2}$
$2.92 \mathrm{~m}^{2}$
$30 \mathrm{~kg} / \mathrm{m}^{2} \mathrm{~s}$
$<120 \mathrm{~Pa}$
$6^{\circ} \mathrm{C}$
$333 \mathrm{~kg} / \mathrm{s}$
$88 \mathrm{~kg} / \mathrm{s}$
$0.30 \mathrm{~m}(1 \mathrm{ft})$
$0.61 \mathrm{~m}(24 \mathrm{in}$.
$0.76 \mathrm{~m}(30 \mathrm{in}$.
$4.11 \mathrm{~m}(13.5 \mathrm{ft})$
$2.44 \mathrm{~m}(8 \mathrm{ft})$

Surface Condenser for Desalinated Water Production

Overall Configuration

Condenser length

Width

Effective height (per section)

Heat-transfer area (per section)

Steam-side flow area

Water-side flow area

Number of water channels

Number of steam channels

$3.05 \mathrm{~m}(10 \mathrm{ft})$

$0.57 \mathrm{~m}(1.87 \mathrm{ft})$

$0.43 \mathrm{~m}(1.4 \mathrm{ft})$

$31.1 \mathrm{~m}\left(334 \mathrm{ft}^{2}\right)$

$0.95 \mathrm{~m}\left(10.3 \mathrm{ft}^{2}\right)$

$0.046 \mathrm{~m}^{2}\left(0.5 \mathrm{ft}^{2}\right)$

12

13

\section{Steam Channels}

Channel spacing

Fin thickness

Fin density section

\section{Water Channels}

Extrusion width

Number of flow channels

Channel size

a

$462.3 \mathrm{~mm}$ (18.2 in.)

b

28

Radius of curvature

$12.7 \mathrm{~mm}$ (0.5 in.)

$12.7 \mathrm{~mm}(0.5$ in.)

$4 \mathrm{~mm}$ (0.16 in.)

Wall thickness

$2.54 \mathrm{~mm}(0.1$ in.)

Equivalent diameter

$13.3 \mathrm{~mm}(0.523 \mathrm{in.})$

Correct heights and nominal diameters of pipes are given in $\mathrm{ft} / \mathrm{in}$. 
Table 5-4. Projected Schedule for Heat Exchangers

Complete concept of direct-contact condenser water distributor and flow-split control

February 1990

Complete design of surface condenser

March 1990

Complete preliminary design of heat exchanger

June 1990

components

Complete final design of heat exchanger

components

September 1990

Fabricate water distributors, packing sections, and internal partitions

March 1991

Install supports in dome

April 1991

Complete installation inside the dome

(depends on availability of structure)

May 1991

Install instrumentation

June 1991

Install turbine diffuser and mist eliminator

June 1991

Install surface condenser

July 1991

Initiate HMTEA tests

July 1991 
Table 5-5. Breakdown of Heat Exchanger Costs

\begin{tabular}{|c|c|c|}
\hline & & Subtotal \\
\hline \multicolumn{3}{|l|}{ Evaporator/Mist Eliminator } \\
\hline Water distributor & $\$ 25 \mathrm{~K}$ & \\
\hline Mist eliminator & $\$ 25 \mathrm{~K}$ & \\
\hline \multirow[t]{2}{*}{ Supports } & $\$ 10 \mathrm{~K}$ & \\
\hline & & $\$ 60 \mathrm{~K}$ \\
\hline \multicolumn{3}{|l|}{ Direct-Contact Condenser } \\
\hline Water distributor and controls & $\$ 45 \mathrm{~K}$ & \\
\hline Packing, fabricated & $\$ 30 \mathrm{~K}$ & \\
\hline Internal supports and partitions & $\$ 30 \mathrm{~K}$ & $\$ 105 \mathrm{~K}$ \\
\hline Shipping & & $\$ 10 K$ \\
\hline Surface Condenser & & $\$ 55 \mathrm{~K}$ \\
\hline \multicolumn{3}{|l|}{ Drawings/Installation } \\
\hline Drawings & $\$ 20 \mathrm{~K}$ & \\
\hline Installation supplies & $\$ 10 \mathrm{~K}$ & $\$ 30 \mathrm{~K}$ \\
\hline \multirow[t]{2}{*}{ Test Instrumentation } & & $\$ 40 \mathrm{~K}$ \\
\hline & Total & $\$ 300 \mathrm{~K}$ \\
\hline
\end{tabular}




\section{CHAPTER 6.0}

\section{ANCILLARY SYSTEMS}

\subsection{Objective}

Responsibilities of the ancillary systems task are the vacuum compression system (VCS), the electrical system, the instrumentation and control system (ICS), and other miscellaneous support systems. The objective of this task is to develop these systems for the HMTEA/NPPE at the STF.

\subsection{Goal}

The task goal is to develop ancillary systems for the NPPE that consume no more than $44 \mathrm{~kW}$ of power at the NPPE design point.

The key ancillary component affecting this goal is the VCS. A target of $20-\mathrm{kW}$ power consumption for the VCS was established early in the program based on performance predictions of an untested, large-scale plant. Later assessments of the overall NPPE power budget indicated that a VCS power consumption target of $40 \mathrm{~kW}$ would still allow the experiment's overall net power goal of $40 \mathrm{~kW}$ to be met. The ancillary systems task team has invested the majority of its conceptual design effort toward developing of a high-efficiency VCS to meet this $40-\mathrm{kW}$ e target.

Other components of the ancillary system do not have unusual requirements. Standard engineering practices are being used in designing the electrical system, the ICS, and the miscellaneous support systems. A total power consumption target of $4 \mathrm{~kW}$ e was set for these last three areas.

The members of the task team at the time of writing are B. Parsons of SERI, R. Davis of PICHTR, and T. Rabas of ANL.

\subsection{Vacuum Compression System}

The VCS must continuously remove noncondensable gases and residual steam from the condenser to maintain system operation. Noncondensable gases are present in the incoming warm and cold seawater. At subatmospheric heat exchanger pressures, the dissolved gases are supersaturated, and between $80 \%$ and $100 \%$ of the noncondensable gases come out of solution. In addition, a small amount of air will leak into the vacuum enclosure from the atmosphere.

Two methods of gas compression were proposed for OC-OTEC systems. The first is a multiple-stage mechanical compression train. The second uses discharge seawater to hydraulically compress after an initial mechanical compression stage. The hydraulic compression option has potential for reducing the overall VCS power consumption but was eliminated from consideration for the HMTEA/NPPE design because of the research and development effort required and the preference for adapting existing and proven hardware into the VCS design.

In the multiple-stage mechanical compression train, interstage gas coolers substantially reduce the power consumption. Cooling the gas before entry into the next compression stage minimizes the work required to compress a given mass of gas and is necessary so the high-temperature limits of the compressor components are not exceeded. The intercoolers can also be used to condense a large portion of the residual steam, therefore 
reducing the gas mass flow rate that must be processed by the downstream compression stages. The VCS also includes compressor motors and a selfcontained lubrication system. The general staged layout is illustrated in Figure 6-1.

\subsubsection{Design Approach}

A simple model was developed to calculate power consumption of a staged compression system using efficient intercoolers. Initial efforts included exercising the model to define key performance parameters. The results are summarized in Table 6-1.

A major effort by SERI and PICHTR personnel was mounted to define commercial compressor efficiencies, sources of inefficiency, and possible improvements.

Using existing equipment was found to be impractical, but the potential for improvement using existing technology and integrating low-loss components was identified (see Section 6.3.3 for details).

The conceptual design effort culminated in the development of a statement of work (SOW) for preliminary design of a VCS. The SOW document defines operating conditions for a VCS using a directcontact precooler. The SOW was issued by PICHTR in September to five compressor designers and manufacturers, and the preliminary design contract was forwarded to Barber-Nichols Engineering in early November 1989. Details of the SOW and contract price are in Section 6.3.8.

\subsubsection{Inlet Conditions}

The overall plant system operating parameters and the condenser performance determine the VCS inlet conditions. Table 6-2 lists the basis for arriving at the requirements for the VCS design.

The final parameter needed to size the vacuum system is the amount of steam leaving the direct-contact condenser. Instrumentation accuracies of HMTSTA tests result in significant uncertainties in condenser outlet steam flow rate. To ensure a more limited range of inlet flow rates to be met by the VCS, a precooler was included in the design. If 
Table 6-1. Key Performance Parameters for a VCS

\begin{tabular}{ll}
\hline \multicolumn{1}{c}{ Parameter } & \multicolumn{1}{c}{ Action } \\
\hline Compressor efficiency & $\begin{array}{l}\text { Engineering development effort required. } \\
\text { Inlet conditions }\end{array}$ \\
considerations and heat exchanger performance. \\
Precooler performance & $\begin{array}{l}\text { None. Performance predictions are based on HMTSTA } \\
\text { direct-contact and surface condenser test results. } \\
\text { Intercooler performance } \\
\text { Experimental verification of direct-contact and surface } \\
\text { condenser predictions at high noncondensable gas con- } \\
\text { centrations is recommended; these tests are } \\
\text { recommended to be carried out at the SERI facilities. }\end{array}$ \\
\hline
\end{tabular}

Table 6-2. Basis for Defining the Requirements for the VCS Design

\begin{tabular}{lcl}
\hline \multicolumn{1}{c}{ Parameter } & Value & \multicolumn{1}{c}{ Note } \\
\hline $\begin{array}{l}\text { Warm-seawater } \\
\text { flow rate }\end{array}$ & $620 \mathrm{~kg} / \mathrm{s}$ & $\begin{array}{l} \pm 10 \% \text { for NPPE tests, }+10 \%,-50 \% \text { for heat } \\
\text { exchanger HMTEA tests. }\end{array}$ \\
$\begin{array}{l}\text { Cold-seawater } \\
\text { flow rate }\end{array}$ & $420 \mathrm{~kg} / \mathrm{s}$ & $\begin{array}{l}\text { Same as above } \\
\begin{array}{l}\text { Cold-seawater plant } \\
\text { delivery temperature }\end{array}\end{array}$ \\
$\begin{array}{l}\text { Condenser-seawater } \\
\text { outlet temperature }\end{array}$ & $6.1^{\circ} \mathrm{C}$ & -- \\
$\begin{array}{l}\text { Percentage dissolved } \\
\text { noncondensable gas } \\
\text { release }\end{array}$ & $11.2^{\circ} \mathrm{C}$ & --- \\
$\begin{array}{l}\text { Atmospheric leakage } \\
\begin{array}{l}\text { Diffuser outlet steam } \\
\text { temperature }\end{array}\end{array}$ & $100 \%$ & $\begin{array}{l}\text { In heat exchangers with no predeaeration, } \\
\text { VCS should accommodate variabilities down } \\
\text { to } 80 \% .\end{array}$ \\
$\begin{array}{l}\text { Normal condenser pressure } \\
\text { drop }\end{array}$ & $11.8^{\circ} \mathrm{C}$ & \begin{tabular}{l} 
$\pm 0.5^{\circ} \mathrm{C}$ design variation. \\
\hline
\end{tabular} \\
\hline
\end{tabular}


it is determined during heat exchanger checkout tests that the condenser is performing at the expected level, the precooler may be removed from operation. To maximize the efficiency of the precooler, a countercurrent direct-contact device using cold seawater (at $6.1^{\circ} \mathrm{C}$ ) was selected.

The VCS inlet operating requirements are listed in Table 6-3. This table covers a range of inlet pressures and a range of noncondensable gas flow rates to encompass the potential range of condenser pressure loss and gas liberation. These conditions are downstream of the precooler and assume a precooler outlet approach temperature (the difference between inlet water temperature and outlet gas temperature) of $0.5^{\circ} \mathrm{C}$. This approach temperature is slightly greater than analytic code predictions. Reducing the assumed approach temperature to zero does not greatly affect the steam flow rate.

Table 6-3. Inlet NPPE Operating Requirements for the Preliminary VCS Design Contract

Inlet Pressure (Pa)
Steam Flow Rate (g/s)

as a Function of Inlet Pressure and Noncondensable Gas Flow Rate

Noncondensable Gas Flow Rate (g/s)

$\begin{array}{llll}15 & 17.5 & 20 & 22.5\end{array}$

\begin{tabular}{lllll}
\hline 1200 & 34.9 & 40.7 & 46.5 & 52.4 \\
1250 & 29.0 & 33.8 & 38.7 & 43.5 \\
1300 & 24.8 & 29.0 & 33.1 & 37.2 \\
1350 & 21.7 & 25.3 & 28.9 & 32.5 \\
\hline
\end{tabular}

Centrifugal and positive-displacement compressors were the two existing commercial types investigated. The third type, the axial compressor, was eliminated from consideration for the following reasons:

- Existing axial commercial hardware is designed for higher volumetric flow rates.

- Extensive development would be required for smaller sizes.

- Lower pressure rise per rotor results in numerous stages and high costs.

We contacted 13 manufacturers of positive-displacement compressors. These machines are typically used at vacuum levels compatible with OC-OTEC, but their typical applications are not overly concerned with efficiency. The primary design advantages of existing positive-displacement compressor hardware are reliability and flexibility of operation. Existing positive-displacement integrated multiple-stage systems typically run with only two or three stages. Resulting stage pressure ratios are higher than desirable for our application, but lower pressure ratio operation is possible. Manufacturers suggested rotary-lobe and rotary-vane machines, with liquid ring pumps acting as the final stage. Rotary-screw types were also mentioned, but the high pressure ratios of these machines made them less attractive. Compressor stage efficiency numbers were difficult to obtain from manufacturers, but inferred efficiencies were found to range from $25 \%-36 \%$. These figures were partially confirmed by measurements on an existing rotary-lobed blower in the SERI heat- and mass-transfer laboratory, which had an efficiency of $32 \%$ over a wide range of operating pressures. 
Two system performance predictions were done with the inferred compressor stage efficiencies to evaluate the feasibility of using existing positive-displacement hardware. Operating conditions for these runs were taken from a nominal point in the preliminary VCS design specification. The first prediction corresponds to using existing rotary positive-displacement compressor stages at typical pressure ratios. The first two stages are rotary-lobed blowers with an overall stage efficiency of $32 \%$, and the final stage is a rotary-vane blower with an efficiency of $28 \%$. The power calculation assumes that efficient intercoolers are used to reduce the steam mass flow rate. Use of intercoolers is an addition to existing positive-displacement system designs, but it would be possible to purchase individual compressors and integrate the stages with intercoolers. Table 6-4 summarizes results. The compressor power consumption projection of $62 \mathrm{~kW}$ clearly indicates that use of existing positive-displacement compressor hardware at typical pressure ratios is not a viable option.

The second prediction regarding existing positive-displacement compressor performance assumes that the pressure ratios can be reduced and that the highest inferred efficiencies are applicable at these lower pressure ratios. Again, efficient intercoolers are used. Results are shown in Table 6-5 for a six-stage equal-pressure-ratio compression train.

The above power estimates are for the compressors only. Pumping lubrication oil or cooling water would require additional power. Based on these calculations, existing positive-displacement pumps are unacceptable for use in the VCS.

We contacted seven manufacturers of centrifugal compressors. Existing centrifugal compressors are not designed to operate at low pressure levels required. Machines are available that could accommodate the gas volumetric flow; however, because they are designed for higher density gases, the drive systems and bearings are sized for large power requirements and lower operating speeds. The mechanical losses associated with existing centrifugal compressor designs operating at higher speeds are excessive for our low-density gas application. As an illustration, Atlas-Copco has an existing centrifugal wheel with approximately $77 \%$ gas compression efficiency. Acting as a first stage, gas compression would require around $8 \mathrm{~kW}$. However, the oversized mechanical system results in losses that increase motor power to $34 \mathrm{~kW}$ and decrease compressor efficiency (not counting the motor) to less than 20\%. Therefore, existing, off-the-shelf centrifugal compressors are also unacceptable for use in the VCS.

Table 6-4. Compression System Power Projection Using Existing PositiveDisplacement Compressor Hardware at Standard Pressure Ratios (Total compressor power required $=61.8 \mathrm{~kW}_{\mathrm{e}}$ )

\begin{tabular}{|c|c|c|c|c|c|c|c|}
\hline \multirow[b]{2}{*}{$\begin{array}{c}\text { Compressor } \\
\text { Number }\end{array}$} & \multirow[b]{2}{*}{$\begin{array}{c}\text { Pressure } \\
\text { Ratio }\end{array}$} & \multirow{2}{*}{$\begin{array}{c}\text { Inlet } \\
\text { Pressure } \\
(\mathrm{kPa})\end{array}$} & \multirow{2}{*}{$\begin{array}{c}\text { Outlet } \\
\text { Pressure } \\
(\mathrm{kPa})\end{array}$} & \multirow{2}{*}{$\begin{array}{c}\text { Steam } \\
\text { Flow } \\
\text { (g/s) }\end{array}$} & \multirow[b]{2}{*}{$\begin{array}{c}\text { Power } \\
\left(k W_{e}\right)\end{array}$} & \multicolumn{2}{|c|}{$\begin{array}{l}\text { Volumetric } \\
\text { Flow Rate }\end{array}$} \\
\hline & & & & & & $\left(\mathrm{m}^{3} / \mathrm{s}\right)$ & (cfs) \\
\hline $\begin{array}{l}1 \\
2 \\
3\end{array}$ & $\begin{array}{l}3.0 \\
4.0 \\
7.3\end{array}$ & $\begin{array}{r}1.2 \\
3.5 \\
14.0\end{array}$ & $\begin{array}{r}3.6 \\
14.1 \\
101.3\end{array}$ & $\begin{array}{r}51.54 \\
10.33 \\
1.60\end{array}$ & $\begin{array}{l}30.92 \\
14.40 \\
16.46 \\
\end{array}$ & $\begin{array}{l}6.865 \\
0.811 \\
0.123\end{array}$ & $\begin{array}{r}14536 \\
1716 \\
261\end{array}$ \\
\hline & & & & & 61.8 & & \\
\hline
\end{tabular}


Table 6-5. Compression System Power Projection Using Existing PositiveDisplacement Compressor Hardware at Lower-Than-Standard Pressure Ratios (Total compressor power required $=44.4 \mathrm{~kW}$ )

\begin{tabular}{|c|c|c|c|c|c|c|c|}
\hline \multirow[b]{2}{*}{$\begin{array}{c}\text { Compressor } \\
\text { Number }\end{array}$} & \multirow[b]{2}{*}{$\begin{array}{c}\text { Pressure } \\
\text { Ratio }\end{array}$} & \multirow{2}{*}{$\begin{array}{c}\text { Inlet } \\
\text { Pressure } \\
(\mathrm{kPa})\end{array}$} & \multirow{2}{*}{$\begin{array}{c}\text { Outlet } \\
\text { Pressure } \\
(\mathrm{kPa})\end{array}$} & \multirow{2}{*}{$\begin{array}{c}\text { Steam } \\
\text { Flow } \\
(\mathrm{g} / \mathrm{s})\end{array}$} & \multirow[b]{2}{*}{$\begin{array}{l}\text { Power } \\
\left(\mathrm{kW}_{\mathrm{e}}\right)\end{array}$} & \multicolumn{2}{|c|}{$\begin{array}{l}\text { Volumetric } \\
\text { Flow Rate }\end{array}$} \\
\hline & & & & & & $\left(\mathrm{m}^{3} / \mathrm{s}\right)$ & (cfs) \\
\hline 1 & 2.1 & 1.2 & 2.5 & 51.54 & 17.82 & 6.865 & 14536 \\
\hline 2 & 2.1 & 2.5 & 5.2 & 22.99 & 9.75 & 1.823 & 3860 \\
\hline 3 & 2.1 & 5.1 & 10.9 & 5.60 & 5.06 & 0.436 & 924 \\
\hline 4 & 2.1 & 10.8 & 22.8 & 2.16 & 4.18 & 0.167 & 353 \\
\hline 5 & 2.1 & 22.8 & 48.0 & 0.94 & 3.87 & 0.072 & 153 \\
\hline \multirow[t]{2}{*}{6} & 2.1 & 48.0 & 101.3 & 0.43 & 3.75 & 0.033 & 70 \\
\hline & & & & & 44.4 & & \\
\hline
\end{tabular}

Conclusions drawn from centrifugal and positive-displacement compressor manufacturers include the following:

- Existing compression stage hardware has excessive mechanical losses that reduce overall efficiency to an unacceptable level for our application.

- Gas compression efficiency appears to be adequate, indicating that existing rotor designs can be used.

- Improvements in mechanical losses appear possible by down-sizing centrifugal drive systems and integrating available low-loss bearings and seals with either type of compressor.

- Engineering design efforts are required to develop a machine with low mechanical losses and to design appropriate intercooler staging integration schemes.

\subsubsection{Gas Condensers and Coolers}

As discussed previously, intercoolers between compression stages are key components in the VCS. The precooler between the direct-contact condenser and the vacuum compression system will also be discussed in this section.

Commercial multistage compression trains use intercoolers to reduce the temperature of the gas. For these gas coolers, cooling water flow rates are relatively low, and heat exchange is easily accomplished as a result of large available temperature differences. A conventional shell-and-tube heat exchanger with the gas on the shell side and water on the tube side is typical.

For our application, both precooler and intercooler act as steam condensers. The primary design consideration is to reduce the steam mass flow by condensation in the presence of high concentrations of noncondensable gases. The concentration of noncondensable gases is about $25 \%$ to $38 \%$ (by mass) at the compressor train inlet, increasing to greater than $95 \%$ at the outlet. This concentration is much greater than typical power plant condensers and OC-OTEC condensers. 
Table 6-6. Summary of Gas Condenser/Cooler Types Considered for the Precooler and Intercooler Designs of the HMTEA/NPPE VCS

\begin{tabular}{|c|c|c|c|}
\hline Cooler Type & Advantages & Disadvantages & Action \\
\hline Direct contact & $\begin{array}{l}\text { Lowest approach } \\
\text { temperature } \\
\text { Lowest cost } \\
\text { Minimal corrosion } \\
\text { consideration } \\
\text { Low gas-side } \\
\text { pressure drop }\end{array}$ & $\begin{array}{l}\text { Siting complications } \\
\text { Flooding problem } \\
\text { Complex piping } \\
\text { arrangement } \\
\text { Potentially higher } \\
\text { cooling-water } \\
\text { parasitics }\end{array}$ & $\begin{array}{l}\text { Use direct contact } \\
\text { for precooler, } \\
\text { carry as an } \\
\text { option for } \\
\text { intercoolers }\end{array}$ \\
\hline Plate-Fin & $\begin{array}{l}\text { Low gas-side } \\
\text { pressure drop } \\
\text { No siting problems } \\
\text { Simple piping } \\
\text { arrangement }\end{array}$ & $\begin{array}{l}\text { Potential higher cost } \\
\text { than direct contact } \\
\text { Higher approach } \\
\text { temperature than } \\
\text { direct contact }\end{array}$ & $\begin{array}{l}\text { Carry as an option } \\
\text { for intercoolers }\end{array}$ \\
\hline $\begin{array}{l}\text { Conventional } \\
\text { shell and tube }\end{array}$ & $\begin{array}{l}\text { Proven cooler type } \\
\text { Typical choice for } \\
\text { standard VCS }\end{array}$ & $\begin{array}{l}\text { Higher percentage } \\
\text { noncondensable } \\
\text { gas concentration } \\
\text { raises performance } \\
\text { doubts } \\
\text { Highest approach } \\
\text { temperature }\end{array}$ & $\begin{array}{l}\text { Carry as an option } \\
\quad \text { for intercoolers }\end{array}$ \\
\hline
\end{tabular}

The three gas condenser/cooler types considered for the precooler and intercooler designs were

- A conventional shell-and-tube heat exchanger as described

- A direct-contact condenser/cooler type

- A plate-fin condenser/cooler type.

Table 6-6 summarizes the advantages and disadvantages of the three options and the status of the precooler and intercooler designs.

Another gas cooler design issue is the type of cold water used. Options include

- Coldest seawater from the supply system at $6.1^{\circ} \mathrm{C}$

- Effluent cold seawater from the condenser discharge at $11.3^{\circ} \mathrm{C}$

- Closed-loop, treated tap water in a liquid/liquid heat exchanger cooled by either of the first two types of cold seawater.

The coldest seawater is most useful for the lowest pressure gas coolers, where the concentration of water vapor is highest. The use of the coldest seawater must be minimized because the total plant flow rate is limited. In addition, corrosion associated with seawater must be considered in the design. 
Main condenser effluent water is cold enough for many cooling needs. Corrosion problems are minimized by using a closed-loop system, and the gain of several degrees Celsius in a liquid/liquid heat exchanger may not be critical.

The precooler is immediately adjacent to the first-stage compressor outside the dome. This will limit the effects of ambient heating of the low-density gas in the large diameter pipe. Piping from the main condenser through the vacuum dome to the precondenser cooler is $0.6 \mathrm{~m}$ in diameter. Assuming $20 \mathrm{~m}$ of pipe with six 90 -deg bends (near $100-\mathrm{m}$ total equivalent length) results in a piping pressure loss of around $15 \mathrm{~Pa}$ for the high flow rate conditions of Table $6-3$.

The precooler performance is important because it determines volumetric and mass flow rate for the first-stage and hence the largest compressor. A direct-contact device with $6.1^{\circ} \mathrm{C}$ seawater was selected to minimize steam flow into the compressor. An approacn temperature of $0.5^{\circ} \mathrm{C}$ was used to develop the VCS design specification. Using a closedloop water supply or a surface condenser results in a larger steam flow rate to the first stage. Using effluent water is not reasonable because even worst-case main condenser performance results in steam temperatures much lower than $11.3^{\circ} \mathrm{C}$.

SERI's direct-contact condenser code was used to check the precooler performance. A gas pressure drop of less than $50 \mathrm{~Pa}$ was predicted. Approach temperatures less than $0.5^{\circ} \mathrm{C}$ were projected to be achievable, but up to $25-\mathrm{kg} / \mathrm{s}$ cold-water flow may be required for worst-case main condenser exit conditions. Up to $1.5 \mathrm{~kW}$ of additional cooling-water pumping power may be required if the precooler is not located at barometric height. Further design work optimizing precooler parameters may result in lower worstcase water flow rates.

Further investigation is required before decisions are made regarding the type of cold water and the type of cooler used for each intercooler. Successively decreasing steam flow rate allows higher liquid loadings to accommodate higher noncondensable gas concentration without increasing water flow rates and pumping power. For higher pressure downstream intercoolers, the gas pressure drop and gas exit approach temperature do not have a great effect on VCS power, so a surface-type heat exchanger may be more appropriate. Using effluent cold water instead of $6.1^{\circ} \mathrm{C}$ seawater for the intercoolers results in a predicted increase of only $1-2 \mathrm{~kW}$ in VCS power, with more than $50 \%$ of the increase resulting from the performance of the first intercooler. Intercooler water flow rate is expected to be between 10 and $25 \mathrm{~kg} / \mathrm{s}$, but it is not as critical as precooler water flow if main condenser effluent seawater is used.

The detailed design of the precooler and intercoolers will be coordinated by the VCS preliminary design contractor with assistance as required from SERI and ANL. Precooler and intercooler costs are estimated to be $\$ 60,000$ over and above the cost of the preliminary and final design contract.

\subsubsection{Compressor Drivers}

Three-phase AC motors were selected to drive the compressors. The power supply corresponds to the turbine/generator output, so no transformers are required. A variablefrequency drive may be used if compressor rotational speed is selected as a control mechanism (a typical variable-speed-drive efficiency is $95 \%$ ).

Some past commercial-scale open-cycle plant designs have used compressors directly driven by the turbine. Direct-drive systems avoid power losses from motor and generator inefficiencies, but the compressors must be located near the turbine shaft and compressor control may be more complicated. 
The motors will be selected by the compressor manufacturers. This will allow starting and steady-state characteristics to be selected to match compressor requirements.

An air-cooled motor may have a design point efficiency of near $90 \%$. Typical data from manufacturers show a few points' increase in efficiency for water-cooled motors; therefore, the compressor manufacturer may consider them. The increase in coolingwater pumping power and the added cost of cooling-water circulation equipment must be considered in the evaluation.

\subsubsection{Other Vacuum Compressor Support Equipment}

The VCS will require lubrication for moving parts. The detailed design of a lubrication system is included in the VCS preliminary design contract. The contractor will select a lubrication system appropriate for their VCS design.

Lubrication system requirements may be very different for positive displacement and centrifugal compressor types because of rotational speed and sealing requirements. A closed-loop oil-circulating system including a pump, oil reservoir, oil filter, and other elements may be required. Another option is sealed, packed bearings, which will be replaced at regular maintenance intervals. Water contamination of the oil must be considered if oil comes in contact with the process gas.

Oil-sealed positive-displacement pumps will use more oil than any other option and will require more oil handling and processing equipment. The lubrication system design is standard practice, and an oil pumping power requirement of less than one $\mathrm{kW}_{\mathrm{e}}$ is expected.

Control of the VCS over the range of expected steady-state operating conditions and during vacuum chamber pump-down is also an issue. Mechanisms for control may be different for centrifugal and positive-displacement machines. For a given rotational speed, centrifugal machines develop a nearly constant head (or pressure ratio if flow rate is constant) as inlet volumetric flow is varied. Positive-displacement machines, on the other hand, have a nearly constant capacity over a wide range of head (see Figure 6-2). Centrifugal machines also have a defined lower limit of inlet flow called the surge limit. If the machine operates near the surge limit, unstable flow, caused by back-flow into the rotor, induces vibrations that can destroy the compressor. Control of either type of machine is feasible through a variety of schemes, including

- Rotor speed control by a variable-speed drive

- Gas bleed-in or recirculation for low-flow conditions

- Parallel flow paths (full or partial compressor trains handling a fraction of the total flow at highest flow rates).

Contractors will define the specific control schemes in the preliminary design.

\subsubsection{Conceptual Design Performance Prediction}

Two predictions of VCS power consumption are important. The first uses expected condenser and system performance levels; the second uses worst-case inlet conditions from the vacuum specification of Table 6-3.

For both cases, an overall compressor stage efficiency of $60 \%$ is used (90\% motor, $94 \%$ variable-speed drive, and $72 \%$ compressor). Effluent water $\left(11.3^{\circ} \mathrm{C}\right)$ is used as the cooling sink for a closed fresh-water loop, resulting in an intercooler water supply 
temperature of $13.5^{\circ} \mathrm{C}$. For these predictions, four compression stages are used with equal pressure ratios in each. Other assumptions are that $100 \%$ of the noncondensable gases are released and the pressure loss between the compressor stages is $200 \mathrm{~Pa}$. Power consumption may be slightly reduced by increasing the number of stages and reducing the pressure ratios of the first two stages.

The expected performance prediction uses a turbine exit temperature of $11.8^{\circ} \mathrm{C}$ and a total pressure drop from the diffuser to the first compressor inlet of $150 \mathrm{~Pa}$. An approach temperature difference of $-0.1^{\circ} \mathrm{C}$ was used (approach can be negative because of the boiling point elevation of seawater), resulting in an inlet steam flow rate of $37.3 \mathrm{~g} / \mathrm{s}$. Power consumption for the compressors was calculated to be $26.5 \mathrm{~kW}$ e

The worst case from the preliminary design specification uses a higher inert gas flow due to higher seawater flow, a lower compressor inlet pressure, and an approach temperature of $0.5^{\circ} \mathrm{C}$. The resulting inlet steam flow rate is 52.4 $\mathrm{g} / \mathrm{s}$. Power consumption for the compressors was calculated to be 31.8 $\mathrm{kW}$.

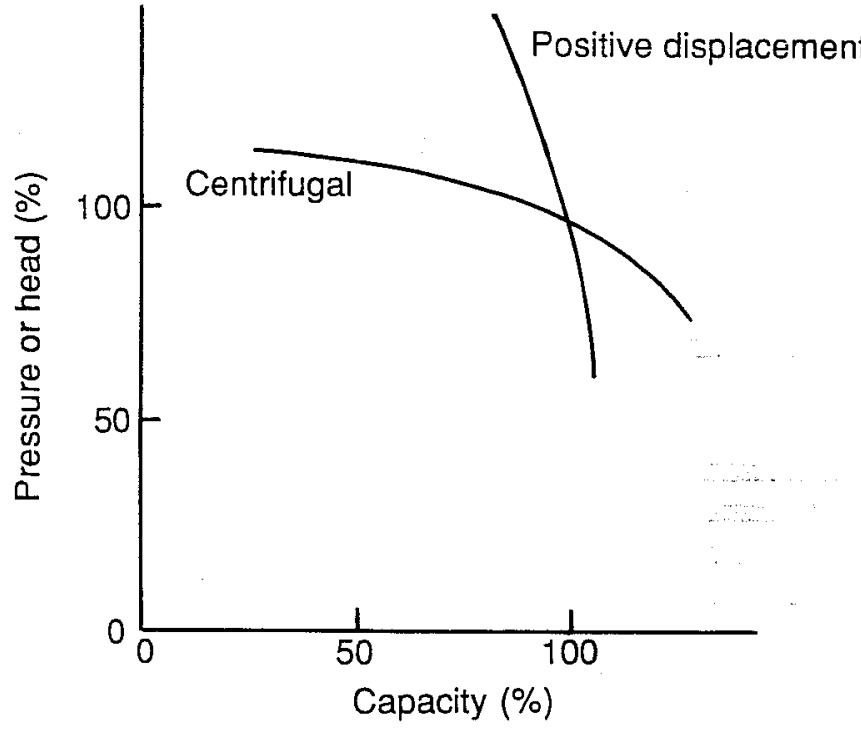

Figure 6-2. Pressure-volume diagram for centrifugal and positive-displacement types of machines. Capacity is usually specified in terms of inlet CFM (at inlet conditions) and head in feet or pressure in PSI for compressors and blowers. For fans, however, the pressure is usually specified in inches of water gauge.

Cooling-water circulation for the gas precooler and intercoolers is expected to consume a total of nearly $5.5 \mathrm{~kW}$ if barometric-height direct-contact devices (or equivalent performance/head loss surface condensers) are used.

Vacuum pump lubrication requirements will be fully defined by the preliminary design contractors, but power to circulate oil is expected to be under $1 \mathrm{~kW}$. The lubricating oil may need to be cooled in a liquid/liquid heat exchanger. Oil cooling-water pumping power is estimated to be $0.5 \mathrm{~kW}$.

Cooling water may be required for the compressor motors, but any water pumping power requirement should be more than offset by reductions in compressor power due to motor efficiency increases.

Total VCS power consumption predictions are $34 \mathrm{~kW}$ if expected performance is achieved and $39 \mathrm{~kW}$ if worst-case inlet conditions are used.

A preliminary layout for the VCS indicates a 6-by-6-m (20-by-20-ft) footprint. Compressor stage dimensions were estimated using existing appropriately sized volumetric-flow, positive-displacement rotary blowers. 


\subsubsection{Preliminary Design Contract}

The conceptual design of the VCS defined inlet conditions, identified limitations of existing equipment, and made power consumption projections based on improved compressor performance. The preliminary design contract involves a compressor manufacturer confirming these improved compressor performance projections and completing the VCS preliminary design. The preliminary design contract is Phase I of a two-phase effort. Phase II includes final design, construction, and testing of the Phase I design. Total cost of both phases is estimated by Barber-Nichols Engineering to be $\$ 225,000$.

\subsubsection{Remaining Issues and Uncertainties}

Remaining issues and uncertainties that must be addressed in the VCS preliminary design are to

- Confirm that compressor mechanical losses will be low and that an overall power consumption of around $40 \mathrm{~kW}$ e can be achieved.

- Experimentally verify direct-contact and surface condenser code predictions of precooler and intercooler performance at high noncondensable gas concentrations.

- Work with the VCS contractor in the final selection and design of the precooler and intercooler.

- Resolve pipe routing and component placement issues to minimize pressure loss, maximize performance, and prevent compressor flooding.

The schedule of key events and deadlines for the VCS is included in the summary section of the report. The primary constraints are the completion of the compression system Phase I and Phase II contracts before beginning heat exchanger checkout tests.

\subsection{Electrical System}

The complete electrical system for the NPPE includes the generator and associated switchgear, wiring and bus connections, interface with the existing NELH grid system, a resistive load bank to dissipate generated power, motor control centers, emergency power supplies, and power monitoring devices.

The requirements for the generator, associated switchgear, and load bank are primarily dictated by turbine start-up and control characteristics; therefore, the specific design of these components is included as part of the turbine design. Start-up scenarios and controls, however, do impose conditions on the remaining electrical components, so close coordination is necessary.

\subsubsection{Design Approach}

The electrical system design is similar to existing power plant designs. Standard engineering practice and hardware are expected to be used for all aspects. PICHTR has primarily undertaken the ancillary electrical system design. As part of that effort, PICHTR contracted with a local (Honolulu) electrical engineer, H. Miura, for much of the detailed work. General electrical requirements were gathered from the systems task team and other component design teams. From these requirements, PICHTR and Mr. Miura developed one-line diagrams, equipment lists, and cost estimates.

\subsubsection{System Requirements and Options}

The ancillary electrical system must supply power for all plant needs and provide protection from faults during start-up, operation, and shutdown. During normal operation, the 
electrical system must be configured to allow determination of net power production from the NPPE.

The general operational scenario is that the turbine/generator will use the existing NELH/Hawaiian Electric Co. (HELCO) power grid for excitation and a synchronization standard. All HMTEA/NPPE power needs will be met by HELCO during start-up. The generator may be used as a motor to bring the turbine up to speed. Once the turbine is up to speed and synchronized, the plant loads essential to operation will be switched over to OTEC power.

If a power outage occurs in the NELH/HELCO system, the experiment will shut down because excitation is provided by the grid. During any power loss or similar shutdown, emergency power must be provided to operate critical components. Two types of emergency power needs were identified. The first cannot tolerate any loss of power and therefore must be backed up by a battery-charged uninterruptable power supply (UPS). Essential data-acquisition and control hardware will be on the UPS. The second type of emergency power need can tolerate a short delay in power. To reduce the size and cost of the UPS, this type of need is met by an emergency engine-driven generator. NELH personnel have indicated that excess capacity from NELH emergency generators could provide the needed HMTEA/NPPE backup with the provision of additional switchgear. Critical power users that may be able to tolerate a momentary delay in power include

- Main and backup lubrication oil and cooling-water pumps (turbine and vacuum system)

- Turbine scavenge oil pump (if shutdown does not include breaking the vacuum in the seal area)

- Air compressor for controls (if required).

In addition, some uses such as emergency lighting and other safety-dictated needs should be on the emergency power system. Preliminary design will include a check of tolerable power delays and emergency power response time to ensure compatibility.

Electrical power needs were divided into two categories, each handled by its own switchboard. Plant loads provide for essential operations and are included in the net power determination. Building and support loads are not a part of the power cycle and are not included in the net power determination. Plant cycle loads include

- Seawater supply and discharge pumps

- Vacuum compressors

- Cooling-water circulation pumps

- Lubrication oil circulation and scavenge pumps

- Backup pumps

- Instrumentation and controls (including air compressor if needed for controls).

Building and support loads include

- Support building receptacles and lighting

- Air-conditioning and ventilation (including any provisions for use of seawater cooling)

- Desalinated-water pump

- Tool air compressor

- Crane or hoists.

Two options were evaluated during this conceptual design phase for net power distribution. The first option routes net power to a power-dissipating load bank, and the second option adds the ability to send power to the utility grid. Cost estimates indicate an additional $\$ 7,700$ would be needed for the option to send power into the grid. 
Discussions held with HELCO and NELH personnel resulted in strong support for the netto-grid option. The systems integration task team concurred, so remaining net power will be routed to the main NELH system to offset a portion of HELCO-supplied power for other NELH users. No OTEC power will actually reach the main HELCO grid because NELH has a continuous need for $80-95 \mathrm{~kW} \mathrm{e}^{\text {. }}$

\subsubsection{Cost Estimates}

The following summarizes the ancillary electric system cost estimate (as included in the ancillary systems task), prepared by $\mathrm{H}$. Miura. It includes material and labor. An estimated $20 \%$ contingency is not included in the summary costs (see Table 6-7).

Electrical equipment associated with the turbine, including generator switchgear, a control panel, the load bank, switching, and relays, was estimated to cost $\$ 207,000$. It is included in the turbine portion of the cost estimate.

\subsubsection{Remaining Issues and Uncertainties}

No critical issues or uncertainties were identified in the ancillary electrical system conceptual design. Refinement of the design is needed as requirements are better defined and revised by other task areas. Preliminary design will require close coordination with the turbine contractor to ensure compatibility with turbine/generator controls and switchgear,

\subsection{Instrumentation and Control Systems}

Only a small effort was mounted in designing instrumentation and control systems. Plant control, dynamics, instrumentation, and data-acquisition design are expected to use standard engineering practices and available equipment. Much of the information required to define a comprehensive plant control system will become available after partial completion of the preliminary design. Two key analyses are planned as part of the control definition. The first is a plant dynamic modeling effort to define required control response times and possible control mechanisms. The second is a failure modes and effects analysis to ensure that controls address plant safety issues. These efforts will be coordinated with the systems integration task team and the seawater systems task team (which is responsible for safety).

For conceptual design, general control and instrumentation philosophy was defined, firstcut instrumentation to monitor the plant and define component performance was

Table 6-7. Cost Estimate for Ancillary Electric System

\begin{tabular}{lr}
\hline \multicolumn{1}{c}{$\begin{array}{c}\text { Ancillary } \\
\text { Electric System }\end{array}$} & $\begin{array}{c}\text { Estimated } \\
\text { Cost }\end{array}$ \\
\hline Motor control centers & $\$ 75,800$ \\
Wiring & 97,000 \\
Switchboards and relays & 33,000 \\
UPS & 26,000 \\
Transformers & 5,100 \\
Miscellaneous & 54,100 \\
Total & $\$ 291,000$ \\
\hline
\end{tabular}
identified, and an order-of-magnitude cost estimate based on typical power plant control and monitoring systems was obtained.

\subsubsection{Design Approach}

The plant controls and instrumentation design will accommodate the following constraints:

- Numerous start/stop cycles expected during initial checkout, with operation for 8-12-h periods 
- Continuous operation ( $24 \mathrm{~h} /$ day), with one operator on duty for an extended period of up to six months with minimal shutdown (short periods of unattended operation)

- Semiautomatic control, with manual backup and overrides and automatic failure detection and shutdown

- Individual components designed to be checked out and run without the full system operating

- An experimental facility that will be instrumented to allow component and system performance to be monitored, recorded, and analyzed.

The turbine, vacuum system, and seawater pumps will have their own local control panel with an interconnect to a main control room. Local and main control and data-acquisition systems (DAS) will be modular to allow expansion and adaptation as experimental needs develop. All key valves and motor controls will be fitted for remote actuation.

Much of the detailed design of the control and instrumentation system will be performed by consultants (with power plant experience), equipment manufacturers such as Foxborough or Rosemount, or both.

Instrumentation required to monitor component and plant performance will be specified by each component design team. For example, the seawater flowmeters will be specified by the seawater systems task team. For these instruments, a standard output signal of $0-10 \mathrm{~V}$ or $4-20 \mathrm{~mA}$ is preferred. When candidate instruments are identified, the ancillary design task team will coordinate the evaluation of overall probable measurement errors.

\subsubsection{Configuration}

Detailed design activity has not begun. The instrumentation and control needs for the turbine/generator are better defined than those for other components because its preliminary design is complete. The MTI Phase I report provides more information. Table 6-8 shows the initial inputs from the task leaders on the channel requirements for the performance monitoring instrumentation.

An overall DAS limit of 128 channels was prescribed by the systems integration task team. The distribution of instrumentation and control channels among the various task areas will clearly need to be looked at in the preliminary design. Cost estimates will be based on this 128-channel limit.

Some data will be logged or displayed on dedicated component control systems and DAS only; other channels will also be routed to the main control panel.

Power meter options for monitoring electricity production and consumption were identified. Specified accuracies range from $0.1 \%$ to $0.2 \%$ for solid-state devices.

\section{Table 6-8. Instrumentation and Controls Needed for the HMTEA/NPPE}

\begin{tabular}{lc}
\hline \multicolumn{1}{c}{ Subsystem } & $\begin{array}{c}\text { Channel } \\
\text { Requirements }\end{array}$ \\
\hline Turbine and structures & 50 \\
Heat exchangers & 48 \\
Seawater systems & 22 \\
Vacuum compression system & 70 \\
Ancillary electrical system & 4 \\
Miscellaneous ancillary systems & 20 \\
Total & 214 \\
\hline
\end{tabular}


Other instrumentation and control needs include

- Protection and safety

- Generator excitation

- Load/speed control for turbines, compressors, and pumps.

The complete configuration of hardware for control and data acquisition remains to be defined.

PICHTR and $\mathrm{H}$. Miura have prepared a draft control room layout including electrical switchboards, motor control centers, and the generator control panel. The layout indicated a plan of $4.9 \mathrm{~m}$ by $6.1 \mathrm{~m}$. Ergonomic layout and electrical interference issues remain to be addressed.

\subsubsection{Cost Estimate}

This first-cut evaluation of DAS needs is based on a channel count of 128. A PC-based system may be used because many flexible configurations are available. The overall DAS (all hardware and software) cost estimate is $\$ 75,000$. The cabling and instrumentation cost estimate is $\$ 175,000$, or $\$ 1,400 /$ channel. This figure was arrived at after consulting with instrumentation manufacturers and examining typical power plant costs. The overall control and instrumentation cost estimate is $\$ 250,000$.

\subsubsection{Remaining Issues}

Control and plant safety issues will be addressed in the upcoming plant dynamics/control study and failure modes and effects analysis.

No remaining design problems were identified or are expected that would require further development of the data-acquisition and control memory and processing units.

Performance monitoring instruments were identified by the turbine preliminary design contract. Other instrumentation is expected to be similar to HMTSTA instruments with two exceptions. Temperature measurements for the HMTSTA tests were performed with platinum RTDs. Drift and frequent calibration needs make these instruments unsuitable for longer term HMTEA/NPPE tests. Industrial thermistors were identified as a possible solution, but further investigation is necessary to prove suitability.

HMTSTA pressure measurements were mostly obtained using capacitance diaphragm transducers. Strain-gauge transducers were originally installed but were not able to withstand the seawater environment. Posttest, it was recognized that the capacitance diaphragm transducer measurement errors were much larger than thought because of temperature- and time-dependent stability. Suitable differential and absolute pressure transducers and appropriate installation and operational guidelines to minimize temperature- and time-dependent errors need to be identified for the HMTEA/NPPE.

Error analysis for all HMTEA/NPPE instruments and derived performance parameters remains to be completed.

Reaeration of the discharge seawater stream may be required for environmental reasons; such needs remain yet to be explored, and power penalties associated with it are yet to be assessed. 


\subsection{Miscellaneous Ancillary Systems}

The miscellaneous ancillary systems include cooling-water circulation systems, ventilation and air-conditioning (in conjunction with the structures task effort), and desalinatedwater systems (downstream of the surface condenser).

\subsubsection{Design Approach}

The miscellaneous ancillary systems design lags behind the main process because requirements are based on support needs. When the needs are defined, the process is straightforward because we do not expect any unusual designs or major effects on the main NPPE goals. The only miscellaneous system that affects net power is cooling-water circulation. Because supplying water for lubrication oil, vacuum system gas condensers and coolers, and possible motor cooling is essential for operation, pumping power is accounted for in net power determination. Other miscellaneous systems do not affect the net power. The designs for all miscellaneous ancillary systems are based on standard engineering practice.

\subsubsection{Cooling-Water Circulation}

Cooling-water circulation is divided into uses that affect net power and supporting uses that are not essential for plant operation. Essential plant water systems service the following needs:

- VCS intercoolers

- Vacuum system and turbine lubrication oil coolers

- Vacuum system motors (an option)

- Control system air compressor.

Supporting water systems service the following needs:

- Tool air compressor

- Seawater air-conditioning loop (an option).

Cold seawater directly from the supply system (at $6.1^{\circ} \mathrm{C}$ ) or condenser effluent seawater (at $11.3^{\circ} \mathrm{C}$ ) will be used as the heat sinks. Use of $6.1^{\circ} \mathrm{C}$ seawater is to be minimized because of the power system requirements of the NPPE. If temperature is not critical, the cold seawater will be pumped through a liquid/liquid heat exchanger cooling a treated fresh-water closed loop. Use of a closed loop eliminates many corrosion issues, and the treated water loop can operate at any design pressure.

Power estimates for pumping the water for the VCS gas coolers are discussed in Section 6.3.7. Seawater at $6.1^{\circ} \mathrm{C}$ will be used in the precooler and possibly in the first intercooler device. A treated-water closed loop is planned for the remaining intercoolers and oil cooler. The first-cut cost estimate is based on $25 \mathrm{~kg} / \mathrm{s}$ (conservative) of $6.1^{\circ} \mathrm{C}$ seawater flow for the precooler and $25 \mathrm{~kg} / \mathrm{s}$ of fresh water for the closed loop, cooled by $25 \mathrm{~kg} / \mathrm{s}$ of $11.3^{\circ} \mathrm{C}$ seawater. Estimates of cost are $\$ 10,000$ for three water pumps, $\$ 10,000$ for piping ( $R O M)$, and $\$ 5,000$ for the liquid/liquid heat exchangers.

Detailed design and siting of these piping systems remains to be completed. No design work has been performed on the turbine oil cooler or control air compressor water loops, but pumping power is expected to be less than $0.5 \mathrm{~kW}$. The requirements may be integrated with the main treated-water closed-loop system at little additional cost. 
Other needs for water may be gland-sealing water for the turbine shaft seals and the main seawater pumps. Flow rates are expected to be low, and design of the system will be included in the seawater systems task.

\subsubsection{Desalinated-Water System}

The desalinated-water storage and distribution system will collect, store, and distribute the condensate from the surface condenser. Pumping power for these units is not part of the determination of net power, and the design is expected to be simple. Because the design is not critical to operation, little work has been completed.

The surface condenser design is part of the heat exchanger task. After maximum net power experiments, up to $10 \%$ of the total steam flow rate will be routed to the surface condenser, resulting in a production rate of approximately $0.32 \mathrm{~kg} / \mathrm{s}(5.0 \mathrm{gal} / \mathrm{min})$ of desalinated water. The water will be pumped to a standard tank with a capacity of approximately 65 gal $(250 \mathrm{~L})$. A water fountain will be placed in the facility's visitors' area. Additional water taps may be made available. A simple treatment system may be required to ensure that potability is maintained in the storage and distribution system. Cost is expected to be less than $\$ 2,000$.

\subsubsection{Air-Conditioning}

Building air-conditioning and ventilation system design is included in the structures task. Conventional systems and designs are expected, including a vapor-compression chilledwater air-conditioning system. However, effluent cold seawater at $11.3^{\circ} \mathrm{C}$ can also be used as an alternative chilled-water heat sink. This option will be carried into the preliminary design, but a vapor-compression system will be used for the purpose of cost estimation.

The cooling load of 10 tons $(35 \mathrm{~kW})_{2}$ was estimated using $150 \mathrm{ft}^{2} /$ ton $\left(4 \mathrm{~m}^{2} / \mathrm{kW}_{\mathrm{e}}\right)$ and a building area of $1500 \mathrm{ft}^{2}\left(140 \mathrm{~m}^{2}\right)$. Typical costs for a vapor-compression airconditioning system using chilled water are $\$ 1,000 /$ ton $\left(\$ 280 / \mathrm{kW}_{e}\right)$. The total airconditioning system cost estimate is $\$ 10,000$.

\subsubsection{Other Miscellaneous Items}

Other miscellaneous pieces of hardware will be required to ensure the HMTEA/NPPE operates smoothly. These small items, which do not clearly fit within the scope of the main component tasks, are included as part of the ancillary systems. We do not expect these to affect net power. Several needs identified are

- Tool air compressor

- Voice communication system

- Lighting system for viewing vacuum vessel internal elements

- Public relations materials (models, displays, etc.).

A detailed cost estimate for these items was not attempted. A $\$ 100,000$ allowance is included in the ancillary systems task cost estimate for these items.

\subsection{Summary}

The conceptual design process for the ancillary systems task addressed key items that affected the overall schedule, performance, and cost. The largest power consumer, the 
Table 6-9. Power Consumption Estimate for Ancillary Systems

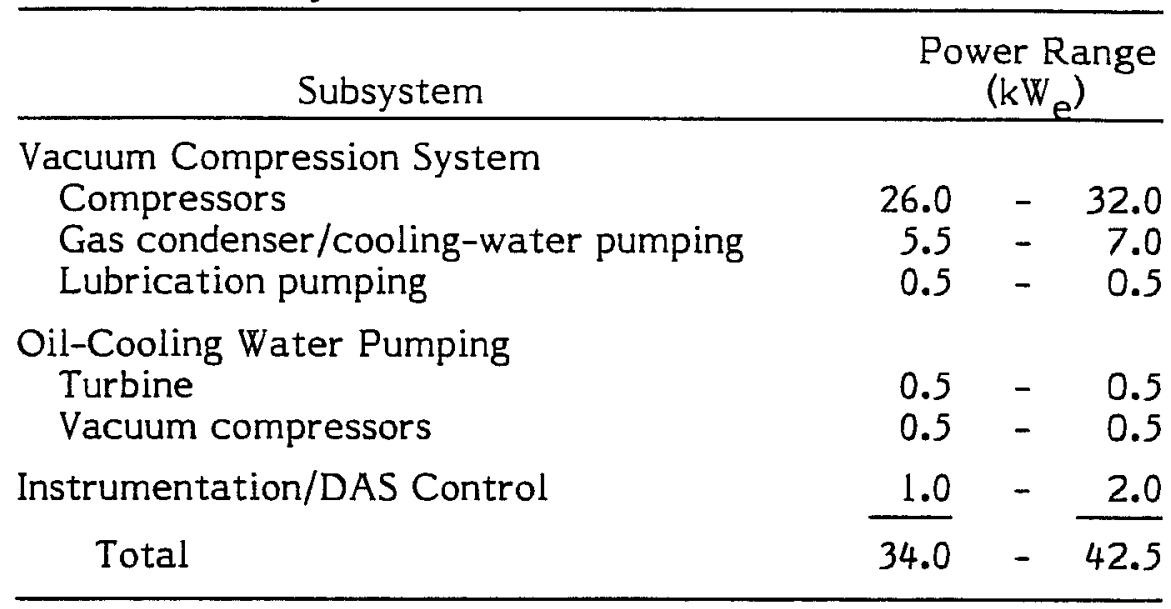

Table 6-10. Cost Estimate for Ancillary Systems

\begin{tabular}{lr}
\hline \multicolumn{1}{c}{ Subsystem } & \multicolumn{1}{c}{$\begin{array}{c}\text { Cost } \\
\text { Estimate }\end{array}$} \\
\hline $\begin{array}{l}\text { Vacuum Compression System } \\
\text { Preliminary and final design }\end{array}$ & $\$ 250,000$ \\
Gas condenser/coolers & 60,000 \\
Ancillary Electric System & 291,000 \\
Instrument and Controls & \\
Computer hardware & 75,000 \\
Instrumentation & 175,000 \\
Miscellaneous & \\
Cooling water & 25,000 \\
Desalinated water & 2,000 \\
Building air-conditioning & 10,000 \\
$\quad$ Other & 100,000 \\
$\quad$ Total & $\$ 988,000$ \\
\hline
\end{tabular}


Table 6-11. Summary Schedule for Ancillary Systems

\begin{tabular}{|c|c|c|}
\hline Subsystem & & \\
\hline \multicolumn{3}{|l|}{ Vacuum System } \\
\hline Preliminary contract & $11 / 89$ & $3 / 90$ \\
\hline Precooler/intercooler design input due & & $1 / 90$ \\
\hline Final design and construction contract & $5 / 90$ & \\
\hline Ready for HMTEA tests & & $7 / 91$ \\
\hline \multicolumn{3}{|l|}{ Ancillary Electrical System } \\
\hline Preliminary design complete & & $4 / 90$ \\
\hline Final design complete & & $10 / 90$ \\
\hline Purchase and installation complete & & $5 / 91$ \\
\hline Controls and Instrumentation & & \\
\hline Dynamics analysis contract & $12 / 89$ & $-3 / 90$ \\
\hline Final design contract & $7 / 90$ & $-10 / 90$ \\
\hline Purchase and installation complete & & $5 / 91$ \\
\hline Ready for HMTEA tests & & $7 / 91$ \\
\hline \multicolumn{3}{|l|}{ Miscellaneous Systems } \\
\hline \multirow{2}{*}{$\begin{array}{l}\text { Preliminary design complete } \\
\text { Final design complete }\end{array}$} & & $6 / 90$ \\
\hline & & $12 / 90$ \\
\hline Purchase and installation complete & & $5 / 91$ \\
\hline
\end{tabular}

vacuum system, will require engineering development to achieve desired performance, but manufacturers' bids and projections associated with the preliminary design indicate that the goal of $40 \mathrm{~kW}$ e can be met. This section summarizes the power consumption projections important in determining net power (Table 6-9), provides an overall cost estimate (Table 6-10), provides a revised summary schedule at the time of writing (Table 6-11), and restates the largest remaining uncertainties.

The ancillary system costs were mentioned in the previous sections. Amounts are for specific hardware design contracts, hardware purchases, and installation. In-program labor, outside review boards, labor for system checkout, and contingencies are not included. Major uncertainties and assumptions regarding the ancillary systems are

- An overall compressor stage efficiency of $60 \%$ (manufacturers will address in preliminary design)

- Performance of gas condenser/coolers (researchers will analytically and experimentally address this during preliminary design)

- VCS precooler inlet conditions

- Cooling-water pumping power (researchers will fully examine flow rates, barometric levels, etc., in preliminary design).

Although uncertainty remains, conceptual design investigations have not identified any major problems, and the potential for reaching the NPPE goals has been clearly illustrated. The schedule shows HMTEA tests starting by July 1991, which is compatible with the overall NPPE being ready by April 1993. 


\section{CHAPTER 7.0}

\section{CONCLUDING REMARKS}

This report describes the conceptual design of an experimental system developed for investigating heat- and mass-transfer processes and assessing the viability of open-cycle ocean thermal energy conversion (OC-OTEC).

The experiment will be developed in two stages, the HMTEA and the NPPE. The goal for the HMTEA is to test heat exchangers to verify performance at the scale needed for the NPPE. The goal for the NPPE is to experimentally verify the feasibility of OC-OTEC by producing a minimum of $40 \mathrm{~kW}$ of net power at reduced technical risk. This will be achieved by installing a turbine and testing the system's power-generating performance.

The design effort was directed to meet the goals of both the HMTEA and the NPPE and minimize development of duplicate hardware. The choices for the design resource water flow rates were made consistent with the availability of cold and warm seawater as a result of the seawater systems upgrade carried out in 1987 in a cooperative effort among DOE, the State of Hawaii, and PICHTR.

The presented design resulted from detailed considerations of pros and cons of a variety of choices for the system configuration. The choices were evaluated based on their projected performance, degree of technical risk, required schedule, and cost.

The conceptual design as described in this report represents a viable practical arrangement for the system which poses no technical difficulties in meeting the research objectives and goals set forth. The estimated cost for the future phase of the design and the development of the HMTEA/NPPE is consistent with the projected future program funding levels.

The HMTEA and NPPE were designed cooperatively by PICHTR, ANL, and SERI under the guidance of the U.S. Department of Energy (DOE).

The experiment will be located at the DOE's Seacoast Test Facility (STF) at the Natural Energy Laboratory of Hawaii (NELH), Kailua-Kona, Hawaii. 


\section{CHAPTER 8.0}

\section{REFERENCES}

\subsection{Open Literature}

Bharathan, D., and T. R. Penney, Jan. 1983, Flash Evaporation from Falling Turbulent Jets, SERI/TP-252-1853, Golden, CO: Solar Energy Research Institute.

Bharathan, D., B. K. Parsons, and J. A. Althof, Oct. 1988, Direct-Contact Condensers for Open-Cycle OTEC Applications: Model Validation with Fresh-Water Experiments for Structured Packings, SERI/TR-252-3108, Golden, CO: Solar Energy Research Institute.

Block, D. L., and J. A. Valenzuela, May 1985, Thermoeconomic Optimization of OCOTEC Electricity and Water Production Plants, SERI/STR-251-2603, Golden, CO: Solar Energy Research Institute.

Crane Co., 1986, Flow of Fluids Through Valves, Fittings, and Pipe, Technical Paper No. 410, New York, NY: Crane Co.

Daniel, T. H., April 1989, "New Seawater Delivery Systems at the Natural Energy Laboratory of Hawaii," Proceedings of the Eleventh Annual ASME Solar Energy Conference, San Diego, CA, April 2-5, New York, NY: ASME.

Dillingham Construction Pacific Ltd., 1987a, Solar Energy Research Institute Open-Cycle OTEC: Heat- and Mass-Transfer Scoping Test Apparatus, Subcontract No. HX-6-05107-1, Honolulu, HI: Dillingham Construction Pacific, Ltd.

Dillingham Construction Pacific Ltd., 1987b, Open-Cycle OTEC: Heat- and MassTransfer Experimental Apparatus, final report on Contract HX-6-05107-1 for the Solar Energy Research Institute.

Fong, K.B.K., S. M. Masutani, and L. C. Neill, July 1989, Preliminary Design of a NPPE Turbine based on Existing Hardware, Pacific Interr tional Center for High Technology Research, prepared under subcontract to tne Solar Energy Research Institute, Contract XX-8-07206-1.

High Technology Development Corporation, Aug. 1985, Final Environmental Impact Statement, Development Plan for the Hawaii Ocean Science and Technology Park and Expansion of the Natural Energy Laboratory of Hawaii, prepared by The Traverse Group, Inc., Honolulu, HI.

Kline, S. J., and F. A. McClintock, 1953, "Describing Uncertainties in Single-Sample Experiments," Mechanical Engineering, Vol. 75, No. 1, pp. 3-8.

Lewis, L. F., L. Trimble, and J. Bowers, Sept. 1987, Open-Cycle OTEC Seawater Experiments in Hawaii, Proceedings, OCEANS-87, Marine Technology Soc., Washington, D.C., pp. 397-402. 
Lewis, L. F., J. Van Ryzin, and L. Vega, 1988, "Steep-Slope Seawater Supply Pipeline," Proceedings of the American Society of Civil Engineers, 21 st International Conference on Coastal Engineering, Costa Del Malaga, Spain, 1988, New York, NY: Am. Soc. Civil Engineers.

Link, H., and B. Parsons, 1986, Potential of Proposed Open-Cycle OTEC Experiments to Achieve Net Power, Oceans 186 Conference Record, Washington, D.C.; Sept. 23-25, New York: Institute of Electrical and Electronics Engineers, Inc., pp. 207-212.

Ludke, R. P., and P. Y. Chow, Feb. 1984, Structural Aspects of an Advanced Research Open-Cycle OTEC Facility, Proceedings of the Third Offshore Mechanics and Arctic Engineering Symposium, Vol. 2.

Mechanical Technology Inc., May 1989, Preliminary Design and Analysis of a Single-Stage Steam Turbine Generator for the Open-Cycle OTEC Experimental Project, MTI/89TR 10, prepared under subcontract XM-8-18072 to the Solar Energy Research Institute, SERI/XM-8-18072-1, Latham, NY: Mechanical Technology Incorporated.

National Oceanic and Atmospheric Administration, U.S. Department of Commerce, 1989, Tide Table 1990, High and Low Water Predictions, West Coast of North and South America Including the Hawaiian Islands, Washington, D.C.: U.S. Dept. of Commerce.

National Oceanic and Atmospheric Administration, U.S. Department of Commerce, 1989, Tide Table 1991, High and Low Water Predictions, West Coast of North and South America Including the Hawaiian Islands, Washington, D.C.: U.S. Dept. of Commerce.

Natural Energy Laboratory of Hawaii, Mar. 1987, Final Supplemental Environmental Impact Statement, Alternative Methods of Seawater Return Flow Disposal, prepared by MCM Planning, Honolulu, HI.

Ocean Data Systems Inc., 1977, OTEC Thermal Resource Report for Hawaii, Monterey, CA: Ocean Data Systems, Inc.

Pacific International Center for High Technology Research (PICHTR), Dec. 1988, Review of the Conceptual Design for a $165-\mathrm{kW}$ (Gross) OC-OTEC Plant, prepared under contract XX-8-07206-1 to the Solar Energy Research Institute.

Panchal, C. B., and L. Genens, Nov. 1989, Surface Condenser Test Unit for HMTSTA/NPPE Experiments, Argonne National Laboratory Report prepared under Contract $\mathrm{W}-31-109-$ Eng-38.

Parsons, B., D. Bharathan, and J. Althof, Sept. 1985, Thermodynamic Systems Analysis of Open-Cycle Ocean Thermal Energy Conversion (OTEC), SERI/TR-252-2234, Golden, CO: Solar Energy Research Institute.

Parsons, B. K., H. F. Link, D. Bharathan, A. A. Pesaran, F. Zangrando, and C. B. Panchal, April 1989, Test Plan for the Heat- and Mass-Transfer Scoping Test Apparatus: Phase I and Phase II Tests, Internal Program Report, SERI/PR-253-3385, Golden, CO: Solar Energy Research Institute. 
Penney, T. R., J. A. Althof, D. Bharathan, and B. Parsons, Jan. 1984, Small-Scale OpenCycle OTEC Power Systems, Preliminary Concept Design, SERI/TR-252-2184, Golden, CO: Solar Energy Research Institute.

Penney, T., D. Bharathan, J. Althof, and B. Parsons, 1984, Open-Cycle OTEC Research: Progress Summary and a Design Study, ASME Paper 84-WA/Sol-26, New York: American Society of Mechanical Engineers.

Schlichting, H., 1968, Boundary Layer Theory, New York: McGraw-Hill.

Schobeiri, T., Aug. 1989, Aero-Thermodynamic Design Study of Single-Inflow Radial and Single-Stage Axial Steam Turbines for OC-OTEC Net Power-Producing Experiment, SERI/TR-253-3559, Golden, CO: Solar Energy Research Institute.

Shelpuk, B., 1985, 165-kW Open-Cycle OTEC Experiment, SERI/TR-251-2725, Golden, CO: Solar Energy Research Institute, 8 pp.

Uniform Building Code, 1988 Edition, ISSN 0896-9655, Whittier, CA: International Conference of Building Officials.

U.S. Department of Energy (DOE), Dec. 1985, Federal Ocean Energy Technology Program, Multi-Year Program Plan, FY85-89, DOE/CH/10093-100.

Valenzuela, J. A., T. Jasinski, W. D. Stacey, B. R. Patel, and F. Y. Dolan, June 1988, Design and Cost Study of Critical OC-OTEC Plant Components, SERI/STR-252-3246, Golden, CO: Solar Energy Research Institute.

Value Engineering Co., May 1979, Ocean Thermal Energy Conversion: Work Breakdown Structure, prepared under DOE contract ET-78-C-02-4931, Alexandria, VA.

Westinghouse Electric Corp., Mar. 1979, 100 MW OTEC Alternate Power Systems, final report, to U.S. DOE under contract EG-77-C-05-1473, Vol. 1.

Zangrando, F., D. Bharathan, H. Link, and C. B. Panchal, Aug. 1989, "Seawater Test Results of Open-Cycle Ocean Thermal Conversion Components," SERI/J-253-0395, Golden, CO: Solar Energy Research Institute (article accepted for publication in Heat Transfer Engineering Journal).

Zangrando, F., D. Bharathan, H. J. Green, H. Link, C. B. Panchal, B. Parsons, J. Parsons, and A. A. Pesaran, 1990, Results of Scoping Tests for Open-Cycle OTEC Components Operating with Seawater, SERI/TR-253-3561, Golden, CO: Solar Energy Research Institute.

\subsection{Internal Documents}

ANL letter from T. Rabas to F. Zangrando, Mar. 10, 1989, "Paper by Nisolle."

ANL letter from T. Rabas to F. Zangrando, Mar. 24, 1989, "ANL Findings for the Matrix of Options for the Desalinated Water Production."

Bharathan, D., May 18, 1989, "Vacuum Enclosure Design Requirements/Options," Memorandum, Golden, CO: Solar Energy Research Institute. 
Department of Accounting and General Services of the State of Hawaii, 1986, Project B, Hawaii Ocean Science and Technology (HOST) Park, First Increment, and Seacoast Test Facility Upgrade, prepared by R. M. Towill Corporation.

Doc. no. 2.1.3.6.8, H. J. Green, Apr. 25, 1989, "Pump Configurations Selected for the NPPE Conceptual Design."

Doc. no. 2.1.3.6.9, H. J. Green, Apr. 25, 1989, "Structural Integrity of NPPE Supply/Discharge Pipes under Vacuum--Current Status."

Doc. no. 2.1.3.6.11, H. J. Green, July 13, 1989, "Preliminary Seawater Systems Layout for the NPPE."

Doc. no. 2.1.3.6.12, H. J. Green, Aug. 3, 1989, "Flow Rate Control for the NPPE."

Doc. no. 2.1.3.6.14, H. J. Green, Sept. 14, 1989, "Design Conditions for the NPPE Seawater Systems, Update: September 14, 1989."

Doc. no. 2.1.3.6.16, H. J. Green, Sept. 25, 1989, "Seawater Systems Pump Configurations."

Doc. no. 2.1.3.6.19, H. J. Green, Aug. 22, 1989, "NPPE Seawater Systems Pump Configurations."

Doc. no. 2.2.3.2, memo from F. Zangrando to A. Trenka dated Mar. 7, 1989, "NPPE heat exchangers subtask meeting of March 2, 1989."

Doc. no. 2.2.3.3, letter from F. Zangrando to T. Rabas, ANL, dated Mar. 16, 1989, "Multiple spout results."

Doc. no. 2.2.3.4, memo from F. Zangrando to D. Bharathan, dated Apr. 21, 1989, "NPPE subtask meeting of April 13, 1989."

Doc. no. 2.2.3.5, memo from F. Zangrando to D. Bharathan dated Aug. 14, 1989, "Proposed NPPE evaporator configuration."

Doc. no. 2.2.3.8, memo from F. Zangrando to G. Nix dated Oct. 26, 1989, "Meetings held at PICHTR on October 18-24, 1989."

Doc. no. 2.2.3.9, memo from F. Zangrando to D. Bharathan dated Oct. 26, 1989, "Potential Benefits of Predeaeration in OTEC Systems and Applicability to the NPPE."

DOE, 1986, Seacoast Test Facility Upgrade at Natural Energy Laboratory of Hawaii, cooperative agreement with the State of Hawaii.

DOE, March 1988, Finding of No Significant Impact for Shallow Trench Disposal of Seawater Effluent at NELH, memorandum.

First Working Group Meeting results, 1989, "NPPE System Development Management Plan," issued by the Solar Energy Research Institute, March 3. 
Flug, H., Sept. 19, 1989, "Comments on Proposed Concrete Vacuum Vessel," letter to ANL, Glendale, CO: United Engineers \& Constructors.

Fong, K., Oct. 1989, "Cost of Vertical Wet Pit Pump Sump Modifications."

Green, H. J., Feb. 1989, seawater systems task presentation to the NPPE First Working Group Meeting.

Masutani, S. M., Aug. 29, 1989, "NPPE Structure Options," letter to SERI, Honolulu, HI: Pacific Center for High Technology Research.

OET program systems team meeting minutes, Sept. 26-27, 1989, Meridian Corporation, Alexandria, VA.

Oswald, C. J., Sept. 15, 1989, "Advice Regarding Proposed Concrete Vacuum Vessel," letter to ANL, San Antonio, TX: Southwest Research Institute.

Pacific International Center for High Technology Research, June 1989, "Flygt Pump Options for NPPE."

Pacific International Center for High Technology Research, Sept. 1989, "Seawater Pump Options for NPPE."

PICHTR letter from S. Masutani to F. Zangrando, Mar. 17, 1989, "PICHTR's Review of the Matrix of Options for Desalinated Water Production."

PICHTR letter from K. Fong to F. Zangrando, Nov. 3, 1989, "NPPE Heat Exchanger Conceptual Design."

Presentation Packages, 1989, Vols. I and II of the NPPE First Working Group Meeting held at the Solar Energy Research Institute February 22-23.

R. M. Towill Corporation, Sept. 1989, "Revised Pre-Final Bid Documents, OTEC Disposal System, Natural Energy Laboratory of Hawaii."

SERI, Mar. 1989, "Results of the NPPE System Development Management Plan First Working Group Meeting" (February 22 and 23, 1989).

Stallman, J. D., July 27, 1989, "Costs for Coring Concrete Walls," letter to SERI, Honolulu, HI: Concrete Coring Company.

Stinnett, R. C., Aug. 9, 1989, "Structural Adequacy of the Concrete Vessel," letter to SERI, Englewood, CO: Stone and Webster Engineering Corp.

Trenka, A. R., Feb. 26, 1987, "Meeting at DOE/HQ on February 15, 1987, Regarding Options for NPPE," SERI memorandum, Golden, CO: Solar Energy Research Institute. 


\section{SELECTED DISTRIBUTION LIST}

Applied Physics Laboratory

Johns Hopkins Road

Laurel, MD 20707

Professor William Avery

Argonne National Laboratory

9700 South Cass Avenue

Argonne, IL 60439

Anthony Thomas

C. B. Panchal

T. Rabas

Barber-Nichols Engineering Company 6325 West 55th Ave.

Arvada, CO 80002

Robert Barber

Center for Energy and Environmental Research

Caparra Heights Station

San Juan, PR 00935

Juna Bonnet

Robert Cohen

Energy Consultant

8402 Donnybrook Drive

Chevy Chase, MD 20815

Creare, Inc.

P.O. Box 71

Hanover, NH 03755

Bharatan Patel

Dartmouth College

Thayer School of Engineering

Hanover, NH 03755

Professor Graham B. Wallis

DOE/Hawaii

Pacific Area Support Office

300 Ala Moana Blvd.

P.O. Box 50168

Honolulu, HI 96850

John Shupe

Electric Power Research Institute Coal Combustion Systems Division

3412 Hillview Ave.

Palo Alto, CA 94303

John A. Bartz
Florida Solar Energy Center

300 State Road 401

Cape Canaveral, FI 32920

David L. Block

Hawaiian Electric Renewable Systems, Inc.

915 Fort Street Mall, Suite 701

Honolulu, HI 96813

Alfred P. Manning

Hawaii Natural Energy Institute

University of Hawaii - Manoa

2540 Dole St.

Holmes 246

Honolulu, HI 96822

Patrick Takahashi

HTRI

1000 South Fremont Ave.

Alhambra, CA 91802

Dr. Duncan Chisholm

Technical Director

Makai Ocean Engineering

P.O. Box 1206

Kailua-Oahu, HI 96734

Joseph C. Van Ryzin

Marine Development Associates

13665 Rassmere Ct.

Saratoga, CA 95070-1409

James G. Wenzel

Lloyd Tremble

Mechanical Technology Inc.

968 Albany-Shaker Road

Latham, NY 12110

William F. Koebbeman

Meridian Corporation

4300 King St.

Alexandria, VA 22302

D. Kerner

Natural Energy Laboratory of Hawaii

P.O. Box 1749

Kailua-Kona, HI 96740

Thomas H. Daniel 
Oklahoma State University

College of Engineering

Stillwater, OK 74074

Professor Kenneth J. Bell

Pacific International Center for High Technology Research

711 Kapiolani Blvd., Suite 200

Honolulu, HI 96814

Andrew Trenka (6)

Luis Vega

Richardson School of Law

Ocean Engineering

Law of Sea Institute

University of Hawaii

Honolulu, HI 96822

Professor John P. Craven

Science Applications, Inc.

2615 Pacific Coast Highway, 非300

Hermosa Beach, CA 90254

A. T. Wassel

State of Hawaii

Dept. of Business and Economic

Development

335 Merchant Street

Honolulu, HI 96804

Maurice H. Kaya
The Munters Corporation

P.O. Box 6428

Ft. Myers, FL 33911

E. A. Winkler

R. M. Towill Corporation

420 Waiakamilo Road, Suite 411

Honolulu, HI 96817-4941

Bud Towill

U.S. Department of Energy

Route CE-351; Room 5E-098

1000 Independence Ave. S.W.

Washington, DC 20585

Carmine Castellano

Lloyd Lewis

R. Loose

R. Kessler

University of Hawaii

J.K.K. Look Laboratory

811 Olomehani Street

Honolulu, HI 96813

Professor Hans-Jurgen Krock

University of Pennsylvania

Mechanical Engineering Department

3451 Walnut St.

Philadelphia, PA 19104

Professor Noam Lior 


\begin{tabular}{|c|c|c|}
\hline $\begin{array}{l}\text { Document Control } \\
\text { Page }\end{array}$ & $\begin{array}{l}\text { 2. NTIS Accession No. } \\
\text { DE90000304 }\end{array}$ & 3. Recipient's Accession No. \\
\hline \multirow{2}{*}{\multicolumn{2}{|c|}{$\begin{array}{l}\text { 4. Title and Subtitle } \\
\text { Conceptual Design of an Open-Cycle Ocean Thermal } \\
\text { Energy Conversion Net Power-Producing Experiment } \\
\text { (OC-OTEC NPPE) }\end{array}$}} & $\begin{array}{l}\text { 5. Publication Date } \\
\text { July } 1990\end{array}$ \\
\hline & & 6. \\
\hline $\begin{array}{ll}\text { 7. Author(s) } & \text { D. Bhar } \\
\text { B.K. Pa }\end{array}$ & $\begin{array}{l}\text { Ehan, H.J. Green, H.F. Link, } \\
\text { sons, J.M. Parsons, F. Zangrando }\end{array}$ & 8. Performing Organization Rept. No. \\
\hline \multirow{2}{*}{\multicolumn{2}{|c|}{$\begin{array}{l}\text { 9. Performing Organization Name and Address } \\
\text { Solar Energy Research Institute } \\
\text { A Division of Midwest Research Institute } \\
\text { 1617 Cole Boulevard } \\
\text { Golden, Colorado } 80401-3393\end{array}$}} & $\begin{array}{l}\text { 10. Project/Task/Work Unit No. } \\
\text { OE91 }\end{array}$ \\
\hline & & $\begin{array}{l}\text { 11. Contract (C) or Grant (G) No. } \\
\text { (C) DE-ACO2-83CH } 10093 \\
\text { (G) }\end{array}$ \\
\hline \multirow{2}{*}{\multicolumn{2}{|c|}{$\begin{array}{l}\text { 12. Sponsoring Organization Name and Address } \\
\text { Solar Energy Research Institute } \\
\text { A Division of Midwest Research Institute } \\
1617 \text { Cole Boulevard } \\
\text { Golden, Colorado } 80401-3393\end{array}$}} & $\begin{array}{l}\text { 13. Type of Report \& Period Covered } \\
\text { Technica1 Report }\end{array}$ \\
\hline & & 14. \\
\hline
\end{tabular}
15. Supplementary Notes

16. Abstract (Limit: 200 words)

This report describes the conceptual design of an experiment to investigate heat and mass transfer and to assess the viability of open-cycle ocean thermal energy conversion (OC-OTEC). The experiment will be developed in two stages, the Heatand Mass-Transfer Experimental Apparatus (HMTEA) and the Net Power-Producing Experiment (NPPE). The goal for the EMTEA is to test heat exchangers. The goal for the NPPE is to experimentally verify OC-OTEC's feasibility by installing a turbine and testing the power-generating system. The design effort met the goals of both the HMTEA and the NPPE, and duplication of hardware was minimal. The choices made for the design resource water flow rates are consistent with the availability of cold and warm seawater as a result of the seawater systems upgrade carried out by the U.S. Department of Energy (DOE), the State of Hawaii, and the Pacific International Center for High Technology Research. The choices regarding configuration of the system were made based on projected performance, degree of technical risk, schedule, and cost. The cost for the future phase of the design and the development of the BMTEA/NPPE is consistent with the projected future program funding levels. The HMTEA and NPPE were designed cooperatively by PICHTR, Argonne National Laboratory, and Solar Energy Research Institute under the guidance of DQQE, The experiment will be located at the DOE's Seacoast Test Facility at the Natural Energy Laboratory of Hawaii, Kailua-Kona, Hawaii.

17. Document Analysis

a. Descriptors Open-Cycle Systems; Systems Analysis; Heat Transfer; Ocean

Thermal Energy Conversion; Ocean Thermal Power Plants; Steam Turbines;

Steam Condensers; Evaporators; Desalination

b. Identifiers/Open-Ended Terms

\section{c. UC Categories}

64

18. Availability Statement

National Technical Information Service

9. No. of Pages

U.S. Department of Commerce

5285 Port Royal Road

Springfield, Virginia 22161

172

20. Price

A08 